\title{
Valuation in the Pharmaceutical Industry
}

by

Kim Trottier

B.Comm., University of Ottawa, 1991

M.Sc., University of British Columbia, 2000

A THESIS SUBMITTED IN PARTIAL FULFILLMENT OF THE REQUIREMENTS FOR THE DEGREE OF

DOCTOR OF PHILOSOPHY

in

THE FACULTY OF GRADUATE STUDIES

(Business Administration)

THE UNIVERSITY OF BRITISH COLUMBIA

(Vancouver)

October 2009

(C) Kim Trottier, 2009 


\begin{abstract}
Valuation models are used extensively in Finance and Accounting to investigate various empirical questions. Conventional valuation models express firm value as a function of discounted dividends, discounted abnormal earnings, discounted cash flows, or price multiples. One limitation from using these models is that they don't capture unique industry valuation characteristics. However, modeling techniques can be used to modify a conventional model in order to reflect specific business processes. In the first chapter of this thesis I use modeling techniques to develop an industry-specific valuation model for pharmaceutical firms. This allows me to explore how investments in research and development, advertising, and production facilities create value for firms in this industry. In particular, the techniques used in this paper allow me to estimate and explore the economic rents generated by these investments. My valuation model is based on the cash inflows and outflows of a typical pharmaceutical firm. In the second chapter of this thesis I test whether the model is improved by adding a system of accounting accruals. I also compare the performance of my valuation model to a model with summary accounting measures to assess the importance of data disaggregation. The value of advertising investments is likely to have changed in the period investigated in this thesis because on August 8, 1997 the Food and Drug Administration announced that it would relax the rules on direct-to-consumer advertising of prescription drugs. The last chapter of this thesis is an event study of this regulatory change. I investigate the effect of the announcement on share price as well as the firm characteristics associated with the price reactions. Each chapter in this thesis answers a different question with respect to valuation in the pharmaceutical industry.
\end{abstract}




\section{TABLE OF CONTENTS}

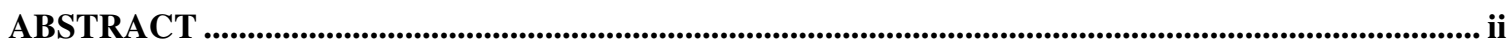

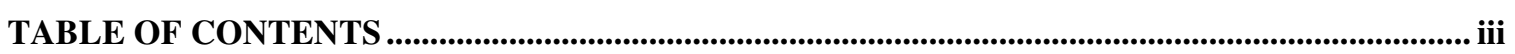

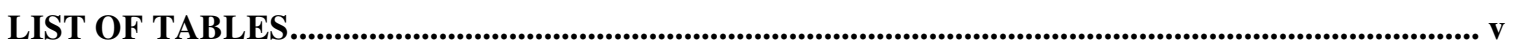

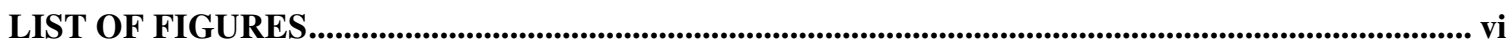

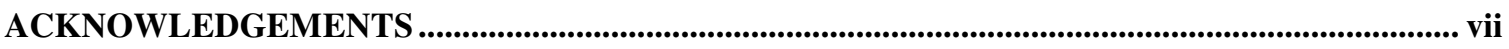

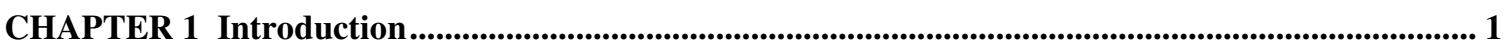

CHAPTER 2 Valuation of Pharmaceutical Firm Investments ......................................................... 7

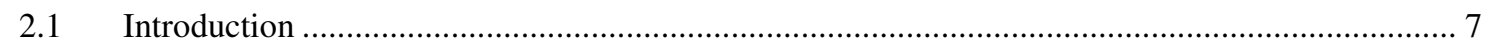

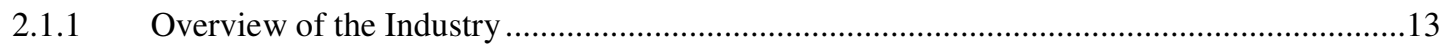

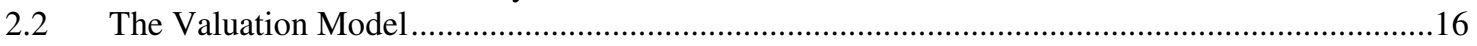

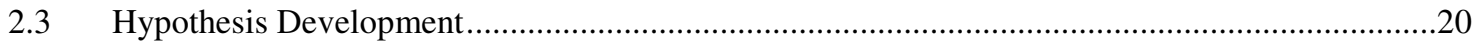

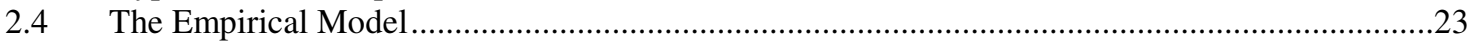

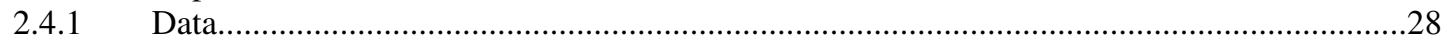

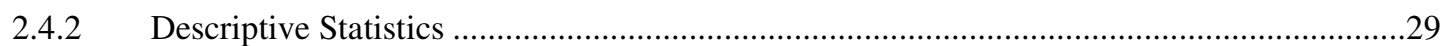

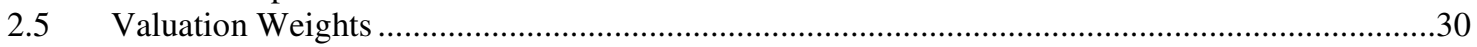

2.5.1 Change in the Advertising Valuation Weight ..........................................................................

2.6 Net Present Value (NPV) Derived from the Valuation Weights ...................................................36

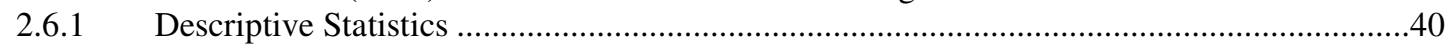

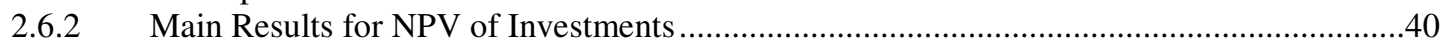

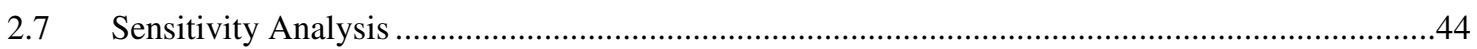

2.7.1 Analysis of Firms that Report Advertising Expenditures ......................................................

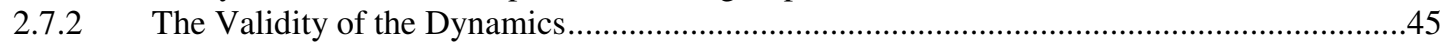

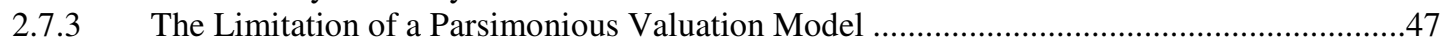

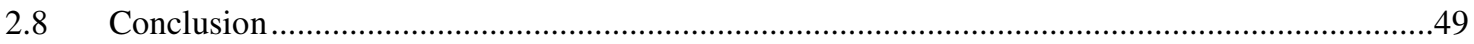

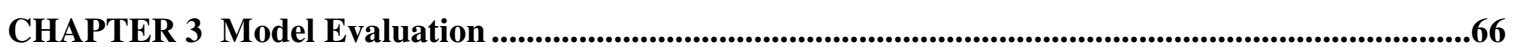

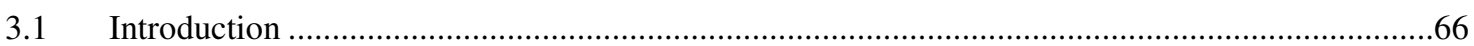

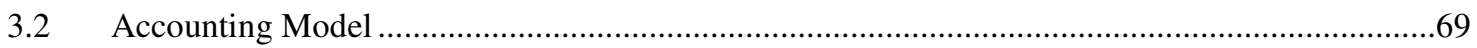

3.2.1 Variables Omitted from the Accounting Model ……..............................................................79

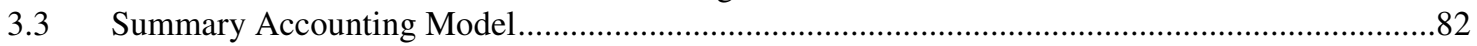

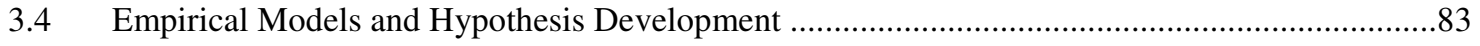

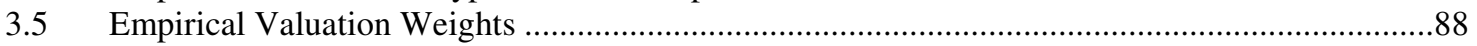

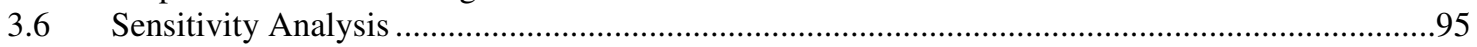

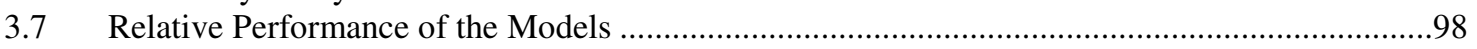

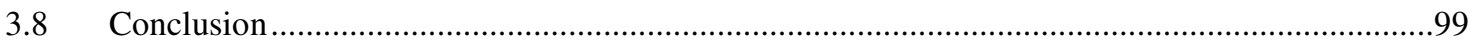

CHAPTER 4 Event Study of the Advertisement Regulatory Change .......................................................104

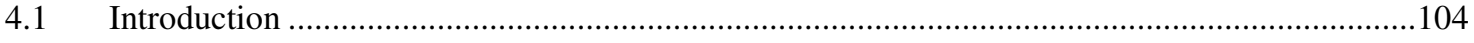

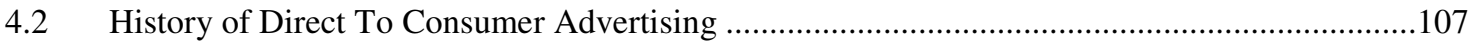

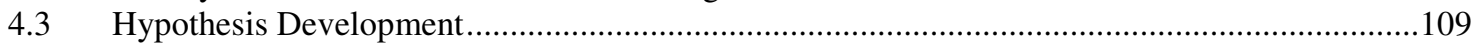

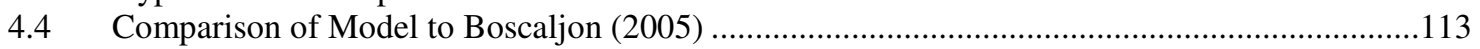

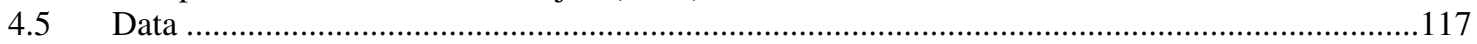

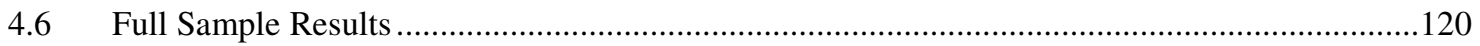

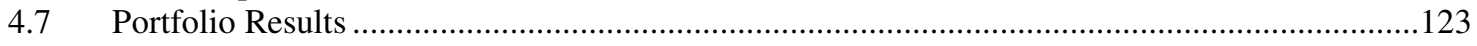

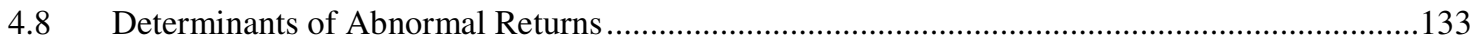

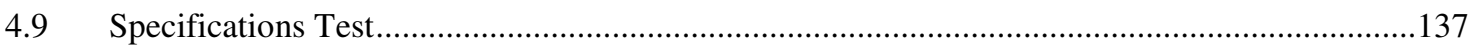

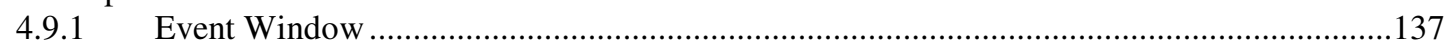

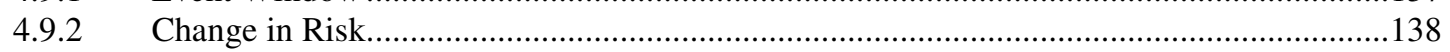

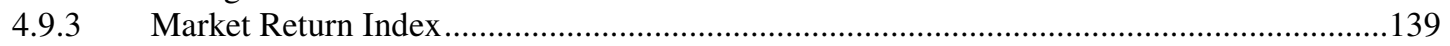

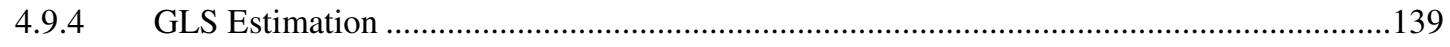




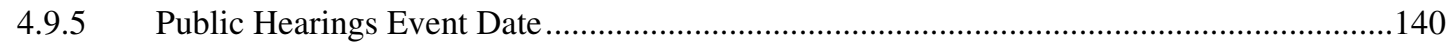

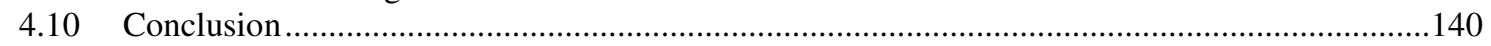

CHAPTER 5 Concluding Remarks ............................................................................................151

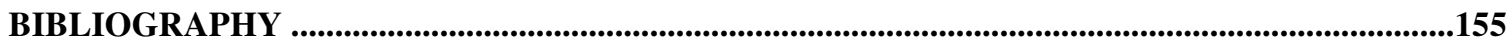

APPENDIX A Definition and Construct of the Empirical Variables .............................................160

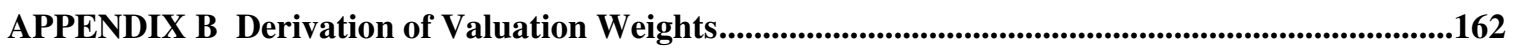

B.1 Derivation of the Cash Flow Valuation Model .......................................................................162

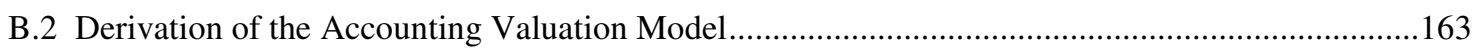




\section{LIST OF TABLES}

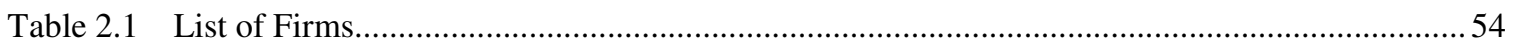

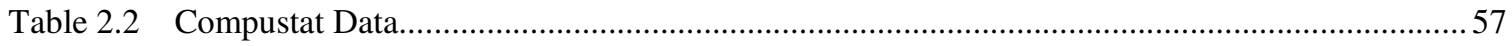

Table 2.3 Mean Values of Regression Variables................................................................................ 58

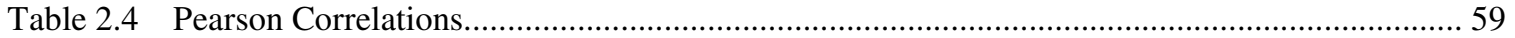

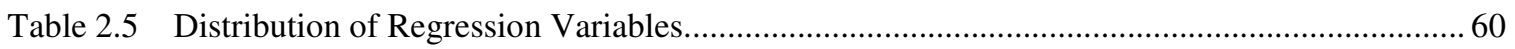

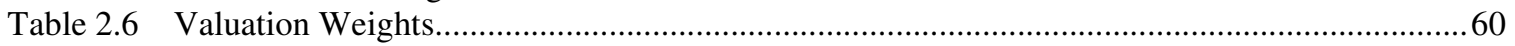

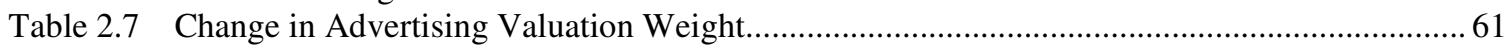

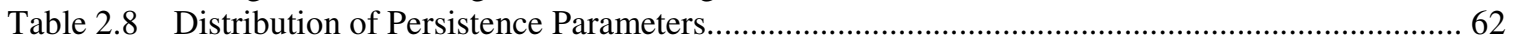

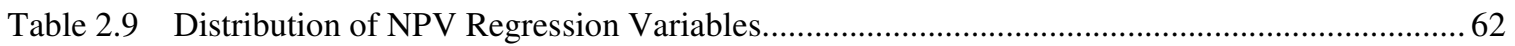

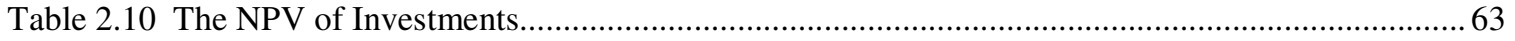

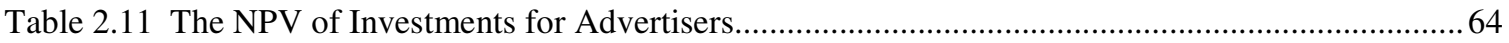

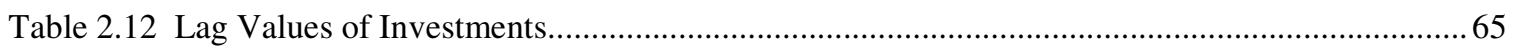

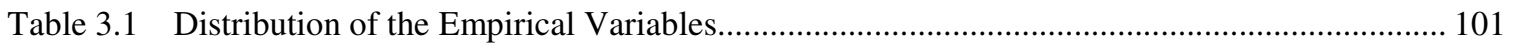

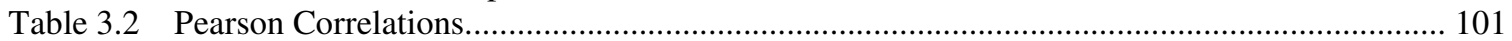

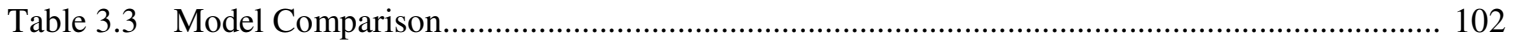

Table 3.4 Residual Operating Income Comparison................................................................................ 103

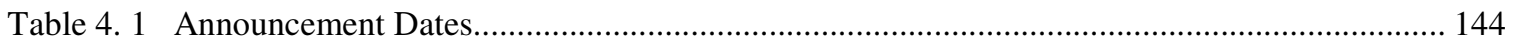

Table 4. 2 Distribution of Daily Returns Variable and Accounting Variables.......................................... 144

Table 4. 3 Abnormal Returns by Firm Type.......................................................................................... 145

Table 4. 4 Abnormal Returns by R\&D Indicator Variable....................................................................... 146

Table 4. 5 Abnormal Returns by Advertising Indicator Variable ............................................................ 147

Table 4. 6 Abnormal Returns by Sales Intensity or Firm Size.................................................................. 148

Table 4. 7 Distribution of the Variables for Cumulative Abnormal Returns Regression............................ 149

Table 4. 8 Determinants of Cumulative Abnormal Returns................................................................. 149

Table 4. 9 Determinants of Cumulative Abnormal Returns.................................................................... 150 


\section{LIST OF FIGURES}

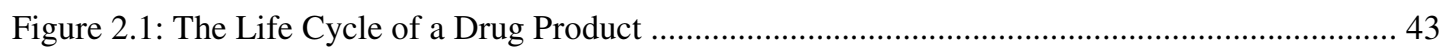




\section{ACKNOWLEDGEMENTS}

I would like to express gratitude to the co-Chairs of my supervisory committee Sandra Chamberlain and Joy Begley for their frequent feedback, insightful suggestions, and moral support. I also appreciate the contributions from Keith Head, a member of my supervisory committee. I would like to thank the participants at a UBC workshop for their helpful comments. This paper would not have been possible without my husband, Dr. K.N. Chi, who provided me with support and first-hand knowledge about clinical trials and the pharmaceutical industry. Finally, I am thankful for my sons Calvin and Max for providing balance in my life. 


\section{CHAPTER 1 Introduction}

Accounting valuation models have been used in the past to investigate the relationship between market price and accounting information. The prevalent models used have been based on the Ohlson (1995) model, where the market value of the firm is associated with book value, residual income, and other information, and the Feltham and Ohlson (1996) model, which adds a conservatism parameter to capture typical accounting practices such as depreciating assets faster than they decay or deferring the recognition of profits until they are realized. The valuation models are typically estimated for a pooled sample of firms from different industries (Frankel and Lee [1998], Penman and Sougiannis [1998], Dechow et al. [1999], Myers [1999], Biddle et al. [2001], Hand and Landsman [2005], and many others listed in Kothari [2001] and Richardson and Tinaikar [2004]), but as discussed in Lo and Lys (2000), cross-sectional aggregation is inappropriate if there are differences in earnings persistence or accounting systems. Some researchers estimate parameters by industry (Begley and Feltham [2002], Barth et al. [1999]) but they use a constant set of information dynamics that does not incorporate industry-specific business processes. Begley, Chamberlain, and Li (2006) address this issue by concentrating on a single industry. They develop an accounting valuation model based on the value-generating activities of the banking industry. Their industry approach is reflected in this thesis, where my main objective is to develop a valuation model that reflects the core activities of pharmaceutical firms. My pharmaceutical valuation model is used to investigate several research questions such as the existence and magnitude of economic rents generated by investments, the importance of accounting accruals, and whether the relaxation of advertising rules that occurred in 1997 was beneficial to pharmaceutical firms.

The pharmaceutical industry is one of the most scrutinized sectors in the North American economy. This may be because the investment choices made by pharmaceutical firms affect not only their shareholders' wealth, but also the quality of the public's health care. Most economic 
papers on the pharmaceutical industry investigate macroeconomic issues, such as entry decisions and pricing. For example, Scott Morton (1999) investigates market conditions associated with the entry of generic drugs and finds that entry is more likely in markets with larger revenues, more hospital sales, and where the drug is used to treat chronic conditions. Acemoglu and Linn (2004) study the relationship between demographic changes and new drug entry, and find that the majority of new drugs treat medical conditions that affect the largest demographic groups. Kyle (2007) provides evidence that pharmaceutical firms avoid or delay the launching of new drugs in countries with price control. Ellison and Wolfram (2006) investigate how pharmaceutical firms respond when threatened with price regulation, and Frank and Salkever (1997) explore price changes after patent expiry. Some researchers use theoretical economic models, such as Chang (2004) who investigates the effect of price control on social welfare, and Brekke and Kuhn (2006) who explore the effect of direct-to-consumer advertising on pricing and profits. These economic papers implicitly assume that pharmaceutical firms attempt to maximize profits. The results in this thesis contribute to economics research on the pharmaceutical industry by providing an empirical approach to estimating economic rents, which is an indication that profits in excess of a normal return on investment are expected. However, a pharmaceutical valuation model must first be formulated in order to estimate economic rents.

The accounting field has produced some industry-specific valuation models. Valuation models for the pharmaceutical industry are developed in Bowen and Shores (2002), Joos (2002), Shortridge (2004), Xu et al. (2007), and Joos and Zhdanov (2008). Each of these models uses accounting information to represent various types of the value-relevant activities of pharmaceutical firms, and all of them specify investments in Research and Development (R\&D) as an important valuation variable. The importance of $R \& D$ in valuation is well established in the broader literature beyond the pharmaceutical industry (Hirschey [1982], Hirschey and Weygandt [1985], Bublitz and Ettredge [1989], Erickson and Jacobson [1992], Chauvin and Hirschey [1993], Sougiannis [1994]). Several papers use valuation relations to explore whether 
investments in $R \& D$ and advertising meet the definition of an asset ${ }^{1}$, and would therefore be worthy of capitalization if this wasn't prohibited by accounting standards. Since pharmaceutical firms are $R \& D$ intensive, the research in this area often includes a separate analysis for pharmaceutical firms, but the papers themselves are not industry-specific. This type of research includes papers by Scherer (1965), Morbey (1988), Lev and Sougiannis (1996), Healy et al. (2002), and Hsieh et al. (2003). They conduct research that is generalizable to a large set of firms but they are not likely to capture all relevant activities of pharmaceutical firms.

My first valuation model is developed in Chapter 2, and is designed to explore the association between market value and the investment choices of a prototypical pharmaceutical firm. The variables in the valuation model are presumed to capture aspects of the drug development process that are expected to be priced in the market. My model allows for three value-generating cash outflows: investments in $R \& D$, advertising, and production facilities. I assume that pharmaceutical firms have two important cash inflows: net revenues from the sale of patented drugs and net revenues from the sale of generic drugs or over-the-counter products. I estimate a valuation weight on each of the cash flow variables with a regression of the market value of equity on selected accounting data for thirty-four firms selling patented drugs during the time period of the study. The regression results indicate that investments in $R \& D$ and production facilities are positively related to the market value of these firms. The result for advertising investments is also positive, but the significance of the valuation weight is not robust to changes in the sample composition. As in other valuation studies the estimated valuation weights on the three types of investments modeled in this paper are relatively large (typically in excess of 10). Using the valuation modeling techniques from Christensen and Feltham (2003), I am able to explain the large weights by partitioning the valuation weights on investments into four

\footnotetext{
${ }^{1} \mathrm{An}$ asset is an expenditure that is expected to generate future benefits. The "Expenditures for advertising or R\&D are excluded from firms' balance sheets by present accounting rules primarily because of the claimed difficulty in determining the magnitude of future benefits from these activities and difficulty in determining the length of time over which benefits will endure," (Bublitz and Ettredge [1989], p.108).
} 
theoretical components: the return of the dollar invested, a parameter that represents expected future investments, the required return on the investment (i.e. the cost of capital), and the Net Present Value (NPV) of each dollar of investment. The NPV component measures the expected cash flows that are in excess of what is required to compensate investors for the riskiness of the investment. By definition, these are economic rents. By directly estimating the other three theoretical components of the valuation weights I am able to derive an NPV component from each of the valuation weights on investments. My results show that the magnitude of the economic rents associated with each dollar invested today is small, but since the investments are large and highly persistent the overall valuation weight is large, reflecting the notion that the market expects firms to continue earning economic rents on their future investments as well. These future economic rents account for a large portion of the valuation effect.

An important regulatory change occurred with respect to advertising in the pharmaceutical industry during the time period investigated in Chapter 2. In 1997 the FDA announced a relaxation of the rules for the Direct-to-Consumer Advertisements (DTCA) of prescription drugs. After the regulatory change, firms no longer had to list all the side effects of their drugs in their advertisements but only had to identify major risks and make a reference to a source for further information. Since pharmaceutical firms lobbied for this change, I hypothesize that pharmaceutical firms would benefit from the relaxation of advertising rules. The structural change in the relationship between firm value and advertising is tested in Chapter 2 with the prediction that the valuation weight on advertising investments increased after 1997. However, there is weak evidence that suggests that the valuation weight on advertising investments may have decreased.

The valuation model in Chapter 2 is based on cash flows since most of the pharmaceutical firm's operations are recorded on a cash basis. Accounting and finance academics are often interested in whether accruals are incrementally informative over cash flows; therefore I explore the usefulness of accruals in Chapter 3. I develop an accounting version of the 
pharmaceutical valuation model by adding a set of accounting rules that capitalizes investments in production facilities and purchased $\mathrm{R} \& \mathrm{D}$, and then expenses these assets as depreciation and amortization. I use a Vuong statistic to test which model is a better representation of the true data generating process. In addition to comparing the performance of the cash flow model to the accounting model, I also compare the performance of both of these models to the standard bivariate model motivated by Ohlson (1995); one with book value of equity and net income as explanatory variables. This comparison is essentially a test of whether the summary measures in the bivariate model are as effective at explaining variations in the market value of pharmaceutical firms as the disaggregated information in the industry specific cash flow and accounting models. The results show that a pharmaceutical valuation model with accruals performs slightly better than a cash flow valuation model, although the test of difference is only weakly significant with a p-value of $10 \%$. This is not surprising since the accruals I add to the accounting model are not likely to contain information that would cause investors to change their beliefs about the future performance of the firm. However, the accounting and cash flow models clearly outperform the standard bivariate model.

The analysis from Chapter 2 suggests that the valuation weight on advertising investments may have decreased after the relaxation of DTCA rules. The valuation weight reflects the long-term association between advertising investments and market value. An alternate way of testing whether the relaxation of advertising rules had an effect on pharmaceutical firms is to analyze the capital market reaction to the announcement of the regulatory change. Chapter 4 is an event study that explores whether the capital market perceived the relaxation of DTCA rules to be beneficial to pharmaceutical firms. Although this regulatory event was first investigated by Boscaljon (2005), the length of my event study is longer and the methodology more robust. I investigate the effect of seven announcement dates on the share price of pharmaceutical firms, which allows me to estimate individual abnormal returns on each announcement date as well as aggregate returns over all event windows. The sample of firms is 
divided into portfolios to investigate whether abnormal returns are a function of firm characteristics such as R\&D investments, the size of the firm, and whether the firm used DTCA. The event study results show some positive and some negative abnormal returns associated with different news announcements leading up to the regulatory change. When abnormal returns are aggregated over the entire event window, the estimates are not significantly different from zero. However, the pattern of returns suggests that the capital market was initially enthusiastic about the regulatory change, but that expectations of excess returns were revised downwards as the DTCA guidelines evolved into their final form. On the date the regulatory change was finally announced, only the firms that ultimately used DTCA were affected, and the market reaction for these firms was negative.

In addition to providing empirical evidence of the value of investments in the pharmaceutical industry, this thesis also makes a pedagogical contribution to the literature on valuation models. Many accounting researchers use Residual Income Valuation (RIV) models to explore valuation questions. The RIV model as described in Ohlson (1995) depicts the market value of the firm as the sum of two components: the current book value of equity, and the present value of expected future residual income. A simple set of dynamics is assumed in order to substitute the infinite series of future residual income with the current value of residual income. One of the first tests of the validity of RIV model is by Dechow et al. (1999) who find general support for the model dynamics when applied across industries. Myers (1999) corrects for some inconsistencies and finds no evidence that the RIV model surpasses a regression of price on book value alone. Begley and Feltham (2002) show that, when analyst forecasts are included in the RIV model to capture "other" information, the long term forecasts receive a positive weight as predicted. But to date only Begley, Chamberlain, and Li (2006) use the RIV structure to develop an industry specific valuation model. Their model is developed uniquely for firms in the banking industry. This thesis demonstrates the versatility of valuation models by developing and evaluating a model that reflects the activities of firms in the pharmaceutical industry. 


\section{CHAPTER 2 Valuation of Pharmaceutical Firm Investments}

\subsection{Introduction}

Residual income valuation models have been used extensively in accounting research to probe the manner in which a particular accounting number translates into valuations established by market participants (e.g. Barth, Beaver, Hand, and Landsman [1999]; Begley and Feltham [2002]; Begley, Chamberlain, and Li [2006]). A frequent theme in this literature is how accounting conservatism is related to accrual biases. However, as pointed out in Feltham and Ohlson (1996), Christensen and Feltham (2003), and Begley, Chamberlain, and Li (2006), a fundamental driver of conservatism is that positive net present value investments are not recorded in the financial statements but are reflected in the market value of the firm. The main objective of this chapter is to obtain a measure of the positive net present value of investments made by firms in the pharmaceutical industry, and to explore how this relates to accounting information.

The tests in this paper are based on the capital markets, which are assumed to provide a relatively objective measure of firm value. Finance theory holds that firm value is equal to the present value of expected future cash flows. Feltham and Ohlson (1996) show how future cash flows can be linked to current and prior investments. I conjecture that the main value-driving investments in the pharmaceutical industry are expenditures in $\mathrm{R} \& \mathrm{D}$, advertising, and production facilities. I estimate a valuation weight on each type of investment and use the structure in Feltham and Ohlson (1996) to partition the valuation weights into components, including the portion that represents the expected Net Present Value (NPV) of a dollar invested. Under the model assumptions the NPV parameter will be equal to zero if the investment generates just enough discounted cash flows to cover the cost of the investment. A market with perfect competition would be characterized by zero NPV investments. An imperfect market may have positive NPV investments such that the discounted cash flows exceed the required return on 
investments. These are essentially economic rents. I propose that economic rents may be generated because of market imperfections associated with each type of investment ${ }^{2}$.

For R\&D investments, the market imperfection comes from patent protection. The patent system provides firms with temporary market exclusivity so that they can recover their R\&D investments. Firms in the pharmaceutical industry need this incentive because the cost of R\&D is extremely high and the chance of success is very $\operatorname{low}^{3}$. An NPV estimate on R\&D that is close to zero suggests that pharmaceutical firms are pricing their therapeutics in order to just recover their initial R\&D investments. In contrast, an NPV estimate that is positive suggests that pharmaceutical firms are able to extract rents through their R\&D investments.

The economic theory of advertising suggests that advertising may be informative or persuasive (Bagwell [2007]). Informative advertising is characterized by imperfect consumer information, which leads to market inefficiencies. In this setting, advertising is a response offered by the market to address these inefficiencies. The effect of advertising is that the firm's demand curve becomes more elastic, thereby promoting competition. In contrast, persuasive advertising alters consumers' tastes and creates product differentiation and brand loyalty. In this setting, advertising makes the firm's demand curve less elastic which leads to higher prices, more profits, and economic rents. A positive NPV estimate on advertising investments suggests that advertising leads to economic rents.

Lastly, the firm size can constitute a barrier to entry which allows larger firms to earn rents. Karakaya (2002) surveys executives from chemical, steel, pharmaceutical, electronics, and metal manufacturing industries and finds that the respondents rank capital requirements as the second highest barrier to entry (out of 25). The pharmaceutical industry is characterized by a small number of very large firms, especially when considering only the firms that sell drugs with

\footnotetext{
${ }^{2}$ Economic rents can also be generated by product innovation or scarce resources but these rents are not discussed in this paper.

${ }^{3}$ Source: Angell, M. (2004). The truth about drug companies . New York: Random House.
} 
patent protection, which is suggestive of a market with limited entry. A positive NPV estimate on investments in production facilities would support a barriers-to-entry argument.

In addition to providing insight into the NPV component of the valuation weights, this paper adds to the literature on the value of investments by exploring the valuation weights themselves. Prior research has generally found $R \& D$ investments to be positively associated with firm value, but the results on advertising investments have been weaker. Using data on the firms listed in the Fortune 500, Hirschey (1982) estimates the relationship between the market value of firms and their R\&D and advertising investments, and finds a positive coefficient on both types of expenditures ${ }^{4}$. Hirschey and Weygandt (1985) extend the Hirschey (1982) results by estimating the portions of each type of investment that provide benefits in future periods. They conclude that the economic amortization rates are between $10 \%$ and $20 \%$ for R\&D investments and between $10 \%$ and $60 \%$ for advertising investments. Chauvin and Hirschey (1993) extend the Hirschey (1982) results by expanding the sample to 1,500 firms listed in Compustat and by testing for size effects and industry differences. To investigate the size effect, they rank the firms based on sales revenues and divide them into three subsamples. They find that firms in the subsample with the highest sales revenue have larger coefficients on both their advertising and R\&D investment variables than firms in the other two subsamples. To investigate the industry effect, the authors choose industries that have relatively large values of R\&D and advertising expenses, and then estimate the regression model by industry ${ }^{5}$. They find that the coefficients on R\&D investment are consistently positive and significant, and that the coefficients on advertising investments are generally positive but with more variability across industries. One of the

\footnotetext{
${ }^{4}$ The control variables used in Hirschey (1982), Hirschey and Weygandt (1985), and Chauvin and Hirschey (1993) are net income adjusted for interest expense, the firm's industry concentration ratio, a proxy for firm risk, and a variable that captures growth in sales. All variables are scaled by the book value of total assets. ${ }^{5}$ The industries selected and the first two digits of their SIC codes are as follows. Advertising intensive industries are: Food and kindred products (20), Printing and publishing (27), Chemicals and allied products (28), Rubber and plastic products (30), and Eating and drinking places (58). R\&D intensive industries are Chemical and allied products (28), Industrial machinery and computer equipment (35), Electronic equipment (36), Transportation equipment (37), Measuring instruments, photography and watches (38), and Business services (73).
} 
industries analyzed in Chauvin and Hirschey (1993) is the pharmaceutical industry. Their regression analysis for pharmaceutical firms produces significant coefficients of 4.8 on advertising expenditures and 12.6 on $\mathrm{R} \& \mathrm{D}$ expenditures. The magnitudes of these coefficients are different from those obtained when the model is estimated with the full sample, which yields a parameter estimate of 6.9 on advertising and 6.5 on $R \& D$ investments.

Bublitz and Ettredge (1989) use stock returns data from various firms across several industries to examine whether advertising and $\mathrm{R} \& \mathrm{D}$ are valued as a long-term asset. Their research method is to estimate a regression that has the firms' cumulative abnormal stock returns as dependent variables and unexpected investments in advertising and $R \& D$ as explanatory variables $^{6}$. They conjecture that a negative coefficient on advertising or R\&D indicates the investment is similar to an expense, while a positive coefficient suggests the investment has future benefits therefore meets the definition of an asset. Based on their regression results, they conclude that R\&D investments have future benefits but advertising outlays are similar to expenses.

Erickson and Jacobson (1992) propose that the positive relationship between the market value of the firm and investments in advertising and $R \& D$ reflects the joint effect of profitability: firms that are profitable have more discretionary spending as well as higher share prices. Their sample is restricted to the 99 firms that report advertising and R\&D expenses continuously in Compustat for the period 1972 to 1986. They first examine how annual stock returns are related to advertising and $R \& D$ expenditures and find the relationship to be positive. However, when return on investments (ROI) is included as an independent variable, the coefficients on advertising and R\&D are no longer significant ${ }^{7}$. They examine the effect of ROI on advertising and $R \& D$ expenditures, and find that ROI significantly influences both advertising and $R \& D$

\footnotetext{
${ }^{6}$ The control variables used in Bublitz and Ettredge (1989) are sales and "other expenses", where the latter is derived by reversing out sales, advertising expenses, and R\&D expenses from net income. All variables are scaled by the number of shares outstanding.

${ }^{7}$ The return on investment (ROI) variable is constructed by adding R\&D and advertising to operating income, then scaling the adjusted variable by total assets.
} 
expenditures $^{8}$. The authors use a simultaneous equation approach to assess the effect of R\&D and advertising on ROI and find no indication that these two types of investments generate profits that are greater than accounting profits.

While the regression coefficients on R\&D investments vary across empirical studies, the coefficients tend to be relatively large: Sougiannis (1994) finds that a one-dollar increase in R\&D expenditures produces a five-dollar increase in market value. Hirschey (1982), Hirschey and Weygandt (1985), and Shevlin (1991) also find significant coefficients on their R\&D variables with parameter estimates ranging from two to eight. Chauvin and Hirschey (1993) get a coefficient of 6.5 when the value of $R \& D$ is estimated across multiple industries, but obtain a much larger coefficient of 12.6 when estimating the model with pharmaceutical firms alone. An explanation for the large magnitudes is explored by Sougiannis (1994). He considers two valuation effects of $R \& D$ investments: an indirect effect due to the impact of $R \& D$ on earnings, and a direct market value effect from new information conveyed directly by the R\&D variable. The technique used by Sougiannis (1994) is to combine the coefficients from two separate regression models estimated cross-sectionally with firms from several industries. The first model is a regression of earnings on seven lagged values of $R \& D^{9}$. He uses the sum of the significant coefficients on lagged $R \& D$ variables as a measure of the $R \& D$ effect on earnings. The second regression model has the market value of equity as a dependent variable, and the book value of equity, adjusted earnings (earnings before $R \& D$ expense), and lagged values of $R \& D$ expense as explanatory variables ${ }^{10}$. The coefficients from the two regression models provide a method to estimate the value of $R \& D$. The indirect earnings effect of $R \& D$ is obtained by multiplying the R\&D effect on earnings (from the first regression) by the coefficient on adjusted earnings from

\footnotetext{
${ }^{8}$ The control variables used in Erickson and Jacobson (1992) are debt and industry concentration when estimating the effect of ROI on advertising and R\&D, and growth when estimating the effect of advertising and $\mathrm{R} \& \mathrm{D}$ on ROI, where growth is industry sales growth.

${ }^{9}$ The control variables in this regression are advertising expenditures and net capital stock, where the latter is measured as the inflation-adjusted sum of net property, plant, and equipment, inventories, intangibles, and other investments.

${ }^{10}$ All variables are scaled by the book value of equity.
} 
the second regression. The informational effect of $R \& D$ is the sum of the coefficients on the lagged values of $R \& D$ from the second regression. Sougiannis (1994) finds that the indirect effect of $R \& D$ is much larger than the direct effect, and concludes that $R \& D$ investments are valued conditional on their impact on earnings. While Sougiannis (1994) investigates the value of R\&D by year (from 1975 to 1985 ) he does not consider the value of R\&D by industry. This study explores the value of $R \& D$ specifically for the pharmaceutical industry. Rather than inferring the indirect effect of $R \& D$ through the coefficient on earnings, the earnings effect is embedded in the coefficient on R\&D.

I first develop a theoretical valuation model that articulates the link between market value and cash flows for pharmaceutical firms. The main cash inflows in my model are cash receipts from the sale of therapeutics. The main cash outflows are for investments in R\&D, advertising, and production facilities. To obtain an estimate of the valuation weights on these cash flows I calibrate the theoretical model with accounting data from the thirty-four firms that sold patented drugs during the time period of 1995 to 2003. The valuation multiples on the three types of investments are decomposed into their theoretical components: the return of the dollar invested, a parameter that represents expected future investments, the required return on the investment (i.e. the cost of capital), and the Net Present Value (NPV) of each dollar of investment. I remove the portions of the regression coefficients that capture the return of the dollar invested, the expected future series of investments, and the cost of capital to isolate the NPV components. My estimates of the NPV components contain more measurement error than the valuation weight estimates because they require additional proxies and assumptions in order to estimate the other components of the valuation weights.

My results are as follows. The regression model assigns large valuation weights to investments in $R \& D(\$ 13.19)$ and advertising (\$15.85), which is consistent with prior research on R\&D and some of the research on advertising. The valuation weight on investments in production facilities is also large and positive $(\$ 19.13)$ but there is no prior literature to compare 
this coefficient to. I perform some sensitivity analysis on the valuation weights and find that the magnitude and significance of the advertising coefficient is sensitive to the inclusion of certain firms, therefore the results on this variable are not robust. With this in mind, I extract the NPV components from the regression coefficients and get a point estimate of $\$ 0.15$ per dollar of $R \& D$ investments, $\$ 0.38$ per dollar of advertising investments, and $\$ 0.15$ per dollar of investments in production facilities. A $75 \%$ confidence interval places the NPV estimate for R\&D between $\$ 0.12$ and $\$ 0.18$, for advertising between $\$ 0.24$ and $\$ 0.46$, and for investments in production facilities between $\$ 0.11$ and $\$ 0.17$. For each type of investment, the NPV of a dollar invested today is much smaller than the entire valuation weight ${ }^{11}$. Most of the valuation weight can be attributed to expected future investments and the rents that will be obtained on these future expenditures.

The following section provides an overview of the pharmaceutical industry. The pharmaceutical valuation model is developed in section 2.2. The direction and magnitude of the NPV parameters are hypothesized for each type of investment in section 2.3. I calibrate the valuation model with the empirical data described in section 2.4. I estimate the valuation weights in section 2.5 and the NPV in section 2.6. Sensitivity analysis is performed in section 2.7 , and section 2.8 concludes this chapter.

\subsubsection{Overview of the Industry}

Pharmaceutical firms are involved in at least one of three areas of drug development: research, manufacturing, or marketing. Each new therapeutic goes through the steps shown in Figure 2.1. The first step is ongoing basic research in the laboratory. Before the 1980's this was generally done by pharmaceutical firms using chemical-based techniques, but advances in

\footnotetext{
${ }^{11}$ However, the magnitudes of the NPV estimates (especially for R\&D and production facilities) seem to be quite reasonable. Given a cost of capital of around 15\% and an NPV per dollar invested of $\$ 0.15$ this implies a total return on investment of around $30 \%$.
} 
molecular biology combined with the Bayh-Dole Act of $1980^{12}$ affected a shift to a biology-based method of discovery. Now biotech firms often conduct the basic research and sometimes the first clinical trial (Phase I), and when sufficient favorable evidence is available they sell or license the rights to other pharmaceutical firms ${ }^{13}$. At least a third of patented drug revenues are currently from products licensed from biotech companies ${ }^{14}$.

The second step is obtaining the Investigational New Drug (IND) approval by the FDA. Once the therapeutic is approved as an IND, the product goes through a series of clinical trials to test its safety and efficacy in humans. Only the large pharmaceutical firms have the production facilities and medical affiliations required to conduct these clinical trials, which effectively becomes a barrier to entry. The large pharmaceutical firms have enormous investments in research. Some firms spend up to $\$ 14$ million a day on $R \& D^{15}$. If a drug is successful in clinical trials, the pharmaceutical firm applies to the FDA for a New Drug Approval (NDA) to sell it. Since the patent is acquired at the discovery stage, there are only 5 to 10 years of market exclusivity remaining at the time of NDA approval. Consequently, the firm must quickly set up the manufacturing facilities and develop a marketing campaign.

The production facilities must be cleaned, reconfigured, and sometimes expanded to manufacture the new drug. The manufacturing process is getting more complex: "Two decades ago, a compound could typically be synthesized in no more than four chemical steps. Modern drugs can require as many as 15 . [The complexity, along with communication issues, time pressure, and the need for scientists to design a method to make the compound]... creates havoc for factory designers, who have no idea until the last moment what kind of equipment they should be installing" (The Economist, Of Processes, Pills, and Profits, Nov 9, 1996). In conjunction

\footnotetext{
${ }^{12}$ The Bayh-Dole Act enabled universities and small businesses to patent discoveries emanating from publicly funded research.

${ }^{13}$ From an accounting standpoint, when a firm purchases the results of another company's R\&D the purchase price is capitalized onto the balance sheet and amortized in a systematic manner.

${ }^{14}$ Source: Angell, M. (2004). The truth about drug companies . New York: Random House.

${ }^{15}$ Source: Astrazeneca annual report for 2003.
} 
with the manufacturing time pressures, the marketing team needs to promptly disseminate information about its new product. The marketing of prescription drugs used to be mainly aimed at hospitals and physicians through visits by a pharmaceutical representative or through advertisements placed in medical journals. But advertising practices have changed in the last decade. In 1997, the FDA changed the regulations on advertising prescription products, allowing firms to refer to a source for additional information on side effects rather than having to list them during the advertisement. Direct-to-consumer advertising, especially through television commercials, has consequently increased dramatically (Rosenthal et al. [2002]).

Once the patent expires, the firm no longer has exclusive marketing rights. Generic drugs enter the market and prices fall by as much as $80 \%{ }^{16}$. FDA approval for generic drugs is subject to a test of bio-equivalence, which is far less rigorous than clinical trials. One strategy to capitalize on the brand name of the drug is to apply for the FDA to switch the product to overthe-counter (OTC) status so that a prescription is no longer required. This tactic is not always successful since OTC drugs are generally not reimbursed by drug plans, and are therefore costly to the patient. In addition, the FDA gives OTC status only to drugs that are relatively safe to selfadminister.

Firms within the pharmaceutical industry are fundamentally different based on their role in the drug development process. In general, biotech firms conduct basic research and earn licensing revenues. The licenses are sold to large pharmaceutical firms that fund the clinical trials and market the therapeutics for as long as they remain protected by patents. Once the patents expire, firms that specialize in generic drugs enter the market and drive the prices to competitive levels. If the drug is ultimately granted OTC status, it enters a market that is similar to other consumer goods. The focus of this paper is on the relatively small portion of firms that sell patented drugs, but some of my analysis includes other types of firms involved in the drug production chain.

${ }^{16}$ FamiliesUSA, Out-of-bounds: Rising Prescription Drug Prices for Seniors, July 2003. 
This overview suggests that the critical observable investments for firms that sell patented drugs are discretionary spending on $\mathrm{R} \& \mathrm{D}$, marketing, and production facilities. The main source of cash receipts are revenues from the sale of therapeutics, which can be differentiated between cash receipts on patented drugs, generic drugs, and OTC products. These elements are considered in my valuation model.

\subsection{The Valuation Model}

As with Begley, Chamberlain, and Li (2006) I develop a valuation model from the primitives of the industry. My valuation model uses the structure from Feltham and Ohlson (1996) to separate cash flows between cash investments and cash receipts from prior investments. Based on the drug development overview in the previous section I assume that cash investments are expenditures on advertising, $\mathrm{R} \& \mathrm{D}$, and production facilities and that cash receipts from prior investments are revenues from patented drugs or generic/OTC drugs ${ }^{17}$. Based on the drug development process I assume the following set of model dynamics: R\&D expenditures $\left(r d_{t-1}\right)$ precede investment in production facilities $\left(\right.$ prodfac $\left._{t}\right)$ and advertising $\left(a d v_{t}\right)$ and these investments then generate cash receipts on patented drugs $\left(\operatorname{crp}_{t+1}\right)$ in the next consecutive period. Other value-relevant cash receipts are from the sale of over-the-counter or generic products (combined as $\operatorname{crg}_{t}$ ) which are unrelated to cash investments.

The information dynamics for $\mathrm{R} \& \mathrm{D}$, advertising, and patented cash receipts follow the structure assumed in Lev and Sougiannis (1996) and in the simulation model developed for pharmaceutical firms by Healy et al. (2002), except that the activities span only three years (time $t-1, t$, and $t+1)$ in my paper. The parsimonious time frame is the result of having a Markovian ${ }^{18}$ setting. A one-year delay between cash receipts on patented drugs and investments in advertising

\footnotetext{
${ }^{17}$ I assume that revenues on generic and OTC products have similar persistence therefore can be grouped together.

${ }^{18}$ The Markovian environment is an explicit assumption in Feltham and Ohlson (1996). This environment is one for which, conditional upon present information, the past and future are independent of current information.
} 
and production facilities is reasonable, but the time delay between $R \& D$ investments and subsequent activities is typically longer than one year. This is addressed in section 2.7 of this paper, where I test the effect of nine lagged values of $\mathrm{R} \& \mathrm{D}$ on $c r p_{t+1}$, cash receipts from patented drugs.

The information dynamics for generic drugs $\left(\mathrm{crg}_{t}\right)$ is based on the drug development process in Figure 2.1. R\&D investments in generic drugs are minimal since the firm only has to show bioequivalence rather than safety and efficacy. Due to the low margin on generic drugs, pharmaceutical firms generally manufacture them only when they have excess production capacity $^{19}$, therefore investments in production facilities are minimal. Finally, firms generally don't advertise generic drugs since the demand for these products comes through government or HMO formularies.

Each variable $i$ persists at a rate $\omega_{i i}$ so that the expected $t+1$ value of each variable is $\omega_{i i}$ times its current number. For example, expected cash receipts on generic/OTC drugs are $\mathrm{E}\left[\mathrm{crg}_{t+l}\right]=\omega_{g g} \operatorname{crg}_{t}$. Cash receipts can persist over time, for example, if first-time customers become habitual purchasers of the same drug.

In addition to being persistent, some variables are affected by the prior period values of other variables. For example, next period's cash receipts on patented drugs $\left(\operatorname{crp}_{t+1}\right)$ are a function of the current period investments in advertising $\left(a d v_{t}\right)$ and production facilities ( prodfac $\left._{t}\right)$ through the parameters $\omega_{p a}$ and $\omega_{p f}$ respectively. These parameters capture the idea that revenues are initiated through the investing activity. Stated differently, the model allows for various investing activities to generate value for the pharmaceutical firm.

Note that the relationship between investments and cash receipts on patented drugs is assumed to be linear. This assumption is consistent with the valuation models literature where researchers are ultimately interested in using regression analysis to analyse data. In reality, the

\footnotetext{
${ }^{19}$ Source: Angell, M. (2004). The truth about drug companies . New York: Random House. Firms specializing in the generic drug market invest in production facilities to manufacture generic products, but the model in this paper is not specified for this type of firms.
} 
functional form of the relationship between investments and cash receipts is likely to be concave due to diminishing marginal returns on investments. In addition, the simple model presented in this chapter does not provide for interaction between the investment variables. While simplifying the information dynamics produces a model that is not an exact depiction of the investment process, my presumption is that the digressions are of a second order effect, and will not materially affect my results.

The time period increment in the linear dynamic model (from $t$ to $t+1$ ) could theoretically correspond to any length of time (a day, month, decade, etc.), but given that the model will be validated with annual data, $t$ is assumed to represent one year in the following information dynamics:

$\operatorname{crg}_{t+1}=\omega_{g g} \operatorname{crg}_{t}+\varepsilon_{g t+1}$

$\operatorname{crp}_{t+1}=\omega_{p p} c r p_{t}+\omega_{p a} a d v_{t}+\omega_{p f}$ prodfac $_{t}+\varepsilon_{p t+1}$

$r d_{t+1}=\omega_{r r} r d_{t}+\varepsilon_{r t+1}$

$a d v_{t+1}=\omega_{a a} a d v_{t}+\omega_{a r} r d_{t}+\varepsilon_{a t+1}$

prodfac $_{t+1}=\omega_{f f}$ prodfac $_{t}+\omega_{f r} r d_{t}+\varepsilon_{f t+1}$

where $\omega_{g g}$ and $\omega_{p p}$ are between zero and one, $\omega_{p a}, \omega_{p f}, \omega_{a r}, \omega_{f r}$ are greater than zero, and $\omega_{r r}, \omega_{a a}$, and $\omega_{f f}$ are positive and less than $(1+\imath) \equiv \mathrm{R}$, where $\mathrm{\imath}$ is the interest rate. The error terms $\left(\varepsilon_{i t+1}\right.$ for $i=g, p, r, a, f)$ capture the "shocks" when realized values are different from expected values. The error terms are assumed mean zero and uncorrelated across the system of equations.

The dynamics in my model are not affected by the life cycle of the firm. For example, a firm in decline that discontinues its R\&D program would no longer need to manufacture new production facilities $\left(\omega_{f r}\right.$ times zero is zero) or incur advertising expenditures $\left(\omega_{a r}\right.$ times zero is zero). Investments would be reduced to spending just enough on facilities to maintain them $\left(\omega_{f f}\right)$ for the duration of the firm's diminishing cash flows. The cash flows would decay at the rates (1$\left.\omega_{g g}\right)$ and $\left(1-\omega_{p p}\right)$ as the firm's products are replaced with new ones introduced by competitors. 
Some of the expected cash flows of a firm, such as interest revenue or expense, relate to financial assets rather than capital investments. Assuming that they are marked-to-market, these financial assets $\left(f a_{t}\right)$ have a one-to-one relationship with firm value $\left(v_{t}\right)$. Without loss of generality $^{20}$, the model can be simplified by removing these financial assets to arrive at the value of operating assets $\left(v o_{t}\right)$ which is a weighted sum of the cash flows from the information dynamics:

$$
v_{t}-f a_{t} \equiv v o_{t}=\pi_{g} c r g_{t}+\pi_{p} c r p_{t}+\pi_{r} r d_{t}+\pi_{a} a d v_{t}+\pi_{f} \text { prodfac }_{t}
$$

with the following weights (derived in Appendix B):

$$
\begin{array}{lll}
\pi_{g}=\Phi_{g} \omega_{g g} & \pi_{p}=\Phi_{p} \omega_{p p} & \pi_{r}=R \Phi_{r} \lambda_{r}+1 \\
\pi_{a}=R \Phi_{a} \lambda_{a}+1 & \pi_{f}=R \Phi_{f} \lambda_{f}+1 &
\end{array}
$$

where:

$$
\begin{aligned}
& \Phi_{i} \equiv \frac{1}{R-\omega_{i i}} \text { for } i=g, p, r, a, f \\
& \lambda_{r} \equiv\left(\Phi_{a} \lambda_{a} \omega_{a r}+\Phi_{f} \lambda_{f} \omega_{f r}-1\right) \\
& \lambda_{a} \equiv\left(\omega_{p a} \Phi_{p}-1\right) \\
& \lambda_{f} \equiv\left(\omega_{p f} \Phi_{p}-1\right)
\end{aligned}
$$

The weights on cash receipts $\left(\pi_{g}=\Phi_{g} \omega_{g g}\right.$ and $\left.\pi_{p}=\Phi_{p} \omega_{p p}\right)$ represent the expected future cash flows from past investments. The structure is similar to the Gordon growth model which has

$$
\text { price }_{t} \quad \begin{aligned}
& =\mathrm{E}\left[\text { dividends }_{t+1}\right] \\
& (\text { return }- \text { growth })
\end{aligned}
$$

except that my model uses next period's expected cash receipts $\left(\omega_{g g} c r g_{t}\right.$ and $\left.\omega_{p p} c r p_{t}\right)$ instead of expected dividends in the numerator, and the growth is captured by the persistence parameters $\left(\omega_{g g}, \omega_{p p}\right)$ in the denominator $\left(\Phi_{g}=\frac{1}{R-\omega_{g g}}\right.$ and $\left.\Phi_{p}=\frac{1}{R-\omega_{p p}}\right)$.

The valuation weights on cash investments $\left(\pi_{r}, \pi_{a}\right.$, and $\left.\pi_{f}\right)$ incorporate the NPV components that I use in this paper to quantify economic rents. Following Christensen and Feltham (2003) the Net Present Value (NPV) of a dollar invested is represented by the $\lambda$ term,

\footnotetext{
${ }^{20}$ See discussion in section 3.2 of this thesis.
} 
which is a function of the assumed information dynamics. For example, the advertising NPV term is $\lambda_{a}=\left(\omega_{p a} \Phi_{p}-1\right)$. In order for advertising to be a positive NPV investment, the present value of the series of cash flows generated $\left(\omega_{p a} \Phi_{p}\right)$ must be greater than the cost of generating them $(-1)$. The cash flow series capture the impact of advertising on cash receipts from patented drugs in the next year $\left(\omega_{p a}\right)$ and in subsequent years based on the decaying pattern of patented drug revenues $\left(\Phi_{p}=\frac{1}{R-\omega_{p p}}\right)$.

In addition to the NPV term $\left(\lambda_{a}\right)$, the valuation weight $\left(\pi_{a}=R \Phi_{a} \lambda_{a}+1\right)$ is a function of one plus the required rate of return $(R)$ and a parameter that captures the value from growth in advertising investments $\left(\Phi_{a}=\frac{1}{R-\omega_{a a}}\right)$, both of which are assumed to be non-negative. If the investment is zero-NPV such that $\lambda_{a}=0$, the first term in the valuation weight drops out and the value is 1: the firm eventually recoups exactly the present value of the amount invested. If the project is positive NPV such that $\lambda_{a}>0$, the valuation weight is greater than 1 and the NPV parameter $\left(\lambda_{a}\right)$ can be derived for given values of $\omega_{p a}$ and $\Phi_{p}$. Note that the model assumes the investment does not generate any cash flows in the period the investment is made. This assumption could be violated for advertising investments, since these often generate immediate cash flows. The model limitation is not likely to affect investments in R\&D or production facilities, which are slower to generate cash flows.

\subsection{Hypothesis Development}

Based on the modeling assumptions proposed in the previous section, all the variables in equation 2.1 are expected to have positive valuation weights. If investments in $R \& D$, advertising, and production facilities are zero NPV their valuation weights should equal one. If they are positive NPV investments then their valuation weights will exceed one. Economic theory suggests that rents should be zero in equilibrium. In the long run, if incumbent firms consistently generate positive NPV projects, entrants are attracted to the industry and the increase in competition reduces the NPV to an equilibrium level of zero. Conversely, if investments turn out 
to be consistently negative NPV projects, firms leave the industry and invest their capital elsewhere. The number of firms that sell patented prescription drugs has remained relatively stable over the last few decades, which suggests that the industry is in equilibrium. However, even in equilibrium, if there are barriers to entry and market inefficiencies it is possible for firms to earn economic rents that are not driven away by competition. This setting does not preclude the occasional occurrence of a negative NPV investment. Investments can have an ex post realized value that is different from its ex ante expected value. Assuming that management's objective is to maximize shareholder wealth, firms would not choose ex ante to invest in negative NPV projects. Since investments in $R \& D$ and advertising are discretionary, management can simply disregard projects that are not expected to earn sufficiently high returns. However, some investments turn out ex post to be negative NPV due to such events as a change in demand, actions by a competitor, or random occurrences. In my model, the NPV is estimated with a measure of the market value of the firm that is contemporaneous with the investment, therefore it captures the ex ante expectations that investors have of the net profits on the investment. Consequently, the NPV parameters investigated in this paper are expected to be non-negative. For each type of investment I consider a form of market imperfection that could lead to positive economic rents in this industry.

When R\&D investments are made, there is much uncertainty about the net cash flows. Inflows may not occur for several years after the initial investment has been made and the probabilities are relatively slim; the FDA approves on average 1 in 5,000 compounds $^{21}$ discovered in laboratories. The patent protection system was designed to promote $R \& D$ by providing a period of temporary market exclusivity during which a firm can recoup its investments by charging prices that are higher than the marginal cost of the drug. Ideally, the length of the period of market exclusivity allows firms to just break even on the cost of their R\&D program. This would generate an NPV parameter of zero on R\&D investments. If the

\footnotetext{
${ }^{21}$ Source: PhRMA, Pharmaceutical Industry Profile 2005.
} 
period of market exclusivity is longer, firms have an opportunity to earn excess returns, which leads to a positive NPV parameter on R\&D.

Both informative and persuasive advertising can affect the NPV of a dollar of advertising investments. With informative advertising the therapeutic markets expand as advertising leads more people to seek medical treatment, and this could generate cash flows that are in excess of the returns required on the investment. With persuasive advertising, rents are generated as a result of shifts or changes in the shape of the demand curve for the product. If marketing is persuasive, advertising shifts both the demand curve and the average cost curve of the firm. In order to recover its investment, the firm must charge a higher price. An increase in price results in lost sales, where the loss is a function of the price elasticity of demand. But the advertising also generates more revenues, and the gain is a function of how sensitive the demand is to advertising. The net of these two effects determines the profitability of advertising. Alternatively, the goal of persuasive advertising can be to change the shape of the demand curve to reduce the elasticity so that prices can be raised without losing sales. With inelastic demand, the firm can charge prices that are above marginal cost, and this leads to economic rents. A positive NPV parameter on advertising investments is consistent with both informative and persuasive advertising.

The valuation weight on advertising investments $\left(\pi_{a}\right)$ may have changed during the time period covered in this paper. On August 8, 1997 the Food and Drug Administration relaxed the rules for Direct-to-Consumer advertising, causing many pharmaceutical firms to intensify their public broadcast marketing. Based on the fact that pharmaceutical firms lobbied for the regulation change ${ }^{22}$, it is likely that these firms expected the new rules to generate higher returns on their advertising investments. I hypothesize that the valuation weight on advertising investments increased after 1997. The derivation from the previous section shows that the increase in the valuation weight could be attributed either to the NPV term $\left(\lambda_{a}\right)$ or the persistence

${ }^{22}$ Source: Donohue (2006). 
parameter $\left(\omega_{a a}\right)$. The new advertising rules could lead to more economic rents, thereby increasing the NPV term. Alternatively the relaxation of rules could lead to a growth in advertising investments, resulting in a higher level of persistence.

Expenditures on production facilities can be positive NPV investments if size serves as a barrier to entry which allows incumbent firms to extract monopoly profits. Size as a barrier to entry is explained by game theory: firms retain surplus capacity as a threat that they will flood the market and depress prices should a competitor enter their niche markets ${ }^{23}$. Size can also be a barrier to entry if incumbents have lower production costs through economies of scale. If size constitutes a barrier to entry, and investments in capital assets are associated with size, then this would generate a positive estimate of the NPV of a dollar invested in production facilities.

Although the NPV parameters were modeled separately in my pharmaceutical valuation model, it is likely that economic rents are the result of an interaction of the market imperfections described in this section. For example, a product that is protected by patents has fewer close substitutes, which makes persuasive advertising more successful. Size as a barrier to entry can also reduce the number of products available in the market, which makes demand more inelastic and improves the effectiveness of advertising.

\subsection{The Empirical Model}

I calibrate the theoretical model represented by equation 2.1 with accounting data in the following regression model:

$$
v o_{j t}=\alpha_{j t}+\beta_{\mathrm{g}} c r g_{j t}+\beta_{\mathrm{p}} c r p_{j t}+\beta_{\mathrm{r}} r d_{j t}+\beta_{\mathrm{a}} a d v_{j t}+\beta_{\mathrm{f}} \operatorname{prodfac}_{j t}+\varepsilon_{j t}
$$

The model, which is specified for firm $j$ at time $t$, is estimated by Ordinary Least Squares (OLS). Proxies for the variables $r d_{j t}, a d v_{j t}$, prodfac $c_{j t}$, and $v o_{j t}$ are readily available from Compustat and are described in Appendix A. The constructs for $r d_{j t}$ and $a d v_{j t}$ are the advertising expenditures

\footnotetext{
${ }^{23}$ See Microeconomic Theory by Mas-Colel, Whinston, and Green (1995), page 406.
} 
and $\mathrm{R} \& \mathrm{D}$ expenditures reported in the income statement. The variable prodfac $c_{j t}$ is capitalized expenditures from the cash flow statement when this data is available. If it is not available in the cash flow statement then it is estimated as the change in property, plant and equipment (PPE) adjusted for depreciation. In constructing a proxy for $v o_{j t}$, I assume that all assets and liabilities are marked-to-market except for PPE and intangibles. All marked-to-market items are subtracted from the market value of equity to arrive at the $v o_{j t} v^{\text {variable }}{ }^{24}$. The proxies for $c r g_{j t}$ and $c r p_{j t}$ are the disaggregated revenues in the notes to the financial statements. These are hand-collected from each annual financial statement, which generally disaggregates the revenues between "sales from patented drugs" and "sales from other products".

A few econometric issues must be addressed before estimating the model. The first econometric problem arises because the regression model has an incomplete list of variables that affect the market value of the firm. As long as the omitted variables are not correlated with the explanatory variables the intercept ${ }^{25}$ will capture the mean effect of the omitted variables. A second problem arises because the sample is comprised of different sized firms. This could lead to spurious correlation simply from the fact that large firms tend to have large market values as well as large cash flows. The size difference also leads to heteroskedastic errors. Since OLS minimizes the squared errors, the large errors generated by large firms have a disproportionate influence. Controlling for size mitigates these problems. Two common control methods used in accounting research are to deflate each variable by a size proxy, or include that proxy as an independent variable. Since the former method is more commonly used and justified by Lo (2005), the regression variables and the intercept are scaled by the prior period value of total

\footnotetext{
${ }^{24}$ The variable $v o$, is the market value of equity minus net financial assets $(f a)$. My construct for $f a$ is [total assets - ppe - intangibles - total liabilities]. Based on the balance sheets typically found in this industry my $f a$ construct captures most items that are recorded approximately at market value (cash, marketable securities, accounts receivable, inventories, prepaid expense, accounts payable, current liabilities, and debt) but it also captures a few balance sheet items that are not as easy to classify. These items (investments accounted for by the equity method, other assets, and deferred taxes) are generally not significant but for completeness, I verify that the main results hold when these items are excluded from $f a$.

${ }^{25}$ Since the intercept is scaled, it will capture the scaled effect of omitted variables. Note that this model specification alters the interpretation of the $\mathrm{R}^{2}$ statistic.
} 
assets $\left(\_s_{i t}\right)$. I choose this scaling variable because I expect that total assets will control for preexisting conditions better than sales, which tend to be volatile, or market value of equity, which is a component of the dependent variable. With scaled variables, regression model 2.2 becomes:

$$
v o \_s_{j t}=1 \_s_{j t}+\beta_{\mathrm{g}} c r g \_s_{j t}+\beta_{\mathrm{p}} c r p \_s_{j t}+\beta_{\mathrm{r}} r d \_s_{j t}+\beta_{\mathrm{a}} a d v \_s_{j t}+\beta_{\mathrm{f}} p r o d f a c \_s_{j t}+\varepsilon_{j t} .
$$

Throughout the rest of the paper I omit the subscript $\left(\_s_{j t}\right)$ on the empirical variables to make my writing more concise. However all variables discussed from this point forward are scaled by the beginning period value of total assets.

An important concern in estimating regression model 2.3 is the potential for measurement error in the investment proxies. For the $a d v$ variable, the measurement error comes from firms inconsistently reporting their advertising expenditures. Firms are not required to provide this information, therefore the act of reporting advertising expenditures could characterize a disclosure strategy that is not modeled in this paper. The estimated valuation weight on advertising $\left(\hat{\beta}_{a}\right)$ may pick up the value associated with the disclosure strategy rather than the value of advertising. When advertising investments are not disclosed separately, there is inconsistent treatment with respect to where they are included in the income statement. Firms that don't segregate advertising expenditures often include it with the selling, general and administration expense (SG\&A) in the income statement. A recent estimate is that marketing expenditures account for about $35 \%$ of a pharmaceutical firm's SG\&A ${ }^{26}$ therefore I run some tests using SG\&A as an alternative proxy for the advertising variable $(a d v)$. Some of the marketing initiatives are grouped with research, presumably because the public is generally more supportive of the latter ${ }^{27}$. Even if firms disclose their advertising investments, the total expenditure is a combination of spending on television, journal, and magazine advertisements as

${ }^{26}$ Source: Angell, M. (2004). The truth about drug companies . New York: Random House.

${ }^{27}$ At a minimum, Phase IV trials (which are done after the drug has been approved to "test" the market response) are reported as research when they are really marketing in nature. 
well as money spent on detailing (marketing) directly to physicians and hospitals. Although each marketing strategy has the potential to reduce the elasticity of demand for the firm's product, the different methods are likely to yield different opportunities for economic rents.

The research expenditure reported in the income statement is a noisy proxy for investments in $R \& D$ for four reasons. The first issue is that $R \& D$ comprises several fundamentally different processes. Clinical trials in Phase I and Phase II represent the risky, innovative investments that we generally think of as $R \& D$, but Phase III trials are similar to a cost of goods sold that should be minimized. The market response on R\&D expenditures would theoretically be different at each Phase. The second issue is that, even within each Phase, some research projects are more valuable than others. This is investigated in a recent paper by $\mathrm{Xu}$, Magnan, and André (2007) who find that the value of R\&D is a function of metrics that are associated with the probability of success (from the perspective of both the firm and the drug) and the market potential of the drug. Since I use the aggregate R\&D expenditure in my model, the estimated coefficient on $r d$ will average out all these effects and the variability will decrease the power of my tests. Thirdly, pharmaceutical firms often have the option of "purchasing" R\&D from universities or biotech companies, and this is a fundamentally different process from the inhouse R\&D depicted in my model. Purchased R\&D consists of product rights and technology obtained through business acquisitions, direct purchases, or licensing agreements. When the purchased R\&D has future expected benefits, the firm capitalizes it with intangibles. Purchased R\&D that has no future benefits are expensed in the income statement. Purchased R\&D investments are not usually material but I include proxies for them in the sensitivity analysis section of this chapter. Lastly, as with advertising, reporting $R \& D$ is a voluntary choice and may be done inconsistently between firms.

My construct for investments in production facilities is an incomplete measure of the investments that deter potential entrants. While this does not affect the statistical properties of the coefficient on the prodfac variable, it is important to be aware of other barriers to entry in this 
industry. Pharmaceutical firms that sell patented drugs generally maintain an extensive network of marketing sales force, which may be more effective than firm size at reducing competition. The cost and complexity of setting up and maintaining a marketing network acts as a barrier to entry in a similar way that a distribution network could deter entrants in other industries. Expenditures on the marketing network consists mainly of annual salary and bonuses to marketing representatives, which is recorded as cost of goods sold or SG\&A therefore they are not included in my investment variables.

The cash flow proxies also contain some measurement error. The variables $c r g$ and $c r p$ are meant to capture the net cash flows from the sale of therapeutics but since few firms report net revenues I use gross revenues as proxies. The bias in the coefficients can be inferred using the profit margins. Based on industry knowledge ${ }^{28}$ and on the financial statements of firms that report net revenues by product type ${ }^{29}$, the profit margin on patented drug is approximately $60 \%$ while the profit margin on generic and OTC drugs is around 40\%. My proxies overstate the true values of $\operatorname{crg}$ and $\operatorname{crp}$ by approximately 2.5 times and 1.7 times respectively ${ }^{30}$, and consequently understate their respective coefficients by the same magnitudes.

One important omitted variable that is likely to affect firm value is the FDA approval of new drugs. At first glance, it appears that this omitted variable may be correlated with the advertising proxy because share price increases in response to the FDA approval while the firm concurrently invests in a large marketing campaign. However, this is not the case. Torabzadeh et al. (1998) investigate the stock price returns surrounding pharmaceutical firm announcements and find that much of the reaction occurs when the drug is approved for testing, and that the reaction at the time of FDA approval is subdued.

\footnotetext{
${ }^{28}$ Angell, M. (2004). The truth about drug companies. New York: Random House.

${ }^{29}$ For example, Barr Pharmaceutical, Annual Report (2003).

${ }^{30}$ To obtain an estimate of the bias, let netcrp be net cash receipts on patented drugs, which is the latent variable that $c r p$ is meant to represent. A $60 \%$ profit margin in patented drugs gives: $c r p-.4 c r p=n e t c r p$ $\rightarrow(1-.4)$ crp $=$ netcrp $\rightarrow .6$ crp $=$ netcrp $\rightarrow$ crp $=1.7$ netcrp. Similarly, if netcrg is net cash receipts on generic drugs, the $40 \%$ profit margin obtains the following bias for these cash flows: $\mathrm{crg}-.6 \mathrm{crg}=n e t c r g$ $\rightarrow .4$ crp $=$ netcrg $\rightarrow$ crg $=2.5$ netcrg .
} 
Finally, the new regulation for Direct-to-Consumer advertising is a structural change in the relationship between advertising and the market value of the firm. I test for a change in the slope of the advertising regression coefficient $\left(\hat{\beta}_{a}\right)$ from regression model 2.3 by adding an indicator variable (postadv) that is equal to advertising expenditures in the years after 1997.

The final regression model has numerous variables but the number of firms selling patented drugs is small. A firm-specific least-squares regression may not have sufficient power to estimate the effect of the variables of interest therefore I construct a pooled cross-sectional time-series sample. I estimate the coefficients with Ordinary Least Squares but I confirm the main results with a two-stage Generalized Least Squares (GLS) regression. With GLS a variance-covariance matrix is estimated in the first stage then used in the second stage in a Generalized Least Squares estimation of the parameters. This technique allows for heteroskedasticity, autocorrelation and contemporaneous correlation.

\subsubsection{Data}

Accounting data for all pharmaceutical firms in NAICS code 325412 (Pharmaceutical Preparation Manufacturing) are obtained from Compustat for the years 1995 to 2003. This yields 2,176 observations on 362 firms. Since time-series data is required to estimate the persistence of investments, the 257 firms with less than ten ${ }^{31}$ years of complete data are removed, reducing the sample to 839 observations on 101 firms $^{32}$.

The dynamics in my model apply to the subset of pharmaceutical firms that sell patented drugs but I run some analysis on the other pharmaceutical firms to investigate their differences. I allocate the firms to three categories based on their primary role in the industry. The firm-type (Big Pharma, OTC-Generic, or Biotech) is based on the Business Description section of their 10-

\footnotetext{
${ }^{31}$ The ten years of data results in only nine observations per firm since the information from the year 1994 is only used as the scaling variable (beginning value of total assets).

${ }^{32}$ My model is developed for firms that sell patented drugs. The firms that are removed are not likely to be the ones that manufacture and sell patented drugs. A comparison of the firms in my sample to prior literature (Table 1) confirms that this is the case.
} 
K reports. Firms are categorized as Big Pharma if they market and sell at least some drugs that have patent protection. The Business Description for these firms typically states that the company is in the business of discovering, developing, manufacturing, and marketing drugs, and includes a discussion of the status of patents. Big Pharma firms that operate in more than one business segment provide disaggregated information in the notes to the financial statements. Of the thirty-four firms classified as Big Pharma, nineteen sell patented drugs exclusively. For the remaining firms, revenues from patented drugs range from $1 \%$ to $92 \%$ of sales $^{33}$, with a mean proportion of $48 \%$.

Firms classified as OTC-Generic sell generic prescription drugs or over-the-counter (OTC) products but not drugs with patent protection. Of the twenty-nine firms in this category, nineteen sell OTC products exclusively, four sell generic drugs exclusively, and six sell both. The OTC products are mainly cosmetics, skin care products, and nutritional supplements.

Biotech firms do not operate in the generic or OTC markets but mainly earn revenues from licensing fees on patented drugs. These fees can be royalties, milestone payments, or revenues from the sale of rights to patented innovations. The thirty-eight Biotech firms generally describe their business strategy as conducting research and partnering with firms that have the marketing expertise to sell therapeutics. Table 2.1 lists the 101 firms that make up the full sample and compares this set of firms to samples used in prior accounting papers.

\subsubsection{Descriptive Statistics}

Table 2.2 shows the classification (positive, negative, or zero) of the Compustat data that make up the variables in my model. The distribution shows that large portions of data \#189 (SELLING, GENERAL, AND ADMINISTRATION EXPENDITURES) is unavailable, which is surprising since this is a standard line items in an income statement. Less surprisingly, only $17 \%$ of data \#18 (INCOME BEFORE EXTRAORDINARY ITEMS) is negative for Big Pharma firms

\footnotetext{
${ }^{33}$ Revenues attributable to patent drugs are $1 \%$ on average for Barr Pharmaceutical and $92 \%$ on average for Sanofi Aventis. The firm averages are calculated over 9 years from 1995 to 2003.
} 
versus 51\% for the Full Sample. Advertising expenditures (data \#45) are reported in only $37 \%$ of the Big Pharma observations, which suggests that this variable has measurement error as discussed in the previous section.

Table 2.3 shows the mean values of the regression variables by firm type as well as the mean scaled values. Big Pharma firms tend to have the largest mean values of the variables but their scaled variables are far less skewed. The Pearson correlations in Panel A of Table 2.4 show that, for Big Pharma firms, the dependent variable (vo) is significantly positively correlated with patent revenues $(c r p), \mathrm{R} \& \mathrm{D}$ expenditures $(r d)$, advertising $(a d v)$, and investments in production facilities (prodfac) and negatively correlated with generic revenues ( $\mathrm{crg}$ ). Patent revenues ( $\mathrm{crp}$ ) are positively correlated with advertising $(a d v), \mathrm{R} \& \mathrm{D}(r d)$, and investments in production facilities (prodfac), which is in line with the information dynamics in my model. These results extend to Biotech companies (Panel C) but not to OTC-Generic firms (Panel B).

The regression variables for the Big Pharma firms seem to be appropriately distributed according to Table 2.5 but when I run the regressions I find that one observation exceeds the Cook's D cutoff value of 2. I remove this outlier, which leaves 302 Big Pharma observations for the analysis ${ }^{34}$.

\subsection{Valuation Weights}

A valuation weight on each type of investment is obtained by estimating regression model 2.3. The regression is estimated not only for the full sample but also by firm-type in order to test whether valuation weights differ based on a firm's role in the production chain. The regression results are reported in Table 2.6. The first column (All Firms) shows the parameter estimates from a regression model with all firms combined. The next three models (Panel A) report the estimates by firm-type: Big Pharma, OTC-Generic, and Biotech. The differences in

\footnotetext{
${ }^{34}$ The outlier is the observation of the firm Inkine for the year 1998. Every Inkine observation is removed when I corroborate the results in this chapter with Generalized Least Squares (GLS) estimates, since GLS requires all firms to have the same number of observations.
} 
parameter estimates are reported in Panel B. The first column of Panel B shows the adjustment that reconciles the OTC-Generic coefficients to the Big Pharma coefficients. The next column reports the adjustments required to get from the Biotech coefficients to the Big Pharma coefficients.

The regression analysis with the full sample (All Firms) produces estimated valuation weights of 8.36 on R\&D expenditures $(r d)$ and 9.93 on advertising investments $(a d v)$. The regression coefficients are statistically significant at the $1 \%$ level and the magnitudes are consistent with prior research. Chauvin and Hirschey (1993) get a coefficient of 12.6 on R\&D and a coefficient of 4.8 on advertising in a regression of the market value of pharmaceutical firms ${ }^{35}$. The estimated valuation weight on investments in production facilities (prodfac) is also large and positive with a coefficient of 18.09 , but there is no prior literature to compare this to.

The valuation weights obtained with the full sample are not appropriate for estimating the NPV of a dollar invested since only Big Pharma firms are expected to have the ability to extract the economic rents discussed in the hypothesis section of this paper. When the regression model is estimated only with Big Pharma firms, the coefficients change. The point estimate on the valuation weights increases from 8.36 to 13.19 for $R \& D$ investments, from 9.93 to 15.85 for advertising investments, and from 18.09 to 19.13 for investments in production facilities. Consequently, including Biotech and OTC-Generic firms in the sample causes a downward bias on the estimated valuation weights.

The regression results in Table 2.6 may be affected by the measurement issues discussed in section 2.4. I test the robustness of the results for Big Pharma firms by observing whether the regression coefficients change if I remove any of the thirty-two Big Pharma firms. My finding is that the valuation weights on investments in $R \& D$ and production facilities are robust to this

\footnotetext{
${ }^{35}$ In their model, the dependent variable is the market value of equity while their explanatory variables are proxies for cash flow, growth, risk, and market share along with advertising and R\&D expenditures.
} 
analysis, but the valuation weight on the advertising investment variable is not ${ }^{36}$. Therefore inference based on results from the advertising variable may not be appropriate and my conclusions include a caveat to this effect.

The Big Pharma regression results in Panel A show that the coefficient of 0.10 on generic cash receipts $(\mathrm{crg})$ is not statistically significant, while the coefficient of 2.12 on cash receipts from patented products (crp) is significant at the $1 \%$ level. As explained in section 2.4 of this paper, the coefficients on $c r g$ and $c r p$ are biased downwards because I use gross cash receipts instead of net cash flows in the regression. Based on the average profit margins on patented and generic drugs presented in section 2.4, the bias leads to an overstatement of the cash receipts variables and an understatement of the regression coefficients with an approximate magnitude of 1.7 for $\operatorname{crp}$ and 2.5 for $\mathrm{crg}$.

The differences in valuation weights by firm-type are explored in Panel B of Table 2.6. The incremental value of the Big Pharma coefficients over OTC-Generic is obtained by adding a set of indicator variables for the Big Pharma firm observations, and estimating the regression model with a combined sample of Big Pharma and OTC-Generic firms. The same is done with Biotech firms to tabulate the last column in Panel B.

The firm-type regression coefficients on the $r d$ variable in Panel A suggest that Big Pharma and OTC-Generic firms have larger valuation weights on R\&D investments (with coefficients of 13.19 and 15.45, respectively) than Biotech firms with a coefficient of 7.96. According to the p-values in Panel B, the difference between the R\&D coefficients for Big Pharma and Biotech is statistically significant.

The coefficient on advertising investments $(a d v)$ is statistically significant for Big Pharma firms and Biotech companies, but not for OTC-Generic firms. The valuation weight on advertising appears to be larger for Biotech firms (with a coefficient of 24.54) than for Big

\footnotetext{
${ }^{36}$ Specifically, if the firm Medicis is removed, the coefficient on the advertising investment variable $(a d v)$ drops to 8.62 with a p-value of .13. If I remove a second firm (either Bausch \& Lomb, Forest Laboratories, or Astrazeneca), the coefficient on $a d v$ once again becomes large and positive.
} 
Pharma firms (with a coefficient of 15.85) but the test of differences in Panel B has a p-value of .12 , which is not significant at conventional levels. The positive coefficient on $a d v$ is consistent with Big Pharma firms using persuasive advertising strategies to earn economic rents. It is also consistent with informative advertising leading to a therapeutic markets expansion that generates revenues in excess of the return required on advertising investments. However, the economic rents hypothesis does not necessarily extend to Biotech firms. I investigate the few Biotech firms that report advertising expenditures and find that these firms promote some of their products to a few small target groups in addition to licensing their products to Big Pharma companies. While it is possible that Biotech companies earn economic rents from persuasive advertising, a more likely explanation is that the valuation weight reflects a market premium for the subset of Biotech firms that advertise. Biotech companies that advertise are likely to be the most successful and established firms in the biotech sector, and the ones with the potential to become a Big Pharma firm.

The coefficients on investments in production facilities (prodfac) are similar for all firmtypes, with an estimate of 19.13 for Big Pharma firms, of 16.16 for OTC-Generic firms, and of 14.67 for Biotech companies. The parameter estimates are not significantly different across firmtypes according to the tests of incremental value in Panel B. Interpretation of these parameter estimates is not immediately intuitive, given that the prodfac variable does not measure the size of the firm. Conceptually, one might expect barriers to entry to be related to the "stock" (total past investments) of production facilities rather than the "flow" (change in total investments) but the theoretical model is formulated such that the benefit of past investments flows through the cash receipt variables ( $\mathrm{crg}$ and $\mathrm{crp}$ ), and the coefficient on prodfac reflects the value of new investments in production facilities. ${ }^{37}$

\footnotetext{
${ }^{37}$ A proxy for the "stock" of investments $\left(p e_{t-1}\right)$ is added to the accounting model in Chapter 3 , but its coefficient is not statistically significant; market value continues to load on the prodfac variable. A profitability measure is added in section 2.6 .2 of this chapter to verify whether profitability is a latent
} 
The coefficients on $a d v, r d$, and prodfac appear to be larger than one, which is consistent with the hypothesis that Big Pharma firms earn economic rents on the three types of investments. The large magnitudes of the coefficients leave little doubt that they are greater than one, but for thoroughness I use an F-statistic (not tabulated) to confirm that each investment coefficient is significantly greater than one for Big Pharma firms, and find that they are.

The results in Table 2.6 are robust to the following four changes in specification (not tabulated). The coefficients are similar when the regression model is estimated by Generalized Least Squares $^{38}$, therefore autocorrelation and cross correlation of error terms are not problematic with this data set. The coefficient estimates are robust to trimming the top and bottom $1 \%$ of the investment variables, except that the valuation weights on advertising investments $(a d v)$ becomes smaller in magnitude and lose some statistical significance ${ }^{39}$. I add a set of annual indicator variables to capture the effect of market fluctuations during the time period and find no material change in the coefficients on the investment variables $(a d v, r d \text {, and prodfac })^{40}$. The estimates are similar if I control for size by adding an independent variable (total assets) instead of scaling except that the coefficient on $\mathrm{crg}$ becomes significant with a coefficient of 2.53 .

\subsubsection{Change in the Advertising Valuation Weight}

An important change in regulation occurred during the time period examined in this paper. In 1997 the Federal Drug Administration relaxed the rules regarding the advertisement of prescription drugs on television. These new rules may have changed the structural relationship between advertising investments and firm value. In this section I test whether the valuation

variable that increases market value and concurrently increases investments in production facilities, but the profitability measure has no effect on the regression results.

${ }^{38}$ The Generalized Least Squares estimation requires that all firms have observations in the same time periods. Since one of Inkine's observations was identified as an outlier and removed, all Inkine observations are removed for the GLS estimation.

${ }^{39}$ The coefficient on $a d v$ remains significant at the $10 \%$ level for Big Pharma firms but not for Biotech firms.

${ }^{40}$ Two of the indicator variables are significant: the intercept is adjusted for the year 1996 (coefficient of 1.45 with p-value of .03) and for the year 2002 (coefficient of -1.67 with p-value of .01). 
weight on advertising changed with the relaxation of direct-to-consumer advertising rules. As a first test, I add an indicator variable $\left(p o s t a d v_{-} s_{j t}\right)$ to regression model 2.3 to estimate the change in the slope coefficient of the advertising investment variable. The indicator variable is the advertising investment variable $(a d v)$ multiplied by an indicator variable that is equal to one in the years after 1997, and zero otherwise. The regression results are reported as Model 1 in the first column of Table 2.7. The estimate of the change in slope coefficient on advertising is negative with a coefficient of -4.56 , but not statistically significant with a p-value of 65 .

Next I divide the sample and estimate the valuation weight before (Pre 1998) and after (Post 1997) the change in regulation to see whether the valuation weight changed. These estimates are presented in Table 2.7 as Model 2. The results using OLS show that the coefficient on the advertising investment $(a d v)$ variable decreased after the regulatory change from a value of 23.84 (p-value of .03) to a point estimate of 6.87 (p-value of .28). The results using the FamaMacBeth approach ${ }^{41}$ show that the coefficient on $a d v$ decreased from 21.08 (p-value of .22) to -.68 (p-value of .78). Since few of the parameter estimates are statistically significant in this analysis, the regression results do not provide convincing evidence that the change in regulation had an effect on the value of advertising. In addition, the measurement issues identified in the previous section cast doubt about the validity of any of the advertising variable coefficients. However, the point estimates suggest that, if anything, the valuation weight on advertising investments decreased after 1997.

A reduction in the regression coefficient on the advertising variable is not necessarily indicative of a decrease in the value of advertisement investments. Investments usually generate diminishing marginal returns, and firms theoretically invest up to the point where the marginal return is equal to zero. If the value of advertising investments increased after 1997, this may have pushed the marginal return above zero, leading to more expenditures on advertising. The value of

\footnotetext{
${ }^{41}$ The Fama-MacBeth method involves estimating the regression model separately each year, then calculating the mean coefficient along with a p-value that the mean is significantly different from zero.
} 
these additional expenditures could be positive but smaller than the mean value of advertising investments before the regulatory change, which reduces the regression coefficient. ${ }^{42}$

An alternative method of testing whether the value of advertising investments changed in conjunction with the relaxation of advertising rules is to examine the capital market reaction to the regulatory change. According to Boscaljon (2005), pharmaceutical firms experienced a $1.75 \%$ average abnormal return on their market value in the two-day window surrounding the announcement of the regulatory change. However, the test statistic used in Boscaljon (2005) is susceptible to type I error, therefore a more robust event study of the regulatory change is conducted in Chapter 4 of this thesis.

\subsection{Net Present Value (NPV) Derived from the Valuation Weights}

The results in section 2.5 show that the three types investments investigated with my pharmaceutical valuation model (advertising, $R \& D$, and production facilities) have regression coefficient estimates that are greater than one, which suggests that they are positive NPV. The remainder of this chapter attempts to quantify and analyze the economic rents in order to make inferences about how the rents compare across the three types of investments, and how they influence the valuation weights.

Based on equation 2.1, the theoretical valuation weights on investments follow the general structure $\pi=\mathrm{R} \Phi \lambda+1$, where $\lambda=\omega \Phi-1$. There are two ways to estimate the NPV parameters $(\lambda)$. One way is to estimate the dynamics by firm, and then plug them into the NPV equations. For example, the valuation weight on advertising investments is $\pi_{a}=R \Phi_{a} \lambda_{a}+1$, where $\lambda_{a}=\left(\omega_{p a} \Phi_{p}-1\right)$. The dynamics $\omega_{p a}$ and $\Phi_{p}$ can be estimated, and then plugged into the equation $\lambda_{a}=\left(\omega_{p a} \Phi_{p}-1\right)$. This method has two drawbacks. The first limitation is that the estimated

\footnotetext{
${ }^{42}$ Donohue et al. (2007) report that annual promotional spending increased in each year from 1997 to 2003 , but it is not possible for me to determine whether the regulatory change was the impetus for the jump in spending in 1998.
} 
information dynamics are rather noisy for many firms ${ }^{43}$, which reduces my ability to calculate the NPV. The second drawback is that inference is conditional upon proper specification of the information dynamics within the NPV parameter.

Another way to quantify the NPV parameter is to infer it from the valuation weight on investments. For advertising investments the theoretical valuation weight $\pi_{a}=R \Phi_{a} \lambda_{a}+1$ can be expressed in terms of the advertising NPV component: $\lambda_{a}=\left(\pi_{a}-1\right)\left(\mathrm{R} \Phi_{a}\right)^{-1}$. The persistence parameter estimates required to construct the growth parameters $\left(\Phi_{a}\right)$ are significant for most firms in my sample ${ }^{44}$, and an estimate of the required rate of return R can be obtained. The NPV $\left(\lambda_{a}\right)$ is then estimated indirectly through the valuation weight on advertising investments $\left(\pi_{a}\right)$. More importantly, the NPV estimate holds under most linear specifications of the dynamics ${ }^{45}$. Therefore I derive the NPV parameters indirectly from the valuation weights on investments instead of estimating the underlying dynamics. Before estimating the NPV parameters, I need to adjust each of the investment variables as shown below. The adjustment in the case of advertising investments (ignoring for the moment the variables that are not directly linked to $a d v$ ) is as follows:

$$
\begin{aligned}
& v o_{\mathrm{t}}=\pi_{\mathrm{a}} a d v_{\mathrm{t}} \\
& v o_{\mathrm{t}}=\left(\mathrm{R} \Phi_{\mathrm{a}} \lambda_{\mathrm{a}}+1\right) a d v_{\mathrm{t}} \\
& v o_{\mathrm{t}}=\mathrm{R} \Phi_{\mathrm{a}} \lambda_{\mathrm{a}} a d v_{\mathrm{t}}+a d v_{\mathrm{t}} \\
& v o_{\mathrm{t}}-a d v_{\mathrm{t}}=\lambda_{\mathrm{a}}\left(a d v_{\mathrm{t}} \mathrm{R} \Phi_{\mathrm{a}}\right)
\end{aligned}
$$

Defining $a d j a d v_{\mathrm{t}}=a d v_{\mathrm{t}} \mathrm{R} \Phi_{\mathrm{a}}$

$$
v o_{\mathrm{t}}-a d v_{\mathrm{t}}=\lambda_{\mathrm{a}} a d j a d v_{\mathrm{t}}
$$

Note that $\mathrm{R} \Phi_{\mathrm{a}}=\frac{R}{\left(R-\omega_{a a}\right)}$

\footnotetext{
${ }^{43}$ The dynamics estimates $(\omega)$ are statistically significant at better than the $10 \%$ level of significance for the following percentage of firms: $\omega_{\mathrm{ar}}=64 \%, \omega_{\mathrm{fr}}=9 \%, \omega_{\mathrm{pr}}=12 \%, \omega_{\mathrm{pa}}=73 \%$, and $\omega_{\mathrm{pf}}=9 \%$.

${ }^{44}$ The growth parameter $\Phi_{\mathrm{i}}$ is a function of the persistence of investment $i\left(\omega_{\mathrm{ii}}\right)$. Estimates of the investment persistence are statistically significant for the following percentage of firms: $\omega_{\mathrm{rr}}=94 \%$, $\omega_{\mathrm{aa}}=100 \%$, and $\omega_{\mathrm{ff}}=97 \%$, where significance is at the $10 \%$ level.

${ }^{45}$ For example, the valuation weight on $R \& D$ is $\pi_{r}=R \Phi_{r} \lambda_{r}+1=R \Phi_{r}\left[\Phi_{a} \lambda_{a} \omega_{a r}+\Phi_{f} \lambda_{f} \omega_{f r}-1\right]+1$. Even if the dynamics, which appear in the equation in the square brackets, are misspecified, the NPV term $\left(\lambda_{\mathrm{r}}\right)$ can be correctly estimated if we know $\pi_{\mathrm{r}}, \mathrm{R}$, and $\Phi_{\mathrm{r}}$ and the linear relation holds.
} 
I adjust all the variables from regression model 2.3 to obtain the NPV regression model specified for firm $j$ at time $t$ :

$a d j v o \_s j=1 \_s_{j t}+\gamma_{\mathrm{g}} c r g \_s_{j t}+\gamma_{\mathrm{p}} c r p \_s_{j t}+\gamma_{\mathrm{r}} a d j r d \_s_{j t}+\gamma_{\mathrm{a}} a d j a d v \_s_{j t}+\gamma_{\mathrm{f}} a d j p r o d f a c \_s s_{j t}+\varepsilon_{j t}$

where:

$$
\begin{aligned}
& \operatorname{adjvo}_{j t}=\left(v o_{j t}-a d v_{j t}-r d_{j t}-\operatorname{prodfac}_{j t}\right), \\
& \operatorname{adjrd}_{j t}=r d_{j t} \frac{R_{j}}{\left(R_{j}-\omega_{j r r}\right)} \\
& a d j a d v_{j t}=a d v_{j t} \frac{R_{j}}{\left(R_{j}-\omega_{j a a}\right)} \\
& \operatorname{adjprodfac}_{j t}=\operatorname{prodfac}_{j t} \frac{R_{j}}{\left(R_{j}-\omega_{j f f}\right)} \quad j=(1 \ldots \mathrm{N})
\end{aligned}
$$

In order to construct the adjusted variables I need estimates for the parameters $R_{j}, \omega_{j r}$, $\omega_{j a a}$, and $\omega_{\text {jff. }}$ I develop firm-specific constructs for these parameters. For the required rate of return $\mathrm{R}_{\mathrm{j}}$, I construct a proxy based on the CAPM theory and assuming an asset beta for the pharmaceutical industry of 1.40 based on Bernardo et al. $(2007)^{46}$. The CAPM expresses each firm's required rate of return on equity $\left(\mathrm{R}_{\mathrm{e}}\right)$ as a function of the market return $\left(\mathrm{r}_{\mathrm{m}}\right)$, the risk free return $\left(r_{f}\right)$, and the firm's equity beta $\left(\beta_{e}\right): R_{e}=r_{f}+\beta_{e}\left(r_{m}-r_{f}\right)$. Under the CAPM, the asset beta $\left(\beta_{\mathrm{a}}\right)$ is a weighted average of the equity beta $\left(\beta_{\mathrm{e}}\right.$ applied to the portion of equity $\left.\mathrm{E}\right)$ and the debt beta $\left(\beta_{\mathrm{d}}\right.$ applied to the portion of debt $\left.\mathrm{D}\right)$ :

$$
\beta_{\mathrm{a}}=\beta_{\mathrm{e}} * \frac{E}{D+E}+\beta_{\mathrm{d}} * \frac{D}{D+E}
$$

If we assume that debt beta is equal to zero:

$$
\beta_{\mathrm{a}}=\beta_{\mathrm{e}} * \frac{E}{D+E}
$$

we can solve for the equity beta:

$$
\beta_{\mathrm{e}}=\beta_{\mathrm{a}}+\beta_{\mathrm{a}} * \frac{D}{E}
$$

\footnotetext{
${ }^{46}$ Bernardo et al. (2007) estimate the asset beta of pharmaceutical firms to be 1.40 by unlevering the equity beta of individual pharmaceutical firms during the time period of 1995-2004. They report the mean asset beta by industry based on the Fama-French industry classification system.
} 
therefore my firm-specific construct for the required rate of return is:

$\mathrm{R}_{\mathrm{j}} \equiv 1+\mathrm{l}=1+\left(\mathrm{r}_{\mathrm{f}}+\beta_{\mathrm{je}}\left(\mathrm{r}_{\mathrm{m}}-\mathrm{r}_{\mathrm{f}}\right)\right)$

where:

the risk free rate is $\mathrm{r}_{\mathrm{f}}=5 \%$ based on the average t-bill rate in the time period investigated ; the estimated market premium is $\left(r_{m}-r_{f}\right)=7 \%$ based on historical excess returns to the $S \& P$ index from 1926 to 2005$)^{47}$;

the asset beta for firm $j$ is $\beta_{\mathrm{je}}=1.40+1.40 * \frac{D_{j}}{E_{j}}$ where the debt-to-equity ratio $\left(\frac{D_{j}}{E_{j}}\right)$ is calculated for each firm $j$ with Compustat data as described in Appendix A.

In this paper I use the mean asset beta for the pharmaceutical industry (1.40) to construct firm-specific required rates of return $\left(\mathrm{R}_{\mathrm{j}}\right)$. An alternative approach is to collect returns data from CRSP and estimate an equity beta parameter for each firm in my sample. The benefit of this approach is that it allows the equity beta to vary directly with the firm's operating and financial risk. The downside is that the estimates produce noisy measures of the firm-specific betas thereby adding more noise to the adjusted variables $\left(\operatorname{adjr}_{j t}, a_{d j a d v_{t}}, \operatorname{adjr}_{j t}\right)$. This concern is articulated in a paper by Fama and French (1997) who state that cost of capital estimates for industries are imprecise but they are likely to be more precise than cost of capital estimates for firms. Therefore I use the asset beta for the pharmaceutical industry but allow for some variability with respect to leverage. Recall that the equity beta is the sum of the asset beta and an adjustment for the leverage of the firm, through the $\frac{D_{j}}{E_{j}}$ term. Therefore variation in the firm leverage is reflected in my proxy for the required rate of return $\left(\mathrm{R}_{\mathrm{j}}\right)$. A possible extension to this section of the paper would be to explore whether my results change when asset betas are also allowed to vary by firm.

The firm-specific persistence parameters $\left(\omega_{j r r}, \omega_{j a a}, \omega_{j f f}\right)$ are proxied by the autoregressive coefficient obtained from regressing the firm's investment variable against the prior year's value of the investment variable. For example, as a proxy for the R\&D persistence parameter for firm $j$

\footnotetext{
${ }^{47}$ From Business Analysis \& Valuation by Palepu and Healy (2008), Fourth Edition, South-Western, p. 8-3.
} 
$\left(\omega_{j r r}\right)$, I use the autoregressive coefficient $\left(\hat{\delta}_{j r}\right)$ from the regression model: $r d_{j t}=\delta_{j r} r d_{j, t-1}+\varepsilon_{j t}$ estimated with nine years of data ${ }^{48}$ for that firm. Similarly, the autoregressive coefficient $\left(\hat{\delta}_{j a}\right)$ from the regression model: $a d v_{j t}=\delta_{j a} a d v_{j, t-I}+\varepsilon_{j t}$ serves as proxy for $\omega_{j a a}$, and the autoregressive coefficient $\left(\hat{\delta}_{j f}\right)$ from the regression model: $\operatorname{prodfac}_{j t}=\delta_{j f} \operatorname{prodfac}_{j, t-1}+\varepsilon_{j t}$ serves as proxy for $\omega_{j f f}$.

\subsubsection{Descriptive Statistics}

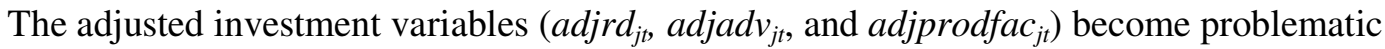
when the persistence constructs $\left(\omega_{j r r}, \omega_{j a a}, \omega_{j f f}\right)$ are very large because the persistence is subtracted from $\mathrm{R}_{\mathrm{j}}$ in the denominator of the adjusted variables. For example, the construct for $\operatorname{adjad} v_{j t}$ has the term $\left(\mathrm{R}_{\mathrm{j}}-\omega_{j a a}\right)$ in the denominator. If the persistence $\left(\omega_{j a a}\right)$ is greater than $\mathbf{R}_{\mathbf{j}}$, my estimate of the denominator is negative and the adjusted investment variable becomes negative when it should in theory be very large. Therefore I adjust observations with large values of persistence. I assume that the maximum rate of investment growth in this industry is $14 \%$ and winsorize persistence parameters that are above this value to 1.14. The distribution of the winsorized persistence parameters is reported in Table 2.8 and appears reasonable except for the adjusted advertising variable, which is zero for many of the firms. Since few firms have persistent advertising investments, I perform additional analysis on this subsample of firms later in this paper. I use the winsorized persistence parameters to construct the explanatory variables for the NPV regression, which are distributed according to Table 2.9.

\subsubsection{Main Results for NPV of Investments}

I use the explanatory variables from Table 2.9 to estimate the NPV of each dollar invested and report the results in Table 2.10. Given the noisiness of the data, the regression coefficients are an imprecise measure of the NPV therefore I also report a $75 \%$ confidence interval around the point estimate of the investment variables. The estimates in Table 2.10 are

\footnotetext{
${ }^{48}$ Each firm has nine years of data except for Inkine, which has eight years of data.
} 
robust to winsorizing the top and bottom $1 \%$ of observations and are similar when estimated with the Fama MacBeth method ${ }^{49}$. There are no observations with undue influence according to the Cook's D test ${ }^{50}$.

The coefficients on $c r g$ and $c r p$ are 1.29 and 3.71 respectively and both are statistically significant. In theory, these coefficients should be identical to the ones estimated with the valuation model in section 2.5 (coefficients of 0.10 on $\mathrm{crg}$ and 2.12 on $\mathrm{crp}$ ) but the point estimates in Table 2.10 are larger than those obtained with the valuation model. Since both models are estimated with the same data, the difference is due to econometrics. The NPV regression model in Table 2.10 is less restrictive because the underlying parameters $R$ and $\Phi_{i}$ are allowed to vary across firms, which leads to larger coefficients on $\operatorname{crg}$ and $c r p$, and causes $\operatorname{crg}$ to become statistically significant.

The coefficients on the adjusted investment variables (adjrd, adjadv, adjprodfac) in Table 2.10 are estimates of the NPV of each dollar invested in R\&D, advertising, and production facilities, respectively. The coefficients are all small but statistically significant. The NPV of the dollars invested are estimated as 0.15 for $\mathrm{R} \& \mathrm{D}, 0.38$ for advertising, and 0.15 for investments in production facilities. The economic interpretation of these coefficients is that a dollar invested in R\&D investments generates $15 \varnothing$ of net cash flows in excess of the returns required to compensate for the riskiness of the investment. By definition, these are economic rents on investments. Economic rents on a dollar invested in production facilities are similar at $15 \phi$ per dollar but rents on advertising investments are higher with an estimate of $38 \notin$ per dollar. This is confirmed with an F-test of the difference in coefficients, which rejects the null hypothesis of no difference between the coefficients on adjadv and the other two investment variables. This is also suggested

\footnotetext{
${ }^{49}$ With Fama-MacBeth the model is regressed by OLS for each year and the mean annual coefficient is reported. The estimated coefficients (not tabulated) are similar to the ones reported in Table 2.10 but the coefficient on adjprodfac is no longer statistically significant. This is likely caused by the lack of power from the Fama-MacBeth test, which has large standard errors since the mean coefficients are estimated with only nine observations (years).

${ }^{50}$ Cook's D tests whether the parameter estimate changes when a specific observation is excluded from the model. I use the standard Cook's D cutoff value of two.
} 
by the fact that the confidence interval of the adjadv coefficient does not overlap with the confidence intervals of the point estimates on adjrd and adjprodfac. A $75 \%$ confidence interval places the NPV estimate between $12 \varnothing$ and $18 \not$ for R\&D investments, between $24 \varnothing$ and $46 \varnothing$ for advertising, and between $11 \phi$ and $17 \phi$ for investments in production facilities.

The results in this section should not be interpreted as suggesting economic rents could be generated in perpetuity. My model assumes a linear relationship between investments and cash flows, and does not capture the more complex relationship between these two variables, which is usually characterized by diminishing marginal returns. Therefore the structure does not provide for inference on a marginal unit of investment. In addition, parameter estimates from a linear regression capture the mean effect of the variable rather than the marginal effect. Therefore the mean economic rent on $\mathrm{R} \& \mathrm{D}$ investments is estimated at $15 \phi$ per dollar but the economic rent on the last dollar invested may very well be close to zero. Economic rents are also likely to vary among the firms in my sample, with the estimated mean reported as the regression coefficient. Consequently the results in this section do not necessarily apply to all firms that sell patented drugs.

Recall from section 2.5 that a sensitivity test of the valuation model reveals that the coefficient on the advertisement variable is not robust to removing one of the firms (Medicis) from the sample. I perform the same test on the NPV regression model and find that the results reported in Table 2.10 are not driven by a specific firm. The coefficients on adjrd, adjadv, and adjprodfac remain significant and positive if any one firm (including Medicis) is removed. This change in robustness is likely due to the difference in model specification, whereby the underlying parameters $\mathrm{R}$ and $\Phi_{\mathrm{i}}$ are allowed to vary across firms in the NPV regression but not in the valuation model.

One interesting outcome of this analysis is that ranking investments based on economic rents results in a different order $($ adjadv $>$ adjprodfac $=$ adjrd $)$ than ranking them based on their valuation weights [(prodfac $>a d v>r d)$ according to their respective coefficients of 19.13, 15.85 
and 13.19 from Table 2.6], which demonstrates that the valuation weight is not necessarily an appropriate measure for making inferences about relative profitability, as it also reflects anticipated persistence of future investments.

The results in this section must be interpreted with caution. The first caveat is that the NPV estimates do not necessarily extend to the pharmaceutical industry in general. My sample consists of large, established firms that sell patented drugs, and this selection bias likely overstates the NPV for the industry as a whole. Similarly the NPV estimates may not extend to other time periods. The second caveat is that the regression coefficient is the mean NPV across firms and doesn't necessarily apply to each individual firm. For example, the expected return on R\&D would vary among firms based on such factors as the firm's technology, historical success rate, and the market for its therapeutics. The last caveat is that measurement error is expected to be compounded in this analysis since the derivation of NPV requires estimating additional variables.

Comparing the NPV estimates in Table 2.10 to the valuation estimates from Table 2.6 shows that the NPV is a small component of the valuation weight. For production facilities, the NPV of 0.15 is less than $1 \%$ of the valuation weight of 19.13 . For advertising investments, the NPV of 0.38 is $2 \%$ of the valuation weight of 15.85 . For R\&D, the NPV of 0.15 is only $1 \%$ of the valuation weight of 13.19 . Using the $R \& D$ as an example, the valuation weight reflects the expectation that a dollar invested in R\&D will not only generate excess profits of $15 \phi$, but will also be followed by more investments in $R \& D$, which will generate excess profits in the future. This comparison leads to an important point: a large regression coefficient on investment variables is not necessarily indicative of large profits. It could be indicative of small profits on investments that are highly persistent.

The NPV results in Table 2.10 are robust to several modifications. I consider different values of the risk free rate to construct the discount rates $R_{j}$ and find that the regression estimates are similar (not tabulated) when I use risk free rates ranging from $2 \%$ to $8 \%$ and when $\mathrm{R}_{\mathrm{j}}$ is 
calculated with the asset beta instead of the equity beta. Therefore assumptions about the discount rate are not driving the results. The results are also similar with different versions of the dependent variable. The results in Table 2.10 are not improved by using other proxies for the investment variables. Substituting SG\&A ( $g g a$ as described in Appendix A) for advertising expenditures in the adjadv construct results in a coefficient on adjadv that is not statistically significant. Adding R\&D that was purchased and then capitalized (caprd as described in Appendix A) does not change the coefficient on adjrd.

Finally, I add an additional explanatory variable based on Erickson and Jacobson (1992) who show that the positive valuation weight on advertising and $R \& D$ expenditures becomes negative once they add a proxy for profitability. The motivation in their paper is that discretionary investments are a signal that the firm is profitable, and that the market response is to the signal of profitability, not to the investments. I include scaled operating income ${ }^{51}$ as a proxy for profitability (not tabulated) and find that the results in Table 2.10 are robust to adding this variable.

\subsection{Sensitivity Analysis}

\subsubsection{Analysis of Firms that Report Advertising Expenditures}

In this section the Big Pharma firms are separated into two samples based on whether they reported advertising expenditures or not. The NPV model from Table 2.10 is estimated separately for each of the two samples and the results are reported in Table 2.11. The first column shows the regression estimates for the firms that report advertising expenditures in at least one of the years of investigation $(a d v>0)$, and the second column shows the results for firms that don't $(a d v=0)$. The power of my test is reduced when I estimate the model with smaller

\footnotetext{
${ }^{51}$ The variable operating income is Compustat data\#178. It is scaled by total assets (Compustat data \#6) for this analysis.
} 
samples, and the advertising variable $(a d v)$ is subject to considerable measurement error, but the breakdown provides some interesting results.

Firms that report advertising expenses generate positive NPV on advertising investments (coefficient of 0.35 with p-value of .00 on adjadv) and investments in production facilities (coefficient of 0.17 with p-value of .00 on adjprodfac). This suggests a possible relationship between advertising and size as a barrier to entry. As discussed in the hypothesis section of this chapter, although the economic rents are modeled separately, there is likely to be an interaction of the market inefficiencies. For example, investments in production facilities can create barriers to entry which results in fewer products being offered, thereby making advertising more effective.

Firms that don't report advertising generate positive NPV on their R\&D investments according to the second column in Table 2.11. The estimated NPV of a dollar invested on R\&D by these firms is 0.16 and the coefficient is statistically significant at the $1 \%$ level. However, firms that don't advertise do not appear to generate rents on investments in production facilities.

\subsubsection{The Validity of the Dynamics}

The proposed information dynamics provide a structure for testing the relationship between the three types of investments and patented revenues. If the proposed dynamics are correct the investments must have a positive effect on patented because it is ultimately through patent revenues that firms generate economic rents on their investments. In this section I explicitly test whether prior investments have an effect on future revenues, and investigate whether the effect is limited to the three-period time lag assumed in my valuation model.

My first test of the dynamics is an investigation of the correlation between patented revenues $\left(\operatorname{crp}_{t}\right)$ and up to nine lags of the investment variables (denoted by subscripts $t-1, t-2, \ldots . t$ $9)^{52}$. The Pearson correlations in the first column of Table 2.12 show that $\operatorname{crp}_{t}$ is positively and

\footnotetext{
${ }^{52}$ The number of lagged values is based on Lev and Sougiannis (1996), who find that operating income is associated with nine lagged values of $R \& D$ for firms in the pharmaceutical industry. For this analysis, I
} 
significantly correlated with every prior investment in advertising, $R \& D$, and production facilities except for the prodfac $t_{t-2}$ variable, which is positive but not statistically significant. This result provides evidence that each of the three types of investments affect patent revenues.

Next I use the correlations in Table 2.12 to test the validity of my model dynamics. In my model I assume the following dynamics: R\&D investments lead to investments in production facilities and advertising, which then generate cash receipts on patented drugs, whereas cash receipts on generic drugs are random shocks that decay over time.

Based on the Pearson correlations in Table 2.12 my dynamics for $\mathrm{crg}_{t}$ are validated. Cash receipts on generic drugs $\left(\mathrm{crg}_{t}\right)$ are not affected by any of the investment variables therefore they follow a random shock process. The fifth column in Table 2.12 shows that investments in advertising also follow a random shock process, and these shocks appear to decay slowly since the correlations of $a d v_{t}$ with prior values of $a d v$ are very high ${ }^{53}$. Rather than being positively associated with the prior year's investment in R\&D as assumed in my model, $a d v_{t}$ is negatively related with several prior values of $r d$ and prodfac, although the correlations are not significant. When only the statistically significant coefficients are considered, the correlations provide weak support for the dynamics between R\&D investments and investments in production facilities in my model: $R \& D$ precedes investments in production facilities according to the significant positive correlations with $r d_{t-8}$ (coefficient of 0.08) and $r d_{t-9}$ (coefficient of 0.19). The effect of the time delay between investments in $R \& D$ and investments in production facilities is discussed in the next section of this paper.

Both the generic and patent revenue streams are positively correlated with their lagged values and negatively correlated with each other, which suggests that even within the Big Pharma category, firms may focus on a product type; it is possible that they specialize either in patented

collect one additional year of data to scale the ninth lagged observation, and these are availalbe for all Big Pharma firms.

${ }^{53}$ When advertising expense is equal to zero, the observation is treated as missing in the correlation calculation therefore carries no weight. This ensures that non-advertisers are not driving the results with (perfectly correlated) advertising patterns of $a d v=0$. 
drugs or in generic therapeutics. Patent revenues are also positively correlated with the subsequent year's advertising expenditure, which suggests a feedback effect between these two variables.

Most of the dynamics assumed in my valuation model are weakly validated. R\&D expenditures lead to investments in production facilities, which have an impact on patented revenues. Advertising also has a positive effect on the next period's patent revenue. But the correlations do not support the dynamics that $R \& D$ precedes investments in advertising. This may be due to measurement error in the $a d v$ variable as discussed earlier in this chapter. Since a portion of advertising (the Phase IV clinical trials) is reported as $R \& D$, the correlation may be picking up the dynamics between advertising and lag R\&D but it shows up as an association between $R \& D$ and lag $R \& D$.

\subsubsection{The Limitation of a Parsimonious Valuation Model}

The results in the previous section suggest that some of the relevant variables are investments made several years prior to the year of the cash inflows. However, my pharmaceutical valuation model considers only three time periods. The main reason for this is that the parsimonious time span simplifies the algebraic manipulations required to solve the valuation weights. Based on the significant correlations in Table 2.12, the true dynamic process would require modeling at least 26 investment variables (nine lagged values each for advertising and $\mathrm{R} \& \mathrm{D}$ expenditures, and eight lagged values of production facilities since the prodfac $t_{t-2}$ variable is not statistically significant) as well as the interaction between them. My choice of limiting the time span to three years reduces the complexity without necessarily losing the first order effects of the investment variables. However, I use R\&D investments to explore how the omission of the lagged variables is likely to affect the valuation weight.

To begin the analysis, I assume that only one prior value of $R \& D$ investment is related to patented cash receipts, but that the relevant $R \& D$ investment is not the one made in the period 
immediately preceding the cash receipts. Here I assess the impact of a longer time span between the $R \& D$ investment and the revenues generated by that investment. In a Markovian environment $^{54}$ with a constant $\mathrm{R} \& \mathrm{D}$ persistence parameter $\left(\omega_{r r}\right)$, a prior value of $\mathrm{R} \& \mathrm{D}$ investments can be represented by the current value of $R \& D$ investments, but this can lead to a bias on the coefficient ${ }^{55}$. To illustrate this, consider that the value of $r d$ from n-periods prior is a multiple of $r d_{t}$ with the general form ${ }^{56}: \mathrm{rd}_{\mathrm{t}-\mathrm{n}}=\omega_{r r}{ }^{-\mathrm{n}} \mathrm{rd}_{\mathrm{t}}$. If the relevant variable is $\mathrm{rd}_{\mathrm{t}-\mathrm{n}}$ then using $\mathrm{rd}_{\mathrm{t}}$ instead of $\operatorname{rd}_{t-n}$ results in a biased variable of the magnitude $\left[\operatorname{rd}_{t}-\omega_{r r}{ }^{-n} \operatorname{rd}_{t}\right]$ which is $\left[\operatorname{rd}_{t}{ }^{*}\left(1-\omega_{r r}{ }^{-n}\right)\right]$. The bias is negative (downward bias) for firms with $\omega_{r r}$ greater than one, and positive (upward bias) otherwise. The bias is increasing in the level of R\&D $\left(r d_{t}\right)$. For example, suppose a firm's cash receipts are generated by $R \& D$ investments made several years earlier. If this firm is experiencing growth in its $R \& D$ program its $R \& D$ persistence $\left(\omega_{r r}\right)$ is greater than one. In this case, using $r d_{t}$ as a proxy for the relevant $\mathrm{R} \& \mathrm{D}$ made several years earlier would overstate the relevant R\&D investment, which leads to a downward bias on the $r d_{t}$ coefficient. Approximately two thirds of the R\&D persistence estimates from Table 2.8 are greater than one, therefore to the extent that the lag between $R \& D$ investments and cash receipts is greater than one year, the coefficient on the R\&D investment variable is likely to be biased downward.

Now consider the case where cash receipts on patented drugs are a function of several prior values of R\&D investments. For example, suppose the relevant model information is the sum of the past three years of $R \& D$ investments $\left(\mathrm{rd}_{\mathrm{t}-1}+\mathrm{rd}_{\mathrm{t}-2}+\mathrm{rd}_{\mathrm{t}-3}\right)$. Using the relation $\mathrm{rd}_{\mathrm{t}-\mathrm{n}}=\omega_{r r}-\mathrm{rd}_{\mathrm{t}}$, each of those three years of prior information can be represented by current $\mathrm{R} \& \mathrm{D}$ information: $\left(\omega_{r r}^{-1} \mathrm{rd}_{\mathrm{t}}+\omega_{r r}^{-2} \mathrm{rd}_{\mathrm{t}}+\omega_{r r}^{-3} \mathrm{rd}_{\mathrm{t}}\right)$. The bias from using the $\mathrm{rd}_{\mathrm{t}}$ variable instead of the relevant value of $\mathrm{R} \& \mathrm{D}$ is $\left[\mathrm{rd}_{\mathrm{t}}^{*}\left(1-\omega_{r r}^{-1}-\omega_{r r}{ }^{-2}-\omega_{r r}{ }^{-3}\right)\right]$ which becomes more negative (downward

\footnotetext{
${ }^{54}$ The Markovian environment is an implicit assumption in my model. This environment is one for which, conditional upon present information, the past and future are independent of current information.

${ }^{55}$ There will be no bias in the special case where $\omega_{r r}=1$.

${ }^{56}$ Prior values of R\&D can be represented by current period R\&D as follows: $\mathrm{rd}_{t}=\omega_{r \mathrm{r}} \mathrm{rd} \mathrm{t}_{\mathrm{t}-1} \rightarrow$ $\mathrm{rd}_{\mathrm{t}-1}=\omega_{r r}{ }^{-1} \mathrm{rd}_{\mathrm{t}}$. Since $\mathrm{rd}_{\mathrm{t}-1}=\omega_{r r} \mathrm{rd}_{\mathrm{t}-2}$ then $\mathrm{rd}_{\mathrm{t}}=\omega_{r r}\left(\omega_{r r} \mathrm{rd}_{\mathrm{t}-2}\right) \rightarrow \mathrm{rd}_{\mathrm{t}-2}=\omega_{r r}{ }^{-2} \mathrm{rd}_{\mathrm{t}}$. In general $\mathrm{rd}_{\mathrm{t}-\mathrm{n}}=\omega_{r r}{ }^{-\mathrm{n}} \mathrm{rd}_{\mathrm{t}}$.
} 
bias) as the number of terms increases. Alternatively, if the relevant information is the mean of the past three years of R\&D investments, then the bias is $\left[\operatorname{rd}_{t}{ }^{*}\left(1-{ }^{1} / 3\left(\omega_{r r}{ }^{-1}-\omega_{r r}{ }^{-2}-\omega_{r r}{ }^{-3}\right)\right)\right]$. The technique of substituting the $\mathrm{rd}_{\mathrm{t}}$ variable for the relevant $\mathrm{R} \& \mathrm{D}$ expenditure can be extended to analyze even more complex $R \& D$ processes.

The analysis above extends to the dynamics of investments in advertising and production facilities. Most firms have persistence parameters greater than one on these investment variables according to Table 2.8, therefore the conclusion of a downward bias on the regression coefficient applies to all investment variables. The discussion in this section suggests that the effect of adopting a parsimonious three-period model is that it is likely to produce a downward bias on the coefficients of the investment variables.

\subsection{Conclusion}

The value of pharmaceutical firm investments is investigated in this chapter of the thesis. Using the structure from Feltham and Ohlson (1996), I develop a valuation model specifically for pharmaceutical firms that sell patented drugs. Based on the drug development process, I conjecture that there are three types of observable investments that generate firm value: investments in Research and Development (R\&D), advertising, and production facilities. A valuation weight is obtained for each of these types of investment by estimating a regression model with the market value of equity as the dependent variable and proxies for cash receipts and the three types of investments as explanatory variables. The regression model is estimated with accounting data from thirty-four firms that sell drugs under patent protection. Each firm has nine observations from the years 1995 to 2003 resulting in a pooled time-series data set, therefore I am able to corroborate the Ordinary Least Squares results with results from a Generalized Least Squares estimation.

The valuation weight on each investment variable is large and statistically significant. The regression model estimates a valuation weight of 13.19 on $R \& D$ investments, which is 
consistent with the prior literature. The valuation weight of 15.85 on advertising expenditures is not robust since it is sensitive to which firms are included in the sample. This finding is a potential contribution to the prior literature, since it offers a plausible explanation for the mixed results found to date on the value of advertising investments. The valuation weight on investments in production facilities is 19.13. As far as I am aware, my study is the first empirical paper to investigate the valuation weight on investments in production facilities for pharmaceutical firms.

Pharmaceutical firms went through a change in regulation during the time period in my sample, and I investigate the effect of this change. In 1997 the FDA relaxed the rules for Directto-Consumer advertising, which resulted in abnormal returns for pharmaceutical firms in the twoday window around the announcement date, according to Boscaljon (2005). I test whether the valuation weight on advertising investments increased after 1997. While my estimate of the change in valuation weight is not statistically significant, the direction of the coefficient in my model suggests a decrease in the valuation weight after 1997. However, a decrease in the valuation weight does not necessarily indicate that deregulation of advertising reduced the rents earned by pharmaceutical firms (since the valuation coefficient represents the average, rather than marginal effect.) Chapter 4 uses an event study to triangulate these findings by providing an analysis of how the deregulation of advertising affected the stock returns of pharmaceuticals.

The magnitude and significance of the coefficients on my investment variables provide information about whether the investments generate value. But there is other useful information embedded in the coefficients. With the additional structure of the theoretical model, the coefficients can be separated into components that allow for further economic interpretation of the valuation weights. This interpretation relies on the set of information dynamics between investments and future cash flows. The techniques demonstrated in Christensen and Feltham (2003) together with the pharmaceutical information dynamics assumed in this chapter provide a means to isolate the component of the valuation weight that represents the Net Present Value 
(NPV) of each dollar invested in R\&D, advertising, and production facilities. The NPV captures the present value of future cash flows that are in excess after returning the original investment and compensating for risk. The NPV is, by definition, a measure of economic rents. I propose that economic rents can be achieved on $\mathrm{R} \& \mathrm{D}$ investments if the patent system provides firms with a period of market exclusivity that is longer than required to recoup the $R \& D$ outlay. Rents on advertising investments occur if marketing decreases the elasticity of demand or increases the total demand of the therapeutic advertised. Economic rents are expected to accrue to investments in production facilities if size is an important barrier to entry.

I estimate the NPV on the set of firms that sell patented drugs and find that all three types of investments are positive NPV. The estimated economic rents are $\$ 0.35$ per dollar invested in advertising and $\$ 0.15$ per dollar invested in either $R \& D$ or production facilities. The result is robust to variations on the regression model. The evidence from this paper supports the argument that firms earn higher economic rents per dollar spent on advertising expenditures than on investments in $\mathrm{R} \& \mathrm{D}$ or production facilities. The results also suggest that economic rents are a small component of the valuation weight on investments. For example, the economic rent on a dollar invested in $\mathrm{R} \& \mathrm{D}(\$ 0.15)$ is about $1 \%$ of the total valuation weight on $\mathrm{R} \& \mathrm{D}$ investments (\$13.19). The rest of the valuation weight is from the normal return on investment and rents from expected future investments in R\&D. Similarly, the valuation weight on advertising (\$15.85) is partially due to the economic rent on a dollar invested (\$0.38) but it is mainly due to expected rents on future investments. The value of investments in production facilities (\$19.13) also emanates from expected returns on future investments in addition to the current rent from a dollar invested (\$0.15). An important caveat to these findings is that the analysis provides estimates of the mean economic rents, which may be different from the marginal economic rents, and may not apply to all firms in the sample.

The model developed and estimated in this chapter is a simplified adaptation of the true business activities of pharmaceutical firms. The theoretical model assumes an identical process 
for all pharmaceutical firms and the regression model assumes that the value of investments is constant across firms and over time. These assumptions are necessary in order to obtain tractable results. The sensitivity analysis in this paper suggests that firms in my sample do not conform exactly to the information dynamics assumed in my theoretical model. However, the information dynamics incorporate what is generally considered to be the main value-driving investments in this industry, and the first order effects from these investments seem to be obtained in spite of model limitations. The model in this chapter provides information on the value of investments and the magnitude of economic rents. In Chapter 3 an accounting system is added to explore the effect of accruals. 
Figure 2.1: The Life Cycle of a Drug Product

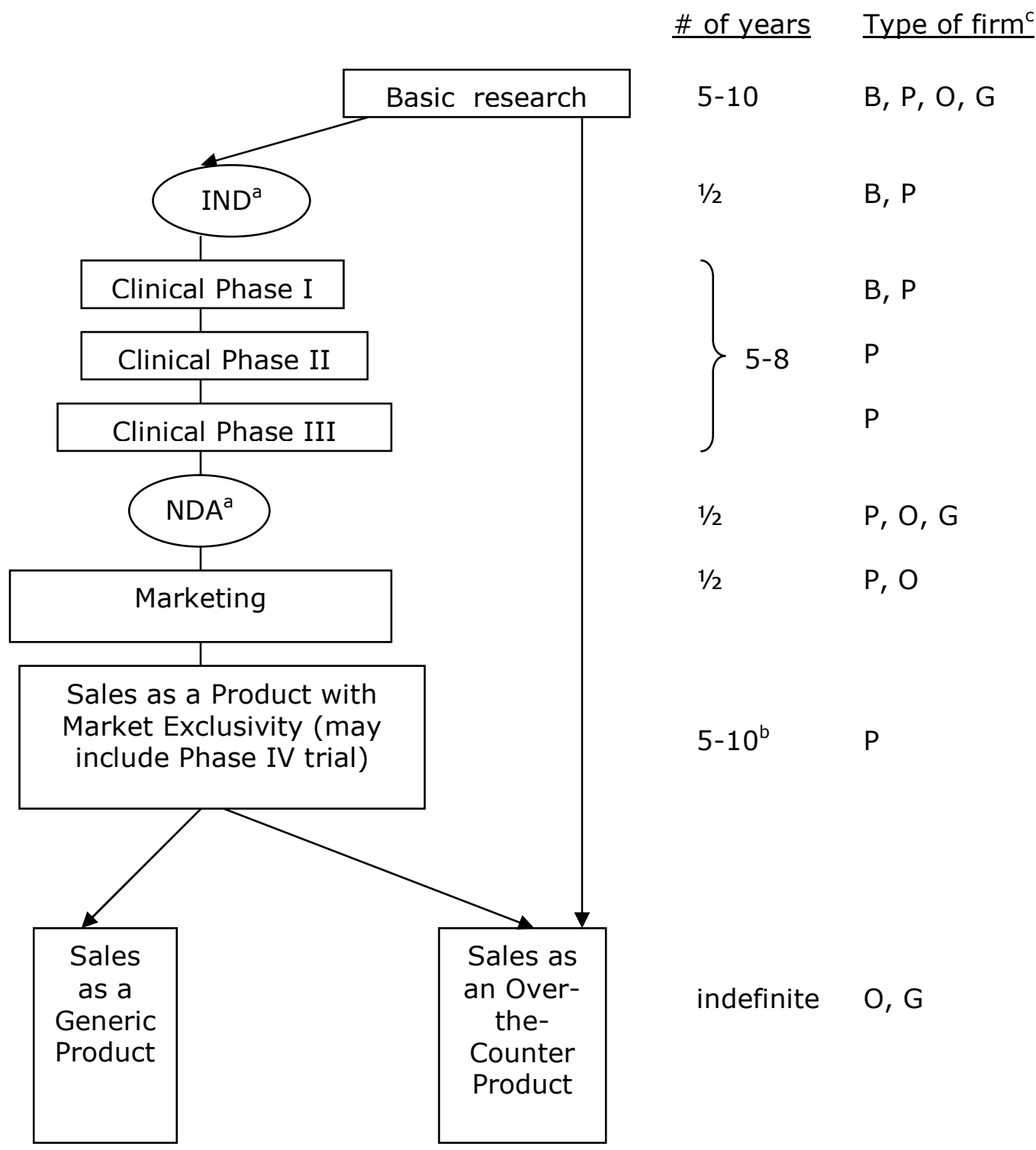

${ }^{a}$ IND (Investigative New Drug) and NDA (New Drug Application) are the two FDA review processes.

${ }^{\mathrm{b}}$ When a drug goes to the market there are usually 5-10 years remaining out of the 20-year patent.

Source: Pharmaceutical Industry Profile 2005. PhRMA. http://www.phrma.org/profiles_\&_reports/.

${ }^{\mathrm{c}}$ See Appendix A for description of Type of Firm: B=Biotech, $\mathrm{P}=\mathrm{Big}$ Pharma, $\mathrm{O}=\mathrm{OTC}, \mathrm{G}=$ Generic. 
Table 2.1 List of Firms

The sample of firms in this paper compared to the samples from Joos (2002) and Bowen and Shores (2002).

\begin{tabular}{|c|c|c|c|c|c|}
\hline FIRM NAME & $\begin{array}{l}\text { FIRM } \\
\text { TYPE }\end{array}$ & $\begin{array}{l}\text { THIS } \\
\text { PAPER }\end{array}$ & JoOs & $\begin{array}{l}\text { BOWEN } \\
\text { AND } \\
\text { SHORES }\end{array}$ & REASON FOR OMISSION \\
\hline Abbott & $\mathrm{P}$ & $\mathrm{x}$ & $\mathrm{x}$ & $\mathrm{x}$ & \\
\hline Able & 0 & $\mathrm{x}$ & & & \\
\hline Access Pharmaceuticals & B & $\mathrm{x}$ & & & \\
\hline Akorn & G & $\mathrm{x}$ & & & \\
\hline Alkermes & B & $x$ & & & \\
\hline Allergan & 0 & $\mathrm{x}$ & & & \\
\hline Alpharma & G & $\mathrm{x}$ & $\mathrm{x}$ & & \\
\hline Alteon & B & $x$ & & & \\
\hline Alza & & & $x$ & & acquired by Abbott in 1996 \\
\hline Amarin & $\mathrm{B}$ & $\mathrm{x}$ & & & \\
\hline Amylin & $\mathrm{B}$ & $\mathrm{x}$ & & & \\
\hline American Home Products & & & $x$ & $\mathrm{x}$ & changed name to Wyeth in 2002 \\
\hline Astrazeneca & $\mathrm{P}$ & $\mathrm{x}$ & & & \\
\hline Atrix & $\mathrm{B}$ & $\mathrm{x}$ & & & \\
\hline Avanir & B & $\mathrm{x}$ & & & \\
\hline Balchem & 0 & $x$ & & & \\
\hline Barr & $P$ & $\mathrm{x}$ & & $\mathrm{x}$ & \\
\hline Bausch \& Lomb & $P$ & $\mathrm{x}$ & & & \\
\hline Bentley & $P$ & $x$ & & & \\
\hline Biospecifics Technology & B & $\mathrm{x}$ & & & \\
\hline Biovail & $P$ & $x$ & & & \\
\hline Boston Life & $B$ & $x$ & & & \\
\hline Bradley & 0 & $\mathrm{x}$ & & & \\
\hline Bristol Myers Squibb & $P$ & $x$ & $x$ & $\mathrm{x}$ & \\
\hline Caraco & 0 & $x$ & & & \\
\hline Carrington & $\mathrm{B}$ & $\mathrm{x}$ & & & \\
\hline Circa & & & $\mathrm{x}$ & & merged with Watson in 1995 \\
\hline Celgene & $\mathrm{B}$ & $\mathrm{x}$ & & & \\
\hline Cephalon & $P$ & $\mathrm{x}$ & & & \\
\hline Chattem & 0 & $x$ & & & \\
\hline Chiron & $\mathrm{B}$ & $\mathrm{x}$ & & & \\
\hline Cima Labs & 0 & $\mathrm{x}$ & & & \\
\hline Columbia Laboratories & $B$ & $x$ & & & \\
\hline Cortex Pharmaceuticals & $\mathrm{B}$ & $x$ & & & \\
\hline Derma Science & 0 & $x$ & & & \\
\hline Draxis Health & $P$ & $x$ & & & \\
\hline Duramed & & & $x$ & & acquired by Barr in 2001 \\
\hline Dusa Pharmaceuticals & 0 & $x$ & & & \\
\hline Elan & $P$ & $x$ & $x$ & & \\
\hline Emisphere Techologies & $B$ & $x$ & & & \\
\hline
\end{tabular}




\begin{tabular}{|c|c|c|c|c|c|}
\hline FIRM NAME & $\begin{array}{l}\text { FIRM } \\
\text { TYPE }\end{array}$ & $\begin{array}{l}\text { THIS } \\
\text { PAPER }\end{array}$ & JoOS & $\begin{array}{l}\text { BOWEN } \\
\text { AND } \\
\text { SHORES }\end{array}$ & REASON FOR OMISSION \\
\hline Epimune & $B$ & $\mathrm{x}$ & & & \\
\hline Faulding & & & $\mathrm{x}$ & & not traded on US exchange since 2001a \\
\hline Forest Laboratories & $P$ & $x$ & $\mathrm{x}$ & $x$ & \\
\hline G.D. Searle & & & & $x$ & acquired by Pharmacia in 2000 \\
\hline Gelsat & 0 & $x$ & & & \\
\hline Genelabs & $B$ & $x$ & & & \\
\hline Genentech & $P$ & $\mathrm{x}$ & $\mathrm{x}$ & $x$ & \\
\hline Glaxosmithkline & $P$ & $x$ & $\mathrm{x}$ & & \\
\hline Guilford Pharmaceuticals & B & $\mathrm{x}$ & & & \\
\hline Halsey & 0 & $x$ & $x$ & & \\
\hline Hi Tech Pharmacal & G & $x$ & & & \\
\hline ICN & & & $\mathrm{x}$ & & changed name to Valeant in 2003 \\
\hline Icos & $B$ & $x$ & & & \\
\hline $\mid \mathrm{GI}$ & 0 & $\mathrm{x}$ & & & \\
\hline Immunogen & $B$ & $x$ & & & \\
\hline Indevus Pharmaceutical & $B$ & $x$ & & & \\
\hline Inkine & $\mathrm{P}$ & $\mathrm{x}$ & & & \\
\hline Insite & $B$ & $\mathrm{x}$ & & & \\
\hline Interpharm & G & $\mathrm{x}$ & & & \\
\hline Isis & $B$ & $x$ & & & \\
\hline Ivax & $\mathrm{P}$ & $\mathrm{x}$ & & & \\
\hline Johnson \& Johnson & $\mathrm{P}$ & $\mathrm{x}$ & $\mathrm{x}$ & $\mathrm{x}$ & \\
\hline KV Pharmaceuticals & $P$ & $\mathrm{x}$ & $x$ & & \\
\hline Lectec & 0 & $\mathrm{x}$ & & & \\
\hline Lesgarden & $\mathrm{B}$ & $\mathrm{x}$ & & & \\
\hline Ligand & $P$ & $\mathrm{x}$ & & & \\
\hline Lilly (Eli) & $\mathrm{P}$ & $\mathrm{x}$ & $\mathrm{x}$ & $\mathrm{x}$ & \\
\hline Macrochem & B & $x$ & & & \\
\hline Manhatten Pharmaceuticals & B & $\mathrm{x}$ & & & \\
\hline Marion Merrell Dow & & & & $\mathrm{x}$ & acquired by Hoechst (now Sanofi Aventis) in 1995 \\
\hline Medicis & $\mathrm{P}$ & $x$ & & & \\
\hline Merck & $\mathrm{P}$ & $\mathrm{x}$ & $\mathrm{x}$ & $\mathrm{x}$ & \\
\hline $\mathrm{MGI}$ & $B$ & $x$ & $x$ & & \\
\hline Mylan & $\mathrm{P}$ & $\mathrm{x}$ & $\mathrm{x}$ & $x$ & \\
\hline Nastech & $\mathrm{B}$ & $\mathrm{x}$ & $\mathrm{x}$ & & \\
\hline Natural Alternative & 0 & $\mathrm{x}$ & & & \\
\hline Natures Sunshine Products & 0 & $\mathrm{x}$ & & & \\
\hline NBTY & 0 & $x$ & & & \\
\hline Nektar Therapeutics & B & $\mathrm{x}$ & & & \\
\hline Neurogen & $\mathrm{B}$ & $\mathrm{x}$ & & & \\
\hline Noven & $B$ & $\mathrm{x}$ & & & \\
\hline Novo-Nordisk & $\mathrm{P}$ & $x$ & $\mathrm{x}$ & & \\
\hline Nutrition 21 & $B$ & $x$ & & & \\
\hline Par Pharmaceutical & 0 & $\mathrm{x}$ & & & \\
\hline Perrigo & 0 & $\mathrm{x}$ & & & \\
\hline Pfizer & $P$ & $\mathrm{x}$ & $x$ & $x$ & \\
\hline
\end{tabular}




\begin{tabular}{|c|c|c|c|c|c|}
\hline FIRM NAME & $\begin{array}{l}\text { FIRM } \\
\text { TYPE }\end{array}$ & $\begin{array}{l}\text { THIS } \\
\text { PAPER }\end{array}$ & JoOS & $\begin{array}{l}\text { BOWEN } \\
\text { AND } \\
\text { SHORES }\end{array}$ & REASON FOR OMISSION \\
\hline Pharmaceutical Resources & & & $x$ & & changed name to Par Pharmaceutical in 2004 \\
\hline Pharmacia & $\mathrm{P}$ & $\mathrm{x}$ & $\mathrm{x}$ & & acquired by Pfizer in 2003 \\
\hline Pharmos & $B$ & $x$ & & & \\
\hline Point Therapeutics & $\mathrm{B}$ & $\mathrm{x}$ & & & \\
\hline Polydex Pharmaceuticals & $\mathrm{B}$ & $\mathrm{x}$ & & & \\
\hline Procyte & 0 & $x$ & & & \\
\hline QLT & $\mathrm{B}$ & $\mathrm{x}$ & & & \\
\hline Questcor & $P$ & $x$ & & & \\
\hline Regeneron & $\mathrm{B}$ & $x$ & & & \\
\hline Regenerex & $\mathrm{B}$ & $\mathrm{x}$ & & & \\
\hline Reliv International & 0 & $\mathrm{x}$ & & & \\
\hline Rhone-Poulenc Rorer & & & $x$ & $x$ & merged with Hoechst (now Sanofi Aventis) in 1999 \\
\hline Roche & $\mathrm{P}$ & $\mathrm{x}$ & & & \\
\hline Sanofi Aventis & $\mathrm{P}$ & $\mathrm{x}$ & & & \\
\hline Scherer & & & $x$ & & manufacturer \\
\hline Schering-Plough & $\mathrm{P}$ & $x$ & $x$ & $x$ & \\
\hline Sciclone Pharmaceuticals & $\mathrm{B}$ & $\mathrm{x}$ & & & \\
\hline Sepracor & $\mathrm{B}$ & $\mathrm{x}$ & & & \\
\hline Sheffield Pharmaceuticals & $\mathrm{B}$ & $\mathrm{x}$ & & & \\
\hline Sicor & 0 & $x$ & & & \\
\hline Syntex & & & $\mathrm{x}$ & $\mathrm{x}$ & acquired by Roche in 1994 \\
\hline Taro Pharmaceuticals & 0 & $\mathrm{x}$ & & & \\
\hline Teva & $\mathrm{P}$ & $x$ & $\mathrm{x}$ & & \\
\hline Theragenics & $\mathrm{P}$ & $\mathrm{x}$ & & & \\
\hline Unimed & & & $x$ & & not traded on US exchange since 1999b \\
\hline United Guardian & $\mathrm{P}$ & $x$ & $\mathrm{x}$ & & \\
\hline Valeant & $\mathrm{P}$ & $\mathrm{x}$ & & & \\
\hline Vertex Pharmaceutical & $\mathrm{B}$ & $\mathrm{x}$ & & & \\
\hline Virbac & 0 & $\mathrm{x}$ & & & \\
\hline Vivus & $\mathrm{B}$ & $\mathrm{x}$ & & & \\
\hline Warner-Lambert & & & $\mathrm{x}$ & $\mathrm{x}$ & merged with Pfizer in 2000 \\
\hline Watson Pharmaceuticals & G & $\mathrm{x}$ & & & \\
\hline Wyeth & $\mathrm{P}$ & $x$ & & & \\
\hline Zila & 0 & $\mathrm{x}$ & & & \\
\hline Zenith Laboratories & & & $x$ & & merged with Ivax in 1994 \\
\hline Zonagen & $B$ & $x$ & & & \\
\hline
\end{tabular}

Firm types are as follows: P is Big Pharma, O is OTC-Generic, and B is Biotech.

${ }^{a}$ Acquired by the Australian firm Mayne Nickless.

${ }^{\mathrm{b}}$ Acquired by the Belgian firm Solvay. 
Table 2.2 Compustat Data

Compustat data categorized as positive, negative, zero or missing.

\begin{tabular}{|c|c|c|c|c|c|c|c|}
\hline \multirow{2}{*}{\multicolumn{2}{|c|}{ Compustat data }} & \multicolumn{3}{|c|}{ PANEL A: FULL SAMPLE $(n=839)$} & \multicolumn{3}{|c|}{ PANEL B: BIG PHARMA FIRMS (n=303) } \\
\hline & & positive & negative & zero/miss & positive & negative & zero/miss \\
\hline \#6 & total assets & 839 & 0 & 0 & 303 & 0 & 0 \\
\hline \#8 & net property,plant,equipment & 836 & 0 & 3 & 303 & 0 & 0 \\
\hline$\# 12$ & sales & 808 & 0 & 31 & 303 & 0 & 0 \\
\hline$\# 14$ & depreciation/amortization & 834 & 0 & 5 & 303 & 0 & 0 \\
\hline$\# 18$ & income before extra items & 410 & 429 & 0 & 251 & 52 & 0 \\
\hline$\# 33$ & intangibles & 450 & 0 & 389 & 228 & 0 & 75 \\
\hline$\# 45$ & advertising expense & 194 & 0 & 645 & 112 & 0 & 191 \\
\hline$\# 46$ & R\&D expense & 790 & 0 & 49 & 303 & 0 & 0 \\
\hline$\# 60$ & common equity (bal sheet) & 793 & 46 & 0 & 299 & 4 & 0 \\
\hline$\# 65$ & amort of intangibles & 311 & 0 & 528 & 142 & 0 & 161 \\
\hline$\# 128$ & capital expenditures (cflow) & 822 & 0 & 17 & 299 & 0 & 4 \\
\hline$\# 178$ & operating income after depn & 450 & 389 & 0 & 263 & 40 & 0 \\
\hline$\# 189$ & selling,general,admin & 554 & 0 & 285 & 261 & 0 & 42 \\
\hline$\# 388$ & in-process $\mathrm{R} \& \mathrm{D}$ expense & 47 & 0 & 792 & 75 & 0 & 228 \\
\hline
\end{tabular}




\section{Table 2.3 Mean Values of Regression Variables}

The mean values and mean scaled ${ }^{a}$ values of the regression variables

\begin{tabular}{|c|c|c|c|c|c|c|}
\hline \multirow[b]{2}{*}{ VARIABLE } & & Iean Value & by firr & Me & Scaled Va & \\
\hline & $\begin{array}{c}\text { Big } \\
\text { Pharma } \\
34 \text { firms } \\
(n=303)\end{array}$ & $\begin{array}{l}\text { OTC- } \\
\text { Generic } \\
29 \text { firms } \\
(n=232)\end{array}$ & $\begin{array}{l}\text { Biotech } \\
38 \text { firms } \\
(n=304)\end{array}$ & $\begin{array}{c}\text { Big } \\
\text { Pharma } \\
32 \text { firms } \\
(n=256)\end{array}$ & $\begin{array}{l}\text { OTC- } \\
\text { Generic } \\
29 \text { firms } \\
(n=232)\end{array}$ & $\begin{array}{l}\text { Biotech } \\
38 \text { firms } \\
(n=304)\end{array}$ \\
\hline crg & 1,721 & 182 & - & 0.22 & 1.35 & 0.00 \\
\hline crp & 5,405 & - & 41 & 0.57 & 0.00 & 0.39 \\
\hline$r d$ & 921 & 14 & 29 & 0.12 & 0.08 & 0.42 \\
\hline$a d v$ & 182 & 3 & 0 & 0.01 & 0.02 & 0.00 \\
\hline prodfac & 576 & 13 & 7 & 0.07 & 0.07 & 0.04 \\
\hline total assets & 8,867 & 200 & 122 & 1.00 & 1.00 & 1.00 \\
\hline
\end{tabular}

See Appendix A for definition of the variables and description of firm-types.

${ }^{a}$ Observations are scaled by the prior period total assets (Compustat data \#6). 
Table 2.4 Pearson Correlations

The Pearson correlations of the scaled ${ }^{\mathrm{a}}$ regression variables reported by firm-type.

PANEL A: BIG PHARMA FIRMS $(\mathbf{n}=\mathbf{3 0 3})$

\begin{tabular}{|l|r|r|r|r|r|r|}
\cline { 2 - 8 } \multicolumn{1}{c|}{} & \multicolumn{1}{c|}{ vo } & \multicolumn{1}{c|}{$c r g$} & \multicolumn{1}{c|}{ crp } & $r d$ & $a d v$ & prodfac \\
\hline vo & 1.00 & & & & & \\
\hline crg & -0.13 & 1.00 & & & & \\
& $(.03)$ & & & & & \\
\hline crp & 0.34 & -0.47 & 1.00 & & & \\
& $(.00)$ & $(.00)$ & & & & \\
\hline$r d$ & 0.25 & -0.12 & 0.15 & 1.00 & & \\
& $(.00)$ & $(.04)$ & $(.02)$ & & & \\
\hline$a d v$ & 0.17 & -0.01 & 0.21 & -0.04 & 1.00 & \\
& $(.00)$ & $(.88)$ & $(.00)$ & $(.50)$ & & \\
\hline prodfac & 0.32 & 0.06 & 0.20 & 0.06 & 0.08 & 1.00 \\
& $(.00)$ & $(.31)$ & $(.00)$ & $(.31)$ & $(.15)$ & \\
\hline
\end{tabular}

PANEL B: OTC-GENERIC FIRMS $(\mathrm{n}=\mathbf{2 3 2})$

\begin{tabular}{|l|r|r|r|l|l|}
\cline { 2 - 6 } \multicolumn{1}{c|}{} & \multicolumn{1}{l|}{$v o$} & \multicolumn{1}{c|}{$c r g$} & $r d$ & $a d v$ & prodfac \\
\hline$v o$ & 1.00 & & & & \\
\hline$c r g$ & 0.00 & 1.00 & & & \\
& $(.98)$ & & & & \\
\hline$r d$ & 0.39 & -0.23 & 1.00 & & \\
& $(.00)$ & $(.00)$ & & & \\
\hline$a d v$ & -0.05 & -0.02 & -0.16 & 1.00 & \\
& $(.42)$ & $(.78)$ & $(.00)$ & & \\
\hline prodfac & 0.20 & 0.16 & 0.23 & 0.09 & 1.00 \\
& $(.00)$ & $(.01)$ & $(.00)$ & $(.14)$ & \\
\hline
\end{tabular}

PANEL C: BIOTECH FIRMS $(\mathbf{n}=\mathbf{3 0 4})$

\begin{tabular}{|l|r|r|r|l|l|}
\cline { 2 - 6 } \multicolumn{1}{c|}{} & \multicolumn{1}{l}{ vo } & $c r p$ & $r d$ & $a d v$ & prodfac \\
\hline$v o$ & 1.00 & & & & \\
\hline$c r p$ & -0.30 & 1.00 & & & \\
& $(.00)$ & & & & \\
\hline$r d$ & 0.49 & 0.12 & 1.00 & & \\
& $(.00)$ & $(.01)$ & & & \\
\hline$a d v$ & 0.14 & 0.21 & -0.01 & 1.00 & \\
& $(.00)$ & $(.00)$ & $(.91)$ & & \\
\hline prodfac & 0.11 & 0.18 & -0.03 & 0.02 & 1.00 \\
& $(.03)$ & $(.00)$ & $(.52)$ & $(.75)$ & \\
\hline
\end{tabular}

See Appendix A for definition of the variables and description of firm-types. ${ }^{a}$ Observations are scaled by the prior period total assets (Compustat data \#6). $\mathrm{P}$-values are in parentheses. 
Table 2.5 Distribution of Regression Variables

The distribution of the scaled ${ }^{\mathrm{a}}$ explanatory variables for the regression of the valuation model for Big Pharma firms ( $\mathrm{n}=302$ observations).

\begin{tabular}{lcccccc} 
& Mean & Low & Q1 & Median & Q3 & High \\
\hline crg & 0.22 & 0.00 & 0.00 & 0.00 & 0.41 & 2.07 \\
$c r p$ & 0.57 & 0.00 & 0.29 & 0.49 & 0.81 & 2.38 \\
$r d$ & 0.12 & 0.00 & 0.05 & 0.08 & 0.14 & 3.48 \\
$a d v$ & 0.01 & 0.00 & 0.00 & 0.00 & 0.01 & 0.17 \\
prodfac & 0.07 & 0.00 & 0.03 & 0.05 & 0.07 & 0.54 \\
\hline
\end{tabular}

See Appendix A for definition of the variables and description of firm-types.

${ }^{a}$ Observations are scaled by the prior period total assets (Compustat data \#6).

Table 2.6 Valuation Weights

Regression model 2.3 estimated by firm type.

Model: $v o \_s s_{j t}=1 \_s_{j t}+\beta_{\mathrm{g}} c r g \_s_{j t}+\beta_{\mathrm{p}} c r p \_s_{j t}+\beta_{\mathrm{r}} r d \_s_{j t}+\beta_{\mathrm{a}} a d v \_s_{j t}+\beta_{\mathrm{f}} p r o d f a c \_s_{j t}+\varepsilon_{j t}$.

\begin{tabular}{|c|c|c|c|c|c|c|}
\hline & \multirow[b]{2}{*}{ All Firms } & \multicolumn{3}{|c|}{$\begin{array}{l}\text { PANEL A: } \\
\text { By firm type }\end{array}$} & \multicolumn{2}{|c|}{$\begin{array}{c}\text { PANEL B: } \\
\text { Incremental value of } \\
\text { Big Pharma over: }\end{array}$} \\
\hline & & $\begin{array}{c}\text { Big } \\
\text { Pharma }\end{array}$ & $\begin{array}{c}\text { OTC- } \\
\text { Generic }\end{array}$ & Biotech & $\begin{array}{c}\text { OTC- } \\
\text { Generic }\end{array}$ & Biotech \\
\hline \multirow[t]{2}{*}{$1 \_s_{j t}$} & 1.28 & 2.72 & 1.21 & 1.46 & 1.49 & 1.25 \\
\hline & $(.00)$ & $(.55)$ & $(.00)$ & (.06) & $(.79)$ & $(.88)$ \\
\hline \multirow[t]{2}{*}{$c r g$} & 0.27 & 0.10 & 0.21 & & -0.10 & \\
\hline & (.10) & $(.81)$ & $(.20)$ & 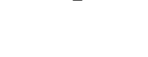 & $(.86)$ & 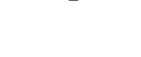 \\
\hline \multirow[t]{2}{*}{$c r p$} & 2.82 & 2.12 & & 2.78 & & -0.65 \\
\hline & $(.00)$ & $(.00)$ & & $(.00)$ & - & $(.47)$ \\
\hline \multirow[t]{2}{*}{$r d$} & 8.36 & 13.19 & 15.45 & 7.96 & -2.25 & 5.23 \\
\hline & $(.00)$ & $(.00)$ & $(.00)$ & $(.00)$ & $(.38)$ & $(.06)$ \\
\hline \multirow[t]{2}{*}{$a d v$} & 9.93 & 15.85 & 3.32 & 24.54 & 12.52 & -8.69 \\
\hline & $(.00)$ & $(.00)$ & $(.43)$ & $(.02)$ & $(.12)$ & $(.51)$ \\
\hline \multirow[t]{2}{*}{ prodfac } & 18.09 & 19.13 & 16.16 & 14.67 & 2.98 & 4.47 \\
\hline & $(.00)$ & $(.00)$ & $(.00)$ & $(.01)$ & $(.56)$ & $(.52)$ \\
\hline n obs. & 838 & 302 & 232 & 304 & 534 & 606 \\
\hline $\operatorname{adj}-R^{2}$ & $51 \%$ & $70 \%$ & $39 \%$ & $51 \%$ & $53 \%$ & $55 \%$ \\
\hline
\end{tabular}

P-values are in parentheses. The variables are described in Appendix A.

Observations are scaled by the prior period total assets (Compustat data \#6). 


\section{Table 2.7 Change in Advertising Valuation Weight}

Test of the change in advertising valuation weight for Big Pharma firms following a change in advertising regulation.

Model 1: vo_s $s_{j t}=1 \_s_{j t}+\beta_{\mathrm{g}} c r g \_s_{j t}+\beta_{\mathrm{p}} c r p \_s_{j t}+\beta_{\mathrm{r}} r d \_s_{j t}+\beta_{\mathrm{a}} a d v_{-} s_{j t}+\beta_{\mathrm{f}} p r o d f a c \_s_{j t}+\beta_{\mathrm{d}} p o s t a d v_{-} s_{j t}+\varepsilon_{j t}$. Model 2: vo_s $s_{j t}=1 \_s_{j t}+\beta_{\mathrm{g}} c r g \_s_{j t}+\beta_{\mathrm{p}} c r p \_s_{j t}+\beta_{\mathrm{r}} r d \_s_{j t}+\beta_{\mathrm{a}} a d v \_s_{j t}+\beta_{\mathrm{f}} p r o d f a c \_s_{j t}+\varepsilon_{j t}$.

\begin{tabular}{|c|c|c|c|c|c|}
\hline & \multirow{3}{*}{$\begin{array}{l}\text { Model } 1 \\
\text { all years }\end{array}$} & \multicolumn{4}{|c|}{ Model 2} \\
\hline & & \multicolumn{2}{|c|}{ OLS } & \multicolumn{2}{|c|}{ Fama-MacBeth } \\
\hline & & Pre 1998 & Post 1997 & Pre 1998 & Post 1997 \\
\hline \multirow{2}{*}{$1 \_s_{j t}$} & 2.56 & 7.54 & -11.41 & 13.94 & -20.13 \\
\hline & $(.58)$ & $(.30)$ & $(.08)$ & $(.42)$ & $(.02)$ \\
\hline \multirow[t]{2}{*}{$\operatorname{crg}$} & 0.10 & -1.23 & 1.58 & -1.18 & 2.63 \\
\hline & $(.82)$ & $(.21)$ & $(.00)$ & $(.08)$ & $(.00)$ \\
\hline \multirow[t]{2}{*}{ crp } & 2.11 & 1.57 & 3.52 & 1.20 & 4.67 \\
\hline & $(.00)$ & $(.04)$ & $(.00)$ & $(.47)$ & $(.00)$ \\
\hline \multirow{2}{*}{$r d$} & 13.27 & 9.97 & 14.67 & 8.63 & 11.69 \\
\hline & $(.00)$ & $(.01)$ & $(.00)$ & $(.05)$ & $(.01)$ \\
\hline \multirow[t]{2}{*}{$a d v$} & 18.30 & 23.84 & 6.87 & 21.08 & -1.68 \\
\hline & $(.02)$ & (.03) & $(.28)$ & $(.22)$ & $(.78)$ \\
\hline \multirow[t]{2}{*}{ prodfac } & 19.16 & 27.51 & 0.81 & 31.64 & -8.18 \\
\hline & $(.00)$ & $(.00)$ & (.86) & $(.05)$ & $(.15)$ \\
\hline \multirow[t]{2}{*}{ postadv } & -4.56 & & & & \\
\hline & $(.65)$ & & & & \\
\hline n obs. & 302 & 100 & 202 & 3 years & 6 years \\
\hline $\operatorname{adj}-R^{2}$ & $70 \%$ & $61 \%$ & $78 \%$ & & \\
\hline
\end{tabular}

Model 1 includes the variable postad $v$ which is an indicator variable that is equal to $a d v_{j t \_} s_{j t}$ if the year is after the regulatory change year of 1997. Model 2 is the valuation model that is estimated in Table 2.6. It is estimated separately on observations before (Pre 1998) and after (Post 1997) the change in regulation to observe whether the coefficient on $a d v$ has changed. With Fama-MacBeth the model is regressed by OLS for each year and the mean annual coefficient is reported. P-values are in parentheses. The variables are described in Appendix A. Observations are scaled by the prior period total assets (Compustat data \#6). 


\section{Table 2.8 Distribution of Winsorized Persistence Parameters}

The distribution of the persistence estimates for Big Pharma firms $(n=34$ firms $)$.

\begin{tabular}{lllllllll} 
Model & Parameter & Proxy for & Mean & Low & Q1 & Median & Q3 & High \\
\hline 1 & $\delta_{j g}$ & $\omega_{j g g}$ & 0.46 & 0.00 & 0.00 & 0.70 & 1.03 & 1.23 \\
2 & $\delta_{j p}$ & $\omega_{j p p}$ & 1.03 & 0.21 & 0.72 & 0.90 & 1.12 & 2.80 \\
3 & $\delta_{j r}$ & $\omega_{j r r}$ & 1.05 & 0.09 & 1.07 & 1.10 & 1.14 & 1.14 \\
4 & $\delta_{j a}$ & $\omega_{j a a}$ & 0.44 & 0.00 & 0.00 & 0.00 & 1.00 & 1.14 \\
5 & $\delta_{j f}$ & $\omega_{j f f}$ & 1.03 & 0.70 & 0.98 & 1.06 & 1.14 & 1.14 \\
\hline
\end{tabular}

The persistence of the explanatory variables is estimated with nine years of data for each of the $34 \mathrm{Big}$ Pharma firms as follows: Model (1) $\mathrm{crg}_{j t}=\delta_{j g} c r g_{j, t-1}+\varepsilon_{j t}$; Model (2) $c r p_{j t}=\delta_{j p} c r p_{j, t-1}+\varepsilon_{j t}$; Model (3) $r d_{j t}=$ $\delta_{j r} r d_{j, t-1}+\varepsilon_{j t} ;$ Model (4) $a d v_{j t}=\delta_{j a} a d v_{j, t-1}+\varepsilon_{j t} ;$ Model (5) prodfac $c_{j t}=\delta_{j p} p \operatorname{prodfac}_{j, t-1}+\varepsilon_{j t}$. The persistence is estimated with the scaled variables but the results are almost identical with levels variables. Large values of persistence are winsorized to the value of 1.14.

Table 2.9 Distribution of NPV Regression Variables

The distribution of the explanatory variables for the regression of the NPV model for Big Pharma firms ( $n=302$ observations).

\begin{tabular}{lcccccc} 
& Mean & Low & Q1 & Median & Q3 & High \\
\hline crg & 0.22 & 0.00 & 0.00 & 0.00 & 0.41 & 2.07 \\
crp & 0.57 & 0.00 & 0.29 & 0.49 & 0.81 & 2.38 \\
adjrd & 2.10 & 0.01 & 0.89 & 2.42 & 6.32 & 9.38 \\
adjadv & 0.57 & 0.00 & 0.00 & 0.00 & 0.10 & 8.08 \\
adjprodfac & 2.47 & 0.00 & 0.21 & 1.61 & 2.09 & 11.75 \\
\hline
\end{tabular}

The variables are described in Appendix A.

Observations are scaled by the prior period total assets (Compustat data \#6). 


\section{Table 2.10 The NPV of Investments}

Regression model 2.4 estimated for Big Pharma firms:

Model: $a d j v o \_s_{j t}=1 \_s_{j t}+\gamma_{g} c r g \_s_{j t}+\gamma_{\mathrm{p}} c r p \_s_{j t}+\gamma_{\mathrm{r}} a d j r d \_s_{j t}+\gamma_{\mathrm{a}} a d j a d v \_s_{j t}+\gamma_{\mathrm{f}} a d j p r o d f a c \_s_{j t}+\varepsilon_{j t}$

\begin{tabular}{ccc} 
Coefficient & $\begin{array}{c}\text { The 75\% Confidence Interval } \\
\text { Around the Coefficient }\end{array}$ \\
\hline$I_{-} s_{j t}$ & -0.73 & \\
& $(.87)$ & \\
crg & 1.29 & \\
& $(.00)$ & \\
crp & 3.71 \\
& $(.00)$ & \\
adjrd & 0.15 & 0.12 to 0.18 \\
& $(.00)$ & \\
adjadv & 0.38 & 0.24 to 0.46 \\
& $(.00)$ & \\
adjprodfac & 0.15 & 0.11 to 0.17 \\
& $(.00)$ & \\
\hline n obs. & 302 \\
adj- ${ }^{2}$ & $68 \%$ & \\
\hline P-values are in parentheses. The variables are described in Appendix A. \\
Observations are scaled by the prior period total assets (Compustat data \#6).
\end{tabular}




\section{Table 2.11 The NPV of Investments for Advertisers}

The regression model 2.4 estimated separately for Big Pharma firms that reported advertising expenditures at least once (Yes) and Big Pharma firms that did not report expenditures (No) during the period of investigation:

MODEL: $a d j v o \_s j=1 \_s_{j t}+\gamma_{\mathrm{g}} c r g \_s_{j t}+\gamma_{\mathrm{p}} c r p \_s_{j t}+\gamma_{\mathrm{r}} a d j r d \_s_{j t}+\gamma_{\mathrm{a}} a d j a d v \_s_{j t}+\gamma_{\mathrm{f}} a d j p r o d f a c \_s_{j t}+\varepsilon_{j t}$

\section{Advertising Expenditures}

\section{Reported}

\begin{tabular}{ccc}
\hline & $(\mathbf{a d v}>\mathbf{0})$ & $(\mathbf{a d v}=\mathbf{0})$ \\
$1 \_s_{i t}$ & -21.81 & 4.17 \\
& $(.03)$ & $(.47)$ \\
crg & 1.81 & 1.62 \\
& $(.05)$ & $(.00)$ \\
crp & 4.77 & 4.48 \\
& $(.00)$ & $(.00)$ \\
adjrd & 0.04 & 0.16 \\
& $(.57)$ & $(.00)$ \\
adjadv & 0.35 & - \\
& $(.00)$ & \\
adjprodfac & 0.17 & -0.15 \\
& $(.00)$ & $(.11)$ \\
n obs. & 134 & 168 \\
adj-R ${ }^{2}$ & $69 \%$ & $69 \%$
\end{tabular}

$\mathrm{P}$-values are in parentheses. The variables are described in Appendix A.

Observations are scaled by the prior period total assets (Compustat data \#6). 
Table 2.12 Lag Values of Investments

The Pearson correlation of each model variable with the lag values of the model variables are reported for Big Pharma firms ( $n=302$ observations).

\begin{tabular}{|c|c|c|c|c|c|c|c|c|c|c|}
\hline & \multicolumn{2}{|c|}{$\operatorname{crp}_{t}$} & \multicolumn{2}{|c|}{$\operatorname{crg}_{t}$} & \multicolumn{2}{|c|}{$a d v_{t}$} & \multicolumn{2}{|c|}{$r d_{t}$} & \multicolumn{2}{|c|}{$\operatorname{prodfac}_{t}$} \\
\hline & Corr & P-val & Corr & P-val & Corr & P-val & Corr & P-val & Corr & P-val \\
\hline $\boldsymbol{c r p} p_{t-1}$ & 0.90 & 0.01 & -0.41 & 0.00 & 0.20 & 0.00 & -0.08 & 0.15 & 0.08 & 0.18 \\
\hline $\operatorname{crg}_{t-1}$ & -0.47 & 0.00 & 0.92 & 0.00 & 0.01 & 0.88 & -0.13 & 0.23 & 0.08 & 0.14 \\
\hline$a d v_{t-1}$ & 0.16 & 0.01 & 0.00 & 0.97 & 0.93 & 0.00 & -0.04 & 0.43 & -0.04 & 0.40 \\
\hline$a d v_{t-2}$ & 0.19 & 0.00 & 0.01 & 0.90 & 0.82 & 0.00 & -0.05 & 0.38 & -0.06 & 0.32 \\
\hline$a d v_{t-3}$ & 0.22 & 0.00 & 0.00 & 0.97 & 0.80 & 0.00 & -0.05 & 0.38 & -0.06 & 0.27 \\
\hline$a d v_{t-4}$ & 0.20 & 0.00 & 0.00 & 0.98 & 0.78 & 0.00 & -0.06 & 0.31 & -0.06 & 0.26 \\
\hline $\boldsymbol{a d} \boldsymbol{v}_{t-5}$ & 0.16 & 0.01 & 0.01 & 0.83 & 0.72 & 0.00 & -0.06 & 0.31 & -0.05 & 0.35 \\
\hline$a d v_{t-6}$ & 0.15 & 0.01 & 0.02 & 0.78 & 0.65 & 0.00 & -0.06 & 0.33 & -0.03 & 0.60 \\
\hline$a d v_{t-7}$ & 0.15 & 0.01 & 0.03 & 0.64 & 0.61 & 0.00 & -0.06 & 0.28 & 0.00 & 0.94 \\
\hline $\boldsymbol{a d} \boldsymbol{v}_{t-8}$ & 0.15 & 0.01 & 0.03 & 0.64 & 0.59 & 0.00 & -0.06 & 0.32 & 0.01 & 0.86 \\
\hline $\boldsymbol{a d} \boldsymbol{v}_{t-9}$ & 0.17 & 0.00 & 0.02 & 0.80 & 0.58 & 0.00 & -0.05 & 0.37 & 0.01 & 0.93 \\
\hline $\boldsymbol{r} \boldsymbol{d}_{t-1}$ & 0.03 & 0.10 & -0.20 & 0.18 & -0.07 & 0.20 & 0.53 & 0.00 & -0.12 & 0.14 \\
\hline $\boldsymbol{r} \boldsymbol{d}_{t-2}$ & 0.09 & 0.01 & -0.19 & 0.17 & -0.05 & 0.38 & 0.47 & 0.00 & -0.14 & 0.12 \\
\hline $\boldsymbol{r} \boldsymbol{d}_{t-3}$ & 0.16 & 0.01 & -0.14 & 0.11 & -0.04 & 0.54 & 0.34 & 0.00 & -0.13 & 0.12 \\
\hline $\boldsymbol{r} \boldsymbol{d}_{t-4}$ & 0.15 & 0.00 & -0.11 & 0.16 & -0.02 & 0.67 & 0.23 & 0.00 & -0.13 & 0.13 \\
\hline $\boldsymbol{r} \boldsymbol{d}_{t-5}$ & 0.19 & 0.00 & -0.09 & 0.11 & -0.01 & 0.80 & 0.14 & 0.01 & -0.10 & 0.17 \\
\hline $\boldsymbol{r} \boldsymbol{d}_{t-6}$ & 0.24 & 0.00 & -0.07 & 0.26 & 0.01 & 0.84 & 0.12 & 0.03 & -0.04 & 0.44 \\
\hline $\boldsymbol{r} \boldsymbol{d}_{t-7}$ & 0.26 & 0.00 & -0.03 & 0.59 & 0.03 & 0.62 & 0.08 & 0.19 & 0.01 & 0.87 \\
\hline $\boldsymbol{r} \boldsymbol{d}_{t-8}$ & 0.24 & 0.00 & -0.01 & 0.87 & 0.05 & 0.43 & 0.02 & 0.72 & 0.08 & 0.10 \\
\hline $\boldsymbol{r} \boldsymbol{d}_{t-9}$ & 0.25 & 0.00 & 0.03 & 0.62 & 0.06 & 0.27 & 0.00 & 0.99 & 0.19 & 0.00 \\
\hline prodfac $_{t-1}$ & 0.12 & 0.03 & 0.09 & 0.20 & -0.04 & 0.52 & -0.13 & 0.12 & 0.74 & 0.00 \\
\hline prodfac $_{t-2}$ & 0.09 & 0.13 & 0.06 & 0.29 & -0.02 & 0.66 & -0.10 & 0.12 & 0.55 & 0.00 \\
\hline $\operatorname{prodfac}_{t-3}$ & 0.10 & 0.09 & 0.05 & 0.34 & -0.02 & 0.69 & -0.10 & 0.14 & 0.45 & 0.00 \\
\hline prodfac $_{t-4}$ & 0.14 & 0.02 & 0.05 & 0.42 & 0.00 & 0.95 & -0.02 & 0.69 & 0.37 & 0.00 \\
\hline prodfac $_{t-5}$ & 0.19 & 0.00 & 0.05 & 0.41 & 0.02 & 0.67 & -0.07 & 0.26 & 0.24 & 0.00 \\
\hline prodfac $_{t-6}$ & 0.20 & 0.00 & 0.06 & 0.28 & 0.06 & 0.26 & -0.06 & 0.28 & 0.16 & 0.01 \\
\hline prodfac $_{t-7}$ & 0.19 & 0.00 & 0.08 & 0.15 & 0.08 & 0.19 & -0.06 & 0.27 & 0.14 & 0.02 \\
\hline prodfac $_{t-8}$ & 0.17 & 0.00 & 0.09 & 0.12 & 0.07 & 0.24 & -0.07 & 0.21 & 0.15 & 0.01 \\
\hline
\end{tabular}




\section{CHAPTER 3 Model Evaluation}

\subsection{Introduction}

For many years, empirical researchers have used a simple model appearing in Ohlson (1995) to justify the inclusion of accounting performance measures such as residual income, net income, and book value in valuation models. The pharmaceutical valuation model in Chapter 2 is based on the free cash flows of the pharmaceutical firms, and makes no reference to such accounting measures. The reason for this is that the modeling in Chapter 2 draws on the approach of Feltham and Ohlson (1996) and from Christensen and Feltham (2003). Those articles start with the premise that value is driven by transactions that generate cash flows. Accounting accruals enter these models through a careful selection of processes that tie accounting numbers to the cash flows. The accounting model is equivalent to the cash flow model, aside from requiring the assumption of a discount rate to construct a residual income variable. However, the accounting model maps the value of the firm to a vector of accounting variables, which enables researchers to investigate the relation between market values and accounting information.

The Christensen and Feltham (2003) approach is used in this chapter. The cash flow model presented in Chapter 2 is adapted to include capital asset accruals that are common in the pharmaceutical industry. The assets are capitalized on the balance sheet and depreciated in the income statement. The depreciation flows through residual income, which also incorporates some of the cash flows and a charge for the use of capital.

The contributions of the pharmaceutical accounting model are threefold. First, the new mapping of firm value provides an economic interpretation to the accounting valuation weights. Second, the inclusion of capitalized balance sheet items identifies whether accounting for depreciation and amortization is conservative in this industry. Third, the performance of the accounting model relative to the performance of the cash flow model provides a specification test for the valuation model used in Chapter 2. The analysis in this chapter is in the spirit of Chapter 
10 of Christensen and Feltham (2003), where they encourage accounting researchers to apply their techniques in other contexts to develop situation-specific models and develop new insights.

The main objective of this chapter is to develop an accounting version of the pharmaceutical valuation model. However, I also develop an accounting model with aggregate measures based on a paper by Ohlson (1995). Many researchers use valuation models motivated by Ohlson (1995) who presents a bivariate model with book value of equity and net income as explanatory variables ${ }^{57}$. I test whether the pharmaceutical accounting model developed in this chapter is better at explaining the variability in firm value than this bivariate model. The pharmaceutical accounting model is expected to perform better since it is less restrictive and it allows for biased accounting. However, Begley, Chamberlain, and Li (2006) find the surprising result that a less restrictive model developed specifically for firms in the banking sector underperforms the parsimonious net income, book value, bivariate model. By performing a similar test with pharmaceutical firms, this chapter sheds light on the generality of their findings.

The performance of the accounting model developed in this chapter is also compared to the cash flow model from Chapter 2 as a specification test. Given the assumed cash flow and accounting dynamics, the theoretical valuations are equivalent. However, the accounting model has additional balance sheet variables, and requires the assumption of a discount rate in order to construct the residual operating income variable. The performance of the accounting model relative to the cash flow model allows me to investigate two issues. First, the results tell us whether accounting information, such as the book value of operating assets, is incrementally informative over the cash flow information. Second, the relative performance test provides some insight into the valuation effect of assuming a discount rate. This complements the research of Lundholm and O'Keefe (2001) who discuss a series of valuation papers (such as Penman and Sougiannis [1998], Francis, Olsson, and Oswald [2000], and Courteau, Kao, and Richardson

\footnotetext{
${ }^{57}$ Ohlson (1995) also models a variable that captures other information, which is sometimes used in empirical papers.
} 
[2000]) that conclude that residual income valuation models outperform cash flow models. Lundolm and O'Keefe (2001) point out that the models are equivalent and should theoretically yield identical valuations. They suggest that one research design issue that can lead to different valuations is based on assumptions about the discount rate.

The salient results from this chapter are as follows. The accounting valuation weights suggest that pharmaceutical firms report conservatively with respect to the positive net present value of their investments. This is consistent with GAAP, which requires delaying the recognition of profits until they are received. However, pharmaceutical firms do not report conservatively or aggressively with respect to depreciation and amortization. The depreciation and amortization policies are chosen among several options offered by GAAP, and prior research shows that firms usually depreciate assets faster than they decay (which is conservative), but this is not the case for pharmaceutical firms.

The relative performance test also provides some interesting insights. The model comparison suggests that the accounting valuation model may be slightly superior to the cash flow model due to the inclusion of the balance sheet variables, but the evidence is weak. Both the accounting model and the cash flow model clearly outperform a model with only net income and book value of equity as explanatory variables, therefore disaggregated information is important for valuing firms in the pharmaceutical industry. Further analysis suggests that the assumption of a discount rate in the accounting valuation model does not lead to material valuation differences.

This chapter is set up as follows. The accounting valuation model is developed in the next section, followed by the development of the summary accounting model based on Ohlson (1995) in section 3.3. The empirical data used to estimate the valuation models are described in Section 3.4, along with econometric issues and hypotheses development. The estimated valuation weights are discussed in section 3.5, with some sensitivity analysis presented in section 3.6. Section 3.7 explores the relative performance of the models, followed by the conclusion in section 3.8. 


\subsection{Accounting Model}

A useful foundation for developing accounting valuation models comes from a seminal paper by Ohlson (1995). He begins with standard assumptions from the finance literature to express the value of a firm $\left(v_{t}\right)$ as the present value of expected future dividends $\left(d_{t}\right)$, discounted at a rate $(\mathrm{R}=1+\imath)$ which is one plus the riskless interest rate $\mathrm{l}$ :

$$
v_{t}=\sum_{\tau=1}^{\infty} R^{-\tau} E_{\tau}\left[d_{t+\tau}\right]
$$

Ohlson (1995) uses the clean surplus relation ${ }^{58}$ to replace the dividend term with net income $\left(n i_{t}\right)$ and the book value of equity $\left(b v_{t}\right): d_{t}=b v_{t-1}+n i_{t^{-}} b v_{t}$. This relation can be substituted for the infinite series of dividends in equation 3.1, and the terms collected such that equation 3.1 is expressed in terms of residual income. ${ }^{59}$ Residual income $\left(r i_{t}\right)$, is defined as net income less a capital charge $(l)$ based on the book value of equity $\left(r i_{t}=n i_{t}-\imath b v_{t-1}\right)$. This obtains an equation that is algebraically equivalent to the dividend relation, but is expressed in terms of residual income:

$$
v_{t}=b v_{t}+\sum_{\tau=1}^{\infty} R^{-\tau} E_{\tau}\left[r i_{t+\tau}\right]
$$

Equation 3.2 provides a useful modeling alternative in settings where future residual income is easier to estimate than future dividends. Ohlson (1995) shows that, if residual income is assumed to follow an autoregressive process represented by the fixed, known parameter $\omega$, such that $\mathrm{E}\left[r i_{t+1}\right]=\omega r i_{t}$ then firm value can be stated as a function of current book value and current residual income: ${ }^{60}$

$$
v_{t}=b v_{t}+\alpha r i_{t}
$$

with $\alpha=\frac{\omega}{(R-\omega)}$, and where $\omega$ is the persistence of residual income, and is constrained to be between zero and one. The valuation weight on book value is implicitly equal to one. This parsimonious model is a good starting point, but it does not provide enough structure to

\footnotetext{
${ }^{58}$ The clean surplus relation requires the change in book value to equal earnings minus dividends: such that $b v_{t}=b v_{t-1}+n i_{t}-d_{t}$.

${ }^{59}$ Christensen and Feltham (2003) present a proof of this in page 282 of their book.

${ }^{60}$ Ohlson (1995) also includes a variable $v$ that captures information other than abnormal earnings. I omit this variable (without loss of generality) because $v$ is not modeled in this paper.
} 
investigate the effect of accounting conservatism. The effect of conservative accounting is best explained through the concept of goodwill. Goodwill $\left(g w_{t}\right)$ is defined as the difference between the market value and the book value of the firm $\left(g w_{t} \equiv v_{t}-b v_{t}\right)$. Equation 3.3 shows that goodwill is entirely attributable to expected future residual income:

$$
g w_{t}=v_{t}-b v_{t}=\alpha r i_{t}=\frac{\omega}{(R-\omega)} r i_{t}
$$

Given an information set $(\psi)$ at time $t$, expected future goodwill is $\mathrm{E}\left[g w_{t+\tau} \mid \psi_{\mathrm{t}}\right]=\left(\frac{\omega}{(R-\omega)}\right)^{\tau+1} r i_{t}$. Since the persistence parameter $\omega$ is between zero and one, expected goodwill goes to zero as $\tau$ goes to infinity. Ohlson (1995) defines accounting systems that have this property as unbiased. Accounting systems are biased towards conservatism if they are expected to persistently generate positive goodwill such that $\mathrm{E}\left[g w_{t+\tau} \mid \psi_{\mathrm{t}}\right]>0$ as $\tau$ goes to infinity.

One accounting practice that leads to conservatism is where assets are depreciated faster than their true economic decay, which leads to a book value that understates the value of equity. On the left-hand-side of equation 3.4, a lower book value will result in a higher goodwill through the relation $g w_{t}=v_{t}-b v_{t}$. On the right-hand-side of equation 3.4, the lower book value reduces the capital charge in the calculation of residual income, and increases $r i_{t}$. Therefore aggressive depreciation is expected to lead to persistent positive goodwill, at least for a hypothetical firm with an infinite life and continuous investments in depreciable assets.

Another accounting practice that leads to conservative book values is the delay in the recognition of the positive net present value (NPV) of investments. The positive NPV portion of investments represents returns in excess of what is required to compensate investors for the riskiness of the investment. When a firm makes an investment, the value (including the excess returns of the investment) is incorporated in share price, but the book value reflects only the cost. Positive NPV investments affect the coefficient on residual income so that the coefficient is not only a function of persistence $(\omega)$, but also of the expected future positive NPV investments. This 
could lead to a coefficient that is greater than one, and expected goodwill that is greater than zero in the limit.

The accounting practices of pharmaceutical firms incorporate at least one type of conservatism. As discussed in Chapter 2, pharmaceutical firms make investments that generate cash flows with positive NPV on at least some of those investments. In addition, they may be following conservative accounting practices with respect to depreciation and amortization. An accounting model developed for pharmaceutical firms should therefore provide for both types of conservatism. Consequently, the Ohlson (1995) model, which assumes unbiased accounting, is not appropriate for this study.

A more appropriate model for pharmaceutical firms is based on papers by Feltham and Ohlson $(1995,1996)$, who develop alternative parsimonious representations of value that allow for biased accounting. They begin by representing the market value of a firm as the sum of the value of financial assets $\left(f a_{t}\right)$ and the value of operating assets $\left(v o_{t}\right):^{61}$

$$
v_{t}=f a_{t}+v o_{t}
$$

The financial assets are assumed to be recorded at current market value and the expected income is equal to the discount rate times the beginning balance of $f a_{t}$. Operating assets are the assets that generate value for the firm. Conservatism derives both from positive NPV investments in operating assets and from accrual policies that drive the book value of operating assets away from its market value $\left(v o_{t}\right)$. The assumption that financial assets are marked-to-market leads to proposition 1 in Feltham and Ohlson (1995), which states that the following three expressions are

\footnotetext{
${ }^{61}$ Note that liabilities are negative assets.
} 
equivalent:

$$
\begin{aligned}
& v_{t}=f a_{t}+\sum_{\tau=1}^{\infty} R^{-\tau} E\left[c_{t+\tau}\right] \\
& v_{t}=b v_{t}+\sum_{\tau=1}^{\infty} R^{-\tau} E\left[r i_{t+\tau}\right] \\
& v_{t}=b v_{t}+\sum_{\tau=1}^{\infty} R^{-\tau} E\left[r o i_{t+\tau}\right]
\end{aligned}
$$

where:

$f a_{t}$ is the book value (and market value) of financial assets;

$c_{t}$ is the free cash flows ${ }^{62}$;

$b v_{t}$ is the book value of equity;

$r i_{t}$ and $r o i_{t}$ are residual income and residual operating income, respectively.

The equivalence of these equations is obtained with the separation of financial and operating activities. The book value of equity is partitioned between the book value of financial assets $\left(f a_{t}\right)$ and the book value of operating assets $\left(o a_{t}\right): b v_{t}=f a_{t}+o a_{t}$. The income statement is also separated into financing $\left(f i_{t}\right)$ and operating $\left(o i_{t}\right)$ components such that net income is the sum of the two components: $n i_{t}=f i_{t}+o i_{t}$. With this structure, residual operating income $\left(r o i_{t}\right)$ is calculated in a similar manner to residual income, with a capital charge based on the opening balance of operating assets: $r o i_{t}=o i_{t}-\iota^{\prime} a_{t-1}$. The equivalence of (3.5a) and (3.5b) is trivial if we consider that (3.5a) is essentially cash accounting. With cash accounting, net income is simply the operating cash inflows minus the operating cash outflows. Cash outflows are not capitalized on the balance sheet, therefore the book value of operating assets is zero resulting in $b v_{t}=f a_{t}$. Since $o a_{t-1}$ is equal to zero, there is no capital charge on the opening balance of operating assets, and residual income is equal to net income, which is simply free cash flows. The equivalence of (3.5b) and (3.5c) is simple if we separate financing and operating components and consider that residual income on financial assets is zero ${ }^{63}$, resulting in $r i_{t}=r o i_{t}=o i_{t}-\imath o a_{t-1}$.

\footnotetext{
62 Operating cash flows are net of financing revenues and expenses.

${ }^{63}$ To see that this is the case, consider that if financial assets $\left(f a_{t}\right)$ are marked-to-market, then the expected income on these assets is $\imath f a_{t}$ and the residual income on financial assets is $\left(\imath f a_{t}-\imath f a_{t}\right)$, which is zero.
} 
The valuation relations $3.5 \mathrm{a}, 3.5 \mathrm{~b}$, and $3.5 \mathrm{c}$ are based on infinite series of variables. Many empiricists operationalize these valuation models by estimating a truncated sequence of the variables, and a terminal value at the truncation date. However, Feltham and Ohlson (1996) invoke the assumption of a Markovian environment ${ }^{64}$, so that the infinite series of variables can be replaced with only the next period's expected values for those variables. In a Markovian setting, the infinite series in equation 3.5a can be replaced with next period's expected values for operating assets $(\mathrm{vo})$ and operating cash flows $(o c)$ to construct a value function that is based on cash flows:

$$
v_{t}-f a_{t}=v o_{t}=R^{-1} E\left[o c_{t+1}+v o_{t+1}\right]
$$

Similarly, the infinite series in expression 3.5c can be replaced with next period's expected values of roi, vo, and $o a$ to construct a value function that is based on accounting variables:

$$
v_{t}-f a_{t}=o a_{t}=R^{-1} E\left[r o i_{t+1}+v o_{t+1}-o a_{t+1}\right]
$$

In order to solve these equations, one assumes a set of information dynamics that allows the next period values to be expressed in terms of current period or historical information. To tailor the valuation model to a firm or industry, the information dynamics should correspond to the business processes that are typical for those firms. As much as possible, I assume cash flows dynamics that depict the production process of pharmaceutical firms, and accounting rules that reflect current practices in the pharmaceutical industry.

As in Feltham and Ohlson (1996), I begin with a cash flow model, and then identify a set of accounting rules that transforms the cash flow variables into residual income ${ }^{65}$. I add a new variable to the model that represents a type of investment that pharmaceutical firms typically capitalize and amortize: purchased R\&D. When firms purchase R\&D (as opposed to generating it in-house), they capitalize the portion that is expected to have future benefits, and amortize this

\footnotetext{
${ }^{64}$ A Markovian environment is one where the process is conditionally independent of past states, given the present (time $t$ ) state.

${ }^{65}$ Some expenditures such as PPE are capitalized as assets and depreciated, whereas other expenditures such as R\&D are expensed.
} 
asset in the income statement. In my cash flow model I assume that capitalized R\&D $\left(\right.$ caprd $\left._{t}\right)$ generates cash receipts on patented drugs $\left(\operatorname{crp}_{t+1}\right)$ in the next period at the rate of $\omega_{p c}$. In my dynamics, I also assume that $\operatorname{caprd}_{t}$ is part of a series of capitalized R\&D investments that persist at the rate of $\omega_{c c}$. I add this new variable to the linear information dynamics from Chapter 2 and get:

$\operatorname{crg}_{t+1}=\omega_{g g} \operatorname{crg}_{t}+\varepsilon_{g t+1}$

$\operatorname{crp}_{t+1}=\omega_{p p} c r p_{t}+\omega_{p a} a d v_{t}+\omega_{p f p} \operatorname{prodfac}_{t}+\omega_{p c} c a p r d_{t}+\varepsilon_{p t+1}$

$r d_{t+1}=\omega_{r r} r d_{t}+\varepsilon_{r t+1}$

$a d v_{t+1}=\omega_{a a} a d v_{t}+\omega_{a r} r d_{t}+\varepsilon_{a t+1}$

prodfac $_{t+1}=\omega_{f f}$ prodfac $t+\omega_{f r} r d_{t}+\varepsilon_{f t+1}$

$\operatorname{caprd}_{t+1}=\omega_{c c} \operatorname{caprd}_{t}+\varepsilon_{c t+1}$

where $\omega_{g g}$ and $\omega_{p p}$ are between zero and one ${ }^{66}, \omega_{a r}, \omega_{f r}, \omega_{p a}, \omega_{p f}$, and $\omega_{p c}$ are greater than zero, and $\omega_{r r}, \omega_{a a}, \omega_{f f}$, and $\omega_{c c}$, are positive and less than $\mathrm{R}=(1+\imath)$. The error terms are mean zero and they indicate that the information is stochastic, not determinalistic.

The information dynamics are designed to characterize the drug development process of a typical drug company ${ }^{67}$, except that the time period is condensed for parsimony. In my dynamics, investments in $\mathrm{R} \& \mathrm{D}\left(r d_{t-1}\right)$ lead to expenditures in advertising $\left(a d v_{t}\right)$ and production facilities $\left(\operatorname{prodfac}_{t}\right)$. These investments, along with purchased R\&D $\left(\operatorname{caprd}_{t}\right)$, generate revenues from patented drugs $\left(\operatorname{crp}_{t+1}\right)$. Revenues from generic drugs $\left(\mathrm{crg}_{t}\right)$ are a separate process that don't require a significant amount of $\mathrm{R} \& \mathrm{D}$, advertising, or investments in manufacturing. The assumptions underlying these dynamics are discussed in section 2.2 of this thesis.

I solve the cash flow model using equation 3.6a. The set of information dynamics allows me to express the next period's expected operating cash flows $\left(o c_{t+1}\right)$ and expected value of operating assets $\left(v o_{t+1}\right)$ in time $t$ information (see Appendix B).

\footnotetext{
${ }^{66}$ The assumption that cash receipts decay infinitely is not realistic but is used for tractability. Feltham and Ohlson (1996) evaluate a firm that invests in projects with finite cash flows and conclude that the basic insights are likely to be similar. The lower bounds (zero) are based on economic reasoning, while the upper bounds (one or R) are for stationarity.

${ }^{67}$ See figure 2.1 .
} 
The cash flow dynamics obtain the following cash flow valuation model:

$$
v_{t}=f a_{t}+\pi_{g} c r g_{t}+\pi_{p} c r p_{t}+\pi_{r} r d_{t}+\pi_{a} a d v_{t}+\pi_{f} \text { prodfac }_{t}+\pi_{c} c a p r d_{t}
$$

with the following valuation weights (derived in Appendix B):

$$
\begin{array}{lll}
\pi_{g}=\Phi_{g} \omega_{g g} & \pi_{p}=\Phi_{p} \omega_{p p} & \pi_{r}=R \Phi_{r} \lambda_{r}+1 \\
\pi_{a}=R \Phi_{a} \lambda_{a}+1 & \pi_{f}=R \Phi_{f} \lambda_{f}+1 & \pi_{c}=R \Phi_{c} \lambda_{c}+1
\end{array}
$$

where:

$\Phi_{i} \equiv\left(R-\omega_{i i}\right)^{-1}$ for $i=g, p, r, a, f, c$

$\lambda_{r} \equiv\left(\Phi_{a} \lambda_{a} \omega_{a r}+\Phi_{f} \lambda_{f} \omega_{f r}-1\right)$

$\lambda_{i} \equiv\left(\omega_{p i} \Phi_{p}-1\right)$ for $i=a, f, c$

The valuation weights on cash receipts reflect the persistence of the receipts $\left(\omega_{g g}\right.$ and $\left.\omega_{p p}\right)$ discounted at a rate that adjusts for growth $\left[\Phi_{g}=\left(R-\omega_{g g}\right)^{-1}\right.$ and $\left.\Phi_{p}=\left(R-\omega_{p p}\right)^{-1}\right]$. The valuation weights on investments are explored in detail in Chapter 2 of this thesis. They incorporate a parameter $\left(\lambda_{i}\right)$ that corresponds to the Net Present Value (NPV) of the investment. The NPV represents the discounted cash flows that are in excess of what is required to compensate investors for the riskiness of the investment. By definition, these are economic rents. In section 2.2 of this thesis, I use advertising investments to demonstrate that the NPV component $\left(\lambda_{a}=\right.$ $\left.\omega_{p a} \Phi_{p}-1\right)$ is positive if the expected benefit of a dollar of advertising $\left(\omega_{p a} \Phi_{p}\right)$ exceeds the cost (1). If the investment is zero NPV, the first term in the valuation weight drops out, leaving a coefficient of one on $a d v_{t}$. The structure of the valuation weight is similar for the other investment variables $\left(r d_{t}\right.$, prodfac $_{t}$ and caprd $\left._{t}\right)$, where the first term in the valuation weight is positive if the investment is positive NPV, leading to a coefficient that is greater than one. The NPV parameters for investments in production facilities and purchased $\mathrm{R} \& \mathrm{D}\left(\lambda_{f}\right.$ and $\left.\lambda_{c}\right)$ are similar to the advertising NPV $\left(\lambda_{a}\right)$, but the elements of the NPV parameter for in-house R\&D investments $\left(\lambda_{r}=\Phi_{a} \lambda_{a} \omega_{a r}+\Phi_{f} \lambda_{f} \omega_{f r}-1\right)$ are different. In-house R\&D can generate positive NPV through its effect on advertising $\left(\omega_{a r}\right)$, but only if advertising is itself a positive NPV investment 
$\left(\lambda_{a}>0\right)$. In-house $\mathrm{R} \& \mathrm{D}$ can also generate positive NPV through investments in production facilities $\left(\omega_{f r}\right)$ if these lead to economic rents $\left(\lambda_{f}>0\right)$.

To adapt this model for accrual accounting, I use the operating income format (equation 3.6b) of the valuation relation and incorporate some capitalization practices typically adopted by pharmaceutical firms and depreciation/amortization policies that lead to tractable results. Based on the practices of the firms, net cash receipts $\left(\mathrm{crp}_{t}\right.$ and $\left.\mathrm{crg}_{t}\right)$ are reported as components of operating income, while investments $\left(a d v_{t}, r d_{t}, \operatorname{prodfac}_{t}\right.$ and $\left.\operatorname{caprd}_{t}\right)$ are either capitalized on the balance sheet or expensed through operating income, in accordance with GAAP. Investments in production facilities $\left(\right.$ prodfac $\left._{t}\right)$ are capitalized as property, plant, and equipment $\left(p e_{t}\right)$, then depreciated $\left(d e p_{t}\right)$ through operating income. Similarly, purchased R\&D that is deemed to have future benefits $\left(\operatorname{caprd}_{t}\right)$ is capitalized as intangibles $\left(\right.$ int $\left._{t}\right)$, then amortized $\left(\right.$ amort $\left._{t}\right)$ through operating income. In contrast, investments in in-house $\mathrm{R} \& \mathrm{D}\left(r d_{t}\right)$ and advertising $\left(a d v_{t}\right)$ are immediately expensed. As in Chapter 10 of Christensen and Feltham (2003), I assume that firms adopt the declining balance method for depreciation and amortization such that $d e p_{t}=(1-\delta) p e_{t-1}$, and amort $_{t}=(1-\chi)$ int $_{t-1} .{ }^{68}$ With this accounting system, the balance sheet is the sum of financial assets $\left(f a_{t}\right)$ and operating assets $\left(o a_{t}\right)$, where the latter is:

$$
o a_{t}=p e_{t}+i n t_{t}=\operatorname{prodfac}_{t}+\operatorname{caprd}_{t}+\delta p e_{t-1}+\chi i n t_{t-1} .
$$

Operating income is net revenues minus depreciation, amortization, and investments in in-house R\&D and advertising ${ }^{69}$ :

$$
o i_{t}=c r p_{t}+c r g_{t}-d e p_{t}-a m o r t_{t}-a d v_{t}-r d_{t}
$$

\footnotetext{
${ }^{68}$ Pharmaceutical firms generally use the straight-line method for depreciation. The purpose of the declining balance method is to ensure that residual income is autoregressive for tractability. With straightline depreciation, depreciation stays constant while the book value of operating assets declines, which results in residual income increasing over time. Feltham and Ohlson (1996) evaluate different depreciation policies and conclude that, while the analysis with straight-line depreciation is more complex, the results are not significantly different from the declining balance approach used here.

${ }^{69}$ Note that pharmaceutical accounting is a combination of accrual accounting for ppe and purchased $R \& D$ and cash flow accounting for advertising and in-house R\&D.
} 
Substituting the depreciation and amortization rates results in the following expression for operating income:

$$
o i_{t}=c r p_{t}+c r g_{t}-(1-\delta) p e_{t-1}-(1-\chi) i n t_{t-1}-a d v_{t}-r d_{t}
$$

This generates the following residual operating income: ${ }^{70}$

$$
r o i_{t}=c r p_{t}+c r g_{t}-(R-\delta) p e_{t-1}-(R-\chi) i n t_{t-1}-a d v_{t}-r d_{t}
$$

Note that several items typically found in financial statements are excluded from this accounting system, which is a concern that I address in section 3.2.1. The accounting system obtains the following pharmaceutical accounting valuation model:

$$
v_{t}=f a_{t}+o a_{t}+\alpha_{r o i} r o i_{t}+\alpha_{g} c r g_{t}+\alpha_{r} r d_{t}+\alpha_{a} a d v_{t}+\alpha_{f} \text { rrodfac }_{t}+\alpha_{c} c a p r d_{t}+\alpha_{e} p e_{t-1}+\alpha_{i} i n t_{t-1}
$$

with the following valuation weights (derived in Appendix B):

$$
\begin{array}{ll}
\alpha_{r o i}=\Phi_{p} \omega_{p p} & \alpha_{g}=\Phi_{g} \omega_{g g}-\alpha_{r o i} \\
\alpha_{r}=R \Phi_{r} \lambda_{r}+1+\alpha_{r o i} & \alpha_{a}=R \Phi_{a} \lambda_{a}+1+\alpha_{r o i} \\
\alpha_{f}=R \Phi_{f} \lambda_{f} & \alpha_{c}=R \Phi_{c} \lambda_{c} \\
\alpha_{e}=R \Phi_{p}\left(\omega_{p p}-\delta\right) & \alpha_{n}=R \Phi_{p}\left(\omega_{p p}-\chi\right)
\end{array}
$$

where:

$\Phi_{j} \equiv\left[R-\omega_{j j}\right]^{-1}$ for $j=p, g, r, a, f, c$

$\lambda_{r} \equiv\left(\Phi_{a} \lambda_{a} \omega_{a r}+\Phi_{f} \lambda_{f} \omega_{f r}-1\right)$

$\lambda_{i} \equiv\left(\omega_{p i} \Phi_{p}-1\right)$ for $i=a, f, c$

By reconciling the weights from the cash flow model (equation 3.7) to the weights from the accounting model (equation 3.8), we observe how sophisticated investors can theoretically "undo the accruals" to derive the cash flows from accounting information. The valuation weight on residual operating income is $\alpha_{r o i}=\Phi_{p} \omega_{p p}$, which is identical to the valuation weight on $\operatorname{crp}_{t}$ from the cash flow model $\left(\pi_{p}=\Phi_{p} \omega_{p p}\right)$. Therefore all elements of $r o i_{t}$ (including $c r g_{t}, a d v_{t}, r d_{t}, d e p_{t}$,

\footnotetext{
${ }^{70}$ To see where the expression $(R-\delta)$ and $(R-\chi)$ come from, consider the deductions that pertain to property, plant, and equipment. The deductions are depreciation $(I-\delta)$ and a capital charge $(l)$, which adds up to $(l+1-\delta)$. Since $\mathrm{R}=1+1$, substitute $l=R-1$ to get $(R-1+1-\delta)=(R-\delta)$.
} 
and amort $\left._{t}\right)$ are constrained to persist at the same rate as revenues from patented drugs $\left(\omega_{p p}\right)$. The assumption that all the earnings components aggregate is implicit in all residual income valuation models. To the extent that they don't aggregate, the valuation weight for each earnings component is adjusted by the valuation weight on roi $_{t}$. For example, the accounting valuation weights on in-house $\mathrm{R} \& \mathrm{D}$ and advertising investments $\left(\alpha_{r}=R \Phi_{r} \lambda_{r}+1+\alpha_{\text {roi }}\right.$, and $\left.\alpha_{a}=R \Phi_{a} \lambda_{a}+1+\alpha_{r o i}\right)$ are identical to their cash flow counterpart $\left(\pi_{r}=R \Phi_{r} \lambda_{r}+1\right.$, and $\left.\pi_{a}=R \Phi_{a} \lambda_{a}+1\right)$ except that the effect from expensing it through residual operating income $\left(\alpha_{r o i}\right)$ is added back to the valuation weight. Conversely, since generic cash receipts are added to operating income, the effect is reversed out by subtracting $\alpha_{r o i}$ from the valuation weight on $\operatorname{crg}_{t}\left(\alpha_{g}=\Phi_{g} \omega_{g g}-\alpha_{r o i}\right)$.

The differences in the remaining valuation weights between the two models are due to the capitalization of investments in production facilities ( prodfac $\left._{t}\right)$ and purchased R\&D $\left(\right.$ caprd $\left._{t}\right)$. The accounting valuation weight on each of these two variables $\left(\alpha_{f}=R \Phi_{f} \lambda_{f}\right.$, and $\left.\alpha_{c}=R \Phi_{c} \lambda_{c}\right)$ is reduced by one relative to their cash flow valuation weights $\left(\pi_{f}=R \Phi_{f} \lambda_{f}+1\right.$, and $\left.\pi_{c}=R \Phi_{c} \lambda_{c}+1\right)$ because the book value of capital investments is now included as a separate term $\left(o a_{t}\right)$ in the accounting model. The cost allocation of these investments flows through operating income as depreciation and amortization, therefore the decay is constrained to be equal to $(1-\delta) \alpha_{\text {roi }}$ for investments in production facilities and $(1-\chi) \alpha_{\text {roi }}$ for purchased $R \& D$. The valuation weights on the lagged values of operating assets ( $p e_{t-1}$ and $\left.i n t_{t-1}\right)$ adjust for the difference between the economic decay and the depreciation or amortization, and provide a measure of accounting conservatism. For example, if accounting for property, plant, and equipment was conservative, the depreciation (1$\delta)$ would be greater than the economic decay $\left(1-\omega_{p p}\right)$. This would result in $(1-\delta)>\left(1-\omega_{\mathrm{pp}}\right)$, which makes $\omega_{\mathrm{pp}}>\delta$, and generates a positive coefficient on $p e_{t-1}$. Similarly, a positive coefficient on int $_{t-1}$ indicates that purchased $\mathrm{R} \& \mathrm{D}$ is reported conservatively, with an amortization rate that is greater than the economic decay of the investment. If accounting is unbiased with respect to depreciation and amortization, then $\delta$ and $\chi$ are equal to $\omega_{p p}$ and the coefficients on $p e_{t-1}$ and int $_{t-1}$ are zero. 
Conservatism from unrecorded positive NPV investments is captured through the NPV parameters. If the firms earn no economic rents on investments, the NPV parameters $\left(\lambda_{r}, \lambda_{a}, \lambda_{f}\right.$, $\left.\lambda_{c}\right)$ are zero. This gives a valuation weight of $\left(\alpha_{r o i}+1\right)$ on $a d v_{t}$ and $r d_{t}$ : the accounting adjustment $\left(\alpha_{r o i}\right)$ is reversed and the firm recoups precisely the amount invested. Zero NPV investments give a valuation weight of zero on prodfac $_{t}$ and $\operatorname{caprd}_{t}$, since the present value of these investment is included in $o a_{t}$. The remaining variables $\left(f a_{t}\right.$ and $\left.o a_{t}\right)$ are not affected by conservatism. ${ }^{71}$

The accounting adaptation leads to a model that is not very different from the cash flow model. In fact, the two models are equivalent except that the accounting model includes three book value variables $\left(o a_{t}, p e_{t-1}\right.$, int $\left.t_{t-1}\right)$, and it incorporates a charge for the cost of capital $\left(\log _{t-1}\right)$ in the computation of the residual operating income $\left(\operatorname{roi}_{t}\right)$ variable. The models are estimated with empirical data described in section 3.4 of this chapter. Comparing the two models empirically is a specification test of whether the assumed discount rate has an important valuation effect, and whether the explanatory power is increased by capitalizing and depreciating the operating assets. My accounting model is designed for this specification tests, and consequently overlooks many items that one would expect to see in a pharmaceutical firm's financial statements. In the next section I discuss the effect of these omissions in the context of a prototypical set of financial statements.

\subsubsection{Variables Omitted from the Accounting Model}

The accounting model from the previous section contains a relatively small subset of variables that one would expect to see in a financial report. I discuss the implications of the omitted variables in this section. From the perspective of the balance sheet there are no omissions since all components are included either as operating or financial assets. This is by

\footnotetext{
${ }^{71}$ Some authors, such as Myers (1999) model both the income statement effect and the book value effect of aggressive depreciation. They assume a set of information dynamics for the book value of equity, including its effect on residual income. In these models, accounting conservatism leads to a coefficient that is greater than one on the book value of equity. In my model, conservatism is captured by the lagged book value of operating assets.
} 
design, since my construct for financial assets is all the balance sheet items except intangibles and property, plant, and equipment. As a result, the financial asset variable is a mixture of balance sheet items. Recall that an assumption of my model is that financial assets $\left(f a_{t}\right)$ are marked-tomarket and are not positive NPV investments. This assumption leads to two model simplifications. The first simplification is that financial assets have a valuation weight of one, therefore $f a_{t}$ can be moved to the left-hand-side of the valuation equation which reduces the number of variables in the model. The second simplification is that residual income on financial assets is zero, therefore financial cash flows can be disregarded in the determination of residual income. To the extent that the assumptions do not hold for some components of my $f a_{t}$ construct, the model will be misspecified.

My financial asset variable is comprised of all balance sheet accounts except intangibles and property, plant, and equipment. At a minimum, all working capital items are included in my measure of $f a_{t}$ : cash, short-term investments, receivables, inventories, other current assets, accounts payable, and debt. The book values of working capital items are likely to be similar to fair market values, therefore the classification is appropriate for these items. ${ }^{72}$ Many firms also have deferred taxes and long-term investments on their balance sheets. While these items are generally not material ${ }^{73}$, their book values are likely to deviate from market values. Amir, Kirscheneheiter, and Willard (1997) estimate the value of deferred taxes with a residual income valuation model, and get a mean valuation weight of 1.12 , which suggests that deferred taxes generate value. However, they don't model the dynamics of deferred taxes, whereas an important objective of this chapter is to make inferences based on the information dynamics. Christensen and Feltham (2003) illustrate the techniques for incorporating taxes in a residual income

\footnotetext{
${ }^{72}$ Christensen and Feltham (2003) devote sections of their book to modeling working capital accruals (page 340) and accounts receivable with bad debt expense (page 352) but the valuation issues on these balance sheet items are likely to be trivial in this industry therefore they are not highlighted in this paper.

${ }^{73}$ In my sample, the mean values of these items as a proportion of total asset is $1 \%$ for deferred taxes, $1 \%$ for investments accounted for by the equity method, and $4 \%$ for other investments.
} 
valuation model ${ }^{74}$ but since deferred taxes are not the focus of this paper, I combine them with financial assets $\left(f a_{t}\right)$. Long-term investments are combined with $f a_{t}$ for similar reasons. Longterm investment may be recorded conservatively (below market value), but the magnitude of the conservatism is not likely to be material in the context of my analysis, and the complexity of modeling long-term investments is beyond the scope of this chapter.

From the perspective of the income statement, several items are excluded. My theoretical construct for residual operating income includes net revenues ${ }^{75}$, advertising expenditures, R\&D expenditures, depreciation, and amortization, but not selling, general, and administration (SG\&A). This is so that I can derive the accounting model directly from the cash flow dynamics. The effect of leaving SG\&A outside the model is that the residual operating income variable is overstated, which results in a downward bias on the regression coefficient on roi $t_{t}$. In section 3.6 of this chapter I investigate the extent of this bias by estimating the accounting model with a residual income variable that incorporates SG\&A.

The remaining income statement items are excluded because they are financial in nature (such as interest income and expense) therefore should have residual income of zero, or because they are transitory (such as gains and losses on investments, discontinued operations, special items, and extraordinary items), and therefore have a theoretical valuation weight of zero. Ohlson (1999) demonstrates why transitory items have a valuation weight of zero. Consider that transitory items have a persistence of zero. The valuation weight on cash receipts (such as the weight of $\pi_{g}=\Phi_{g} \omega_{g g}$ on generic cash receipts) is a multiple of the persistence (ie. $\omega_{g g}$ ), therefore if the persistence is zero, the valuation weight should be zero as well.

\footnotetext{
${ }^{74}$ See appendix 9A (Tax Effects) of their book.

${ }^{75}$ In the theoretical model the revenues are net of cost of goods sold, but as discussed in section 3.4, my empirical proxies are gross revenues which are not net of cost of goods sold.
} 


\subsection{Summary Accounting Model}

One of the objectives of this paper is to investigate whether we lose useful information when we aggregate accounting data into summary accounting numbers. I use a model that is ubiquitous in the accounting literature; one that express the market value of equity as a function of book value of equity and net income (see for example, Collins et al. [1997], Barth et al. [1999], Easton and Harris [1991] and model comparisons by Begley, Chamberlain, and Li [2006]). I call this the summary accounting model. The only theoretical foundation for this model is a representation in the paper by Ohlson (1995). He shows that, with unbiased accounting the residual income model in equation 3.3 can be restated such that the value of the firm is expressed in terms of book value of equity $\left(b v_{t}\right)$, net income $\left(n i_{t}\right)$, and dividends $\left(d_{t}\right)$ :

$$
v_{t}=(1-\mathrm{k}) b v_{t}+\mathrm{k}\left(\varphi n i_{t}-d_{t}\right)
$$

where $\mathrm{k}=(\mathrm{R}-1) \omega /(\mathrm{R}-\omega), \varphi=\mathrm{R} /(\mathrm{R}-1)$, and $\omega$ is the persistence of residual income, such that $0 \leq \omega \leq 1$. He identifies two special cases based on the boundary points of $\omega$. If $\omega=1$, then $k=1$, and $v_{t}$ is a function of only net income and dividends. If $\omega=0$, then $\mathrm{k}=0$, and $v_{t}$ is a function of book value alone. For all other values of $\omega$, the market value of the firm is based on a weighted average of book value and net income minus dividends. Therefore $v_{t}$ is likely to be a function of all three variables $\left(b v_{t}, n i_{t}\right.$, and $\left.d_{t}\right)$. In spite of this, most empiricists ignore dividends and use a reduced model with only net income and book value of equity.

In order to improve the comparability of the models, I separate the book value of equity between financial assets $\left(f a_{t}\right)$ and operating assets $\left(o a_{t}\right)$, and obtain the following summary accounting model:

$$
v_{t}=f a_{t}+o a_{t}+\zeta n i_{t}
$$

where $\zeta$ does not have a defined theoretical valuation weight. The summary accounting model (equation 3.10) is not expected to perform as well as the pharmaceutical accounting valuation model from the previous section (equation 3.8) for two reasons. The first reason is that omitting 
dividends from the summary model results in model misspecification. The second reason is that equations 3.9 and 3.10 are based on equation 3.3. As explained earlier, equation 3.3 does not provide for different sources of conservatism and assumes that residual income follows an autoregressive process characterized by the persistence parameter $\omega$. In contrast, the accounting model (equation 3.8) is designed to accommodate conservatism from positive NPV investments as well as conservatism from aggressive depreciation policies. In addition, the accounting model allows the components of residual income to persist at different rates by including each component in the valuation relation, which is less restrictive than having a single persistence parameter.

\subsection{Empirical Models and Hypothesis Development}

I estimate the three valuation models (equations 3.7, 3.8, and 3.10) with the archival data presented in Chapter 2 of this paper, plus a few new ones described in Appendix A. As in Chapter 2, I scale the data by the beginning value of total assets to reduce heteroskedasticity of the error term. In this chapter, I add a standard intercept to capture the mean (unscaled) effect of the unmodeled factors that affect firm value and get the following regression models with cash flows:

$$
\begin{aligned}
& v_{-} s_{j t}=\beta_{o}+\beta_{f a} f a \_s_{j t}+\beta_{g} c r g \_s_{j t}+\beta_{p} c r p \_s_{j t}+\beta_{r} r d \_s_{j t}+\beta_{a} a d v \_s_{j t}+\beta_{f} p r o d f a c \_s j \\
& +\beta_{c} c a p r d \_s_{j t}+\varepsilon_{t}
\end{aligned}
$$

with disaggregated accounting information:

$$
\begin{aligned}
& v_{-} s_{j t}=\beta_{o}+\beta_{f a} f a \_s j+\beta_{g} c r g \_s_{j t}+\beta_{r} r d \_s_{j t}+\beta_{a} a d v \_s_{j t}+\beta_{f} p r o d f a c \_s s_{j t}+\beta_{c} c a p r d \_s j+ \\
& \beta_{o a} o a \_s_{j t}+\beta_{r o i} r o i \_s_{j t}+\beta_{e} p e_{t-1 \_} s_{j t}+\beta_{i} i n t_{t-1} s_{j t}+\varepsilon_{t}
\end{aligned}
$$

and with summary accounting information:

$$
v \_s_{j t}=\beta_{o}+\beta_{f a} f a \_s j+\beta_{o a} o a \_s_{j t}+\beta_{n i} n i \_s_{j t}+\varepsilon_{t}
$$


where the underscore term $\left(s_{j t}\right)$ indicates that the variable has been scaled by the beginning value of total assets, and $\varepsilon_{t}$ is the ordinary least squares error at time $t .{ }^{76}$ The variables (described in Appendix A) are from Compustat, except for $\mathrm{crp}_{t}$ and $\mathrm{crg}_{t}$, which are hand-collected from the financial statements. The proxies for $r d_{t}, a d v_{t}$, and $n i_{t}$ are the advertising expenditures, R\&D expenditures, and income before extraordinary items numbers from the income statement. From the balance sheet I use the opening balance of property, plant, and equipment to represent $p e_{t-1}$, and intangibles to proxy for $i n t_{t-1}$. The book value of operating assets $\left(o a_{t}\right)$ is the sum of the current value of these two variables. The rest of the net assets are allocated to financial assets $\left(f a_{t}\right)$. The variable prodfac t $_{t}$ is capitalized expenditures from the cash flow statement, and the construct for caprd $_{t}$ is the change in intangibles, adjusted for amortization. Residual operating income $\left(r o i_{t}\right)$ is constructed by aggregating the operating income variables $\left(c r p_{t}+c r g_{t}-r d_{t}-a d v_{t}\right.$ - dep $_{t}-$ amort $_{t}$ ), then deducting a capital charge equal to $6 \%$ of the beginning balance of operating assets $\left(o a_{t-1}\right)$.

As explained in Chapter 2, I expect some noise and measurement error in my proxies. First, the value of a dollar invested R\&D is likely to differ based on the stage of the research project and on the characteristics of the firm that conducts the research. The variability of the true parameter incorporates noise in the estimation of the coefficient on $r d_{t}$. Second, the constructs for cash receipts $\left(\operatorname{crg}_{t}\right.$ and $\left.\operatorname{crp}_{t}\right)$ are the gross revenues reported in the notes to the financial statements, not the revenues net of cost of goods sold. The result is that the coefficients $\hat{\beta}_{g}$ and $\hat{\beta}_{p}$ will be understated by a scalar equal to the inverse of one plus the profit margin on generic and patent products. Third, the advertising variable $\left(a d v_{t}\right)$ is not likely to fully capture investments in advertising since most firms include some or all of their advertising expenditures with SG\&A. To some extent, the $a d v_{t}$ variable will pick up the valuation effect of the disclosure instead of the valuation effect of the investment, and due to the small number of firms that report

\footnotetext{
${ }^{76}$ The observations are pooled (across time and across firms), but for simplicity I omit the subscript for the firm.
} 
advertising expenses, the empirical model may not have sufficient power to detect a valuation effect at all. In addition, the analysis in Chapter 2 suggests that coefficients estimated with the advertising investment variable are not robust to changes in the sample composition. Fourth, the financial asset variable $\left(f a_{t}\right)$ comprises an assortment of balance sheet accounts. Any component of $f a_{t}$ that is not marked-to-market would have a valuation weight different from one, which would bias the estimated coefficient on $f a_{t}$. Finally, I also expect measurement error in my proxies for purchased R\&D $\left(\operatorname{caprd}_{t}\right)$ and residual operating income $\left(\right.$ roi $\left._{t}\right)$, and perform some sensitivity analysis on these two variables as discussed below.

The purchased R\&D variable ( caprd $_{t}$ ) should represent new intangibles, which usually consists of purchased rights to patents or technology. The proxy for $\operatorname{caprd}_{t}$ was intended to be the change in intangible assets adjusted for amortization. However, the data on intangible assets were restructured in Compustat during the time period of my study to accommodate a change in accounting standards. In 2001, accounting rules SFAS 141 and 142 were adopted, requiring firms to separate intangibles from goodwill and subjecting both to impairment tests rather than annual amortization. ${ }^{77}$ Prior to 2001, Compustat included both intangibles and accounting goodwill from business acquisitions in Compustat data \#33. Beginning in 2001, Compustat reports intangibles (data \#352) separately from goodwill (data \#204) as well as providing the sum of these two variables in Compustat data \#33. In order to be consistent over the time period I use Compustat data \#33 to construct the caprd $_{t}$ variable but I gauge the measurement error caused by this approach with two tests. Since the accounting goodwill component of Compustat data \#33 changes with business acquisitions, my first test is to estimate the coefficient on purchased $R \& D$ after removing firm-years associated with business acquisitions. My second test involves estimating the coefficient on purchased $R \& D$ using only the firm-years where intangibles were reported separately as Compustat data \#352. The results are in the sensitivity analysis section of this chapter.

\footnotetext{
${ }^{77}$ Except for finite-lived intangibles, which continue to be amortized.
} 
The proxy for residual operating income is the aggregated accounting variables $\left(\mathrm{crp}_{t}+\right.$ $\left.c r g_{t}-r d_{t}-a d v_{t}-d e p_{t}-a m o r t_{t}\right)$ minus $6 \%$ of the beginning balance of operating assets $\left(o a_{t-1}\right)$. The rate of $6 \%$ is based on the average t-bill rate during the time period covered by my sample. This risk-free rate of return is theoretically correct if investors are risk-neutral, or if the information dynamics are stochastic with risk-neutral probabilities. I relax these assumptions by verifying that my results hold with higher rates of return that are consistent with risk-aversion. Additionally, the residual operating income construct is missing two items that are typically included in the calculation of operating income: cost of goods sold (COGS) and selling, general and administration expenses (SG\&A). I test whether my results are sensitive to this omission by using Compustat data \#178 (operating income after depreciation, which includes a charge for COGS and SG\&A) in the construct of the $r_{0} i_{t}$ variable, and then re-estimating the model. The sensitivity tests on the residual operating income variable are discussed in section 3.6.

I use the theoretical valuation weights from equations 3.7 and 3.8 to form my predictions about the regression coefficients, and state the hypotheses in the alternative form. The regression coefficients are denoted with a subscript to differentiate the coefficients estimated with the accounting model (ACC) from those estimated with the cash flow model (CF), or with the summary accounting model (SUM). My first prediction relates to the investment variables. In the cash flow model, the parameters are equal to one plus the NPV of a dollar invested. I assume that firms do not undertake negative NPV investments, therefore the coefficients on the investment variable should be greater than or equal to one $\left(\beta_{r \mid C F} \geq 1, \beta_{a \mid C F} \geq 1, \beta_{f \mid C F} \geq 1, \beta_{c \mid C F} \geq 1\right)$.

My next set of predictions relates to the persistence of cash flows and income. Under the assumption that cash receipts persist into the future, the coefficients on $\operatorname{crp}_{t}$ and $\mathrm{crg}_{t}$ should be positive $\left(\beta_{g \mid C F}>0, \beta_{p \mid C F}>0\right)$. Similarly, residual operating income is also expected to persist into the future, leading to a positive coefficients on the roi $_{t}$ variable $\left(\beta_{\text {roilACC }}>0\right)$. The theoretical valuation weights on lagged values of operating assets $\left(p e_{t-1}\right.$ and $\left.i n t_{t-1}\right)$ are either positive, negative, or zero, depending on whether the depreciation rate is higher, lower, or equal to the rate 
of decay. Since there is no a priori reason to expect pharmaceutical firms to choose a certain depreciation regime, I make no prediction on the direction of these coefficients $\left(\beta_{e \mid A C C}=\right.$ ? and $\beta_{i \mid A C C}=$ ?). The coefficient on the book value of net assets $\left(f a_{t}\right.$ and $\left.o a_{t}\right)$ should theoretically be equal to one $\left(\beta_{f a}=1, \beta_{o a}=1\right.$ with all models). This is because the effect of conservatism manifests through the other variables in the model: conservatism from the unrecorded positive NPV is captured by the coefficients on the investment variables $\left(\beta_{r}, \beta_{a}, \beta_{f}, \beta_{c}\right)$, while conservatism from aggressive depreciation is captured by the coefficients on the lag values of operating assets $\left(\beta_{e}\right.$, $\beta_{i}$ ). Finally, I expect the coefficient on net income to be positive since this is the result generally found in prior literature $\left(\beta_{\text {nilSUM }}>0\right)$.

My predictions on the remaining coefficients from the accounting model $\left(\beta_{g \mid A C C}, \beta_{r \mid A C C}\right.$, $\beta_{a \mid A C C}, \beta_{f \mid A C C}$, and $\left.\beta_{c \mid A C C}\right)$ are stated in relation to the coefficients from the cash flow model. Reconciling the theoretical valuation weights from the cash flow model $\left(\pi_{g}, \pi_{p}, \pi_{r}, \pi_{a}, \pi_{f}, \pi_{c}\right.$ from equation 3.7) to the theoretical valuation weights from the accounting model $\left(\alpha_{r o i}, \alpha_{g}, \alpha_{r}, \alpha_{a}, \alpha_{f}, \alpha_{c}\right.$ from equation 3.8) gives me a hypothesized direction for the relative magnitude of the coefficients. While I can observe the differences between the estimated valuation weights, I do not run tests of the statistical significance of the differences.

The theoretical models show that $\alpha_{r o i}=\pi_{p}$, which tells us that the coefficients on residual operating income $\left(\right.$ roi $\left._{t}\right)$ and cash receipts from patented drugs $\left(\operatorname{crp}_{t}\right)$ should be the same $\left(\beta_{\text {roilACC }}\right.$ $\left.\beta_{p \mid C F}=0\right)$. The second cross-model difference occurs because each component of operating income requires an adjustment to its accounting valuation weight to "undo" the constraint implicit in $\alpha_{\text {roi }}$ that they persist at the same rate as patent revenues. The reconciliation of the weights on generic cash receipts $\left(\alpha_{g}=\pi_{g}-\alpha_{r o i}\right)$ suggests that, provided $r o i_{t}$ is positive, then the coefficient on $\mathrm{crg}_{t}$ should be smaller in the accounting model than in the cash flow model $\left(\beta_{g \mid A C C}<\beta_{g \mid C F}\right)$. The reconciliation of the weights on $\operatorname{R\& D}\left(\alpha_{r}=\pi_{r}+\alpha_{r o i}\right)$ suggest that $r d_{t}$ should have a larger valuation weight in the accounting model than in the cash flow model $\left(\beta_{r \mid A C C}>\beta_{r \mid C F}\right)$ if roi $_{t}$ is 
positive. Similarly, the weight on advertising $\left(\alpha_{a}=\pi_{a}+\alpha_{r o i}\right)$ should be larger in the accounting model because the (positive) coefficient on roi $_{t}$ is added back $\left(\beta_{a \mid A C C}>\beta_{a \mid C F}\right)$.

The next set of adjustments arises because the valuation weights on capitalized investments are reduced by one in the accounting model since these investments are included in the book value of operating assets. The relative weights on investments in production facilities $\left(\alpha_{f}=\pi_{f}-1\right)$ suggest that $\beta_{f \mid A C C}<\beta_{f \mid C F}$. Similarly, the relative weights on purchased R\&D $\left(\alpha_{c}=\right.$ $\left.\pi_{c}-1\right)$ suggest that $\beta_{c \mid A C C}<\beta_{c \mid C F}$.

I estimate the regressions with the data from firms that sell patented drugs (labeled as Big Pharma firms in Chapter 2) during the years 1995-2003. I trim the top and bottom $1 \%$ of the observations for each variables (except where the bottom of the distribution has values of zero) and get a sample with 264 observations ${ }^{78}$.

\subsection{Empirical Valuation Weights}

The descriptive statistics on the empirical variables are reported in Table 3.1. Most variables appear to be slightly skewed to the right (the means are slightly larger than the medians except for $\operatorname{roi}_{t}$ and $n i_{t}$ ), and some have negative values. Obtaining negative values for the financial assets variable $\left(f a_{t}\right)$ is reasonable. Recall that the $f a_{t}$ construct is total assets, less operating assets, less liabilities. Negative values pertain to firm-years where financial liabilities are greater than financial assets. Net income $\left(n i_{t}\right)$ and residual operating income $\left(r o i_{t}\right)$ have some negative values as well, because a few firms experienced poor performance in some of the years. The variables $f a_{t}, c r g_{t}, c r p_{t}$, and $o a_{t}$ have some values that are greater than one, which means that the unscaled variable was larger in magnitude than the scaling variable, which is the lag value of total assets. I investigate whether the large values of $f a_{t}$ and $o a_{t}$ are the result of business acquisitions, and find that they are due to firms that are growing through successful re-investment of capital. I investigate whether the large values of $\operatorname{crg}_{t}$ and $\operatorname{crp}_{t}$ (values > 1) are related to outlier

\footnotetext{
${ }^{78}$ I do not trim the bottom end of variables that have values of zero, such as the advertising variable.
} 
firm or year, and find that these observations are spread across many firms (23 out of 34 firms) and across all years. I conclude that the distribution of the variables is reasonable for pharmaceutical firms with a going concern.

In Table 3.2, I report the Pearson correlations of the explanatory variables, and find that only one pair of variables is highly correlated (which I define as $|\rho|>.60$ ). Residual operating income $\left(r o i_{t}\right)$ is highly correlated with net income $\left(n i_{t}\right)$ based on $\rho=0.88$, which is not surprising since the former is a component of the latter. The correlation is not problematic because the two variables are used in different models.

The regression result for each valuation model is reported in Table 3.3. The results are robust to the specifications discussed in the sensitivity analysis in section 3.6. The first set of columns reports the regression results for the cash flow model (Model 1), followed by results for the accounting model (Model 2), and the summary model (Model 3). The first column within each set of results shows the parameter estimate, followed by p-values in the next two columns. I include the p-value that leads us to reject the null hypothesis that the parameter is zero $(\beta=0)$, so that I can test whether the valuation weights on cash receipts $\left(\operatorname{crp}_{t}\right.$ and $\left.c r g_{t}\right)$, residual operating income $\left(\right.$ roi $\left._{t}\right)$, and opening value of operating assets $\left(p e_{t-1}\right.$ and $\left.i n t_{t-1}\right)$ are positive. I also include the p-values that lead us to reject the null hypothesis that the parameter is equal to one $(\beta=1)$, which tells us whether investments $\left(r d_{t}, a d v_{t}, \operatorname{prodfac}_{t}\right.$, and $\left.\operatorname{caprd}_{t}\right)$ are positive NPV. The pvalues for $\beta=1$ are also used to test whether the valuation weight on the asset variables $\left(f a_{t}\right.$ and $\left.o a_{t}\right)$ are consistent with their theoretical weight of one.

In this paragraph, I discuss the valuation weights on the balance sheet variables $\left(f a_{t}\right.$ and $o a_{t}$ ), then discuss the remaining coefficients for each model (cash flow, accounting, and summary) in subsequent paragraphs. The parameter estimates on financial assets $\left(f a_{t}\right)$ are positive and significant with all models in Table 3.3. Model 1 (cash flow) has a parameter estimate of 2.21 on $f a_{t}$, while Model 2 (accounting) has an estimate of 3.18, and Model 3 (summary) has a coefficient of 2.75. The p-values lead us to reject the hypotheses that the 
coefficients are zero as well as the hypotheses that the coefficients are one, which suggests that the valuation weight on financial assets is greater than its theoretical value of one. This indicates that the $f a_{t}$ variable includes assets that generate value for the firm. There are two likely reasons for this. Either value-generating operating assets are erroneously included in the $f a_{t}$ proxy, or the financial assets are generating value. The latter possibility is investigated by Callen and Segal (2005), who analyze the mean coefficient of 3.01 that they get on their financial asset variable. ${ }^{79}$ They test various theories to determine why the coefficient is different from one. They find that the magnitude of the coefficient on $f a_{t}$ does not vary with leverage, therefore conclude that their results are not due to the value of tax shields associated with the debt component of $f a_{t}$. They observe that the magnitude is similar for positive and negative observations of $f a_{t}$, therefore conclude that the magnitude is not a function of the capital structure. Finally, they test whether the coefficient on $f a_{t}$ is a function of the firm's past track record, under the assumption that profitable firms have better access to debt financing, and find weak evidence to support this theory.

In contrast to financial assets, the parameter estimate on the book value of operating assets $\left(o a_{t}\right)$ is indistinguishable from the value of one. With the accounting model (Model 2), the coefficient on $o a_{t}$ is 2.89 with p-values of .02 (for $\beta=0$ ) and .13 (for $\beta=1$ ). The first p-value (.02) is used to reject the null hypothesis that the coefficient on $o a_{t}$ is zero. The second p-value (.13) is such that we cannot reject the null hypothesis that $\beta=1$. The results are similar with the summary model (Model 3). With the summary model, the coefficient of 3.00 on the $o a_{t}$ variable has a pvalue (.01) that leads us to reject the null hypothesis that $\beta=0$, and a $\mathrm{p}$-value (.10) that does not lead to a rejection of the null hypothesis that $\beta=1$, albeit the latter is only weakly significant. Therefore some of the empirical evidence suggests that the valuation weight on operating assets is

\footnotetext{
${ }^{79}$ Their regression model has market value of the firm as a dependent variable, and the following explanatory variables: financial assets, residual operating income, change in residual operating income, and change in operating assets.
} 
consistent with the theoretical valuation weight. Next, I discuss the regression coefficients on the remaining variables for each of the three models.

The coefficients estimated with the cash flow model (Model 1) are all positive as predicted. The statistically significant coefficients of 1.48 on generic cash receipts $\left(\mathrm{crg}_{t}\right)$ and 2.77 on patent cash receipts $\left(\mathrm{crp}_{t}\right)$ indicate that both types of revenues are persistent. The valuation weights on R\&D expenditures (20.04 on $r d_{t}$ ) and on investments in production facilities (8.68 on prodfac $_{t}$ ) are large and significant. They are significantly larger than zero with p-values of .00 in the $\beta=0$ column, and significantly larger than one based on p-values of .00 in the $\beta=1$ column. This suggests that expenditures on R\&D and production facilities are positive NPV investments. However, the parameter estimates on investments in advertising $\left(0.25\right.$ on $\left.a d v_{t}\right)$ and on purchased $\mathrm{R} \& \mathrm{D}\left(6.66\right.$ on $\left.\operatorname{caprd}_{t}\right)$ are not significantly different from zero based on their p-values (in the $\beta=0$ column) of 0.96 and 0.71 , respectively. The parameter estimates are not significantly different from one, based on the p-values (in the $\beta=1$ column) of .89 for advertising $\left(a d v_{t}\right)$ and .75 for purchased R\&D $\left(\right.$ caprd $\left._{t}\right)$. The inference with respect to these two types of investments is inconclusive. It is possible that the data are too noisy to accurately estimate the regression coefficients. As mentioned in Section 3.4, the infrequent occurrences and small magnitudes of the $a d v_{t}$ and $\operatorname{caprd}_{t}$ proxies reduce the power of my tests. Alternatively, these results suggest a misspecification of my theoretical model in the sense that these variables do not represent valuegenerating activities.

The result on the advertising investment variable from Model 1 has important implications with respect to my conclusions in Chapter 2 of this thesis. The coefficient on advertising investment $\left(a d v_{t}\right)$ is considerably different from the one obtained in Table 2.6, therefore the results from Chapter 2 may not be as robust as indicated. There are three differences in specifications that may have altered the coefficient on $a d v_{t}$. First, the regression in this chapter utilizes a standard intercept instead of a scaled one. This changes the interpretation of the coefficients but it is done to allow for a comparison of the performance of competing 
models in section 3.7. The standard intercept is statistically significant for all three models in this chapter but the scaled intercept is not significantly different from zero in chapter 2, which suggests that changing the intercept has an important effect. The second difference is the addition of balance sheet variables $\left(o a_{t}\right.$ and $\left.f a_{t}\right)$ in the model from this chapter, which may have been correlated omitted variables in the model from Chapter 2. The third possibility is that the trimming method used in this chapter may have removed outliers that had undue influence in estimating the valuation weight on advertising investments in Chapter $2^{80}$. Alternatively, trimming the data removed a large enough portion of the $a d v_{t}$ variable to change the results. The difference in the coefficient on the advertising variable is likely to be a combination of these three changes in specification.

The coefficients estimated with the accounting model (Model 2) are positive for each variable except the proxy for cash receipts on generic drugs $\left(\mathrm{crg}_{t}\right)$. A negative coefficient on $\mathrm{crg}_{t}$ is feasible based on the hypothesis in the previous section. According to the analysis in section 3.4, the $\mathrm{crg}_{t}$ variable should pick up the valuation weight from the cash flow model (which is 1.48 in Model 1) and reverse out an amount equal to the valuation weight on roi $_{t}$ (which is 2.93 in Model 2) to eliminate the effect of aggregating generic cash receipts with residual operating income. This would lead to a valuation weight of $-1.45(1.48-2.93=-1.45)$ on $\mathrm{crg}_{t}$ in the accounting model, which is close to the observed value of -1.26 on $\operatorname{crg}_{t}$ in Model 2.

The direction of the parameter estimates for the investment variables are consistent with the relative valuation weights between the cash flow and accounting valuation models. As discussed in section 3.4 , the valuation weights on R\&D investments $\left(r d_{t}\right)$ and advertising expenditures $\left(a d v_{t}\right)$ should be higher with the accounting model (Model 2) than with the cash flow model (Model 1), by an amount equal to the valuation weight on roi $_{t}$ (2.93). Table 3.3

\footnotetext{
${ }^{80}$ The variables in Chapter 2 were not trimmed but were subject to a Cook's D analysis so that only the obvious outliers were removed. This was done in order to minimize the loss of observations since the results in Chapter 2 were corroborated with Generalized Least Squares (GLS). The GLS estimation requires all firms to have the same number of observation for the same dates, therefore each observation lost led to the removal of an entire firm's data.
} 
shows that the estimate for R\&D investments $\left(r d_{t}\right)$ is higher in the accounting model (coefficient of 25.15) than in the cash flow model (coefficient of 20.04), but the difference is greater than the coefficient of 2.93 on $\operatorname{roi}_{t}$. Similarly, the estimate for $a d v_{t}$ is higher in the accounting model (coefficient of 5.24) than in the cash flow model (coefficient of 0.25), but with a larger difference than expected. The difference in valuation weights between the two models is also larger than expected for investments in production facilities $\left(\operatorname{prodfac}_{t}\right)$ and purchased R\&D $\left(\operatorname{caprd}_{t}\right)$. Based on the hypothesis development in section 3.4, the accounting model (Model 2) coefficients are reduced by one, because investments in $\operatorname{prodfac}_{t}$ and $\operatorname{caprd}_{t}$ are included as operating assets $\left(o a_{t}\right)$ in the accounting model. The coefficient on prodfac $t_{t}$ is smaller in the accounting model (coefficient of 3.88) than in the cash flow model (coefficient of 8.68) but with a difference of 4.8. The relative valuation weight on $\operatorname{caprd}_{t}$ is also smaller in the accounting model (coefficient of 2.30) than in the cash flow model (coefficient of 6.66) but the difference is larger than one.

The direction of the coefficient on residual operating income $\left(\right.$ roi $\left._{t}\right)$ is positive, as expected. The coefficient on roi $_{t}(2.93)$ is significantly different from both zero and one according to the p-values of .00 in both the $\beta=0$ column and the $\beta=1$ column. The point estimate is consistent with prior research, such as Begley and Feltham (2002), who get a regression coefficient of 2.5 on residual income for pharmaceutical firms. The relative valuation weight on $r o i_{t}$ is also consistent with section 3.4 , which hypothesizes that the valuation weight on $r o i_{t}$ (coefficient of 2.93) from the accounting model should be the same as the weight on crp $_{t}$ (coefficient of 2.77) from the cash flow model. Finally, the regression coefficients on the lag values of property, plant, and equipment $\left(p e_{t-1}\right)$ and intangibles $\left(\right.$ int $\left._{t-1}\right)$ are both positive (coefficients of 0.97 and 2.43, respectively), but they are not significantly different from zero. Therefore the evidence does not suggest that pharmaceutical firms allocate the cost of assets at a rate that is different from the rate of economic decay.

The last model in Table 3.3 is the one with summary accounting measures (Model 3). The coefficients on the book value of financial assets $\left(f a_{t}\right)$ and the book value of operating assets 
$\left(o a_{t}\right)$ are similar to the other two models as discussed earlier in this section. The regression parameter on net income $\left(n i_{t}\right)$ is positive with a coefficient of 1.84 . The magnitude of this coefficient is not directly comparable to prior research, because few researchers estimate valuation models by industry ${ }^{81}$.

The findings in this section indicate that there are differences between the cash flow model and the accounting model, though they should theoretically be equivalent if the cash flow dynamics are correctly specified. The Vuong test in section 3.6 provides a formal test of the differences but I discuss potential reasons for the incongruity in this paragraph. The differences between the two models arise from two sources: the omission of some balance sheet variables $\left(o a_{t}, p e_{t-1}\right.$, and $\left.i n t_{t-1}\right)$ from the cash flow model, and the cost of capital charge imputed in the residual operating income $\left(\right.$ roi $\left._{t}\right)$ variable in the accounting model. The consequence of excluding variables from the cash flow model (in particular the $o a_{t}$ variable, which is statistically significant) is that it leads to potentially biased coefficient estimates on the variables that are correlated with the excluded variables. The consequence of calculating a capital charge in the construct of $\mathrm{roi}_{t}$ is that it leads to measurement errors that are contemporaneously correlated with the disturbance terms. I investigate how each discrepancy affects valuation by re-estimating the cash flow model (not tabulated) with the additional balance sheet variables $\left(o a_{t}, p e_{t-1}\right.$, and int $\left.t_{t-1}\right)$. This eliminates the inter-model differences caused by omitting these variables from the cash flow model. Essentially, I am comparing two models that are identical except that one has the $c r p_{t}$ variable and the other has the $r o i_{t}$ variable, which has an imputed discount rate. The result of adding $o a_{t}, p e_{t-1}$, and $i n t_{t-1}$ to the cash flow model is that the coefficient on $\operatorname{crp}_{t}$ (coefficient of 2.84 with p-value of .00 , not tabulated) becomes more comparable to the coefficient on roit (coefficient of 2.93 per Table 3.3), and both models have the same explanatory power with an

\footnotetext{
${ }^{81}$ Barth, Beaver, and Landsma (1999) regress the market value of equity on book value of equity and net income for a cross section of firms. Their analysis is done separately for three industries. For the pharmaceutical industry they obtain coefficients of 15.34 on net income and 1.19 on book value of equity However, their model is estimated with level variables rather than scaled variables, which reduces the comparability of our results.
} 
adjusted $\mathrm{R}^{2}$ of $44 \%$. Therefore I conclude that assuming a single (across time periods and across firms) discount rate in the calculation of residual income does not lead to significant valuation differences in this sample. The differences between the cash flow model and the accounting model are mainly due to including balance sheet information in the latter.

The results in this section are mostly in accordance with my hypotheses from section 3.4. The coefficients are in the direction predicted, but the valuation weight on financial assets is larger than its theoretical value of one, and the valuation weights on investments in advertising and purchased R\&D are not statistically significant. The theoretical structure in this chapter allows me to make predictions with respect to the difference between the coefficients obtained with the cash flow model and the coefficients obtained with the accounting model. When I estimate the coefficients, I find that the differences are all in the direction predicted. Finally, the regression results confirm that pharmaceutical firm investments generate positive net present value investments in production facilities and $R \& D$, but their accounting practices appear to be unbiased with respect to depreciation and amortization policies.

\subsection{Sensitivity Analysis}

In this section, I test the robustness of the results from Table 3.3 by estimating alternative specifications of the valuation models. I describe the coefficients of these alternative models as being "similar" if they are in the same direction as the coefficients in Table 3.3 and they retain their statistical significance.

The first specification issue relates to the choice of intercepts. The regression models in Table 3.3 are estimated with a standard intercepts so that the models can be compared with a Vuong statistic. However, for purposes of inference, the intercept should be scaled. In addition, the regression model should include a separate intercept for each year to control for temporal fixed effects. I re-estimate all the models (Model 1, Model 2, and Model 3) with scaled intercepts and an indicator variable for each year and get similar coefficients. 
The second specification test is a robustness check on the effect of using the risk-free rate of return in the calculation of residual operating income. Investors are likely to be risk-averse, therefore they will require more than a $6 \%$ return on their capital investments. I re-estimate the accounting model (Model 2) using discount rates ranging from $2 \%$ to $20 \%$ in the roi $i_{t}$ construct. I get regression coefficients that are similar to those in Table 3.3 therefore the results are not sensitive to the assumed discount rate.

In my third test, I investigate whether the noise in the purchased R\&D variable $\left(\operatorname{caprd}_{t}\right)$ can be reduced as explained in section 3.3. Purchased R\&D is capitalized as intangibles, but prior to 2001, the Compsutat database combines goodwill from business acquisitions with intangibles in Compustat data \#33. Starting in 2001, the intangibles asset has its own data cell (Compustat data \#352). In order to separate out the noise that may be caused by the goodwill portion included in Compustat data \#33, I re-estimate the regressions for Model 1 and Model 2 two ways. In the first test, I estimate the regressions after removing the firm-years that are associated with business acquisitions (based on positive values in Compustat data \#129, "use of funds for acquisitions"). In the second test, I keep the years (2001-2003) where intangibles were reported separately, then re-estimate the regressions using Compustat data \#352 in the caprd construct. The caprd $_{t}$ does not become significant with either method. Therefore, I cannot improve the proxy for caprd $_{t}$ with the data at hand.

Finally, I run a series of regressions to test the stability of the coefficients on the balance sheet variables. First, I test whether the results change if I force the financial asset variable $\left(f a_{t}\right)$ to be equal to one. This is done by moving the $f a_{t}$ to the left hand side of the regression model by subtracting it from the dependent variable $\left(v_{t}\right)$. The regression results from Table 3.3 remain similar, except that the operating assets variable $\left(o a_{t}\right)$ loses its significance in the summary model (Model 3). Next, I move both balance sheet variables $\left(f a_{t}\right.$ and $\left.o a_{t}\right)$ to the left hand side of the regression to investigate whether the empirical model is sensitive to the assumption that the 
valuation weight on $o a_{t}$ is theoretically equal to one. The regression results from Table 3.3 remain similar for all three models.

As mentioned in section 3.3, the residual operating income proxy (roi $\left.i_{t}\right)$ used in my regression models does not include a charge for Cost of Goods Sold (COGS) and Selling, General, and Administration expenses (SG\&A). This overstates the residual operating income variable, which leads to a downward bias on the roi $i_{t}$ coefficient. I explore whether the coefficient on the roi $i_{t}$ variable changes when these expenditures are added. I use the "operating income after depreciation" line item from the financial statement ${ }^{82}$ (which incorporates both COGS and SG\&A) to construct a new residual operating income variable: $r o i_{t}=$ operating income after depreciation - .06oa $a_{t-1}$ and re-estimate the accounting model with this new variable. The result is reported as Model 2 in Table 3.4. Regression results obtained with the original roi $_{t}$ variable (from Table 3.3) are included as Model 1 for comparison. Table 3.4 shows that the coefficient on $r i_{t}$ increases from an estimate of 2.93 (in Model 1) to an estimate of 5.52 (in Model 2) when the operating income data from Compustat is used in the roi $i_{t}$ construct, which is consistent with the downward bias expected on the original variable.

Finally, I test whether the results in Table 3.3 change when I control for size with an independent variable instead of scaling each variable in the regression model. I run each of the three model regressions with unscaled data and add the beginning value of total assets as an explanatory variable. The coefficient on the size variable (lag value of total assets) is not significant in any of the models, but the modification causes some variables from Model 2 to lose their statistical significance. In particular, the p-value on $\delta a_{t}$ and $\operatorname{crg}_{t}$ are no longer significant at the $10 \%$ level, which suggests that these two proxies are sensitive to scaling.

\footnotetext{
${ }^{82}$ This is Compustat data \#178
} 


\subsection{Relative Performance of the Models}

In this section I test the relative power of the three valuation models with the likelihood ratio test proposed by Vuong (1989) and described by Dechow (1994). The test in this section has two purposes. The first purpose is to determine whether including the book value of operating assets significantly improves the valuation model. As discussed in section 3.5, the explanatory power of the cash flow model increases when the variables $o a_{t}, p e_{t-1}$, and $i n t_{t-1}$ are added, but I need a statistic to test whether the incremental explanatory power is significant. The second purpose of this section is to determine whether the performance of the model is reduced by using only summary measures of accounting, such as net income and book values. One would expect the disaggregated models (such as Model 1 and Model 2 from Table 3.3) to perform better than a model with summary measures of accounting (such as Model 3), since the latter is more restrictive. But Begley, Chamberlain, and Li (2006) find the opposite in their paper.

The lower section of Table 3.3 shows that the explanatory power of the cash flow model (Model 1) and the accounting model (Model 2) are slightly different. The sum of squared errors, or unexplained variation, is slightly lower with the accounting model ( $\mathrm{SSE}=1319)$ than with the cash flow model ( $\mathrm{SSE}=1430)$, and the adjusted $\mathrm{R}^{2}$ is slightly higher (44\% versus $\left.40 \%\right)$. Both models appear to have higher explanatory power than the summary model (Model 3), which has the largest unexplained variance $(\mathrm{SSE}=2130)$ and the lowest adjusted $\mathrm{R}^{2}(11 \%)$. A valid method of comparing the models is with the Vuong statistic.

The Vuong statistic is a likelihood-ratio based statistic that tests the null hypothesis that two competing models are equally close to the true data generating process, against the alternative hypothesis that one is closer. The Vuong statistics, which have a standard normal distribution, are reported as z-statistics in the last two lines of Table 3.3. The line above the bottom line reports the z-statistic that compares Model 1 to Model 2. The z-statistic reported in this line has a value of -1.72 . The direction of the z-statistic tells us that the performance of the 
cash flow model (Model 1) is inferior to the performance of the accounting model (Model 2), but the p-value of $10 \%$ suggests that this is not a strong conclusion. This is not surprising since my accounting model is very basic and does not incorporate the richness of information that might be included in other accounting numbers, such as working capital accruals. The last line of Table 3.3 gives evidence to evaluate whether the cash flow model (Model 1) and the accounting model (Model 2) provide a better representation of the data generating process than the summary model (Model 3). The z-statistic of 4.35 (p-value of .00) tells us that the cash flow model performs significantly better than the summary model. The z-statistic of 4.54 (p-value of .00) tells us that the accounting model also outperforms the summary model.

My results are different from Begley, Chamberlain, and Li (2006), who find that a model with only net income as the explanatory variable outperforms other models that they consider in their banking paper. This is likely due to the fact that they use a balance sheet approach in developing their banking model, therefore net income does not have an opportunity to play a role in valuation in their paper. The pharmaceutical valuation model in this paper has both balance sheet and income statement elements, which capture both the value of stock and flow.

My results are also different from Myers (1999) who estimates models with data pooled across industries, and finds that his summary measure model performs better than more complex ones. Myers (1999) concludes that residual income valuation models perform no better than a model with book value alone. The difference is probably due to having a model that is tailored to one industry in this paper, and estimating the model with relatively homogeneous firms.

\subsection{Conclusion}

In this chapter I evaluate the performance of my pharmaceutical valuation model from Chapter 2, which is a model based on cash flows. Following Feltham and Ohlson (1996) and Christensen and Feltham (2003), I allow for a representation of depreciation and amortization policies by restating my model in terms of accounting numbers rather than cash flows. I use a 
Vuong statistic to investigate whether using accounting numbers changes the performance of the model but do not find strong evidence that the explanatory power is improved. The difference in performance would likely be more substantial if the cash flow model was compared to a more complex accounting model.

As well as providing a specification test of my cash flow model, the accounting model allows me to investigate issues that are interesting to accounting academics. With the accounting model I investigate the two sources of conservatism that create a discrepancy between the book value of a firm and its market value: aggressive depreciation and a delay in the recognition of the positive net present value (NPV) of investments. I find evidence of conservatism from unrecorded positive NPV investments (consistent with the cash flow model from Chapter 2), but no evidence to suggest that pharmaceutical firms select aggressive depreciation policies.

Finally, the cash flow and accounting valuation models are compared to one with summary accounting measures: a model with only book value of equity and net income. As well as offering little intuition, the model with summary accounting measures has the least explanatory power. The results suggest that disaggregated accounting information provides a better representation of the process that generates value for the firm, and that modeling the economics that underlie the accounting provides useful intuition. 


\section{Table 3.1 Distribution of the Empirical Variables}

The distribution of the scaled ${ }^{\mathrm{a}}$ explanatory variables for the regressions of the valuation model for Big Pharma firms ( $n=264$ observations).

\begin{tabular}{lrrrrrr} 
& Mean & Low & Q1 & Median & Q3 & High \\
\hline$f a_{t}$ & 0.19 & -0.50 & -0.07 & 0.14 & 0.44 & 1.59 \\
crg $_{t}$ & 0.23 & 0.00 & 0.00 & 0.00 & 0.45 & 1.58 \\
crp $_{t}$ & 0.55 & 0.00 & 0.29 & 0.49 & 0.79 & 1.71 \\
$r d_{t}$ & 0.10 & 0.00 & 0.05 & 0.08 & 0.13 & 0.49 \\
adv $_{t}$ & 0.01 & 0.00 & 0.00 & 0.00 & 0.01 & 0.15 \\
prodfac $_{t}$ & 0.06 & 0.00 & 0.03 & 0.05 & 0.07 & 0.37 \\
caprd $_{t}$ & 0.01 & 0.00 & 0.00 & 0.00 & 0.00 & 0.10 \\
oa $_{t}$ & 0.42 & 0.00 & 0.29 & 0.42 & 0.53 & 1.09 \\
roi $_{t}$ & 0.13 & -0.59 & 0.08 & 0.16 & 0.25 & 0.50 \\
pet $_{t-1}$ & 0.23 & 0.00 & 0.15 & 0.23 & 0.29 & 0.59 \\
int $_{t-1}$ & 0.13 & 0.00 & 0.00 & 0.10 & 0.23 & 0.50 \\
nit $_{t}$ & 0.07 & -0.98 & 0.03 & 0.10 & 0.17 & 0.48 \\
\hline Obsit & & & & &
\end{tabular}

${ }^{a}$ Observations are scaled by the prior period total assets (Compustat data \#6) and have been trimmed of the top and bottom $1 \%$ (except where the bottom of the distribution had values of zero).

The variables are described in Appendix A.

Table 3.2 Pearson Correlations

The Pearson correlations of the scaled ${ }^{\mathrm{a}}$ regression variables are reported.

\begin{tabular}{|c|c|c|c|c|c|c|c|c|c|c|c|c|}
\hline & $f a_{t}$ & $\mathrm{crg}_{t}$ & $c r p_{t}$ & $r d_{t}$ & $a d v_{t}$ & prodfac $_{t}$ & caprd $_{t}$ & $o a_{t}$ & $r o i_{t}$ & $p e_{t-1}$ & int $_{t-1}$ & $n i_{t}$ \\
\hline$f a_{t}$ & 1.00 & & & & & & & & & & & \\
\hline $\mathrm{crg}_{t}$ & .03 & 1.00 & & & & & & & & & & \\
\hline$c r p_{t}$ & -.04 & -.52 & 1.00 & & & & & & & & & \\
\hline$r d_{t}$ & .01 & -.20 & .18 & 1.00 & & & & & & & & \\
\hline$a d v_{t}$ & .05 & .04 & .10 & .01 & 1.00 & & & & & & & \\
\hline prodfac $_{t}$ & -.04 & .12 & .15 & .06 & -.04 & 1.00 & & & & & & \\
\hline $\operatorname{caprd}_{t}$ & -.04 & -.06 & -.04 & -.06 & .07 & -.05 & 1.00 & & & & & \\
\hline$o a_{t}$ & -.45 & -.03 & .08 & -.07 & -.07 & .50 & .01 & 1.00 & & & & \\
\hline$r o i_{t}$ & -.10 & .12 & .49 & -.16 & .22 & .23 & .02 & .36 & 1.00 & & & \\
\hline$p e_{t-1}$ & -.31 & .02 & .32 & .07 & .01 & -.01 & -.08 & .36 & .44 & 1.00 & & \\
\hline int $_{t-1}$ & -.38 & -.05 & -.19 & -.25 & -.07 & .20 & .14 & .43 & .01 & -.33 & 1.00 & \\
\hline$n i_{t}$ & .01 & .13 & .37 & -.03 & .15 & .24 & .04 & .35 & .88 & .39 & -.07 & 1.00 \\
\hline
\end{tabular}




\section{Table 3.3 Model Comparison}

The regression models for equations 3.11CF (Model 1), 3.11 ACC (Model 2), and 3.11SUM (Model 3) are estimated by ordinary least squares, and the relative performance is tested with a Vuong statistic:

Model 1: $v_{-} s_{j t}=\beta_{o}+\beta_{f a} f a \_s_{j t}+\beta_{g} c r g \_s_{j t}+\beta_{p} c r p \_s_{j t}+\beta_{r} r d \_s_{j t}+\beta_{a} a d v \_s_{j t}+\beta_{f} p r o d f a c \_s t$ $+\beta_{c}$ caprd_s $s_{j t}+\varepsilon_{t}$

Model $2 v \_s_{j t}=\beta_{o}+\beta_{f a} f a \_s_{j t}+\beta_{g} c r g \_s_{j t}+\beta_{r} r d \_s_{j t}+\beta_{a} a d v \_s_{j t}+\beta_{f} p r o d f a c \_s t+\beta_{c} c a p r d \_s_{j t}+$ $\beta_{o a} o a_{-} s_{j t}+\beta_{\text {roi }} r o{ }_{-} s_{j t}+\beta_{e} p e_{t-1} s_{j t}+\beta_{i} i n t_{t-1} s_{j t}+\varepsilon_{t}$

Model 3: $v_{-} s_{j t}=\beta_{o}+\beta_{f a} f a_{-} s_{j t}+\beta_{o a} O a \_s_{j t}+\beta_{n i} n i_{-} s_{j t}+\varepsilon_{t}$

\begin{tabular}{|c|c|c|c|c|c|c|c|c|c|}
\hline \multirow[b]{4}{*}{ Intercept } & \multicolumn{3}{|c|}{$\begin{array}{c}\text { Model } 1 \\
\text { Cash Flow }\end{array}$} & \multicolumn{3}{|c|}{$\begin{array}{c}\text { Model } 2 \\
\text { Accounting }\end{array}$} & \multicolumn{3}{|c|}{$\begin{array}{c}\text { Model } 3 \\
\text { Summary }\end{array}$} \\
\hline & \multirow[b]{2}{*}{ parameter } & \multirow{2}{*}{\multicolumn{2}{|c|}{$\begin{array}{l}p \text {-value } \\
\text { reject: }\end{array}$}} & \multirow[b]{2}{*}{ parameter } & & \multirow[b]{2}{*}{ parameter } & \multicolumn{2}{|c|}{ p-value } \\
\hline & & & & & $\beta=0$ & $\begin{array}{l}\text { ject: } \\
\qquad \beta=1\end{array}$ & & $\beta=0^{r e}$ & $\begin{array}{l}t: \\
\beta=1\end{array}$ \\
\hline & -0.92 & .03 & & -2.78 & .00 & & 1.94 & .00 & \\
\hline$f a_{t}$ & 2.21 & .00 & .00 & 3.18 & .00 & .00 & 2.75 & .00 & .00 \\
\hline $\operatorname{crg}_{t}$ & 1.48 & .01 & & -1.26 & .0 & & & & \\
\hline$c r p_{t}$ & 2.77 & .00 & & & & & & & \\
\hline$r d_{t}$ & 20.04 & .00 & .00 & 25.15 & .00 & .00 & & & \\
\hline$a d v_{t}$ & 0.25 & .96 & .89 & 5.24 & .3 & .45 & & & \\
\hline prodfac $_{t}$ & 8.68 & .00 & .00 & 3.88 & .06 & .35 & & & \\
\hline $\operatorname{caprd}_{t}$ & 6.66 & .71 & .75 & 2.30 & .85 & .94 & & & \\
\hline$o a_{t}$ & & & & 2.89 & .02 & .13 & 3.00 & .01 & .10 \\
\hline roi $_{t}$ & & & & 2.93 & .00 & & & & \\
\hline$p e_{t-1}$ & & & & 0.97 & .58 & & & & \\
\hline int $_{t-1}$ & & & & 2.43 & .16 & & & & \\
\hline$n i_{t}$ & & & & & & & 1.84 & .07 & \\
\hline n obs. & & 264 & & & 264 & & & 264 & \\
\hline SSE & & 1430 & & & 1319 & & & 2130 & \\
\hline \multirow[t]{2}{*}{ adjusted $R^{2}$} & & $40 \%$ & & & $44 \%$ & & & $11 \%$ & \\
\hline & \multicolumn{9}{|c|}{ Model is superior if z-stat $>0$ or inferior if $z$-stat $<0$. } \\
\hline Vuong Test & z-stat & & alue & z-stat & & value & & & \\
\hline vs Model 2 & -1.72 & & 10 & & & & & & \\
\hline vs Model 3 & 4.35 & & 00 & 4.54 & & .00 & & & \\
\hline
\end{tabular}

The Vuong test is described in Dechow (1994). The Vuong test utilizes a likelihood ratio to form a z-statistic that has a standard normal distribution. The z-statistic tests the null hypothesis that the two models are equally close to the true data generating process. The variables are described in Appendix A. The roi $i_{t}$ variable in this table is constructed as $\left(c r p_{t}+c r g_{t}-r d_{t}-a d v_{t}-d e p_{t}\right.$ amort $\left._{t}\right)-6 \%$ of $o a_{t-1}$. 
Table 3.4 Residual Operating Income Comparison

The regression model for the accounting valuation model (equation 3.11ACC) is estimated with residual operating income $\left(r o i_{t}\right)$ constructed two ways:

Model 1: residual operating income is $r o i_{t}=c r p_{t}+c r g_{t}-r d_{t}-a d v_{t}-d e p_{t}-a m o r_{t}-.06 o a_{t-1}$.

Model 2: residual operating income is roi $t_{t}=\left(\text { operating income after depreciation }^{*}\right)_{t}-.06$ oa $_{t}$ Both regressions are estimated as: $v_{-} s_{j t}=\beta_{o}+\beta_{f a} f a \_s_{j t}+\beta_{g} c r g \_s_{j t}+\beta_{r} r d \_s_{j t}+\beta_{a} a d v_{-} s_{j t}+$ $\beta_{f}$ prodfac_s $s_{j t}+\beta_{c} c a p r d \_s_{j t}+\beta_{o a} o a \_s_{j t}+\beta_{r o i} r o i \_s_{j t}+\beta_{e} p e_{t-1} s_{j t}+\beta_{i} i n t t_{t-1} s_{j t}+\varepsilon_{t}$

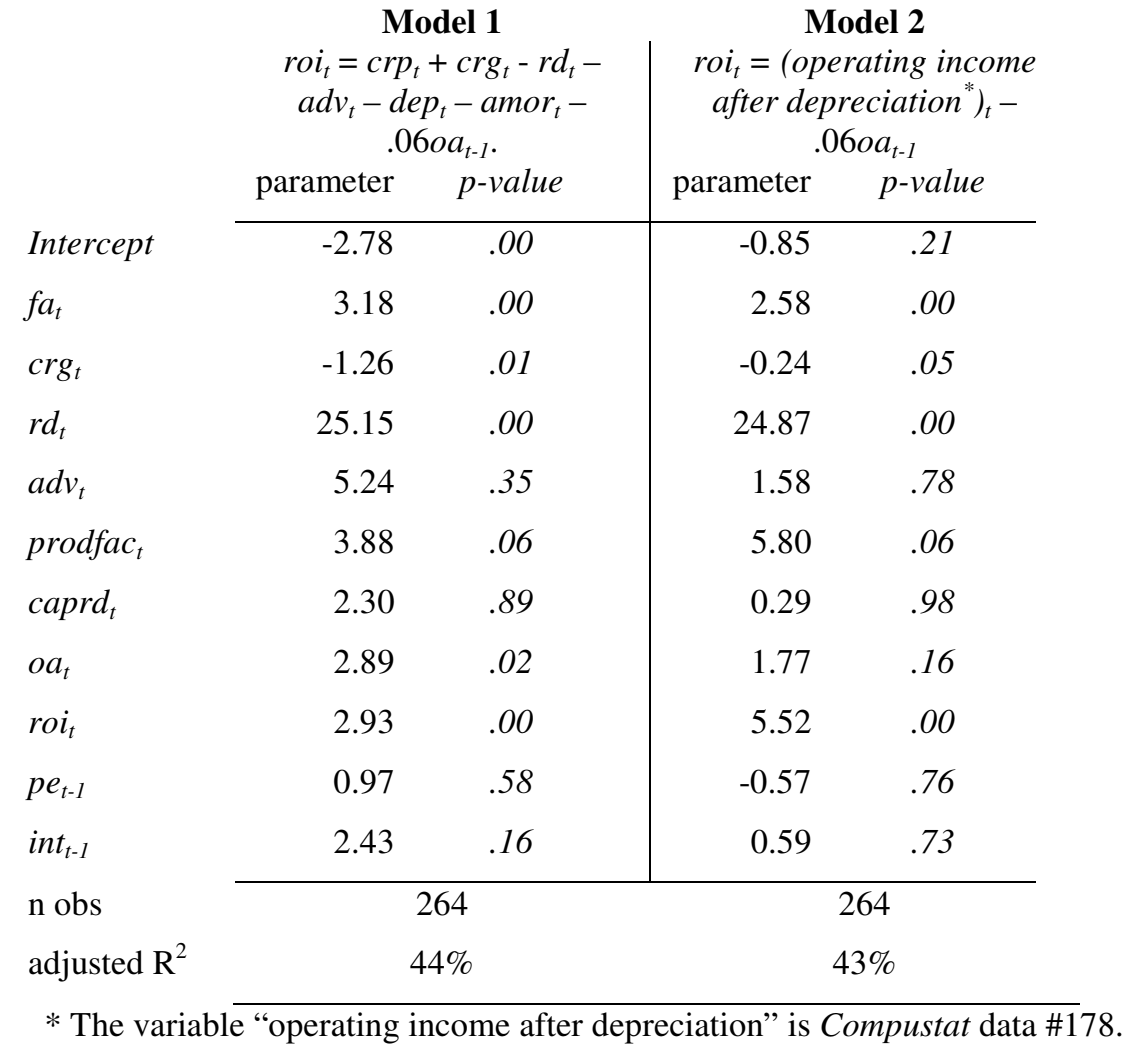




\section{CHAPTER 4 Event Study of the Advertisement Regulatory Change}

\subsection{Introduction}

On August 8, 1997, the Food and Drug Administration (FDA) announced a new regulation that would facilitate the advertising of prescriptions drugs. The new regulation would make Direct-to-Consumer broadcast advertising easier by permitting the advertisements to list the major risks and refer to a source of information, rather than having to fully describe the side effects of the drug ${ }^{83}$. This facilitated television promotion of prescription drugs in particular, which were not suited to the lengthy disclosure required before the regulatory change. According to Boscaljon (2005), the capital market reacted favorably to the FDA announcement with a $1.74 \%$ abnormal return on the market value of pharmaceutical firms in the two-day window surrounding the announcement. The positive abnormal returns indicate that investors expected the change in regulation to increase net cash flows. However, the test of the change in the valuation coefficient (from Chapter 2) remains inconclusive with respect to whether DTCA increased the value of advertising. This chapter further tests the effect of DTCA by revisiting the regulatory event.

My event study is different from the Boscaljon (2005) paper in three respects. First, I expand the returns model to include multiple announcement dates. Regulatory changes evolve slowly over time, so focusing on the final event date can miss changes in market expectations that are updated (in theory) at each juncture in this process. In the case of the relaxation of marketing laws for the pharmaceutical industry, the regulatory change can be seen to have begun as early as 1995 when the FDA responded to the threat of lawsuits over advertising constraints. The second difference is the methodology used. The test statistics from the approach used in Boscaljon

\footnotetext{
${ }^{83}$ The new regulation reduced the disclosure requirements for broadcast advertisements. Prior to the regulatory change, drug companies had to include a "brief summary" in their advertisements, regardless of the advertising medium. This "brief summary" provides information relating to side effects, contraindications, and effectiveness, and is long enough to warrant its own page in most print ads. After the regulatory change, television broadcast advertisements had to disclose only the product's major risks, and provide sources for other information such as healthcare providers or a toll-free number.
} 
(2005) can lead to Type I errors ${ }^{84}$ if the residuals from the model are correlated across firms or over time. Cross-correlation of the residuals is likely to be problematic in this event study since the sample is comprised of pharmaceutical firms, and the regulatory change is likely to have affected them all in a similar way. In this paper, I use an approach that controls for this problem. A final key difference between this paper and Boscaljon (2005) is the method of classifying firms. Both papers attempt to identify firms that sell prescription drugs under patent protection since the new regulation pertains to these drugs. Boscaljon (2005) categorizes firms as selling patented drugs if their $R \& D$ intensity ( $R \& D$ expenditures scaled by total assets) is above the median. In this paper, firms are classified into firm-types based on their business process. Specifically I use the business description in their $10-\mathrm{K}$ filings to categorize firms as selling patented drugs, generic drugs ${ }^{85}$, or operating as a biotech company. As in Boscaljon (2005), I also explore whether abnormal returns are increasing in R\&D intensity.

In this paper, abnormal returns are estimated with a market model that is expanded to include a set of indicator variables that are equal to one during announcement date windows. The model components include an intercept and the stock market index returns, thereby capturing the normal returns-generating process of the firm. The indicator variables capture returns that are in excess of normal returns, hence the "abnormal returns" generated in response to the announcements. In most tests, the return-generating process is estimated using a portfolio of stocks to prevent overstatement of test statistics.

I investigate seven announcement dates and find that significant abnormal returns were generated on three of these dates, with the first one occurring two years before the FDA announced the adoption of the new regulation. The first significant capital market reaction occurred on August 31, 1995 when the FDA reported it would be holding public hearings to solicit input on the issue of Direct-to-Consumer Advertising (DTCA). Abnormal returns in the

\footnotetext{
${ }^{84}$ Type I error is falsely rejecting the null hypothesis of no effect.

${ }^{85}$ Firms that sell over-the-counter products are included in this category.
} 
three-day window surrounding this announcement were 3\%. These returns were offset by abnormal returns of $-3.36 \%$ on the second significant announcement date. The second capital market reaction occurred on April 1, 1997 when the Wall Street Journal announced that the FDA and marketers could not agree on what should be disclosed in the advertisements. The third significant capital market response occurred on August 8, 1997 when the FDA announced the regulatory change. The announcement affected only a subset of firms in my sample: the stock price reaction to the FDA announcement resulted in negative abnormal returns for the thirteen firms that ended up using DTCA. This result is not immediately intuitive. Based on the stock market reaction, firms that used DTCA were better off with the more restrictive regulations that were in place before August 8, 1997. However, the theoretical model developed by Brekke and Khun (2006) offers a potential explanation for this outcome. Their model is discussed in the analysis of this chapter, and gives a sense of how complex the effect of advertising investments can be.

Three announcement dates are associated with significant abnormal returns, but when the abnormal returns are aggregated over the seven announcement dates, the cumulative effect is not significantly different from zero. There is no evidence of cross-sectional differences in abnormal returns based on $R \& D$ intensity, size, or whether the firm reports positive advertise expenditures. However, there appears to be some differences between firm-types. The results in this chapter suggest that abnormal returns were increasing in asset turnover (sales divided by total assets) for firms that sell generic drugs $s^{86}$, and increasing in $R \& D$ intensity for firms that sell patented drugs. These findings suggest that, while some of firms were expected to be better off than others, the overall effect of the DTCA regulatory change was not significant. This is consistent with my findings in Chapter 2, where the valuation weight on advertising investments does not change after the relaxation of advertising rules.

\footnotetext{
${ }^{86}$ Firms that sell over-the-counter products are included in this category.
} 
A history of DTCA is presented in section 4.2, followed by the hypothesis development in section 4.3. In section 4.4, I discuss the findings of Boscaljon (2005) and compare his statistical method to the one used in this paper. Abnormal returns are estimated using the data in section 4.5, and reported for the full sample in section 4.6 and by portfolio in section 4.7. The firm characteristics associated with cumulative abnormal returns are investigated in section 4.8. I test the robustness of my results with sensitivity analysis in section 4.9 and summarize my findings in the conclusion in section 4.10 .

\subsection{History of Direct To Consumer Advertising}

The history of Direct-to-Consumer Advertising (DTCA) starts in the early 1980s when firms began using TV advertisements to reach the public ${ }^{87}$. The FDA was concerned that DTCA was not appropriate for prescription drugs and therefore called for a voluntary moratorium in September 1983 so that they could conduct research and seek public input. During the next two years the FDA studied the issue of advertising and found that the public was generally interested in receiving more information. On September 9, 1985 the FDA ruled that advertising would be permitted as long as it was written as if aimed at health care professionals, such as providing all the relevant information on side effects. Since this was difficult to do in a short TV commercial, the next ten years saw mainly "help-seeking" advertisements, which encouraged the consumer to seek help by identifying a particular disorder rather than identifying a specific drug. These ads were not as informative as the FDA had intended, therefore in October 1995, the FDA held public hearings to investigate ways of changing DTCA. The outcome of the hearings was that the FDA recognized that the current regulation was a barrier to communication, but it remained reluctant to change it. In January 1997 the FDA Commissioner Dr. David Kessler, who was a strong opponent of DTCA, left the agency. This, coupled with pressure from pharmaceutical firms, resulted in the draft change in regulation announced on August 8, 1997.

\footnotetext{
${ }^{87}$ Based on an article by Donohue (2006).
} 
The history of this regulatory change suggests that there are several possible dates when the capital market may have revised its estimate of the effect of DTCA on pharmaceutical firm value. Some changes in expectation are likely to have occurred over the past two decades but I restrict my analysis to the time period of 1995 to 1997 . This constitutes a trade-off in research design because some potentially significant market reactions are excluded by reducing the time period, but the smaller date range results in a larger sample size since more firms have all the necessary returns data. The cutoff date of 1995 is chosen because DTCA investments were negligible before mid-1995 (Rosenthal et al. [2002]) and because there were no important DTCA news releases in the decade before 1995, based on a preliminary search on LexisNexis ${ }^{88}$.

To identify the dates that the capital market may have changed its expectations, I search for public announcements between January 1995 and December 1997 in the following information sources: the Wall Street Journal, the FDA website, the US Federal Registry, and LexisNexis. My search uses the following terms: advertising, marketing, prescription, pharmaceutical, drugs, regulation, DTC, DTCA, FDA, FTC, and Food and Drug Administration $^{89}$. The dates of the public announcements that I've identified with this search are listed in Table 4.1 along with indicator variables that I assign to each date in order to test for abnormal returns. For each event date in Table 4.1, I also search for other pharmaceutical industry announcements that could confound the results, and find none. However, even in a carefully designed event study, there is a risk that an important announcement date has not been identified, and that abnormal returns on that omitted date could lead to significantly different findings and conclusions. There is also a risk that some of the event dates may be associated with confounding effects that the announcement may have on other events affecting the pharmaceutical industry. In particular, a stock market reaction to FDA Commissioner Kessler's

\footnotetext{
${ }^{88}$ The few news articles found in this search were commentaries on the difficulties of meeting the FDA requirements for DTCA. These announcements would not likely lead an expected change in regulation. 89 The FTC (Federal Trade Commission) is included in the search because this organization is responsible for disseminating consumer related information.
} 
resignation could be caused by expected changes in other policies affecting the pharmaceutical industry, and not necessarily to the DTCA policy.

According to my search, the impetus towards a change in advertising regulation occurred on July 20, 1995 when a policy group threatened to sue the FDA under the First Amendment if it didn't relax the rules to DTCA. They claimed that, under the First Amendment commercial speech is permitted as long as it is truthful and non-misleading, therefore DTCA should not be by censored by the FDA. The FDA responded on August 31, 1995 by announcing that it would hold a public hearing on the issue of DTCA to solicit information on how prescription drugs should be promoted. The public hearings were held on October 18 and 19, 1995, which I list as the third announcement date in Table 4.1. Announcements in 1996 suggested that the regulatory change would take place. In May 1996 the FDA announced it might loosen advertising restrictions, while in November 1996 the press announced the departure of Commissioner Kessler. However, the outlook seemed less favourable in April, 1997 when the Wall Street Journal reported the dissention among drug marketers with respect to the information that should be disclosed in the advertisements. The last event date identified in my search is the one where the FDA announced the regulation change on August 8, 1997.

\subsection{Hypothesis Development}

Donohue (2006) points out that the pharmaceutical firms took a leading role in taking steps to relax DTC advertising rules. She proposes that the introduction of "lifestyle" drugs and an increase in the consumer's role in medical decision-making were reasons why pharmaceutical firms began to argue that "prescription drug advertising empowered consumers" (p. 686) ${ }^{90}$. The pharmaceutical firms' attempt to reach those consumers may explain the large number of

\footnotetext{
${ }^{90}$ Lifestyle drugs would not typically be prescribed by physicians since these drugs focus on improving life rather than on treating diseases.
} 
advertisements that violated FDA regulation before the relaxation of DTCA rules ${ }^{91}$. Such actions suggest that advertising restrictions in existence before 1997 placed real constraints on the optimal decisions that could be made by pharmaceutical firms. To the extent that the 1997 policy change was anticipated to loosen these constraints, firms would be expected to profit from the change in regulation. Accordingly, my first hypothesis is that the cumulative share price reaction of pharmaceutical firms to announcements that suggested a relaxation of DTCA constraints was positive:

H1: Pharmaceutical firms are predicted to earn positive overall abnormal returns in response to news announcements about the regulatory change.

The positive market reaction predicted by $\mathrm{H} 1$ would unambiguously be the expected outcome if the firms in my sample operated in a monopolistic market. However, the pharmaceutical industry is better characterized as an oligopoly, or even as a collection of duopolies when analyzed at the level of their therapeutic markets. Therefore the effect of relaxing a binding constraint is more complex, and will reflect the interaction of each firm's pricing and supply strategy. It is likely that firms were affected differentially by the regulatory change, some with larger reactions, others with smaller or even negative reactions. The overall effect of the regulatory change can be muted by combining these differential responses, especially if negative reactions offset the positive ones. A cross-sectional analysis of returns can help to understand whether an observed average reaction is due to the hypothesized forces. The next three hypotheses explore firm characteristics that could lead to a differential market response.

If DTCA leads to additional profits, they are likely to accrue to the firms that sell the products advertised. DTCA involves the advertising of prescription drugs, therefore abnormal returns should be higher for firms that sell prescription products, as opposed to over-the-counter

\footnotetext{
${ }^{91}$ Donohue et al. (2007) report that the number of letters sent by the FDA to pharmaceutical manufacturers regarding violations of drug advertising decreased from 142 in 1997 to 21 in 2006, however, they cannot determine whether this reflects better industry compliance with advertising regulation or a worsening of the FDA oversight.
} 
products. Some prescription drugs are sold under generic name brands, but since generic products are sold in a competitive marketplace and have very small profit margins, the additional profits due to DTCA are not likely to be significant on these products. These facts combined suggest that the regulatory change is expected to mainly affect firms that sell prescription products under patent protection. Accordingly, the second hypothesis is:

\section{H2: Pharmaceutical firms that sell or develop prescription drugs under patent} protection are predicted to have larger abnormal returns in response to news announcements about the regulatory change than firms that do not.

My study includes biotech companies that discover patented therapeutics but do not sell their products directly to consumers. Biotech companies generally sell the rights to their therapeutics to large firms that manufacture and market them. Depending on the degree to which biotech firms are able to capture rents on the sale of the rights, a positive cash flow reaction to the relaxation of DTCA regulation will extend to this sector. While I examine the share price reaction of biotech firms to the regulatory event, I make no prediction about the relative magnitudes of abnormal returns for biotech firms versus large pharmaceutical manufacturing firms.

The next hypothesis relates to a variable explored in Boscaljon (2005). He tests whether abnormal returns are affected by the R\&D intensity (Research and Development expenditures scaled by total assets) of a firm. In his paper, the R\&D intensity variable not only delineates firms between those that sell patented and generic products, but also serves as a measure of the drugs in the firm's pipeline. Boscaljon (2005) conjectures that firms with high R\&D intensity garner more benefits from DTCA since advertising allows them to gain their market share more quickly, thereby giving them more time to earn profits before their patents expire. My hypothesis is similar to Boscaljon (2005) but with a slightly different perspective. In this paper, the R\&D intensity variable is conjectured to represent the future sales potential of the firm. If DTCA leads to increased profits, then (ceteris paribus) the capital market response to the new regulation 
should be increasing in the volume of therapeutics that the firm is expected to sell. Abnormal returns should be larger for R\&D intensive firms since they should (on average) have more drugs under development, leading to higher future drug sales. An alternative measure of sales potential is the firm's current sales. To the extent that future sales are correlated with current sales ${ }^{92}$, the benefit of DTCA should be associated with current sales. Consequently abnormal returns should be increasing in sales intensity, where sales intensity is revenues scaled by total assets. Note that this ratio is commonly called the asset turnover, but I use the term sales intensity because the construct is similar to R\&D intensity variable. The sales potential perspective leads to the third hypothesis:

H3: Firms with high $R \& D$ intensity and firms with high sales intensity are predicted to have larger abnormal returns in response to news announcements about the regulatory change than firms with low $R \& D$ intensity and firms with low sales intensity.

The third hypothesis also relates to a firm characteristic investigated by Boscaljon (2005). He explores whether the firms that used DTCA (ex post) earned larger abnormal returns than firms that did not. His premise is that DTC advertisers are more concerned about brand name recognition and are more likely to have drugs under patent protection, therefore should benefit more from a loosening of advertising regulation. I propose a hypothesis that is similar to Boscaljon (2005) except that I use two measures to identify the firms that are likely to use DTCA. The first method uses reported advertising expenditures to identify firms that have a propensity to advertise. The second method uses the firms that Boscaljon (2005) identifies as DTC advertisers based on an advertising journal (Med Ad News, June 1998). The fourth hypothesis is:

H4: Firms with that used DTCA in 1997 and firms that report advertising expenditures are predicted to have larger abnormal returns in response to news

\footnotetext{
${ }^{92}$ Revenues on patented drugs are fairly persistent on average according to the persistence parameter distribution from Table 2.8.
} 
announcements about the regulatory change than firms that did not use DTCA and firms that did not report advertising expenditures.

The effect of the regulatory change is incorporated in share price based on the expected net cash flows associated with the event and the probability that the event will take place. Assuming that the regulatory change is expected to benefit pharmaceutical firms, an increase in the probability of the event occurring will be associated with an increase in share price, while a decrease in the probability of the event occurring will lead to a decrease in share price. Several of the announcements listed in the previous section suggest that the FDA will relax DTCA guidelines $\left(D_{1}, D_{2}, D_{4}, D_{5}\right.$, and $D_{7}$ in Table 4.1$)$, therefore I hypothesize that the coefficients will be positive on each of these indicator variables. One announcement suggests that the new DTCA regulation may not pass as expected. The debates and "sharp division" reported on April 1, 1997 reduces or corrects expectations that DTCA will lead to increased firm value. Therefore, I hypothesize that the coefficient on the indicator variable $\mathrm{D}_{6}$ will be negative. Finally, the actual hearings on October 18 and 19, 1995 may have increased or decreased beliefs about whether DTCA would be approved, depending on the discussions at the hearings. Therefore I make no prediction on the coefficient of the indicator variable $\mathrm{D}_{3}$.

In summary, in this paper I test for abnormal returns for the pharmaceutical industry as a whole, but I also investigate whether the share price reaction to the regulatory change is a function of the type of products sold by the firm, sales intensity, R\&D intensity, and whether the firm reported advertising expenditures or used DTCA in the year of the regulatory change. Since television ads are expensive, large firms are more likely to use this type of media than small firms, therefore I also investigate whether abnormal returns are a function of size.

\subsection{Comparison of Model to Boscaljon (2005)}

The methodology used in this event study is significantly different from Boscajon (2005). He identifies one event date (August 8, 1997) and uses a residuals-based method to estimate 
abnormal returns in the two-day window surrounding this date. He estimates market model parameters over the period $\mathrm{t}=-301$ to $\mathrm{t}=-46$ around event date $\mathrm{E}$ (August 8,1997 where $\mathrm{t}=0$ ) for each firm $j$ based on the following model:

$$
r_{j t}=\alpha_{j}+\beta_{j} r_{m t}+\varepsilon_{j t}
$$

The estimated market model parameters $\left(\hat{\alpha}_{j}\right.$ and $\left.\hat{\beta}_{j}\right)$ are used to calculate abnormal returns $\left(A R_{j E}\right)$ on August 7 and August 8, 1997:

$$
A R_{j E}=r_{j E}-E\left[r_{j E}\right]
$$

where:

$r_{j E}$ is the security return for firm $j$;

$E\left[r_{j E}\right]=\hat{\alpha}_{j}+\hat{\beta}_{j} r_{m E} ;$

$r_{m E}$ is the market return for day $\mathrm{t}=-1$ and $\mathrm{t}=0$ around event $\mathrm{E}$ which occurs on August 8, 1997, based on the CRSP value-weighted index.

The abnormal returns $\left(A R_{j E}\right)$ are standardized by an adjusted standard deviation $\left(S_{j t}\right)$ :

$$
S_{j t}=\sqrt{\left[V_{j}^{2}\left(1+\frac{1}{M}+\frac{\left(r_{m t}-\bar{r}_{m}\right)^{2}}{\sum_{i=1, M}\left(r_{m i}-\bar{r}_{m}\right)^{2}}\right)\right]}
$$

where:

$V_{j}^{2}$ is the variance of the residuals from firm $j$ 's market model regression;

$M$ is the number of days in the estimation period;

$r_{m t}$ is the day $t$ market return during the event period;

$r_{m i}$ is the day $i$ market return during the estimation period;

$\bar{r}_{m}$ is the mean market return during the estimation period.

The standardized abnormal returns are summed to generate the two-day excess returns, and then averaged across all firms to form a test statistic. This approach is common in event studies.

Using this methodology, Boscaljon (2005) finds significant average abnormal return of $1.74 \%$ for his full sample. He divides his sample between firms with high or low R\&D intensity ( $R \& D$ expenditures scaled by total assets) and finds that the former have large abnormal returns 
( $2.76 \%$ on average) while the latter have returns that are not statistically significant. Boscaljon (2005) estimates abnormal returns separately for the subset of firms that used DTCA in 1997, and gets estimated mean returns of $-.48 \%$ but the estimate is not statistically significant. My results can be different from his since I use a different sample (described in section 4.5) as well as a different method of estimating abnormal returns.

My objective is similar to Boscaljon (2005) but I use another estimation method that is accepted in the literature: a regression model that comprises market model variables to capture the normal returns-generating process and a set of indicator variables that allows the returngenerating process to shift in mean when information is released to market participants. My measure of abnormal returns is based on the following regression model, estimated by Ordinary Least Squares (OLS):

$$
r_{j t}=\alpha_{j}+\beta_{j} r_{m t}+\Sigma_{(k=1 \text { to } 7)} \delta_{j k} D_{k}+\varepsilon_{j t}
$$

where:

$r_{j t}$ is the returns for firm $j$ at date $t$;

$r_{m t}$ is the market returns at date $t$;

$D_{k}$ is an indicator variable which is set equal to one if the date is within the window of event date $k$, where $k=1 . .7$ based on the specific announcement dates listed in Table 4.1. If there is no trading on one of the days in the window, the indicator variable is set equal to one on the first subsequent trading day; $t=$ trading days from Jan 1, 1995 to Dec 31, 1997.

The abnormal returns estimated with the method used by Boscaljon (2005) are comparable to the coefficients obtained on the indicator variables in my model. In particular, the estimated abnormal return on August 8, 1997 is the coefficient $\delta_{j 7}$, where the number 7 corresponds to the seventh announcement date in Table 4.1. The approach in model 4.1 can easily accommodate multiple event dates, and is estimated in one step rather than two. 
A problem that is inherent in regulatory event studies is the issue of autocorrelation and cross-correlation. For example, Boscaljon (2005) averages the abnormal returns across firms and over time. However, if the abnormal returns across the two event windows are correlated or if the covariance between the firm-specific abnormal returns is different from zero, aggregating them gives a test statistic with a distribution that is not appropriate for hypothesis testing. The event dates are clustered in this study since the sample consists of all pharmaceutical firms and the event relates to the pharmaceutical industry, therefore the covariances between abnormal returns are likely to be positive. This problem of cross-correlation affects regression model 4.1 as well because observations are not likely to be independent. Indeed there should be a tendency towards positive correlation and therefore an overstating of test statistics. However, the cross-correlation effect can be eliminated if the model is estimated by portfolio as follows:

$$
r_{p t}=\alpha+\beta r_{m t}+\Sigma_{(k=1 \text { to } 7)} \delta_{k} D_{k}+\varepsilon_{t}
$$

where:

$r_{p t}$ is the mean return on date $t$ for firms in the portfolio;

$r_{m t}, D_{k}$, and $t$ are as described under equation 4.1 .

Firms are grouped together in a portfolio ${ }^{93}$ and then the mean daily portfolio return is calculated for each date $t$. The vector of mean daily portfolio returns becomes the dependent variable, and the explanatory variables are as described in model 4.1. The portfolio method removes the crosscorrelation between firms, and also removes some of the time-series correlation. The time-series correlation comes from having many observations for the same firm over time. By using the mean portfolio returns as observations, the firm-specific residuals tend to offset each other within the portfolio. The regression coefficients obtained with this method are identical to those obtained with model 4.1 because both capture the mean effect of the firms.

\footnotetext{
${ }^{93}$ A portfolio could comprise all firms in the sample or the firms could be divided into more than one portfolio based on some criteria.
} 
Alternatively the cross-correlation in model 4.1 can be handled by incorporating the variance-covariance structure in a GLS estimation of the regression model. With GLS, each share's prediction error is standardized by a factor that reflects both the variance of the market model residual and the covariance of that residual with the residuals from other shares. Historically, event studies such as those by Schipper and Thompson (1983) have calculated test statistics using standardized residuals on portfolios of returns. Their test statistics should approximate those yielded under GLS. The GLS estimation is simple to perform with current technology, but still requires that the researcher make assumptions about the variance-covariance structure, which can lead to biased coefficient estimates. I estimate abnormal returns with the equally weighted portfolio method (which is more conservative than GLS) and I then corroborate the results with those obtained from a GLS estimation of model 4.1 as a robustness check ${ }^{94}$.

\subsection{Data}

Regression model 4.2 is estimated by portfolio to obtain a measure of abnormal returns. Since there are seven indicator variables, the model produces a separate abnormal return estimate for each of the seven announcement dates. The parameter $\delta_{\mathrm{k}}$ represents the abnormal returns associated with announcement date $k$. Assuming that the regulatory change is expected to be beneficial to pharmaceutical firms, the five event dates associated with an increase in the likelihood of a regulatory change $\left(\mathrm{D}_{1}, \mathrm{D}_{2}, \mathrm{D}_{4}, \mathrm{D}_{5}\right.$, and $\left.\mathrm{D}_{7}\right)$ are predicted to generate positive regression coefficients. Therefore the coefficients $\hat{\delta}_{1}, \hat{\delta}_{2}, \hat{\delta}_{4}, \hat{\delta}_{5}$ and $\hat{\delta}_{7}$ are expected to be greater than or equal to zero. The event date associated with a decrease in the likelihood of a regulatory change $\left(D_{6}\right.$, the day of an announced disagreement regarding DTCA implementation) is predicted to lead to a negative regression coefficient, therefore $\hat{\delta}_{6}$ is expected to be less than or equal to zero. The effect of event date $\mathrm{D}_{3}$ (the public hearings) is not known a priori therefore there is no

\footnotetext{
${ }^{94}$ The covariance structure that I assume for the GLS estimation is a first-order autocorrelation of the residuals and a variance-covariance matrix determined by a first pass OLS estimation of the model.
} 
predicted direction for the coefficient $\hat{\delta}_{3}$. The estimated market model coefficients $(\hat{\alpha}$ and $\hat{\beta})$ are expected to be non-negative.

Each abnormal return coefficient is estimated by event dummy variables, which essentially capture the mean excess return over the announcement window. To obtain the abnormal return over the entire announcement window, each of the reported coefficients must be multiplied by the number of days in the window. In this study I use a three-day event window to provide for the possibility of a one-day lag in the formal reporting of the event, or of an announcement occurring after the close of trading. The indicator variable $\mathrm{D}_{\mathrm{k}}$ is assigned a value of one on the trading day preceding the event, on the trading day of the event, and on the trading day after the event. Therefore to obtain the magnitude of the abnormal returns, each abnormal return coefficient must be multiplied by three.

To evaluate the cumulative effect of the regulatory change, the returns can be aggregated across announcement dates. Since some event dates are associated with positive returns and some with negative returns, there are two ways to investigate the aggregate abnormal returns. The first method, which I call the aggregate portfolio, combines the estimated announcement date coefficients from regression model 4.2 giving all dates a common weight of 1 . This generates an estimate of the net effect of the regulatory change. The second method, which I call the trading portfolio, adjusts for expected negative abnormal returns by setting the indicator variable for announcement date $\mathrm{D}_{6}$ equal to -1 in estimating regression model 4.2. This produces an estimate of the returns that would be obtained with a trading strategy that was short in the period associated with a decrease in the probability of a regulation change, and long otherwise. This trading strategy is hypothetical since it requires a priori knowledge of announcement dates and announcement effects, but it provides a measure of the full magnitude of the response rather than the net effect.

The set of firms used to estimate regression model 4.2 is obtained from Compustat. I select firms in NAICS code 325412 (Pharmaceutical Preparation Manufacturing) with accounting 
information available on Compustat during all of the years from 1995 to 1997 . This generates a sample of 158 firms. The sample is subject to a survivorship bias, but requiring all years ensures that my sample has a full set of returns data for each firm over the entire period of the regulation change $^{95}$. I collect the following Compustat information for the fiscal year ending in 1997 to form my portfolios: total assets (data \#6), sales (data \#12), research and development expense (data \#46), and advertising expense (data \#45). The R\&D (data \#46) and advertising (data \#45) variables are likely to contain measurement error. The reporting of these data in Compustat is discretionary, and some firms are likely to have chosen not to provide this information. In addition, there may be a bias towards overstating R\&D expenditures and understating advertising expenditures, since the public is more favourable of the former than the latter.

The returns data are collected from CRSP. Returns $\left(\mathrm{r}_{\mathrm{jt}}\right)$ are the holding period returns for firm $j$ on date $t$. The daily returns for the 158 firms in my sample generate a total of 119,922 observations on 759 days. The proxy for market returns $\left(\mathrm{r}_{\mathrm{mt}}\right)$ is the daily return of the stock market index. CRSP provides two return indices based on prices on the NYSE, Amex, and Nasdaq. The value-weighted index gives more weight to firms with higher market capitalization. The equal-weighted index applies the same weight to each firm. Some researchers use the former (Bryant and Martzoukos [1998], Clem et al. [2004],and Gara [2007]), while others use the latter (Berger[1993], Beatty et al. [1996], and Cornett et al. [1996]). In this paper I use the valueweighted index since my focus is on large firms that are likely to advertise prescription drugs to consumers, but I also verify that the results hold with the equal-weighted index.

My sample is different from Boscaljon (2005), which could lead to different results. Boscaljon (2005) selects firms in NAICS codes 325411, 325412, and 325414. Firms in NAICS code 325411 (Medicinal and Botanical Manufacturing) are involved in grading, grinding, milling, and selling the uncompounded medicinal chemicals (essentially the raw materials) to

\footnotetext{
${ }^{95}$ The effect of the survivorship bias is difficult to establish. If the reaction to the regulation is stronger for firms that are likely to use DTCA, then the bias induced by my research design works in favour of finding results since new firms and firms in distress are not likely to be concerned about advertising.
} 
pharmaceutical firms. Firms in NAICS code 325414 (Biological Product [except Diagnostic] Manufacturing) manufacture biological products, such as blood and plasma used in vaccines. The outputs from firms in these two NAICS categories are not sold to the general public, and are therefore not likely to benefit directly from DTCA. It is possible that, like biotech companies, these firms may be indirectly affected by the regulatory change but the likelihood is small therefore I exclude them from my sample. ${ }^{96}$ Also, Boscaljon (2005) limits his sample to firms that reported positive values for $R \& D$ expenditures (data \#46) in 1997 and had returns available from CRSP over his entire estimation period (from 301 to 46 days before the event date of August 8, 1997). His method produces a sample of 275 firms. In contrast, I impose no conditions on R\&D expenditures but limit my sample to NAICS's Pharmaceutical Preparation Manufacturing category, which generates a sample of 158 firms.

\subsection{Full Sample Results}

Descriptive statistics for the regression variables are reported in Table 4.2. The first row shows the distribution of the mean daily returns, where the mean daily return is calculated over the entire period of the event study (759 days) for each firm. The mean daily return across firms is $.16 \%$, and is generally positive, which suggests that share prices increased over the period of investigation for the firms in my sample. This trend is likely to be partly attributable to my selection bias, but it is also due to calculating this statistic as an arithmetic mean rather than a geometric mean. The arithmetic mean overstates the positive returns relative to the negative returns. $^{97}$

\footnotetext{
${ }^{96}$ For completeness, I estimate the model for firms in these NAICS categories (not tabulated) and find no significant results.

${ }^{97}$ To see how the arithmetic mean overstates returns, consider the following share price sequence over time: $\mathrm{P}_{\mathrm{t}}=\$ 100, \mathrm{P}_{\mathrm{t}+1}=\$ 80, \mathrm{P}_{\mathrm{t}+2}=\$ 100$. The arithmetic mean return is . $5\left(\frac{80-100}{100}\right)+.5\left(\frac{100-80}{80}\right)=2.5 \%$, while the geometric mean return is $\sqrt{\left(\frac{80}{100}\right)\left(\frac{100}{80}\right)}-1=0 \%$. The geometric mean is more accurate but the accounting literature generally reports the arithmetic mean.
} 
The distribution of the accounting variables suggests that there is a mixture of small firms (with minimum total assets of around \$1 million) and large firms (with a maximum of over \$27 billion in assets). At least $75 \%$ of firms report sales values (sales) and R\&D expenses $(r d)$ that are greater than zero, however fewer than $25 \%$ of firms report positive values for advertising $(a d v)$. This validates the concern that many pharmaceutical firms may not report their advertising expenditures separately, which indicates that this variable contains measurement error.

The next four tables (Table 4.3 to Table 4.6) tabulate the results from estimating the returns model for the full sample as well as by portfolios. I use the first column of Table 4.3 (All Firms) to explain the layout of the tables. Each table has three panels. Panel A provides descriptive statistics for the variables by portfolio. Panel B reports the coefficients from estimating regression model 4.2. To adjust the coefficients for the averaging effect over the three-day event window, the coefficients must be multiplied by three. To interpret the return in percentage terms, they must also be multiplied by 100. For example, the coefficient $\hat{\delta}_{1}$ for All Firms is estimated at .0033 , which means that the total estimated abnormal return associated with event date $D_{1}$ is $.0033 \times 300=0.99 \%$, or almost $1 \%$. Panel $C$ tests for a difference between the coefficients across portfolios. The parameters in Panel $\mathrm{C}$ are obtained by combining the observations of both portfolios and then adding a set of indicator variables to represent the variables of one portfolio type. The coefficients on the indicator variables are estimates of the incremental effect of each variable for the portfolio type, while the p-values provide a measure of whether the incremental effect is statistically significant.

The model regression results for All Firms in Table 4.3 show that few event dates are associated with statistically significant abnormal returns. The coefficients $\hat{\delta}_{1}, \hat{\delta}_{3}, \hat{\delta}_{4}, \hat{\delta}_{5}$ and $\hat{\delta}_{7}$ are not statistically significant at the $10 \%$ level. The two event dates that are significant are the ones associated with indicator variables $\mathrm{D}_{2}$ and $\mathrm{D}_{6}$. These indicator variables correspond to the date that the FDA announced it would be holding public hearings $\left(\mathrm{D}_{2}\right)$, and to the date that the 
Wall Street Journal reported that drug companies had different views on what should be disclosed in DTC advertisements $\left(D_{6}\right)$. When the public hearings were announced, the pharmaceutical firms in the full sample (All Firms) experienced an abnormal stock price increase of 3\% (.0100x300). When the Wall Street Journal announced a "sharp division" among marketers, the pharmaceutical firms experienced an abnormal stock price decrease of 3.36\% (-.0112x300). A measure of aggregate abnormal returns is required to identify whether the capital market reaction on these two announcement dates offset each other.

The individual coefficients $\left(\hat{\delta}_{1}, \hat{\delta}_{2}, \hat{\delta}_{3}, \hat{\delta}_{4}, \hat{\delta}_{5}, \hat{\delta}_{6}\right.$ and $\left.\hat{\delta}_{7}\right)$ represent the estimated abnormal return associated with each individual event date. The aggregate effect of the event can also be obtained from the mean portfolio abnormal return estimates reported near the bottom of the table. The mean portfolio abnormal return is obtained by estimating regression model 4.2 with a single indicator variable that is set equal to 1 in all the announcement date windows. This coefficient is reported near the bottom of the table as "aggregate portf (mean $\delta$ )". To obtain the magnitude of the aggregate abnormal returns, the coefficient is multiplied by twenty-two (the number of event window days $)^{98}$, and then by 100 to interpret it in percentage terms. The aggregate portfolio returns for the full sample (All Firms) is estimated as $-.22 \%(-.0001 \times 2200)$ which is not statistically significant at the $10 \%$ level.

A different measure of the aggregate effect of the event is obtained by estimating the abnormal returns that would be generated with a trading strategy that is long in the portfolio shares during the time periods associated with an increase in the probability of a regulatory change, and short otherwise. This measure provides an estimate of the absolute value of the regulatory change. The returns on the trading strategy are obtained by estimating regression model 4.2 with a single indicator variable set equal to 1 on announcement dates that were expected to increase the probability that the regulatory change would be adopted $\left(D_{1}, D_{2}, D_{4}, D_{5}\right.$,

\footnotetext{
${ }^{98}$ There are twenty-two event dates: four for event $\mathrm{D}_{3}$ since it occurs over two days, and three days for each of the remaining six events.
} 
and $\mathrm{D}_{7}$ ), and -1 on the announcement date associated with a decrease in the likelihood of adoption $\left(D_{6}\right)$. Note that there was no sign predicted for event date $D_{3}$. I assign a value of 1 on this event date and verify in section 4.9 that the results hold when $\mathrm{D}_{3}$ is assigned a value of -1 . The mean abnormal returns estimate obtained with this method is reported as "trading portf (mean $\delta$ )" near the bottom of the table. The results for the full sample (All Firms) indicate that such a trading strategy would have yielded significant abnormal returns of $6.6 \%(.0030 x 2200)$, which provides evidence that the market reacted to the regulatory change announcements.

The results for the full sample (All Firms) suggest that, while capital markets responded to two of the announcements, the second response negated the first one for a net effect of zero. In addition, there was no response on the actual date the FDA announced the change in regulation ( $\hat{\delta}_{7}$ is not statistically significant), which is different from the results in the Boscaljon (2005) paper. Overall the results are inconsistent with hypothesis $\mathrm{H} 1$, which predicted positive abnormal returns for firms in the pharmaceutical industry. It is possible that only some of the firms were expected to benefit from the regulatory change, and that grouping them with the rest of the firms in the full sample introduces too much noise in the data to estimate abnormal returns. In the next section, I explore this possibility by estimating the regression model by portfolios.

\subsection{Portfolio Results}

In this section I separate the full sample into different subgroups to test whether abnormal returns are associated with certain firm characteristics. Recall that my second hypothesis (H2) proposes that firms that sell prescription drugs under patent protection are expected to benefit the most from the change in regulation, and are therefore expected to have larger abnormal returns in response to the relaxation of DTCA rules. To test this, I separate the firms in my sample into three firm-type portfolios using the classification system that I developed in Chapter 2 of this thesis. I classify firms based on whether they sell products with patent protection (Big Pharma), sell over-the-counter or generic products exclusively (OTC-Generic), or operate as a biotech 
company (Biotech). The descriptive statistics for the variables are reported by firm-type in Panel A of Table 4.3, followed by estimates of the abnormal returns in Panel B.

Based on the information in Table 4.3, Big Pharma firms are the largest with mean assets of $\$ 5,550$ million. OTC-Generic and Biotech firms are considerably smaller, on average. Panel B shows the model estimation for all firms in the first column, then for each type of firm in the subsequent three columns. The last three columns (Panel C) test for a difference in parameter estimates among the firm types.

The regression results by firm-type show that only two of the seven announcement dates are associated with statistically significant abnormal returns. On the date the public hearings were announced $\left(D_{2}\right)$, each firm-type earned significant abnormal returns and the returns were positive, as predicted. Estimated abnormal returns on this date are largest for Biotech firms at $3.87 \%(.0129 \times 300)$, followed by OTC-Generic firms at $2.52 \%(.0084 \times 300)$, then by Big Pharma firms at $2.34 \%(.0078 \times 300)$. However, the differences are not statistically significant when compared across firm types in Panel $\mathrm{C}$ of Table 4.3. On the date the Wall Street Journal announced the disagreements with respect to the terms of the new regulation $\left(\mathrm{D}_{6}\right)$, two of the three firm-types earned significant abnormal returns, and the returns were negative, as predicted. Big Pharma and Biotech firms experienced abnormal returns of $-3.27 \%(-.0109 \times 300)$ and $-5.58 \%$ (-.0186x300), respectively on this announcement date. Once again, the test in Panel C does not detect a significant difference in returns between firm-types.

The abnormal returns on the two announcement dates effectively offset each other for a net effect that is not significantly different from zero according to the aggregate portfolio measure at the bottom of Table 4.3. However, the trading portfolio suggests that the market reaction to the DTCA announcements was statistically significant for Biotech firms. A trading portfolio that held the shares of Biotech firms over each event window except $\mathrm{D}_{6}$, when they were sold short, would have generated abnormal returns of $9.24 \%(.0042 \times 2200)$. Estimates of the trading portfolio returns are not statistically significant for either Big Pharma or OTC-Generic firms. 
However, the test in Panel $\mathrm{C}$ shows that trading portfolio returns are not significantly different among firm-types. These results do not support hypothesis H2. Abnormal returns were not larger for firms that sell patented prescription drugs.

Next I test hypothesis H3, which states that abnormal returns should be increasing in the level of R\&D expenditures. Abnormal returns by R\&D portfolios are estimated in Table 4.4 The first set of columns in Panel B reports the results when the sample is partitioned on R\&D Intensity ( $R \& D$ scaled by total assets), which is a common partitioning variable in the accounting literature, and the one used by Boscaljon (2005). Firms are classified as High if their R\&D Intensity is above the median value of $R \& D$ Intensity, or Low if their R\&D Intensity measure is below the median. The descriptive statistics in Panel A show that firms in the High R\&D intensity category are generally smaller, with mean assets of $\$ 526$ million versus the mean assets of $\$ 2,611$ million for firms with Low R\&D Intensity. I present two possible rationales for the relative size of firms in each portfolio. It is possible that R\&D intensive firms report lower levels of assets because their $R \& D$ expenditures are expensed rather than capitalized, leaving them with a lower book value of assets compared to less $R \& D$ intensive firm. It is also possible that the R\&D partitioning categorizes small start-up firms in the High $R \& D$ Intensity portfolio because these firms tend to have small values for assets. I investigate the composition of the High R\&D Intensity portfolio and find that only $31 \%$ (13 out of 42) of the Big Pharma firms are in the High R\&D Intensity. By comparison 23\% (12 out of 53) of the OTC-Generic firms and 86\% (54 out of 63) of the Biotech firms are in the High R\&D Intensity portfolio. This means that the High Intensity portfolio is mainly comprised of Biotech firms at $68 \%$ (54 out of 79) of the total, followed by Big Pharma firms at around 17\% (13 out of 79) of the total, and with OTC-Generic firms making up the remaining 15\% (12 out of 79). Thus the composition of firms in the High R\&D Intensity category is different from what is assumed in Boscaljon (2005) ${ }^{99}$. In his paper, he

\footnotetext{
${ }^{99}$ I verify whether this result is driven by firms that report R\&D expenditures of zero, and are therefore omitted from the Boscaljon (2005) sample. I remove the sixteen (out of 158) firms that have zero values
} 
assumes that he captures the Big Pharma type of firms in the High R\&D Intensity category. But in effect, grouping firms together based on their R\&D intensity results in a mixture of firms that have fundamentally different business processes.

The results by R\&D Intensity show that both the High and Low portfolios generated significant positive abnormal returns on announcement date $\mathrm{D}_{2}$ and significant negative abnormal returns on announcement date $D_{6}$. The test of differences in portfolios (Panel C) suggests that abnormal returns were similar between the two portfolios of firms. The net effect of the two announcement dates is not different from zero based on the fact that the aggregate portfolio measure is not statistically significant. But the trading portfolio for firms in the High category earned a statistically significant return of $9.46 \%$ (.0043 x 2200), which suggests that the market reaction to the regulatory change was stronger for these firms than for firms in the Low $R \& D$ Intensity portfolio. However, the test of differences between the trading portfolios reports a coefficient of .0027 that is not statistically significant. The trading portfolio returns for the High R\&D Intensity firms (coefficient of .0043) are similar to the trading portfolio returns for Biotech companies in Table 4.3 (coefficient of .0042 ), which is probably due to the fact that $68 \%$ of the High R\&D Intensity firms are Biotech companies. The results on the R\&D intensity variable are not consistent with Boscaljon (2005), who obtains significant abnormal returns of $2.76 \%$ for high $\mathrm{R} \& \mathrm{D}$ intensive firms, and abnormal returns that are not significantly different from zero for low R\&D intensive firms. In contrast, I find no abnormal market response on the date the FDA announced the regulatory change (event date $D_{7}$ ), and the abnormal returns estimated with my model do not differ based on R\&D intensity.

Given the ambiguity of the firm characteristics captured by the R\&D Intensity partition, I conduct an alternate test of hypothesis H3. I separate firms between the 142 firms that reported

for R\&D: four Biotech firms and twelve OTC-Generic firms. This causes the median value to change, and requires me to shift six Biotech firms and two OTC-Generic firms from the High R\&D Intensity category to the Low R\&D Intensity category. The effect on the distribution of firms within each category is not material. 
R\&D expenditures in 1997 ( $\mathrm{rd}>0$ ) versus the sixteen firms that reported no R\&D investments $(\mathrm{rd}=0)$. The results from estimating the model for these two portfolios are reported in the last two columns of Panel B in Table 4.4. The results suggest that firms that invested in $R \& D(r d>0)$ had a significant abnormal share price response to announcement dates $D_{2}$ and $D_{6}$. These firms earned abnormal returns of $3.12 \%(.0104 \times 300)$ at the time the hearings were announced, and abnormal returns of $-3.63 \%(-.0121 \times 300)$ when the press announced that marketers were disagreeing on the terms of the new regulation. The trading portfolio with firms that reported R\&D expenditures $(\mathrm{rd}>0)$ earned $7.04 \%(.0032 \times 2200)$ which suggests a significant overall market response to the regulatory change for this set of firms. These results do not extend to firms that did not report investments in $R \& D(r d=0)$. None of the event parameters are significant for these firms. However, this is possibly due to the lack of power from having a small number of observations in this portfolio. The overall results are inconclusive; there is not enough evidence to support the hypothesis that firms with larger investments in R\&D earned higher abnormal returns.

The next set of results provides information to help assess whether firms that were likely to use DTCA generated abnormal returns that were different from firms that weren't expected to use DTCA. In order to explore this question, I partition the sample between firms that are likely to undertake DTCA and those that are not. As a first test, I divide the firms based on whether or not they reported advertising expenditures in their financial statements in 1997. The parameter estimates for these two portfolios are reported in the first two columns of Panel B in Table 4.5. Since advertising expenditures are not necessarily DTCA expenditures, I also investigate a second set of portfolios. For the second test, I use a forward-looking variable and divide the firms between those that actually decided to use DTCA in 1997 (according to Med Ad News) and those that decided not to. This is identical to the partitioning technique used by Boscaljon (2005) to explore abnormal returns for DTCA users. The regression results for these portfolios are reported in the last two columns of Panel B in Table 4.5. Surprisingly, some firms that used 
DTCA in 1997 according to Med Ad News reported no advertising expenditures in Compustat. This confirms the measurement error concerns that have been raised throughout this thesis with respect to the advertising ( $a d v)$ variable. When firms disclose their advertising expenditures separately so that they can be picked up by Compustat, this is a voluntary disclosure choice and does not necessarily reflect the full amount the firm is spending on its advertising.

Table 4.5 shows that abnormal returns on event date $\mathrm{D}_{2}$ are not significant for firms that report advertising expenditures ( $\mathrm{adv}>0$ ) but they are positive and significant for firms that did not report advertising $(\mathrm{adv}=0)$. Abnormal returns for the latter set of firms are estimated as $3.51 \%$ (.0117x300). As with the previous portfolios, these positive abnormal returns were offset by negative abnormal returns on event date $\mathrm{D}_{6}$, which were $-3.81 \%(-.0127 \times 300)$ for firms with no advertising investments $(\mathrm{adv}=0)$. The returns from a trading portfolio of these firms would be approximately $8.8 \%(.0040 \times 2200)$ based on the statistically significant trading portfolio coefficient for this group of firms. This is a higher return than would be obtained on a trading portfolio of firms that reported advertising $(\mathrm{adv}>0)$, based on the significant coefficient of -.0056 in Panel C.

When the sample is partitioned between the thirteen firms that used DTCA in 1997 and the 145 firms that didn't, the results are consistent with the ones from the advertising portfolios: the firms that did not use DTCA $(\mathrm{dtca}=0)$ earned positive abnormal returns during event $\mathrm{D}_{2}$ based on the significant coefficient of $\hat{\delta}_{2}=0.110$, and negative abnormal returns during event $\mathrm{D}_{6}$ based on the significant coefficient of $\hat{\delta}_{6}=-0.120$. These regression coefficients are significantly different from the ones obtained on the portfolio of firms that used DTCA (dtca $>0)$ based on the coefficients of -.0018 on $\hat{\delta}_{2}$ and of .0100 on $\hat{\delta}_{6}$ in Panel C of Table 4.5. The differences in coefficients is not surprising given than neither $\hat{\delta}_{2}$ nor $\hat{\delta}_{6}$ is statistically significant for firms that use DTCA (dtca $>0)$. However, there is one regression coefficient that is significant for these firms. Panel B of Table 4.5 shows that firms that used DTCA (dtca $>0)$ were the only ones to 
experience a share price reaction on the date that the FDA announced the relaxation of DTCA rules on August 8, 1997. These firms experienced significant abnormal returns of $-2.16 \%$ ($.0072 \times 300$ ) on announcement date $D_{7}$, which suggests that the market expected the new regulation to have an adverse effect on these firms' future profits. This is not consistent with hypothesis H4, which predicted higher abnormal returns for DTCA users. However, the result is consistent with the sign of the point estimate from Boscaljon (2005). Although his test statistic is not statistically significant, he estimates abnormal returns of $-.48 \%$ on August 8, 1997 for the subset of firms that engaged in DTCA.

I test whether the results are caused by an outlier by estimating model 4.1 separately for each of the thirteen firms that used DTCA (not tabulated), and find that 11 out of the 13 firms have negative estimates for the coefficient on $\mathrm{D}_{7}$. Therefore the reaction seems to apply to most of the portfolio. Based on the descriptive statistics in Panel A of Table 4.5, the firms that used DTCA (dtca $>0$ ) are large, with mean assets of $\$ 11,561$ million. It is possible that the results in Table 4.5 are caused by firm size rather than the relationship between abnormal returns and the likelihood that the firm would use DTCA. The analysis near the end of this section investigates the firm size effect.

The next set of portfolios tests whether abnormal returns are a function of the firm's sales. Hypothesis $\mathrm{H} 3$ predicts that abnormal returns should be increasing in sales intensity. The sales intensity measure (sales scaled by total assets) is constructed and then firms are divided into two portfolios based on whether their sales intensity was above (High) or below (Low) the median value. Table 4.6 reports the results from estimating regression 4.2 for each of these two portfolios. The regression coefficients suggest that firms in the Low sales intensity portfolio experienced a stronger capital market reaction to the event than did firms in the High sales intensity portfolio. Abnormal returns on announcement date $\mathrm{D}_{2}$ were $3.9 \%$ (.0130 x 300) for Low firms, compared to $2.16 \%(.0072 \times 300)$ for High firms but the difference is not statistically significant based on the test in Panel C. However, abnormal returns on announcement date $\mathrm{D}_{6}$ 
were $-5.13 \%(-.0171 \times 300)$ for Low firms and not significantly different from zero for High firms, leading to a difference that is significant at the $10 \%$ level according to the test in Panel C. The trading portfolio return measures the overall effect as an abnormal return of $9.24 \%(.0042 \mathrm{x}$ 2200) for firms with low sales intensity, while firms with high sales intensity have a trading portfolio return that is not significantly different from zero. These results do not support hypothesis H3, which predicts that abnormal returns should be larger for firms with high sales intensity. This could be due to the same potential confounding effect that occurred with the R\&D Intensity results in Table 4.4.

The descriptive statistics in Panel A of Table 4.6 show that the High Sales Intensity portfolio is comprised of larger firms, with mean total assets of $\$ 2,960$ million versus mean assets of $\$ 176$ million for Low Sales Intensity firms. The R\&D Intensity portfolios have the reverse composition, with large firms in the Low R\&D Intensity category. In the R\&D Intensity analysis, the Biotech firms are more heavily represented than OTC-Generic or Big Pharma firms in the High category because they have small values for assets. In the Sales Intensity analysis, the Biotech firms may be grouped into the Low category because they have low values for sales. I investigate this and find that $71 \%$ (45 out of 63) of Biotech firms are in the Low Sales Intensity portfolio therefore they comprise a large proportion $(60 \%$ based on the ratio of 45 out of 79 firms) of the Low Sales Intensity firms. The disproportionate number of Biotech firms in the Low Sales Intensity category results in the two portfolios having the same estimated trading portfolio abnormal return parameter (.0042 in Tables 4.3 and 4.6).

The last set of portfolios is designed to test whether abnormal returns are affected by the size of the firm, although I make no predictions about the relationship between size and abnormal returns for this event study. This test is meant to provide information about whether the size of the firm is a confounding factor in the analysis presented thus far in this section. The sample is divided between firms that have total assets valued above the median value (Large), or below the median value (Small). The third and fourth columns in Panel B of Table 4.6 report the regression 
results from estimating the Large and Small portfolios separately. The results for the Total Assets partition show that both small and large firms earned significant positive abnormal returns on announcement date $\mathrm{D}_{2}$, as well as significant negative abnormal returns on announcement date $\mathrm{D}_{6}$. There is no significant difference in abnormal returns between the two categories of firm size according to the test of differences in Panel C, therefore firm size does not appear to be an important determinant of the market reaction to the regulatory change.

The findings in this section suggest that there was a share price reaction to three of the seven announcements regarding DTCA regulation. In general, the reaction was positive on the date that the FDA announced it would be holding hearings to discuss the issue of DTCA. However, these positive abnormal returns were offset by negative abnormal returns around the date that newspapers announced a "sharp division" among drug marketers about the new DTCA regulation. The net of the two effects is not significantly different from zero for any of the portfolios, nor for the full sample. The only other announcement date that led to abnormal returns was on August 8, 1997 when the FDA announced the regulatory change. On this date, firms that were expected to use DTCA (based on the list of firms that ex post used DTCA) earned negative abnormal returns of $2.16 \%$. This is the only result that is somewhat consistent with the findings in Boscaljon (2005), perhaps because our samples are identical only for this analysis. Our results are inconsistent with our hypotheses and intuition, but the theoretical model by Brekke and Kuhn (2006) offers a potential explanation for this outcome.

Brekke and Kuhn (2006) propose two effects of DTCA. First, DTCA increases the potential market for a therapeutic drug as it makes patients aware that they may be sick. Intuitively this expands the market for a drug through an increase in volume, and total profits increase as long as prices don't decrease. This is essentially the premise for hypothesis $\mathrm{H} 1$ in this paper, which posits that pharmaceutical firms will benefit from the regulatory change. However, Brekke and Khun (2006) provide more richness by modeling the effect of DTCA within a therapeutic market. In their model, substitute drugs exist for a given therapeutic condition (for 
example, Viagara, Levitra, and Cialis are not materially different from each other), and ultimately the demand for the drug is determined by physicians who prescribe it. A second effect of DTCA is that it causes an increase in advertising to physicians (detailing) both by the DTCA firm and by suppliers of the competing drugs. Indirectly, the firm conducting DTCA could lose market share and face a more elastic demand curve due to the marketing by competitors to physicians. The predicted increase in detailing is in line with the empirical work by lizuka and Jin (2005), who find that DTCA leads to an increase in the number of patient visits, but has no effect on physicians' choice of prescriptions. It is also consistent with the actual spending patterns observed. DTCA increased from $\$ 800$ million in 1996 to $\$ 2.5$ billion in 2000 , but detailing also increased from $\$ 8$ to $\$ 13$ billion in the same period. ${ }^{100}$

If the Brekke and Khun (2006) model is approximately true, the effect of DTCA on profits is a function of the two effects and is not determinable. It is conceivable that the disadvantage of the increased competition was perceived to be greater than the advantage of the market expansion for firms that ultimately used DTCA, resulting in negative abnormal returns for this set of firms. It is also conceivable that these firms invested in DTCA in spite of the loss in profits because the alternative (not to invest in DTCA) would have yielded even lower profits. This suggests that firms with highly visible brands can be made worse off with a relaxation of advertising rules. This is what Eckard (1991) finds when he investigates the effect of the 1970 ban on cigarette advertising. Eckard (1991) analyzes the market shares of cigarettes by brandname before and after the ban. He finds that after the advertising ban, the market shares of leading brand-name cigarettes increased. He also finds that new brand entry virtually ceased, which may have further increased the profits of firms with leading brand-name products.

The portfolio analysis in this section attempts to identify firm characteristics that could lead to a differential market response to the regulatory change. Some of the results are obfuscated by trying to isolate only one characteristic at a time. In particular, the effect of R\&D

\footnotetext{
${ }^{100}$ Source: Rosenthal et al. (2002).
} 
intensity and sales intensity effects are possibly confused with the firm-type effect since the high R\&D intensity portfolio and the low sales intensity portfolio mainly consist of Biotech firms. In the next section, I separate firm-effect from other firm characteristics by estimating a regression model with interactive terms for each firm-type.

\subsection{Determinants of Abnormal Returns}

In the previous section I use portfolios to investigate whether abnormal returns from the DTCA regulation change are a function of certain firm characteristics. In this section, I estimate a regression model that disentangles the firm-type effect from the firm characteristics effect. This is done by first constructing abnormal returns variable for each firm, and then regressing the abnormal returns on explanatory variables that represent firm characteristics as well as interactive variables for the firm types. Abnormal returns are constructed separately for each firm, and then aggregated across all announcement dates for each firm to obtain one dependent variable per firm. First I estimate the following market model parameters $\left(\alpha_{\mathrm{j}}\right.$ and $\left.\beta_{\mathrm{j}}\right)$ for each firm using the last 150 trading days of 1994 as the estimation period:

$$
r_{j t}=\alpha_{j}+\beta_{j} r_{m t}+\varepsilon_{j t}
$$

Then I use the market model coefficients $\left(\hat{\alpha}_{j}\right.$ and $\left.\hat{\beta}_{j}\right)$ to calculate the residuals in each of the three-day windows surrounding each event date. These residuals are the announcement date abnormal returns. For each firm $j$ I aggregate the abnormal returns across announcement dates to obtain an estimate of the cumulative abnormal returns $\left(c a r_{j}\right)$ generated by the regulatory change. The cumulative abnormal returns $\left(\mathrm{car}_{j}\right)$ are regressed against the following variables:

$$
\begin{aligned}
& \text { car }=\alpha+\alpha_{\mathrm{p}} \text { pharma_dum }{ }_{j}+\alpha_{\mathrm{b}} \text { bio_dum }{ }_{j}+\beta_{\mathrm{sale}} \text { saleint }+\beta_{\mathrm{psale}} \text { pharma_sale } \\
& +\beta_{\mathrm{bsale}} \text { bio_sale }{ }_{j}+\beta_{\mathrm{rd}} \text { rdint }+\beta_{\mathrm{prd}} \text { pharma_rd }{ }_{j}+\beta_{\mathrm{brd}} \text { bio_rd }_{j}+\beta_{\mathrm{size}} \text { size }_{j} \\
& +\beta_{\mathrm{psize}} \text { pharma_size } e_{j}+\beta_{\mathrm{bsize}} \text { bio_size } e_{j}+\beta_{\mathrm{dtca}} d t c a d u m_{j}+\mathrm{e}_{j}
\end{aligned}
$$

where:

$\operatorname{car}_{j}$ is the cumulative abnormal returns construct for firm $j$; 
pharma_dum ${ }_{j}$ is a indicator variable set to one if firm $j$ is of type Big Pharma and zero otherwise;

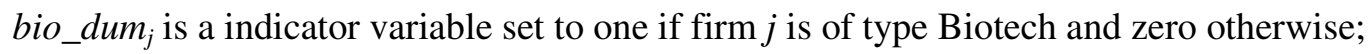
saleint $_{j}$ is the sales intensity variable (Compustat data \#12 divided by data \#6) for firm $j$; pharma_sale $_{j}$ is the saleint $_{j}$ variable if firm $j$ is of type Big Pharma and zero otherwise; bio_sale $e_{j}$ is the saleint $t_{j}$ variable if firm $j$ is of type Biotech and zero otherwise; rdint $t_{j}$ is the R\&D intensity variable (Compustat data \#46 divided by data \#6) for firm $j$; pharma_rd $d_{j}$ is the $r d i n t_{j}$ variable if firm $j$ is of type Big Pharma and zero otherwise; bio_r $d_{j}$ is the $r d i n t_{j}$ variable if firm $j$ is of type Biotech and zero otherwise; size $_{j}$ is the natural log of total assets (Compustat data \#6) for firm $j$; pharma_size $e_{j}$ is the $s_{i z e}$ variable if firm $j$ is of type Big Pharma and zero otherwise; bio_size $_{j}$ is the size $_{j}$ variable if firm $j$ is of type Biotech and zero otherwise; dtcadum $_{j}$ is a indicator variable set equal to one if firm $j$ used DTCA in 1997.

Note that the dependent variable is similar to the aggregate portfolio measure in the previous section. While the aggregate portfolio returns are not significantly different from zero for any of the portfolio regressions, there is nevertheless an opportunity for cross-sectional variations in this measure. Also note that, since all the firms that used DTCA were Big Pharma firms, there is no need to include interactive variables to capture the firm-type effect of DTCA usage. The regression model has interactive variables for Biotech firms and for Big Pharma firms therefore by design, the non-interactive (or base) variables capture the effects for OTC-Generic firms.

The explanatory variables allow me to investigate whether cumulative abnormal returns are associated with sales intensity, $R \& D$ intensity, and size by firm-type. For example, the sales intensity effect for OTC-Generic firm is captured by the coefficient $\hat{\beta}_{\text {sale }}$ on the saleint variable, and is allowed to differ for Big Pharma firms through the coefficient $\hat{\beta}_{p s a l e}$ on the pharma_sale variable, and for Biotech firms through the coefficient $\hat{\beta}_{\text {bsale }}$ on the bio_sale variable. The differential effect of R\&D intensity is captured by the pharma_rd coefficient for Big Pharma firms and by the bio_rd coefficient for Biotech firms. Similarly, the differential effect of size is captured by the coefficients on pharma_size and bio_size. Finally, the intercept $(\hat{\alpha})$ provides an 
estimate of the mean cumulative abnormal returns for OTC-Generic firms, and this estimate must be added to the coefficients $\hat{\alpha}_{p}$ on pharma_dum and $\hat{\alpha}_{b}$ on bio_dum to estimate the mean cumulative abnormal returns for Big Pharma and Biotech firms, respectively.

Regression model 4.3 is estimated cross-sectionally using all 158 firms in the sample. While I make no prediction on the mean abnormal returns for OTC-Generic firms (coefficient $\hat{\alpha}$ ), hypothesis H1 states that abnormal returns should be larger for Big Pharma and for Biotech firms, therefore the coefficients on pharma_dum $\left(\hat{\alpha}_{p}\right)$ and bio_dum $\left(\hat{\alpha}_{b}\right)$ are expected to be positive. Based on hypothesis $\mathrm{H} 3$, the stock price reaction should be increasing in the sales potential of the firm. My proxies for sales potential are sales intensity (saleint) and R\&D intensity (rdint). The coefficients on saleint and rdint capture the effect of sales potential for OTC-Generic firms, and these are expected to be non-negative. The coefficients on pharma_sale, bio_sale, pharma_rd, and bio_rd provide estimates of the incremental effect of the sales potential for Big Pharma firms and Biotech firms, and these are expected to be positive since these variables encompass the combined effect of hypotheses $\mathrm{H} 2$ and $\mathrm{H} 3$, which are both expected to be positive. I make no prediction on the direction of the coefficient on $s i z e_{j}$ since size is an exploratory variable in this paper. Hypothesis H4 states that firms that use DTCA should have higher abnormal returns therefore the coefficient on $d_{t c a d u m}$ is expected to be positive.

Descriptive statistics for the variables (except for the indicator variables) are presented in Table 4.7, and the results from the regression are reported in Table 4.8. The results in Table 4.8 show that only two coefficients from regression model 4.3 are statistically significant at the $10 \%$ level. The significant coefficient $\hat{\beta}_{\text {sale }}=.0701$ on the saleint variable suggests that cumulative abnormal returns are increasing in sales intensity, at least for OTC-Generic firms. The significant coefficient $\hat{\beta}_{\text {prd }}=.6652$ on the pharma_rd variable indicates that cumulative abnormal returns are higher for Big Pharma firms that are R\&D intensive. 
To contemplate the coefficients by firm-type, the base coefficients and the coefficients on the interactive terms from Table 4.8 are combined, and the linear combinations are tested with an F-statistic. For example, to investigate the coefficient on the sale variable for Big Pharma firms, the base coefficient on saleint $\left(\hat{\beta}_{\text {sale }}=.0701\right)$ is added to the interactive saleint variable coefficient for Big Pharma firms $\left(\hat{\beta}_{\text {psale }}=-.1423\right)$ to obtain an estimate of -.0722. The firm-type coefficients are reported in Table 4.9 along with the p-values from the F-statistics. The results show that only two linear combinations of parameter estimates from regression model 4.3 are statistically significant. The sales intensity variable is only significant for OTC-Generic firms, and the R\&D intensity variable is only significant for Big Pharma firms.

The R\&D intensity result for Big Pharma firms is consistent with hypotheses H2 and H3, which predicted higher abnormal returns for firms that sell prescription drugs and for firms that invest large amounts in R\&D. The sales intensity result for OTC-Generic firms supports hypothesis $\mathrm{H} 3$, which proposes that abnormal returns should be increasing in sales intensity, but is not consistent with the prediction that firms that sell patented prescription drugs would benefit more from the relaxation of DTC advertising rules than firms that sell generic products. The latter result suggests that perhaps the OTC-Generic firms were expected to benefit from freeriding on the market-expanding effect of DTCA without incurring any of the advertising expenditures, which is in the spirit of the Brekke and Khun (2006) model.

This section provides some evidence that the regulatory change had a differential effect based on certain firm characteristics, but the evidence is scant. The statistical test in this section is based on the same econometric specifications used by Boscaljon (2005) and discussed in section 4.4 of this chapter, therefore the inference is subject to the same concerns about crosscorrelation. In the next section I run some specification tests to explore whether the findings are caused by my research design. 


\section{9 $\quad$ Specifications Test}

\subsubsection{Event Window}

The main misspecification problem in event studies is from incorrect identification of the event window. I test the specification of my event window two ways. First, it is possible that the news was unofficially "leaked" prior to the announcement date, and reflected in price a few days early. Therefore I estimate the models (not tabulated) with event windows ranging from two to four days before and after the event date and find that the results remain similar. Another possible misspecification could occur if an important event date is omitted from my model. I test for this with a simple measure of abnormal returns. I assume that the market beta is equal to one for all firms, and construct an abnormal return measure $\left(a b n_{i t}\right)$ as the difference between firm returns and market returns $\left(\mathrm{abn}_{\mathrm{it}}=\mathrm{r}_{\mathrm{it}}-\mathrm{r}_{\mathrm{mt}}\right)$ for firm $i$ at date $t$. I extend the period of analysis to cover the years 1993 to 1997 . First, I separate the abnormal return variables $\left(\mathrm{abn}_{\mathrm{it}}\right)$ between positive and negative values. Then, I calculate the mean and standard deviations for each of these two subsets. For the subset of firms with positive values of $\mathrm{abn}_{\mathrm{it}}$, I select the observations that are greater than 1.5 times the standard deviation. For the subset of firms with negative values of $\mathrm{abn}_{\mathrm{it}}$, I select the observations that are less than -1.5 times the standard deviation. This yields a group of observations with large positive abnormal returns and a group of observations with large negative abnormal returns. I sort these by date and identify the days that had the most positive or negative abnormal returns. I search several databases for news articles around these dates and find no mention of the regulatory change. In general, the "abnormal returns" on these dates are related to news about strong quarterly financial results for the industry as a whole, and to news about the FDA reform with respect to accelerating the drug approval process. As mentioned earlier, I also look for other important announcements during the event windows used in this study but find none that could have a confounding effect. However it is possible that other 
important news articles were released during my event study, and that I've attributed the response to the DTCA regulation change.

\subsubsection{Change in Risk}

A regulatory change may change the risk of the firm, where the risk is represented by beta $(\beta)$ in model 4.2. Lamdin (2001) suggests adding an interaction term to capture changes in the beta coefficient from the model used to estimate abnormal returns. I test for a change in risk by adding interaction terms to the portfolio regression that I estimated for the full sample:

$$
r_{p t}=\alpha+\beta r_{m t}+\sum_{(k=1 \text { to } 7)} \delta_{k} D_{k}+\sum_{(i=1 \text { to } 3)} \gamma_{i} B_{i} * r_{m t}+\varepsilon_{t}
$$

where:

$r_{p t}, r_{m t}$, and $D_{k}$, are as described in equation 4.2;

$B_{i}$ is a indicator variable equal to one if the date is within Beta estimation period $i$, where $\mathrm{i}=1$

to 3 ;

$t=$ trading days from Jan 1, 1995 to Dec 31, 1997.

I identify three Beta estimation periods where either $\mathrm{B}_{1}, \mathrm{~B}_{2}$, or $\mathrm{B}_{3}$ is set to one, based on the following timeline:
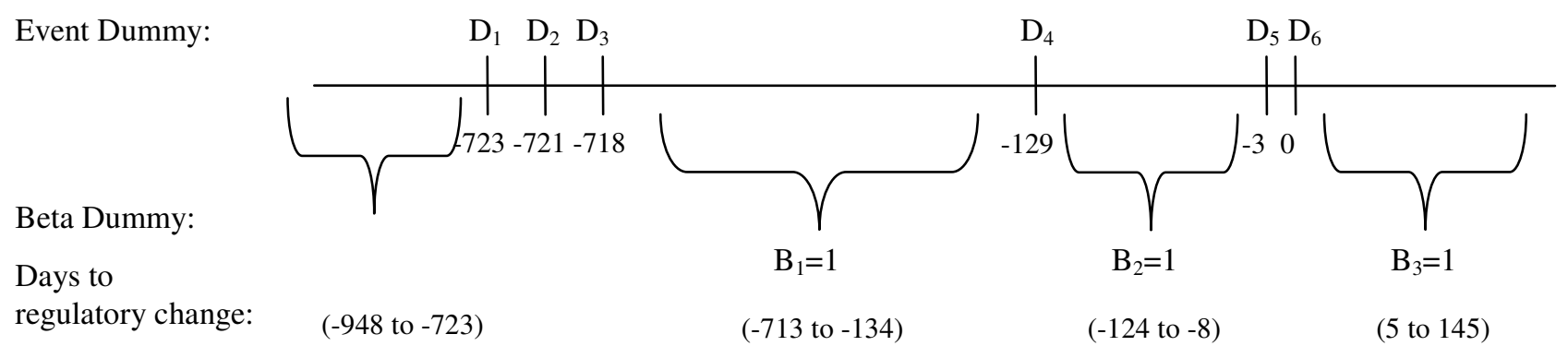

regulatory change:

(-948 to -723$)$

$(-124$ to -8$)$

(5 to 145 )

My method of assigning the time periods to each Beta dummy variable is somewhat arbitrary: I choose beta time periods that are several months in duration and at least a week away from any announcement date. Note that the range of days-to-event (-723 to 145) results in a total 
of 759 trading days ${ }^{101}$. Regression model 4.4 is estimated using the same portfolio method as for the All Firms portfolio in Table 4.3. The results (not tabulated) are that none of the coefficients on the beta indicator variables $\left(\mathrm{B}_{1}, \mathrm{~B}_{2}, \mathrm{~B}_{3}\right)$ are significant, while the coefficients on the event study variables $\left(D_{k}\right)$ remain similar to the ones tabulated as All Firms in Table 4.3. Consequently, the results in this paper do not appear to be affected by a change in risk.

\subsubsection{Market Return Index}

As mentioned in section 4.5, the equal-weighted stock market index is perhaps a better representation of the market returns $\left(\mathrm{r}_{\mathrm{mt}}\right)$ for small firms than the value-weighted stock market index. I test whether the choice of index is important for the firms in my sample by re-estimating some regressions with equal-weighted returns instead of value-weighted returns from CRSP. The results (not tabulated) are not materially different, which indicates that the choice of index is not influencing the results of this study.

\subsubsection{GLS Estimation}

Regression model 4.1 can be more efficiently estimated by Generalized Least Squares (GLS), because GLS removes the autocorrelation and cross-correlation of the residuals and leaves a smaller estimate of the variance in the calculation of the test statistics. The main drawback of GLS is that it requires an estimation of the variance-covariance matrix.

In this section I replicate the results in this paper with GLS estimations as follows. First, the observations are stacked by firm and by date. For example, in the estimation of the Full Sample in the first column of Table 4.3, each of the 158 firms would have 759 returns-dates for a total of 119,922 observations. The autocorrelation is estimated for each firm, and the crosscorrelation is estimated for each date to form a variance-covariance matrix. The observations are

\footnotetext{
${ }^{101}$ Note that the range of days-to-event (-948 to 145) exceeds the number of days in the sample (759 days) because the days-to-event counter includes non-trading days, such as weekends and holidays. The range of days-to-event results in 1,093 days, which is 334 days more than the days in the sample. These 334 days represent 312 weekend dates ( 3 years x 52 weeks x 2 weekend days) plus roughly 9 holidays per year.
} 
scaled by the inverse of the variance-covariance matrix, and then estimated by Ordinary Least Squares (OLS). The result is a GLS estimation that corrects for autocorrelation and crosscorrelation. This is done for each regression model in Tables 4.3 to 4.7. The results from the GLS estimation are similar to those reported in this paper; the coefficients with GLS are identical to OLS but the test statistics are different. The p-values with GLS are very similar but some are slightly smaller than the p-values obtained with OLS using portfolios. However, none of the pvalues are improved to the point of changing the inference. Therefore the cross-correlation and autocorrelation does not appear to cause significant econometric problems.

\subsubsection{Public Hearings Event Date}

When calculating the trading portfolio returns, I set the indicator variables equal to -1 if they were associated with a decrease in the likelihood of a regulatory change (see section 4.7) and is set equal to 1 otherwise. The effect of announcement date $\mathrm{D}_{3}$ on capital market expectations was not clear. Announcement date $\mathrm{D}_{3}$ is associated with two days of public hearings held on October 19 and 19, 1995. It is unclear whether the discussions at the hearings led to an increase or decrease in the likelihood of the regulatory change, therefore I let the indicator variable $\mathrm{D}_{3}$ take a value of one in the calculation of trading returns. In this section I test whether the results in this paper change if the indicator variable $\mathrm{D}_{3}$ is set equal to -1 instead. The result (not tabulated) is that assigning a value of -1 to variable $\mathrm{D}_{3}$ does not change the sign of the coefficients on trading portfolio returns or the statistical significance of the parameter estimates.

\subsection{Conclusion}

On August 8, 1997 the Food and Drug Administration (FDA) announced it would relax the rules for Direct-to-Consumer Advertising (DTCA) of prescription drugs. This decision was the final outcome of deliberations that began in earnest in 1995, when a policy group threatened 
to sue the FDA under the First Amendment if it didn't change the rules to DTCA. This paper is an event study of the share price reaction to this regulatory change.

A search for news releases during the time period of 1995 to 1997 reveals seven announcements that pertain to this event. The capital market reaction on these announcement dates is estimated with a regression model that incorporates market model variables (an intercept and a market return index) as well as indicator variables that capture abnormal returns on each announcement date. The model is estimated for the 158 firms in the Pharmaceutical Preparation Manufacturing category of the North American Industry Classification System (NAICS) that had returns data from 1995 to 1997.

The following three announcement dates are associated with statistically significant abnormal returns. On August 31, 1995 the pharmaceutical firms in my sample earned abnormal returns of $3 \%$ when the FDA announced it would be holding public hearings to solicit input on the issue of DTCA. On April 1, 1997 the capital markets responded negatively to a report by the Wall Street Journal about a "sharp division" between what marketers believed should be included in the television advertisements. The response on this date resulted in abnormal returns of $3.36 \%$. The net effect of the two announcement dates is not significantly different from zero. The third significant announcement date was on August 8, 1997 when the FDA announced it would adopt the new DTCA regulation. The capital market response on this date was negative, with abnormal returns of $-2.16 \%$, but only for the small subset of firms that would eventually use DTCA as part of their marketing strategy.

The results suggest that the capital market was enthusiastic about changes in DTCA regulation when the idea was proposed in 1995, but changed its perception of the benefits of DTCA in 1997. It is plausible that the "sharp division" among marketers was connected to a clearer understanding of the new rules of DTCA, and that the capital markets reacted to the terms of DTCA rather than to the actual dispute between marketers. Once the terms of the new 
regulation were clear, the economic implications were that DTCA would not provide pharmaceutical firms with excess profits as originally anticipated.

The negative abnormal returns earned by the thirteen firms that used DTCA is potentially explained by the Brekke and Kuhn (2006) model, which shows that there are costs and benefits to DTCA. The benefits come from the expansion of the therapeutic market as more people seek treatment for a particular disorder. The costs are from increased competition as firms increase their detailing efforts (marketing to physicians) within the therapeutic market. It is conceivable that firms that used DTCA lost some of their profit margins due to increased detailing.

The market reaction for a given pharmaceutical firm is expected to be a function of characteristics that relate to revenues from DTCA. Abnormal returns are predicted to be larger for firms that sell prescription drugs under patent protection. To investigate this characteristic, firms are categorized according to the products they sell (firm-type). Abnormal returns are also expected to be a function of the firm's sales potential. The proxies used for sales potential are sales intensity (sales divided by total assets) and R\&D intensity ( $R \& D$ divided by total assets). Since sales are generally expected to persist into the future, then future sales are associated with current sales intensity. Future sales are also associated with R\&D spending, because products in the R\&D pipeline are expected to generate future revenues. I estimate abnormal returns by separating firms into portfolios that are designed to capture these characteristics. In addition to exploring individual announcement dates, the analysis considers the aggregate effect of the event. My tests do not identify any significant differences along the firm characteristics investigated in this paper. The lack of results may be caused by confounding effects due to firm-types. For example, most of the firms in the high $\mathrm{R} \& \mathrm{D}$ intensity portfolio are Biotech companies. It is possible that the lack of significance on the coefficients from this portfolio regression is caused by the combined effect of R\&D intensity and firm-type.

To alleviate the confounding effect, cumulative abnormal returns are estimated for each firm in the sample, and the determinants of the cumulative abnormal returns are investigated in a 
regression analysis. The regression analysis is designed to allow the coefficients to vary by firmtype. The results show that firms that sell over-the-counter and generic products had abnormal returns that were increasing in their sales intensity. Cumulative returns were increasing in $R \& D$ intensity for firms that sell patented prescription drugs.

This paper provides some evidence of a share price reaction to the DTCA regulatory change. The evidence suggests that the positive abnormal returns generated in the early announcement dates were offset by negative abnormal returns generated as the DTCA guidelines evolved into their final form. While there is little evidence of differential responses based on firm characteristic explored in this paper, the results suggest that firms that invested in DTCA were made worse off by the relaxation of advertising rules. This result is not intuitive based on the conventional thinking that firms use advertising strategies that are beneficial to them, but is plausible in the context of the more complex model proposed by Brekke and Khun (2006). The combined effect of positive and negative abnormal returns results in aggregate returns that not significantly different from zero, which is different from prior literature but consistent with the findings in Chapter 2. The analysis in Chapter 2 suggests that the valuation weight on advertising investments did not increase after the regulatory change. 
Table 4. 1 Announcement Dates

Sources ${ }^{\mathrm{a}}$, Descriptions, and Indicator Variables.

\begin{tabular}{|c|c|c|c|c|}
\hline Date & Source & Event & Variable & $\begin{array}{c}\text { Expected } \\
\text { effect }\end{array}$ \\
\hline July 20,1995 & AP & $\begin{array}{l}\text { A policy group threatens to sue the FDA under the First Amendment if } \\
\text { it doesn't ease the way it regulates DTCA. }{ }^{102}\end{array}$ & $\mathrm{D}_{1}$ & + \\
\hline Aug 31,1995 & FR & $\begin{array}{l}\text { The Federal Register announces that the FDA will hold a public hearing } \\
\text { on October 18-19, } 1995 \text {, to solicit information related to the promotion } \\
\text { of prescription drug products directly to consumers. }\end{array}$ & $\mathrm{D}_{2}$ & + \\
\hline Oct $18-19,1995$ & FR & Public hearings are held. & $D_{3}$ & $?$ \\
\hline May 14, 1996 & FR & $\begin{array}{l}\text { The FDA publishes a notice indicating that the agency may loosen } \\
\text { advertising restrictions. At the same time the FDA clarifies its position } \\
\text { that ads never required pre-clearance by the FDA. }\end{array}$ & $\mathrm{D}_{4}$ & + \\
\hline Nov 26, 1996 & NYT & $\begin{array}{l}\text { The press announces that Commissioner Dr. Kessler will be leaving the } \\
\text { FDA. }\end{array}$ & $\mathrm{D}_{5}$ & + \\
\hline Apr 1,1997 & WSJ & $\begin{array}{l}\text { The Wall Street Journal states that the regulation is being debated and } \\
\text { there is a "sharp division among drug marketers" about what } \\
\text { information should be disclosed in the advertisements. }\end{array}$ & $\mathrm{D}_{6}$ & - \\
\hline Aug 8, 1997 & WSJ & $\begin{array}{l}\text { The FDA announces the change in regulation that allows DTCA with a } \\
\text { reference to a source for information on side effects instead of a full list } \\
\text { of side effects. }\end{array}$ & $\mathrm{D}_{7}$ & + \\
\hline
\end{tabular}

${ }^{a}$ The sources are: Associated Press (AP), the Federal Register (FR), the New York Times (NYT), and the Wall Street Journal (WSJ).

Table 4. 2 Distribution of Daily Returns Variable and Accounting Variables (in \$millions) for $\mathbf{n}=158$ firms.

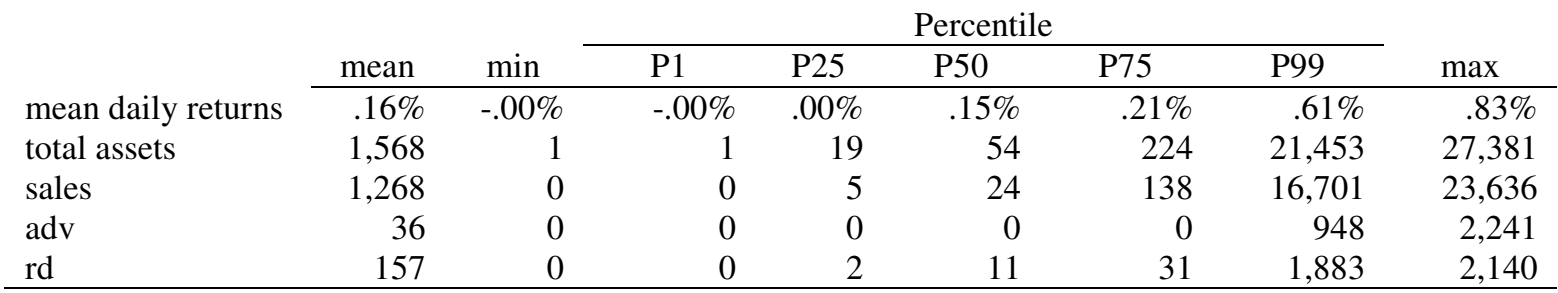

The accounting variables are the firm specific values of Compustat data reported at the year ended 1997: total assets is data \#6, sales is data \#12, adv is data \#45, rd is data \#46. The mean daily returns are the holding period returns from CRSP. A mean value of returns is calculated for each firm over the time period under investigation (759 days), and the distribution of the firm specific means is reported above.

\footnotetext{
${ }^{102}$ Under the First Amendment commercial speech need only be truthful and non-misleading. Also under the First Amendment, the policy group claimed that the pre-screening of ads required by the FDA constituted censorship.
} 
Table 4. 3 Abnormal Returns by Firm Type

Panel A: Descriptive Statistics:

The means and medians of returns (in \%), total assets (in \$millions), and accounting variables (scaled by total assets).

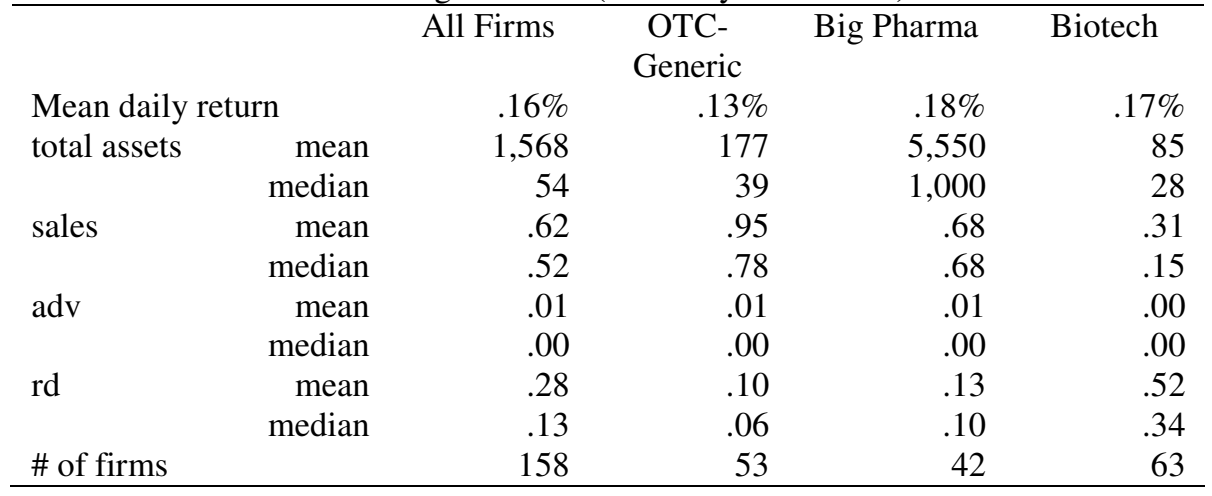

Panel B:

Model Estimation (by portfolio):

\begin{tabular}{|c|c|c|c|c|c|c|c|c|c|c|c|}
\hline \multirow[b]{2}{*}{$\alpha$} & \multicolumn{2}{|c|}{ All Firms } & \multicolumn{2}{|c|}{$\begin{array}{l}\text { OTC- } \\
\text { Generic }\end{array}$} & \multicolumn{2}{|c|}{$\begin{array}{c}\text { Big } \\
\text { Pharma }\end{array}$} & \multicolumn{2}{|c|}{ Biotech } & $\begin{array}{l}\text { OTC- } \\
\text { Generic vs. } \\
\text { Big Pharma }\end{array}$ & $\begin{array}{c}\text { OTC- } \\
\text { Generic vs. } \\
\text { Biotech }\end{array}$ & \multirow{2}{*}{$\begin{array}{l}\text { Big Pharma } \\
\text { vs. Biotech } \\
.0002\end{array}$} \\
\hline & .0006 & $*$ & .0005 & $\ddagger$ & .0008 & $*$ & .0006 & $\ddagger$ & -.0003 & -.0001 & \\
\hline$\beta$ & .9014 & $*$ & .7120 & $*$ & .9422 & $*$ & 1.042 & $*$ & -.2302 & -.3300 & -.0998 \\
\hline$\delta_{1} \quad(+)$ & .0033 & & .0053 & & -.0016 & & .0050 & & .0069 & .0003 & -.0066 \\
\hline$\delta_{2} \quad(+)$ & .0100 & * & .0084 & $\ddagger$ & .0078 & $\dagger$ & .0129 & $\dagger$ & .0006 & -.0045 & -.0051 \\
\hline$\delta_{3}(?)$ & -.0004 & & .0000 & & .0018 & & -.0021 & & -.0018 & .0021 & .0039 \\
\hline$\delta_{4} \quad(+)$ & -.0002 & & .0023 & & -.0025 & & -.0008 & & .0048 & .0031 & -.0017 \\
\hline$\delta_{5} \quad(+)$ & -.0018 & & -.0008 & & -.0041 & & -.0010 & & .0033 & .0002 & -.0031 \\
\hline$\delta_{6} \quad(-)$ & -.0112 & $*$ & -.0027 & & -.0109 & $*$ & -.0186 & $*$ & .0082 & .0159 & .0077 \\
\hline$\delta_{7} \quad(+)$ & -.0004 & & .0021 & & -.0025 & & -.0012 & & .0046 & .0033 & -.0013 \\
\hline adjusted $\mathrm{R}^{2}$ & $50 \%$ & & $28 \%$ & & $52 \%$ & & $36 \%$ & & & & \\
\hline $\begin{array}{l}\text { aggregate portf. } \\
(\text { mean } \delta)\end{array}$ & -.0001 & & .0020 & & -.0016 & & -.0009 & & .0036 & .0029 & -.0007 \\
\hline $\begin{array}{l}\text { trading portf. } \\
\quad(\text { mean } \delta)\end{array}$ & .0030 & $\dagger$ & .0027 & & .0015 & & .0042 & $\ddagger$ & -.0042 & -.0069 & -.0027 \\
\hline $\begin{array}{l}\text { aggregate portf. } \\
\left(\text { mean } \delta_{2} \text { and } \delta_{6}\right)\end{array}$ & -.0006 & & .0028 & & -.0015 & & -.0028 & & .0043 & .0056 & .0013 \\
\hline
\end{tabular}

Significant coefficients are denoted as $*$ if at the $1 \%$ level, $\uparrow$ if at the $5 \%$ level, or $\ddagger$ if at the $10 \%$ level (two-tailed test). The regressions are estimated with returns data from January 1995 to December 1997 . The models are estimated by first forming portfolios, then calculating the mean daily return for each day within each portfolio and using these mean returns as dependent variables. The independent variables are identical for each portfolio: the market returns $\left(\mathrm{r}_{\mathrm{mt}}\right)$ and the dummy variables $\left(D_{1}, D_{2}, D_{3}, D_{4}, D_{5}, D_{6}\right.$, and $\left.D_{7}\right)$.In this table, the portfolios are formed based on whether firms sell patented products (Big Pharma), over-the-counter or generic products exclusively (OTC-Generic), or operate as a biotech firm (Biotech), based on the business description in their 10-K report. The test of difference (Panel C) is obtained by combining the observations of two firm-types, then adding a set of indicator variables to represent the variables of one of the firm types. The coefficients on the indicator variables represent the increment (or difference) in the firm type's parameters. 
Table 4. 4 Abnormal Returns by R\&D Indicator Variable

Panel A: Descriptive Statistics:

The means and medians of returns (in \%), total assets (in \$millions), and

accounting variables (scaled by total assets).

\begin{tabular}{|c|c|c|c|c|c|c|c|c|c|c|c|}
\hline & & & \multicolumn{4}{|c|}{ R\&D Intensity } & \multicolumn{4}{|c|}{ R\&D Expenditures } & \\
\hline & & & \multicolumn{2}{|l|}{ High } & \multicolumn{2}{|l|}{ Low } & \multicolumn{2}{|c|}{$\mathrm{rd}>0$} & \multicolumn{2}{|c|}{$\mathrm{rd}=0$} & \\
\hline \multicolumn{3}{|c|}{ Mean daily return } & \multicolumn{2}{|c|}{$.16 \%$} & \multicolumn{2}{|c|}{$.15 \%$} & \multicolumn{2}{|c|}{$.15 \%$} & \multicolumn{2}{|c|}{$.21 \%$} & \\
\hline \multirow[t]{2}{*}{ total Asset } & \multirow{2}{*}{\multicolumn{2}{|c|}{$\begin{array}{r}\text { mean } \\
\text { median }\end{array}$}} & \multicolumn{2}{|c|}{526} & \multicolumn{2}{|c|}{2,611} & \multicolumn{2}{|c|}{1,728} & \multicolumn{2}{|c|}{148} & \\
\hline & & & & 37 & \multicolumn{2}{|c|}{98} & \multicolumn{2}{|r|}{35} & \multicolumn{2}{|c|}{35} & \\
\hline \multirow[t]{2}{*}{ sales } & \multirow{2}{*}{\multicolumn{2}{|c|}{$\begin{array}{r}\text { mean } \\
\text { median }\end{array}$}} & \multicolumn{2}{|c|}{.32} & \multirow{2}{*}{\multicolumn{2}{|c|}{$\begin{array}{l}.93 \\
81\end{array}$}} & \multicolumn{2}{|r|}{.59} & \multicolumn{3}{|c|}{.95} \\
\hline & & & \multicolumn{2}{|c|}{.16} & .81 & & \multicolumn{2}{|c|}{.48} & & .8 & \\
\hline $\mathrm{adv}$ & & & & 01 & & 1 & & .01 & & .0 & \\
\hline & & & & 00 & & 00 & & .00 & & .0 & \\
\hline $\mathrm{rd}$ & & & & 50 & & 05 & & .31 & & .0 & \\
\hline & & & & 34 & & 55 & & .16 & & .0 & \\
\hline \# of firms & & & & 79 & & 79 & & 142 & & 1 & \\
\hline $\mathrm{r}_{\mathrm{t}}=\alpha+\beta \mathrm{r}_{\mathrm{m}}$ & $\begin{array}{r}\text { Mode } \\
\delta_{1} \mathrm{D}_{1}+\varepsilon\end{array}$ & Est & $\begin{array}{l}\text { Panel B: } \\
\text { hation (by } \\
\delta_{3} D_{3}+\delta_{4}\end{array}$ & $\begin{array}{l}\text { por } \\
4+\end{array}$ & $\begin{array}{l}\text { olio): } \\
\mathrm{D}_{5}+\delta_{6} \mathrm{I}\end{array}$ & 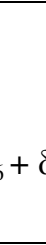 & $\partial_{7}+e_{t}$ & & $\begin{array}{r}\text { Test of } \\
r_{t} \\
+\beta^{\prime}{ }^{\prime} r \\
\text { 'denot }\end{array}$ & $\begin{array}{r}\text { H } \\
\text { diffe } \\
=\alpha+ \\
=\alpha+ \\
\mathrm{mt}+\sum \\
\mathrm{es} \mathrm{ob} \\
\mathrm{rd} \\
\end{array}$ & $\begin{array}{l}\text { anel C: } \\
\text { ences in portfolios: } \\
r_{m t}+\sum_{i} \delta_{i} D_{i}+\alpha^{\prime} \\
\delta_{i}^{\prime} D^{\prime}+e_{i}, \text { where } \\
\text { of either High or } \\
0 \text { firms. }\end{array}$ \\
\hline & & D I & ensity & & $\mathrm{R} \&$ & Ex & enditures & & High v & & Positive vs, zero \\
\hline & Higl & & Low & & $\mathrm{rd}>$ & & $\mathrm{rd}=0$ & & $\begin{array}{l}\text { Low Rd } \\
\text { Intensi }\end{array}$ & & R\&D Expenditures \\
\hline$\alpha$ & .0006 & $\ddagger$ & .0006 & $*$ & .0006 & $\dagger$ & .0015 & $*$ & .0000 & & -.0009 \\
\hline$\beta$ & 1.015 & * & .7864 & * & .9258 & * & .6654 & $*$ & .2286 & * & .2604 \\
\hline$\delta_{1}(+)$ & .0042 & & .0023 & & .0034 & & .0017 & & .0019 & & .0017 \\
\hline$\delta_{2} \quad(+)$ & .0130 & $\dagger$ & .0071 & $\dagger$ & .0104 & $*$ & .0069 & & .0059 & & .0035 \\
\hline$\delta_{3} \quad(?)$ & .0001 & & -.0016 & & -.0007 & & .0029 & & .0017 & & -.0036 \\
\hline$\delta_{4}(+)$ & -.0014 & & .0010 & & .0010 & & -.0114 & & -.0024 & & .0124 \\
\hline$\delta_{5} \quad(+)$ & -.0020 & & -.0016 & & -.0024 & & .0038 & & -.0004 & & -.0062 \\
\hline$\delta_{6} \quad(-)$ & -.0160 & $*$ & -.0062 & $\ddagger$ & -.0121 & * & -.0031 & & -.0098 & & -.0090 \\
\hline$\delta_{7} \quad(+)$ & .0002 & & -.0011 & & -.0006 & & .0017 & & .0013 & & -.0023 \\
\hline djusted $\mathrm{R}^{2}$ & $38 \%$ & & $48 \%$ & & $50 \%$ & & $9 \%$ & & & & \\
\hline $\begin{array}{l}\text { regate portf. } \\
(\text { mean } \delta)\end{array}$ & -.0001 & & -.0001 & & -.0002 & & .0005 & & .0000 & & -.0007 \\
\hline $\begin{array}{l}\text { ing portf. } \\
\text { nean } \delta \text { ) }\end{array}$ & .0043 & $\dagger$ & .0016 & & .0032 & $\dagger$ & .0013 & & .0027 & & .0019 \\
\hline $\begin{array}{l}\text { regate portf. } \\
\text { an } \delta_{2} \text { and } \delta_{6} \text { ) }\end{array}$ & -.0015 & & .0005 & & -.0008 & & .0019 & & -.0020 & & -.0027 \\
\hline
\end{tabular}

Significant coefficients are denoted as $*$ if at the $1 \%$ level, $\dagger$ if at the $5 \%$ level, or $\$$ if at the $10 \%$ level (two-tailed test). The regressions are estimated with returns data from January 1995 to December 1997 . The models are estimated by first forming portfolios, then calculating the mean daily return for each day within each portfolio and using these mean returns as dependent variables. The independent variables are identical for each portfolio: the market returns $\left(\mathrm{r}_{\mathrm{mt}}\right)$ and the dummy variables $\left(D_{1}, D_{2}, D_{3}, D_{4}, D_{5}, D_{6}\right.$, and $\left.D_{7}\right)$. In this table, the portfolios are formed two ways using data reported as at the year ended 1997. The first set of results (R\&D Intensity) separates firms between those that are above (High) or below (Low) the median value for R\&D intensity (Compustat data \#46 divided by data \#6). The second set of results (R\&D Expenditures) divides the sample between firms that report positive values ( $\mathrm{rd}>0$ ) for $\mathrm{R} \& \mathrm{D},($ Compustat data \#46), and those that don't report $R \& D(r d=0)$. The test of difference (Panel $C$ ) is obtained by adding a set of indicator variables to represent the observations of firms in one of the portfolios. The coefficients on the indicator variables represent the increment (or difference) in the portfolio's parameters. 
Table 4. 5 Abnormal Returns by Advertising Indicator Variable

Panel A: Descriptive Statistics:

The means and medians of returns (in \%), total assets (in \$millions), and

accounting variables (scaled by total assets).

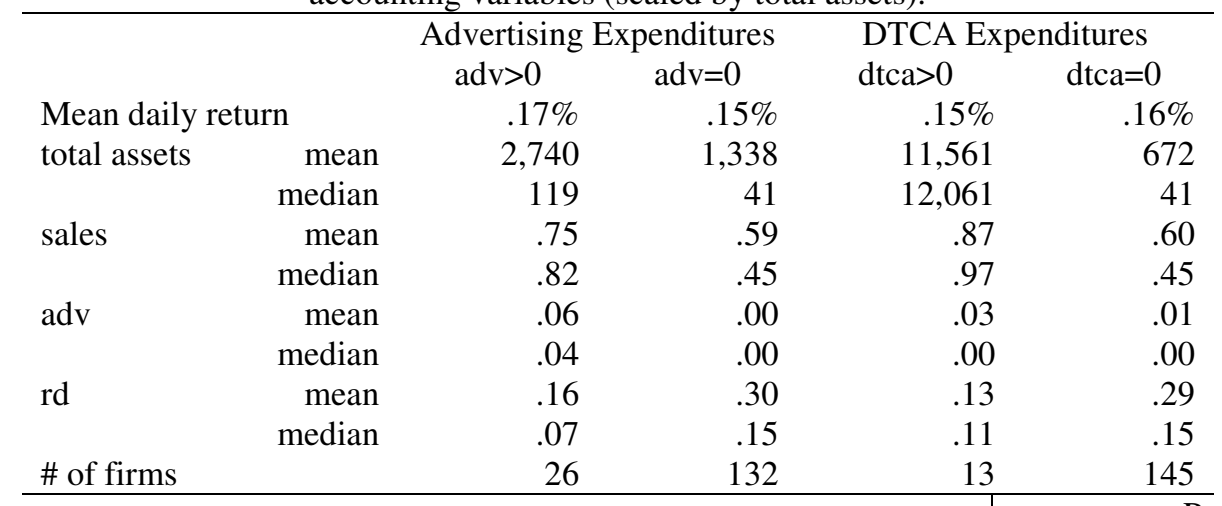

Panel B:

Model Estimation (by portfolio):

$r_{t}=\alpha+\beta r_{m t}+\delta_{1} D_{1}+\delta_{2} D_{2}+\delta_{3} D_{3}+\delta_{4} D_{4}+\delta_{5} D_{5}+\delta_{6} D_{6}+\delta_{7} D_{7}+e_{t}$

Test of differences in portfolios:

$\mathrm{r}_{\mathrm{t}}=\alpha+\beta \mathrm{r}_{\mathrm{mt}}+\sum_{\mathrm{i}} \delta_{\mathrm{i}} \mathrm{D}_{\mathrm{i}}+\alpha^{\prime}$

$+\beta^{\prime} \mathrm{r}^{\prime}{ }_{\mathrm{mt}}+\sum_{\mathrm{i}} \delta^{\prime}{ }_{\mathrm{i}} \mathrm{D}_{\mathrm{i}}^{\prime}+\mathrm{e}_{\mathrm{t}}$, where

'denotes obs. of $\mathrm{adv}>0$ or dtca $>0$

firms.

Positive vs. Positive vs. zero

zero adv. dtca

expenditures Expenditures

$\begin{array}{ccc}\mathrm{adv}>0 & \mathrm{adv}=0 \\ .0009 & .0006 & \mathrm{dtca}>0 \\ .0380 & .0005\end{array} \quad \begin{gathered}\mathrm{dtca}=0 \\ .0007\end{gathered} * \begin{array}{lll}\text { expenditures } & \text { Expenditures } \\ .0003 & -.0002\end{array}$

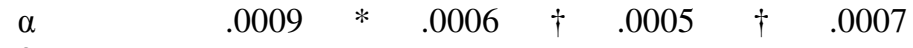

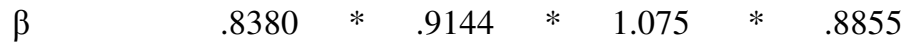

$\begin{array}{lllll}\delta_{1}(+) & -.0048 & .0050 & -.0011 & .0037\end{array}$

$\delta_{2}(+) \quad .0022$

$\delta_{3}(?) \quad-.0037$

$.0117 * \quad .0008 \quad .0110$

$\begin{array}{lll}.0003 & .0031 & -.0007\end{array}$

* $\quad-0764$

$-.0002$

$-.0764$

.1895

$-.0048$

$-.0118 \dagger$

$\delta_{4}(+) \quad-.0019$

$\begin{array}{lll}.0001 & -.0011 & -.0001\end{array}$

* $\quad-.0095$

$-.0095$

.0038

$-.0010$

$\delta_{5} \quad(+) \quad-.0032$

$-.0015$

.0015

$-.0021$

$\delta_{6}(-) \quad-.0039$

$-.0127$

$\delta_{7} \quad(+)$

$-.0031$

adjusted $\mathrm{R}^{2}$

aggregate portf.

(mean $\delta$ )

$32 \%$

.0001

* -.0020

$-.0072$

$-.0027$

.0005

$-.0009$

trading portf.

(mean $\delta$ )

aggregate portf.

$-.0016$

.0040

$-.0008$

$-.0005$

$-.0013$

$-.0005$

Significant coefficients are denoted as $*$ if at the $1 \%$ level, $\uparrow$ if at the $5 \%$ level, or $\ddagger$ if at the $10 \%$ level (two-tailed test). The regressions are estimated with returns data from January 1995 to December 1997 . The models are estimated by first forming portfolios, then calculating the mean daily return for each day within each portfolio and using these mean returns as dependent variables. The independent variables are identical for each portfolio: the market returns $\left(\mathrm{r}_{\mathrm{mt}}\right)$ and the dummy variables $\left(D_{1}, D_{2}, D_{3}, D_{4}, D_{5}, D_{6}\right.$, and $\left.D_{7}\right)$. In this table, the portfolios are formed two ways using data reported as at the year ended 1997. The first set of results (Advertising Expenditures) divides the sample between firms that report positive values ( $\mathrm{adv}>0$ ) for advertising (Compustat data \#45), and those that don't report advertising $(\mathrm{adv}=0)$. The second set of results (DTCA Expenditures) separates firms between those used DTCA in 1997 (dtca>0) according to the June 1998Med Ad News report, and firms that did not use DTCA (dtca=0). The test of difference (Panel C) is obtained by adding a set of indicator variables to represent the observations in one of the portfolios. The coefficients on the indicator variables represent the increment (or difference) in the portfolio's parameters. 
Table 4. 6 Abnormal Returns by Sales Intensity or Firm Size

Panel A: Descriptive Statistics:

The means and medians of returns (in \%), total assets (in \$millions), and accounting variables (scaled by total assets).

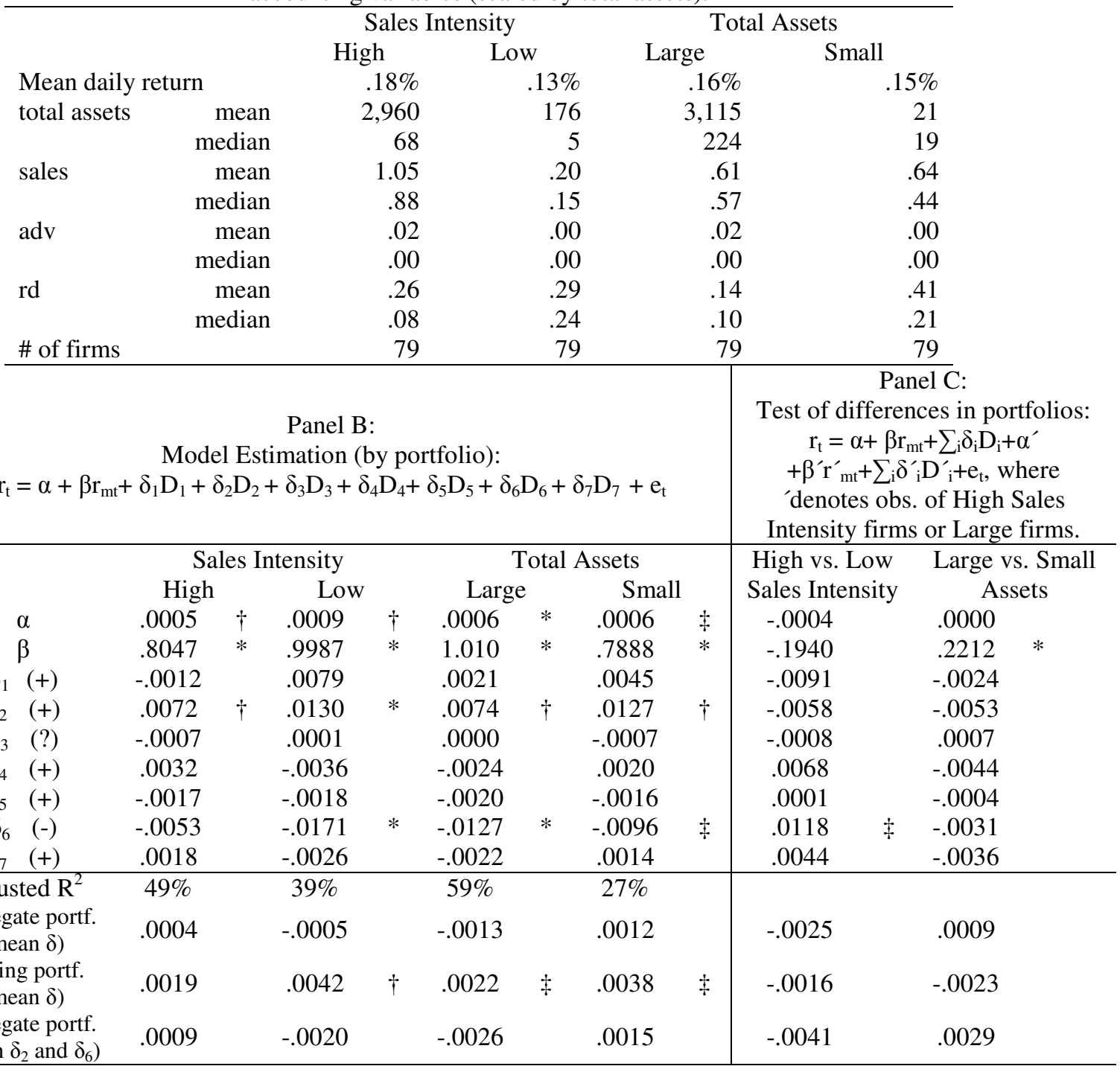

Significant coefficients are denoted as * if at the $1 \%$ level, $\uparrow$ if at the $5 \%$ level, or $¥$ if at the $10 \%$ level (two-tailed test). The regressions are estimated with returns data from January 1995 to December 1997. The models are estimated by first forming portfolios, then calculating the mean daily return for each day within each portfolio and using these mean returns as dependent variables. The independent variables are identical for each portfolio: the market returns $\left(\mathrm{r}_{\mathrm{mt}}\right)$ and the dummy variables $\left(\mathrm{D}_{1}, \mathrm{D}_{2}, \mathrm{D}_{3}, \mathrm{D}_{4}, \mathrm{D}_{5}, \mathrm{D}_{6}\right.$, and $\left.\mathrm{D}_{7}\right)$. In this table, the portfolios are formed two ways using data reported as at the year ended 1997. The first set of results (Total Assets) divides the sample between firms that are above (Large) or below (Small) the median value for total assets (Compustat data \#6). The second set of results (Sales Intensity) separates firms between those that are above (High) or below (Low) the median value for sales intensity (Compustat data \#12 divided by data \#6). The test of difference (Panel C) is obtained by adding a set of indicator variables to represent the observations in one of the portfolios. The coefficients on the indicator variables represent the increment (or difference) in the portfolio's parameters. 


\section{Table 4. 7 Distribution of the Variables for Cumulative Abnormal Returns Regression}

\begin{tabular}{|c|c|c|c|c|c|c|c|c|}
\hline & & & & & Percentil & & & \\
\hline & mean & $\min$ & P1 & P25 & P50 & P75 & P99 & $\max$ \\
\hline car & -.05 & -.72 & -.37 & -.18 & -.05 & .09 & .61 & .86 \\
\hline size & 4.5 & -.37 & -.11 & 2.95 & 3.99 & 5.41 & 10.1 & 10.2 \\
\hline saleint & .62 & 0 & 0 & .14 & .51 & .88 & 2.93 & 5.88 \\
\hline$r d i n t$ & .28 & 0 & 0 & .05 & .14 & .34 & 1.38 & 7.79 \\
\hline
\end{tabular}

Table 4. 8 Determinants of Cumulative Abnormal Returns

Model:car $=\alpha+\alpha_{\mathrm{p}}$ pharma_dum $_{j}+\alpha_{\mathrm{b}}$ bio_dum ${ }_{j}+\beta_{\mathrm{sale}}$ saleint $_{j}+\beta_{\mathrm{psale}}$ pharma_sale ${ }_{j}$ $+\beta_{\text {bsale }}$ bio_sale $_{j}+\beta_{\mathrm{rd}} r d i n t_{j}+\beta_{\mathrm{prd}}$ pharma_rd $d_{j}+\beta_{\mathrm{brd}}$ bio_rd ${ }_{j}+\beta_{\mathrm{size}}$ size $_{j}+\beta_{\mathrm{psize}}$ pharma_size ${ }_{j}$

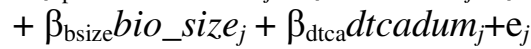

\begin{tabular}{|c|c|c|c|}
\hline Variable & \multicolumn{2}{|c|}{ Parameter estimate } & $\begin{array}{c}\mathrm{p}- \\
\text { value }\end{array}$ \\
\hline Intercept & $\alpha$ & -.0035 & .97 \\
\hline pharma_dum & $\alpha_{p}$ & -.1336 & .46 \\
\hline bio_dum & $\alpha_{b}$ & -.1008 & .53 \\
\hline saleint & $\beta_{\text {sale }}$ & .0701 & .04 \\
\hline pharma_sale & $\beta_{\text {psale }}$ & -.1423 & .20 \\
\hline bio_sale & $\beta_{\text {bsale }}$ & -.0395 & .66 \\
\hline rdint & $\beta_{\mathrm{rd}}$ & -.1596 & .51 \\
\hline pharma_rd & $\beta_{\mathrm{prd}}$ & .6652 & .06 \\
\hline bio_rd & $\beta_{\text {brd }}$ & .1484 & .55 \\
\hline size & $\beta_{\text {size }}$ & -.0102 & .65 \\
\hline pharma_size & $\beta_{\text {psize }}$ & .0156 & .58 \\
\hline bio_size & $\beta_{\text {bsize }}$ & .0126 & .70 \\
\hline dtcadum & $\beta_{\mathrm{dtca}}$ & .0646 & .49 \\
\hline & $\begin{array}{l}\text { \# ofob } \\
\text { adj- } R^{2}\end{array}$ & $\begin{array}{l}15 \\
49\end{array}$ & \\
\hline
\end{tabular}

The cumulative abnormal returns $\left(\right.$ car $\left._{j}\right)$ are calculated for each firm as the sum of the residuals for 3-day event windows surrounding each of the seven event dates listed in Table 4.1. The residuals are from the market model in equation 4.2. The explanatory variables are designed to estimate the determinants of cumulative abnormal returns by firm-type. The determinants are sales intensity (saleint), R\&D intensity (rdint) and size. The base firm-type is OTC-Generic firms. The incremental effect of the determinants for Big Pharma firms are obtained by including an indicator variable equal to one if the firm is of the type Big Pharma, then multiplying the indicator variable by saleint, rdint, and size to obtain pharma_sale, pharma_rd, and pharma_size. A similar method produces bio_sale, bio_rd, and bio_size to estimate the incremental effects for Biotech firms. The variables are described in Appendix A. 


\section{Table 4. 9 Determinants of Cumulative Abnormal Returns}

By Firm Type (Based on the coefficients from Table 4.8) OTC-Generic

\begin{tabular}{|c|c|c|c|c|c|c|c|c|c|}
\hline \multirow[b]{3}{*}{ Inter } & \multicolumn{3}{|c|}{ OTC-Generic } & \multicolumn{3}{|c|}{ Big Pharma } & \multicolumn{3}{|c|}{ Biotech } \\
\hline & & neter & p-value & paral & & p-value & param & & $\mathrm{p}$-value \\
\hline & $\alpha$ & -.0035 & .97 & $\alpha+\alpha_{p}$ & -.1371 & .29 & $\alpha+\alpha_{b}$ & 1043 & .30 \\
\hline saleint & $\beta_{\text {sale }}$ & .0701 & .04 & $\beta_{\text {sale }}+\beta_{\text {psale }}$ & -.0722 & .49 & $\beta_{\text {sale }}+\beta_{\text {bsale }}$ & .0306 & .71 \\
\hline rdint & $\beta_{\mathrm{rd}}$ & -.1596 & .51 & $\beta_{\mathrm{rd}}+\beta_{\mathrm{prd}}$ & .5056 & .05 & $\beta_{\mathrm{rd}}+\beta_{\mathrm{brd}}$ & .0112 & .72 \\
\hline $\begin{array}{c}\text { size } \\
\text { dtcadum }\end{array}$ & $\beta_{\text {size }}$ & -.0102 & .65 & $\begin{array}{c}\beta_{\text {size }}+\beta_{\text {psize }} \\
\beta_{\text {dtca }}\end{array}$ & $\begin{array}{l}.0054 \\
.0649\end{array}$ & $\begin{array}{l}.76 \\
.49\end{array}$ & $\beta_{\text {size }}+\beta_{\text {bsize }}$ & .0024 & .92 \\
\hline
\end{tabular}

The $\mathrm{p}$-values are from F-tests of the linear combination of the coefficients. The variables are described in Appendix A. 


\section{CHAPTER 5 Concluding Remarks}

This thesis explores several issues concerning valuation in the pharmaceutical industry. The purpose of my analysis is to achieve a better understanding of the activities that create value for pharmaceutical firms, as well as explore some of the strengths and limitations inherent in some of the valuation models used in capital markets research. To accomplish these objectives, I develop a pharmaceutical valuation model and estimate the value of the three types of investments that I assume are important in this industry: investments in Research and Development (R\&D), advertising, and production facilities. The valuation model is used to explore several issues. In Chapter 2 the model is used to estimate the market value associated with the three types of investments and then estimate the component of market value that represents economic rents. In Chapter 3 an accounting system is added to the model to explore the effect of adding some accruals. In Chapter 4, a change in the value of advertising is investigated by testing whether the relaxation of advertising rules affected the market value of firms in the pharmaceutical industry.

One contribution of this thesis is that it provides an estimate of the valuation weight that the capital market places on each of the three types of investments in my model. Prior research shows that R\&D investments have a positive association with market value, which is the result I obtain in Chapter 2. Prior literature on advertising investments finds mixed results, which is consistent with my analysis since my estimate of the value of advertising is sensitive to whether I include or exclude certain firms in the sample. The results in this paper provide new information on the value of investments in production facilities, since these investments are not generally tested in accounting valuation research. My results show that expenditures on production facilities are positively priced in the capital market. 
Another contribution of this thesis is that I use modeling techniques to isolate the component of the valuation weight that theoretically represents economic rents. Using empirical proxies of persistence and assumptions regarding required rates of return on capital, I am able to estimate the magnitude of economic rents generated by one dollar invested in each of the three types of investments. The analysis on economic rents is an important contribution from Chapter 2 because to my knowledge, this is the first paper that uses the theoretical structure of valuation models to isolate a component that represents economic rents, and then uses accounting information to estimate the magnitude of the rents. A possible extension to this research would be to estimate the magnitude of economic rents across industries, or test whether my estimates of rents are associated with measures of market power from the economics literature.

In Chapter 3, I add a system of accruals and test whether the valuation model with accounting accruals is better representation of the true data generating process than the cash flow model from Chapter 2. In addition, I compare the performance of these models to one that has been used frequently in accounting research: a valuation model with only the book value of equity and net income as explanatory variables. This analysis adds to the literature on residual income valuation models. My findings suggest that accruals may be incrementally informative over cash flows, but the evidence is weak. The test could be improved by incorporating accruals that are expected to be richer in information than the ones I use, such as working capital accruals. My results provide evidence that disaggregated accounting and cash flow data are better than summary accounting measures at explaining the variability in the market value of pharmaceutical firms. This test could be repeated on a larger sample of firms to obtain more evidence on the usefulness of disaggregated data, which is a current topic in accounting since international accounting standards may soon require firms to present more line items in their financial statements $^{103}$.

\footnotetext{
${ }^{103}$ See the discussion paper by the International Accounting Standards Board: Preliminary Views on Financial Statement Presentation, Oct 2008.
} 
The analysis in Chapter 4 is not directly related to the valuation models developed in this paper but it clarifies the results obtained on the advertisement investment variable in Chapter 2 .

One of the tests in Chapter 2 relates to a change in advertising regulation. In 1997 the FDA announced it would relax the rules for the direct-to-consumer advertising of prescription drugs. Although I expect this to lead to an increase in the valuation weight on advertising, the evidence from Chapter 2 suggests that the valuation weight may have decreased. Chapter 4 is an event study of the capital market reaction to this regulatory change. Based on the results from Chapter 4, pharmaceutical firms earned positive abnormal returns when the regulatory change was initially anticipated, but as the final form of the guideline became known, these gains were offset by negative abnormal returns, yielding an overall return that does not differ from zero. In fact, on the date that the new guideline was finally adopted, a subset of firms that can be verified to have used DTCA experienced a somewhat surprising abnormal drop in share price. These results are different from those obtained in prior literature. It is possible that my results differ due to the different sample composition and more robust estimation method. However, despite the fact that these results contrast to prior research, they can be shown to be consistent with a theoretical model that suggests that gains from the market-expanding effect of DTCA could be dominated by losses from competition within the therapeutic markets. This research outcome could be of interest to marketing academics and FDA regulators.

While this thesis makes several contributions to capital markets research, many assumptions are made in order to produce tractable results. As with most empirical work, the results are only valid to the extent that the assumptions are reasonable. For the theoretical valuation model, the main assumption relates to the set of linear information dynamics that I propose for a prototypical pharmaceutical firm. The assumed information dynamics generate the valuation weights that I use in Chapter 2 to estimate the value of investments and the magnitude of economic rents. The information dynamics are not likely to be an exact representation of the pharmaceutical firms' operations, but I presume that they capture the first order effect of the main 
value-driving activities in this industry. When the theoretical model is empirically tested, the empirical proxy variables are measured with error, which I find to be particularly severe for the advertising investment proxy. The noisiness in my constructs is also likely to be problematic for the variables used to estimate economic rents since these variables require additional assumptions and estimates. In addition to measurement error there is always a risk that the empirical model is misspecified. While I include sensitivity analysis to moderate the econometric concerns in this paper, one potential improvement is to search for improved statistical techniques that will produce more robust estimates of valuation weights and economic rents.

The models in this thesis provide a good basis for valuation research on pharmaceutical firms. The models are designed to allow for an investigation of issues that are important in this industry. But the information in the model is not an exhaustive list of variables that could explain the market value of pharmaceutical firms. Further work could be done to incorporate some nonaccounting variables into the model. For example, Joos (2002) and Shortridge (2004) include New Drug Applications (NDAs) as an explanatory variable in their models, and Xu et al. (2007) include clinical data and strategic alliance information in theirs. Alternatively, the variables in my model could be refined. For example, the advertising variable could be separated into dollars spent on detailing and medical journal advertising as in Bowen and Shores (2002), and data may now be available to construct measures of dollars spent on television advertisements. Another possible extension is to include more lagged variables in my model to depict the actual length of the information dynamics. My valuation model could be adjusted to incorporate these variables. More importantly, the techniques used to tailor my valuation models for pharmaceutical firms could be repeated in a number of different settings. 


\section{BIBLIOGRAPHY}

Acemoglu D. \& Linn, J. (2004). Market size in innovation: theory and evidence from the pharmaceutical industry. Quarterly Journal of Economics 119, 1049- 1090.

Amir, E., Kirscheneheiter, M., \& Willard, K. (1997). The valuation of deferred taxes.

Contemporary Accounting Research 14, 597-622.

Angell, M. The truth about drug companies. New York: Random House, 2004.

Bagwell, K. The Economic Analysis of Advertising. U.K.: Edward Elgar Press, 2007.

Barth M.E., Beaver, W.H., Hand, J.R.M., \& Landsman, W.R. (1999). Accruals, cash flows, and equity values. Review of Accounting Studies 4, 205-229.

Beatty, A., Chamberlain, S. \& Magliolo, J. (1996). An empirical analysis of the economic implications of fair value accounting for investment securities. Journal of Accounting \& Economics 22, 43-77.

Begley, J., Chamberlain S.L., \& Li Y. (2006). Modeling goodwill for banks: a residual income approach with empirical tests. Contemporary Accounting Research, 23, 31-68.

Begley, J. \& Feltham, G.A. (2002). The relation between market values, earnings forecasts, and reported earnings. Contemporary Accounting Research 19, 1-48.

Berger, P. (1993). Explicit and implicit tax effects of the R\&D tax credit. Journal of Accounting Research 31, 131-171.

Bernardo, A.E., Chowdry B., \& Goyal A. (2007). Growth options, beta, and the cost of capital. Financial Management 36 (Summer), 5-18.

Biddle, G.C., Chen, P. \& Zhang, G. (2001). When capital follows profitability: non-linear residual income dynamics. Review of Accounting Studies 6, 229-265.

Boscaljon B. (2005). Regulatory changes in the pharmaceutical industry. International Journal of Business, 10(2), 151-164.

Bowen R.M. \& Shores, D. (2002). Determinants of economic and accounting components of residual income: an application to the pharmaceutical industry. Working Paper at the University of Washington Business School.

Brekke, K.R. \& Kuhn, M. (2006). Direct to consumer advertising in pharmaceutical markets. Journal of Health Economics, 25, 102-130.

Bryant, S.K. \&Martzoukos, S.H. (1998). The impact of the financial institutions reform, recovery, and enforcement act (FIRREA) on the value of S\&L stocks. Journal of Economics and Finance 22, 67-76.

Bublitz B. \& Ettredge M. (1989). The information in discretionary outlays: advertising, research and development. The Accounting Review 64, 108-124. 
Callen, J.L., \& Segal, D. (2005). Empirical tests of the Feltham-Ohlson (1995) model. Review of Accounting Studies 10, 409-429.

Chang, S. (2004). Ambiguous social welfare effect of price regulation under imperfect competition. Journal of Economics, 81, 53-60.

Chauvin, K.W. \& Hirschey M. (1993). Advertising, R\&D expenditures and the market value of the firm. Financial Management 22, 128-140.

Christensen P.O. \& Feltham G.A. (2003). Economics of accounting volume I, information in markets. Kluwer.

Clem, A., Cowan, A.R. \& Jeffrey, C. (2004). Market reaction to proposed changes in accounting for purchased research and development in R\&D-intensive industries. Journal of Accounting, Auditing \& Finance 19, 405-428.

Collins, D.W., Maydew, E.L., \& Weiss, I.S. (1997). Changes in the value-relevance of earnings and book values over the past forty years. Journal of Accounting and Economics 24, 39-67.

Cornett, M.M., Rezaee, Z. \&Tehranian, H. (1996), An investigation of capital market reactions to pronouncements on fair value accounting. Journal of Accounting and Economics 22, 119-154.

Courteau, L., Kao, J., \& Richardson, G. (2000). The equivalence of dividend, cash flows and residual earnigns approaches to equity valuation employing ideal terminal value expression. Accounting \& Finance 46, 553-575.

Dechow, P.M. (1994). Accounting earnings and cash flows as measures of firm performance; the role of accounting accruals. Journal of Accounting and Economics 18, 3-42.

Dechow, P.M., Hutton, A.P., \& Sloan, R.G. (1999). An empirical assessment of the residual income valuation model. Journal of Accounting and Economics, 26, 1-35.

Donohue, J. (2006). A history of drug advertising: the evolving roles of consumer and consumer protection. Milbank Quarterly 84, 659-699.

Donohue, J., Cevasco, M., \& Rosenthal, M.B. (2007). A decade of direct-to-consumer advertising of prescription drugs. The New England Journal of Medicine 357, 673-681.

Easton, P.D. \& Harris, T.S. (1991). Earnings as an explanatory variable for returns. Journal of Accounting Research 29, 19-36.

Eckard, E.W. (1991). Competition and the cigarette TV advertising ban. Economic Enquiry 29, 119-134.

Ellison, S.F. \& Wolfram, C. (2006). Coordinating on lower prices: pharmaceutical pricing under political pressure. Rand Journal of Economics 37, 324-340.

Erickson, G. \& Jacobson, R. (1992). Gaining comparative advantage through discretionary expenditures: the returns to R\&D and advertising. Management Science 38, 1264-1279. 
Fama, E.F. \& French, K.R. (1997). Industry cost of equity. Journal of Financial Economics 43, 153-193.

Feltham, G.A. \& Ohlson, J.A. (1995). Valuation and clean surplus accounting for operational and financial activities. Contemporary Accounting Research 11, 689-731.

Feltham, G.A. \& Ohlson, J.A. (1996). Uncertainty resolution and the theory of depreciation measurement. Journal of Accounting Research, 34, 209-234.

Francis, J., Olsson, P., \& Oswald, D.R. (2000). Comparing the accuracy and explainability of dividend, free cash flow, and abnormal earnings equity value estimates. Journal of Accounting Research 38, 45-69.

Frank, R.G. \& Salkever, D.S. (1997). Generic entry and the pricing of pharmaceuticals. Journal of Economics \& Management Strategy 6, 75-90.

Frankel, R. \& Lee, C.M.C. (1998). Accounting valuation, market expectations, and crosssectional stock returns. Journal of Accounting Economics 25, 283-219.

Gara, S.C. (2007). Market reaction to accounting regulatory changes: adoption of SFAS 142.

Journal of American Academy of Business 10, 289-295.

Hand, J.R.M. \& Landsman, W.R. (2005). The pricing of dividends in equity valuation. Journal of Business Finance \& Accounting 32, 435-469.

Healy, P.M., Myers S.C., \& Howe C.D. (2002). R\&D accounting and the tradeoff between relevance and objectivity. Journal of Accounting Research, 40, 677-710.

Hirschey, M. (1982). Intangible capital aspects of advertising and R\&D expenditures. Journal of Industrial Economics 20, 375-390.

Hirschey, M. \& Weygandt J.J. (1985), Amortization policy for advertising and research and development expenditures. Journal of Accounting Research 23,

Hsieh, P.H., Mishra, C.S. \& Gobeli, D.H. (2003). The return on R\&D versus capital expenditures in pharmaceutical and chemical industries. Engineering Management, 50, 141-150.

Iizuka, T. \& Jin, G.Z. (2005). The effect of prescription drug advertising on doctor visits. Journal of Economics \& Management Strategy 17, 701-727.

Joos, P. (2002). Explaining cross-sectional differences in market-to-book ratios in the pharmaceutical industry, Working Paper at Rochester University.

Joos, P. \& Zhdanov, A. (2008). Earnings and equity valuation in the biotech industry: theory and evidence. Financial Management 37, 431-459.

Karakaya F. (2002). Barriers to entry in industrial markets. The Journal of Business \& Industrial Marketing 17, 379-388.

Kothari, S.P. (2001). Capital markets research in accounting. Journal of Accounting and Economics 31, 105-231. 
Kyle, M.K. (2007). Pharmaceutical price controls and entry strategies. The Review of Economics and Statistics 89, 88-99.

Lamdin, D.J. (2001). Implementing and interpreting event studies of regulatory changes. Journal of economics and business 34, 171-183.

Lev B. \& Sougiannis T. (1996). The capitalization, amortization, and value-relevance of R\&D. Journal of Accounting and Economics, 21, 107-38.

Lo K. (2005). The effect of scale differences on inferences in accounting research: coefficient estimates, tests of incremental association, and relative value relevance. Working Paper at the University of British Columbia.

Lo, K. \& Lys, T. (2000). The Ohlson model: contribution to valuation theory, limitations, and empirical applications. Journal of Accounting Auditing and Finance 15, 337-367.

Lundholm, R. \& O'Keefe, T.O. (2001). Reconciling value estimates from the discounted cash flow model and the residual income model. Contemporary Accounting Research 18, 311-335.

Morbey, G.K. (1988). R\&D: its relationship to company performance. Journal of Product Innovation Management 5, 191-200.

Myers, J.N. (1999). Implementing residual income valuation with linear information dynamics. The Accounting Review, 74, 1-28.

Ohlson, J.A. (1995). Earnings, book values, and dividends in security valuation. Contemporary Accounting Research 11, 661-687.

Ohlson, J.A. (1999). On transitory earnings. Review of Accounting Studies 4, 145-162.

Penman, S.H. \& Sougiannis, T. (1998). A comparison of dividend, cash flow, and earnings approach to equity valuation. Contemporary Accounting Research 15, 343-383.

Richardson, G. \& Tinaikar, S. (2004). Accounting based valuation models: what have we learned? Accounting and Finance 44, 223-255.

Rosenthal, M.B., Berndt, E.R., Donohue, J.M., Frank, R.G. \& Epstein, A.M. (2002). Promotion of prescription drugs to consumers. New England Journal of Medicine 346, 498-505.

Scherer, F.M. (1965). Corporate inventive output, profits, and growth. The Journal of Political Economy 73, 290-297.

Schipper, K. \& Thompson, R. (1983). The impact of merger-related regulations on the shareholders of acquiring firms. Journal of Accounting Research (Spring), 184-221.

Scott Morton, F.M. (1999). Entry decisions in the generic pharmaceutical industry. Rand Journal of Economics 30, 421-440. 
Seiler, M.J. (2000). The efficacy of event-study methodologies: measuring ereit abnormal performance under conditions of induced variance. Journal of Financial and Strategic Decisions $13,101-112$.

Shevlin, T. (1991). The valuation of R\&D firms with R\&D limited partnerships. The Accounting Review 66, 1-21.

Shortridge, R.T. (2004). Market valuation of successful versus non-successful R\&D efforts in the pharmaceutical industry. Journal of Business Finance \& Accounting 31, 1301-1325.

Sougiannis, T. (1994). The accounting based valuation of corporate R\&D. The Accounting Review 69, 44-68.

Torabzadeh K.M., Woodruff C.G., \& Nilanjan S. (1998). FDA decisions on new drug applications and the market value of pharmaceutical firms. American Business Review, June 1998.

Vuong, Q.H. (1989). Likelihood ratio tests for model selection and non-nested hypotheses. Econometrica 57, 307-333.

Xu, B., Magnan M.L., \& André P.E. (2007). The stock market valuation of R\&D information in biotech firms. Contemporary Accounting Research 24, 1291-1318. 


\section{APPENDIX A Definition and Construct of the Empirical Variables}

\begin{tabular}{|c|c|c|}
\hline Variable & Definition & Construct \\
\hline $\operatorname{adjadv}$ & $a d v$ variable adjusted for NPV calculation & $a d v^{*}\left(\mathrm{R}_{\mathrm{j}} /\left(\mathrm{R}_{\mathrm{j}}-\delta_{\mathrm{ja}}\right)\right.$ \\
\hline adjrd & $r d$ variable adjusted for NPV calculation & $r d^{*}\left(\mathrm{R}_{\mathrm{i}} /\left(\mathrm{R}_{\mathrm{j}}-\delta_{\mathrm{jir}}\right)\right.$ \\
\hline adjprodfac & prodfac variable adjusted for NPV calculation & $\operatorname{prodfac} *\left(\mathrm{R}_{\mathrm{j}} /\left(\mathrm{R}_{\mathrm{j}}-\delta_{\mathrm{jf}}\right)\right.$ \\
\hline adjvo & $v o$ variable adjusted for NPV calculation & $v o-a d v-r d-p r o d f a c$ \\
\hline$a d v$ & advertising investments & Compustat data \#45 \\
\hline amort & amortization & Compustat data \#65 \\
\hline$B_{1}, B_{2}, B_{3}$ & beta period indicator variable & $\begin{array}{l}\text { a variable equal to one if the date is within the beta } \\
\text { period corresponding to the figure in section } 4.10 .2\end{array}$ \\
\hline bio_dum & Biotech indicator variable & a variable equal to one if firm type is Biotech \\
\hline bio_sale & Biotech sale indicator variable & a variable equal to saleint if firm type is Biotech \\
\hline bio_size & Biotech size indicator variable & a variable equal to size if firm type is Biotech \\
\hline bio_rd & Biotech R\&D indicator variable & a variable equal to $r$ dint if firm type is Biotech \\
\hline caprd & $\begin{array}{l}\text { capitalized intangibles (proxy for purchased } \\
\text { R\&D) }\end{array}$ & Compustat (data\#33 + data\#65 - lag(data\#33)) \\
\hline car & cumulative abnormal returns & $\begin{array}{l}\text { an estimate of abnormal returns obtained from } \\
\text { aggregating residuals from the market model } \\
\text { around all 3-day event windows according to the } \\
\text { method described in section } 4.9 \text {. }\end{array}$ \\
\hline crg & cash receipts on generic drugs & Notes to the financial statements \\
\hline crp & cash receipts on patent drugs & Notes to the financial statements \\
\hline $\begin{array}{l}D_{1}, D_{2}, D_{3}, D_{4} \\
D_{5}, D_{6}, D_{7}\end{array}$ & announcement window indicator variables & $\begin{array}{l}\text { a variable equal to one if the date is within the } \\
\text { event window identified by the subcript and its } \\
\text { association with events listed in Table } 4.1 \text {. }\end{array}$ \\
\hline$\overline{D_{j} / E_{j}}$ & debt to equity ratio for firm $j$ & Compustat ((data\#9 + data\#34)/ mve ) for firm $j$ \\
\hline dep & depreciation & Compustat data \#103 \\
\hline dtcadum & $\begin{array}{l}\text { a dummy variable equal to one if the firm used } \\
\text { direct-to-consumer advertising }\end{array}$ & List of firms from Med Ad News, June 1998 \\
\hline$f a$ & financial assets & Compustat (data\#6 - oa-data\#181) \\
\hline firm type & $\begin{array}{l}\text { BIG PHARMA firms have at least some revenues } \\
\text { OTC-Generic firms sell generic and/or over-the-ce } \\
\text { BIOTECH earn license revenues, usually from the }\end{array}$ & $\begin{array}{l}\text { on patented drugs } \\
\text { ounter (non-prescription) drugs but not patent drugs } \\
\text { Patent firms that sell their products }\end{array}$ \\
\hline int & intangibles & Compustat data\#33 \\
\hline mve & market value of equity & Compustat (data \#25 x data \#199) \\
\hline$n i$ & net income before extraordinary items & Compustat data \#18 \\
\hline$o a$ & operating assets & Compustat (data\#8 + data\#33) \\
\hline$p e$ & property, plant, and equipment (net) & Compustat data\#8 \\
\hline pharma_dum & Big Pharma indicator variable & a variable equal to one if firm type is Big Pharma \\
\hline pharma_sale & Big Pharma sale indicator variable & $\begin{array}{l}\text { a variable equal to saleint if firm fype is Big } \\
\text { Pharma }\end{array}$ \\
\hline pharma_size & Big Pharma size indicator variable & a variable equal to size if firm fype is Big Pharma \\
\hline pharma_rd & Big Pharma R\&D indicator variable & a variable equal to $r$ dint if firm fype is Big Pharma \\
\hline postadv & $\begin{array}{l}\text { a variable representing advertising expense in } \\
\text { the years after } 1997\end{array}$ & $\begin{array}{l}\text { postadv is equal to } a d v \text { if the year is after } 1997 \text {, } \\
\text { and zero otherwise. }\end{array}$ \\
\hline prodfac & investment in production facilities & $\begin{array}{l}\text { Compustat data \#128 if available or (data\#8 }+ \\
\text { data\#14 - data\#65 - lag(data\#8)) }\end{array}$ \\
\hline$R_{j}$ & firm-specific discount rate & $1+\left(.05+.02\left(1.40+1.40 * D_{j} / E_{j}\right)\right)$ \\
\hline$r_{j t}$ & holding period returns for firm $j$ at time $t$ & $C R S P$ date (ret) \\
\hline
\end{tabular}




\begin{tabular}{|c|c|c|}
\hline Variable & Definition & Construct \\
\hline$r_{m t}$ & market returns at time $t$ & $\begin{array}{l}\text { For main test: } C R S P \text { data (vwretd) } \\
\text { For robustness test: } C R S P \text { date (ewretd) }\end{array}$ \\
\hline roi & residual operating income & $\begin{array}{l}\text { For main test: } c r g+c r p-r d \text {-adv-dep-amort }-6 \% \mathrm{x} \\
\text { lag }(o a) \\
\text { For robustness test: Compustat data } \# 178-6 \% \mathrm{x} \\
\text { lag }(o a)\end{array}$ \\
\hline$r d$ & research and development expense & Compustat data\#46 \\
\hline rdint & R\&D intensity & Compustat data\#46 divided by data \#6 \\
\hline sales & sales & Compustat data\#12 \\
\hline saleint & sales intensity & Compustat data\#12 divided by data \#6 \\
\hline size & size & the natural log of total assets \\
\hline $\operatorname{sga}$ & selling, general, and administration expense & Compustat data\#189 \\
\hline$-s_{i t}$ & $\begin{array}{l}\text { scaling variable (prior period value of total } \\
\text { assets) }\end{array}$ & lag (Compustat (data\#6)) \\
\hline total assets & total assets & Compustat data\#6 \\
\hline$v$ & market value of equity & Compustat (data \#25 x data \#199) \\
\hline vo & value of operating assets & $v-f a$ \\
\hline$\delta_{\mathrm{ja}}$ & an estimate of $a d v$ persistence for firm $j$ & obtained from the regression: $a d v_{j t}=\delta_{j a} a d v_{j, t-1}+\varepsilon_{j t}$ \\
\hline$\delta_{\mathrm{jr}}$ & an estimate of $r d$ persistence for firm $j$ & obtained from the regression: $r d_{j t}=\delta_{j r} r d_{j, t-1}+\varepsilon_{j t}$ \\
\hline$\delta_{\mathrm{jf}}$ & an estimate of prodfac persistence for firm $j$ & $\begin{array}{l}\text { obtained from the regression: } \text { prodfac }_{j t}= \\
\delta_{j f \text { prodfac }}=\end{array}$ \\
\hline
\end{tabular}

\section{Compustat data definitions}

\#6

$\# 8$

\#9

$\# 12$

$\# 14$

$\# 25$

\#33

\#34

\#45

\#46 total assets

net property, plant, and equipment long term debt

sales

depreciation and amortization

common shares outstanding

intangibles

debt in current liabilities

advertising expense

research and development expense
\#60 book value of equity

\#65 amortization of intangibles

\#128 capital expenditures (cflow stmt)

\#103 depreciation expense

\#178 operating income after depreciation

\#181 total liabilities

\#189 selling, general, and admin. expense

\#199 price - fiscal year close

\#388 in-process R\&D expense 


\section{APPENDIX B Derivation of Valuation Weights}

\section{B.1 Derivation of the Cash Flow Valuation Model}

Conjecture that the value of operating assets is a function of the cash flow variables for any time $t$ :

$\mathrm{vo}_{\mathrm{t}}=\pi_{\mathrm{g}} \mathrm{crg}_{\mathrm{t}}+\pi_{\mathrm{p}} \mathrm{crp}_{\mathrm{t}}+\pi_{\mathrm{r}} \mathrm{rd}_{\mathrm{t}}+\pi_{\mathrm{a}} \mathrm{adv}_{\mathrm{t}}+\pi_{\mathrm{f}} \operatorname{prodfac}_{\mathrm{t}}$

Expected value of operating assets for $t+1$ is:

$$
\mathrm{E}\left[\mathrm{vo}_{\mathrm{t}+1}\right]=\pi_{\mathrm{g}} \mathrm{crg}_{\mathrm{t}+1}+\pi_{\mathrm{p}} \mathrm{crp}_{\mathrm{t}+1}+\pi_{\mathrm{r}} \mathrm{rd}_{\mathrm{t}+1}+\pi_{\mathrm{a}} \mathrm{adv}_{\mathrm{t}+1}+\pi_{\mathrm{f}} \text { prodfac }_{\mathrm{t}+1}
$$

Expected cash flows for $t+1$ are:

$$
\mathrm{E}\left[\mathrm{oc}_{\mathrm{t}+1}\right]=\mathrm{crg}_{\mathrm{t}+1}+\mathrm{crp}_{\mathrm{t}+1}-\mathrm{rd}_{\mathrm{t}+1}-\mathrm{adv}_{\mathrm{t}+1}-\operatorname{prodfac}_{\mathrm{t}+1}
$$

Let $\mathrm{R}=\beta^{-1}$ and plug the above equations into equation 3.6a from Chapter 3 of this thesis: $v o_{t}=$ $\beta_{t+1}\left\{\mathrm{E}\left[o c_{t+1}+v o_{t+1}\right]\right\}$ to get:

$\pi_{\mathrm{g}} \operatorname{crg}_{\mathrm{t}}+\pi_{\mathrm{p}} \operatorname{crp}_{\mathrm{t}}+\pi_{\mathrm{r}} \mathrm{rd}_{\mathrm{t}}+\pi_{\mathrm{a}} \mathrm{adv}_{\mathrm{t}}+\pi_{\mathrm{f}} \operatorname{prodfac}_{\mathrm{t}}=\beta\left\{\mathrm{E}\left[\mathrm{crg}_{\mathrm{t}+1}+\operatorname{crp}_{\mathrm{t}+1}-\mathrm{rd}_{\mathrm{t}+1}-\operatorname{adv}_{\mathrm{t}+1}-\right.\right.$ prodfac $\left._{\mathrm{t}+1}\right]+$ $\mathrm{E}\left[\pi_{\mathrm{g}} \mathrm{crg}_{\mathrm{t}+1}+\pi_{\mathrm{p}} \mathrm{crp}_{\mathrm{t}+1}+\pi_{\mathrm{r}} \mathrm{rd}_{\mathrm{t}+1}+\pi_{\mathrm{a}} \mathrm{adv}_{\mathrm{t}+1}+\pi_{\mathrm{f}}\right.$ prodfac $\left.\left._{\mathrm{t}+1}\right]\right\}$

Collect terms:

$\pi_{\mathrm{g}} \operatorname{crg}_{\mathrm{t}}+\pi_{\mathrm{p}} \mathrm{crp}_{\mathrm{t}}+\pi_{\mathrm{r}} \mathrm{rd}_{\mathrm{t}}+\pi_{\mathrm{a}} \mathrm{adv}_{\mathrm{t}}+\pi_{\mathrm{f}} \operatorname{prodfac}_{\mathrm{t}}=\beta\left\{\mathrm{E}\left[\left(\pi_{\mathrm{g}}+1\right) \mathrm{crg}_{\mathrm{t}+1}+\left(\pi_{\mathrm{p}}+1\right) \operatorname{crp}_{\mathrm{t}+1}+\left(\pi_{\mathrm{r}}-1\right) \mathrm{rd}_{\mathrm{t}+1}+\left(\pi_{\mathrm{a}}\right.\right.\right.$ $\left.\left.-1) \operatorname{adv}_{\mathrm{t}+1}+\left(\pi_{\mathrm{f}}-1\right) \operatorname{prodfac}_{\mathrm{t}+1}\right]\right\}$

Express expected values in terms of parameters from the information dynamics:

$\pi_{\mathrm{g}} \mathrm{crg}_{\mathrm{t}}+\pi_{\mathrm{p}} \operatorname{crp}_{\mathrm{t}}+\pi_{\mathrm{r}} \mathrm{rd}_{\mathrm{t}}+\pi_{\mathrm{a}} \mathrm{adv}_{\mathrm{t}}+\pi_{\mathrm{f}}$ prodfac $_{\mathrm{t}}=\beta\left\{\left(\pi_{\mathrm{g}}+1\right) \omega_{\mathrm{gg}} \mathrm{crg}_{\mathrm{t}}+\left(\pi_{\mathrm{p}}+1\right)\left(\omega_{\mathrm{pp}} \mathrm{crp}_{\mathrm{t}}+\omega_{\mathrm{pa}} \mathrm{adv}_{\mathrm{t}}+\right.\right.$ $\omega_{\mathrm{pp}_{\mathrm{f}}}$ rodfac $\left._{\mathrm{t}}\right)+\left(\pi_{\mathrm{r}}-1\right) \omega_{\mathrm{rr}} \mathrm{rd}_{\mathrm{t}}+\left(\pi_{\mathrm{a}}-1\right)\left(\omega_{\mathrm{aa}} \mathrm{adv}_{\mathrm{t}}+\omega_{\mathrm{ar}} \mathrm{rd}_{\mathrm{t}}\right)+\left(\pi_{\mathrm{f}}-1\right)\left(\omega_{\mathrm{ff}}\right.$ prodfac $\left.\left._{\mathrm{t}}+\omega_{\mathrm{fr}} \mathrm{rd}_{\mathrm{t}}\right)\right\}$

Solve for each parameter, letting $\Phi_{\mathrm{i}}=\left[\mathrm{R}-\omega_{\mathrm{ii}}\right]^{-1}$ for $\mathrm{i}=\mathrm{g}, \mathrm{p}, \mathrm{a}, \mathrm{f}, \mathrm{r}$,

solve for crg

$\pi_{\mathrm{g}}=\beta\left[\left(\pi_{\mathrm{g}}+1\right) \omega_{\mathrm{gg}}\right]$

$\pi_{\mathrm{g}}=\beta\left[\pi_{\mathrm{g}} \omega_{\mathrm{gg}}+\omega_{\mathrm{gg}}\right]$

$\pi_{\mathrm{g}}-\beta \pi_{\mathrm{g}} \omega_{\mathrm{gg}}=\beta \omega_{\mathrm{gg}}$

$\pi_{\mathrm{g}} \mathrm{R}-\pi_{\mathrm{g}} \omega_{\mathrm{gg}}=\omega_{\mathrm{gg}}$

$\pi_{\mathrm{g}}\left(\mathrm{R}-\omega_{\mathrm{gg})}=\omega_{\mathrm{gg}}\right.$

$\pi_{\mathrm{g}}=\Phi_{\mathrm{g}} \omega_{\mathrm{gg}}$

solve for crp by symmetry with crg:

$\pi_{\mathrm{p}}=\beta\left[\left(\pi_{\mathrm{p}}+1\right) \omega_{\mathrm{pp}}\right] \Rightarrow \pi_{\mathrm{p}}=\Phi_{\mathrm{p}} \omega_{\mathrm{pp}}$ 
solve for adv

$$
\begin{aligned}
& \pi_{\mathrm{a}}=\beta\left[\left(\pi_{\mathrm{p}}+1\right) \omega_{\mathrm{pa}}+\left(\pi_{\mathrm{a}}-1\right) \omega_{\mathrm{aa}}\right] \\
& \pi_{\mathrm{a}}=\beta\left[\left(\pi_{\mathrm{p}}+1\right) \omega_{\mathrm{pa}}+\pi_{\mathrm{a}} \omega_{\mathrm{aa}}-\omega_{\mathrm{aa}}\right] \\
& \pi_{\mathrm{a}}=\beta\left[\left(\pi_{\mathrm{p}}+1\right) \omega_{\mathrm{pa}}-\omega_{\mathrm{aa}}\right]+\beta \pi_{\mathrm{a}} \omega_{\mathrm{aa}} \\
& \pi_{\mathrm{a}}-\beta \pi_{\mathrm{a}} \omega_{\mathrm{aa}}=\beta\left[\left(\pi_{\mathrm{p}}+1\right) \omega_{\mathrm{pa}}-\omega_{\mathrm{aa}}\right] \\
& \pi_{\mathrm{a}}\left(1-\beta \omega_{\mathrm{aa}}\right)=\beta\left[\left(\pi_{\mathrm{p}}+1\right) \omega_{\mathrm{pa}}-\omega_{\mathrm{aa}}\right] \\
& \pi_{\mathrm{a}}\left(\mathrm{R}-\omega_{\mathrm{aa}}\right)=\left[\left(\pi_{\mathrm{p}}+1\right) \omega_{\mathrm{pa}}-\omega_{\mathrm{aa}}\right] \\
& \pi_{\mathrm{a}} \Phi_{\mathrm{a}}^{-1}=\left[\left(\Phi_{\mathrm{p}} \omega_{\mathrm{pp}}+1\right) \omega_{\mathrm{pa}}-\omega_{\mathrm{aa}}\right] \\
& \pi_{\mathrm{a}} \Phi_{\mathrm{a}}^{-1}=\left[\left(\omega_{\mathrm{pp}}+\left(\mathrm{R}-\omega_{\mathrm{pp}}\right)\right) \omega_{\mathrm{pa}-}-\omega_{\mathrm{aa}}\right] \\
& \left(\mathrm{R}-\omega_{\mathrm{pp}}\right) \\
& \pi_{\mathrm{a}} \Phi_{\mathrm{a}}^{-1}=\left[\left(\underline{\omega}_{\mathrm{pp}}+\mathrm{R}-\omega_{\mathrm{pp}}\right) \omega_{\mathrm{pa}}-\omega_{\mathrm{aa}}\right] \\
& \left(\mathrm{R}-\omega_{\mathrm{pp}}\right) \\
& \pi_{\mathrm{a}} \Phi_{\mathrm{a}}^{-1}=\left[\frac{\left.\mathrm{R} \omega_{\mathrm{pa}}-\omega_{\mathrm{aa}}\right]}{\left(\mathrm{R}-\omega_{\mathrm{pp}}\right)}\right. \\
& \pi_{\mathrm{a}} \Phi_{\mathrm{a}}^{-1}=\left[\mathrm{R} \omega_{\mathrm{pa}} \Phi_{\mathrm{p}}-\mathrm{R}+\mathrm{R}-\omega_{\mathrm{aa}}\right] \\
& \pi_{\mathrm{a}} \Phi_{\mathrm{a}}^{-1}=\mathrm{R}\left(\omega_{\mathrm{pa}} \Phi_{\mathrm{p}}-1\right)+\left(\mathrm{R}-\omega_{\mathrm{aa}}\right) \\
& \pi_{\mathrm{a}} \Phi_{\mathrm{a}}^{-1}=\mathrm{R}\left(\omega_{\mathrm{pa}} \Phi_{\mathrm{p}}-1\right)+\Phi_{\mathrm{a}}^{-1} \\
& \pi_{\mathrm{a}}=\mathrm{R} \Phi_{\mathrm{a}}\left(\omega_{\mathrm{pa}} \Phi_{\mathrm{p}}-1\right)+1 \\
& \pi_{\mathrm{a}}=\mathrm{R} \Phi_{\mathrm{a}} \lambda_{\mathrm{a}}+1
\end{aligned}
$$$$
\text { where } \lambda_{\mathrm{a}} \equiv\left(\omega_{\mathrm{pa}} \Phi_{\mathrm{p}}-1\right)
$$

solve for prodfac by symmetry with adv:

$$
\pi_{\mathrm{f}}=\beta\left[\left(\pi_{\mathrm{p}}+1\right) \omega_{\mathrm{pf}}+\left(\pi_{\mathrm{f}}-1\right) \omega_{\mathrm{ff}}\right] \Rightarrow \pi_{\mathrm{f}}=\mathrm{R} \Phi_{\mathrm{f}} \lambda_{\mathrm{f}}+1 \quad \text { where } \lambda_{\mathrm{f}} \equiv\left(\omega_{\mathrm{pf}} \Phi_{\mathrm{p}}-1\right)
$$

solve for $\mathrm{rd}$

$$
\begin{aligned}
& \pi_{\mathrm{r}}=\beta\left[\left(\pi_{\mathrm{r}}-1\right) \omega_{\mathrm{rr}}+\left(\pi_{\mathrm{a}}-1\right) \omega_{\mathrm{ar}}+\left(\pi_{\mathrm{f}}-1\right) \omega_{\mathrm{fr}}\right] \\
& \pi_{\mathrm{r}}=\beta\left(\pi_{\mathrm{r}} \omega_{\mathrm{rr}}\right)+\beta\left[\left(\pi_{\mathrm{a}}-1\right) \omega_{\mathrm{ar}}+\left(\pi_{\mathrm{f}}-1\right) \omega_{\mathrm{fr}}-\omega_{\mathrm{rr}}\right] \\
& \pi_{\mathrm{r}}-\beta \pi_{\mathrm{rd}} \omega_{\mathrm{rr}}=\beta\left[\left(\pi_{\mathrm{a}}-1\right) \omega_{\mathrm{ar}}+\left(\pi_{\mathrm{f}}-1\right) \omega_{\mathrm{fr}}-\omega_{\mathrm{rr}}\right] \\
& \pi_{\mathrm{r}}\left(\mathrm{R}-\omega_{\mathrm{rr}}\right)=\left(\pi_{\mathrm{a}}-1\right) \omega_{\mathrm{ar}}+\left(\pi_{\mathrm{f}}-1\right) \omega_{\mathrm{fr}}-\omega_{\mathrm{rr}} \\
& \pi_{\mathrm{r}} \Phi_{\mathrm{r}}^{-1}=\left(\mathrm{R} \Phi_{\mathrm{a}} \lambda_{\mathrm{a}}+1-1\right) \omega_{\mathrm{ar}}+\left(\mathrm{R} \Phi_{\mathrm{f}} \lambda_{\mathrm{f}}+1-1\right) \omega_{\mathrm{fr}}-\omega_{\mathrm{rr}}+\mathrm{R}-\mathrm{R} \\
& \pi_{\mathrm{r}} \Phi_{\mathrm{r}}^{-1}=\mathrm{R}\left(\Phi_{\mathrm{a}} \lambda_{\mathrm{a}} \omega_{\mathrm{ar}}+\Phi_{\mathrm{f}} \lambda_{\mathrm{f}} \omega_{\mathrm{fr}}-1\right)+\left(\mathrm{R}-\omega_{\mathrm{rr}}\right) \\
& \pi_{\mathrm{r}} \Phi_{\mathrm{r}}^{-1}=\mathrm{R}\left(\Phi_{\mathrm{a}} \lambda_{\mathrm{a}} \omega_{\mathrm{ar}}+\Phi_{\mathrm{f}} \lambda_{\mathrm{f}} \omega_{\mathrm{fr}}-1\right)+\Phi_{\mathrm{r}}^{-1} \\
& \pi_{\mathrm{r}}=\mathrm{R} \Phi_{\mathrm{r}} \lambda_{\mathrm{r}}+1 \\
& \text { where } \lambda_{\mathrm{r}} \equiv\left(\Phi_{\mathrm{a}} \lambda_{\mathrm{a}} \omega_{\mathrm{ar}}+\Phi_{\mathrm{f}} \lambda_{\mathrm{f}} \omega_{\mathrm{fr}}-1\right)
\end{aligned}
$$

\section{B.2 Derivation of the Accounting Valuation Model}

Define goodwill as $g w_{t}=b v_{t}-f a_{t}-o a_{t}$

Conjecture that goodwill is a function of the accounting variables:

$$
\mathrm{gw}_{\mathrm{t}}=\alpha_{\mathrm{roi}} \mathrm{roi}_{\mathrm{t}}+\alpha_{\mathrm{g}} \mathrm{crg}_{\mathrm{t}}+\alpha_{\mathrm{r}} \mathrm{rd}_{\mathrm{t}}+\alpha_{\mathrm{a}} \mathrm{adv}_{\mathrm{t}}+\alpha_{\mathrm{f}} \operatorname{prodfac}_{\mathrm{t}}+\alpha_{\mathrm{c}} \mathrm{caprd}_{\mathrm{t}}+\alpha_{\mathrm{pe}} \mathrm{pe}_{\mathrm{t}-1}+\alpha_{\mathrm{i}} \mathrm{int}_{\mathrm{t}-1}
$$


Expected goodwill is:

$$
\mathrm{E}\left[\mathrm{gw}_{\mathrm{t}+1}\right]=\alpha_{\mathrm{o}} \mathrm{roi}_{\mathrm{t}+1}+\alpha_{\mathrm{g}} \operatorname{crg}_{\mathrm{t}+1}+\alpha_{\mathrm{r}} \mathrm{rd}_{\mathrm{t}+1}+\alpha_{\mathrm{a}} \mathrm{adv}_{\mathrm{t}+1}+\alpha_{\mathrm{f}} \operatorname{prodfac}_{\mathrm{t}+1}+\alpha_{\mathrm{c}} \mathrm{caprd}_{\mathrm{t}+1}+\alpha_{\mathrm{pe}} \mathrm{pe}_{\mathrm{t}}+\alpha_{\mathrm{i}} \mathrm{int}_{\mathrm{t}}
$$

Residual operating income is:

$$
\begin{aligned}
& \operatorname{roi}_{\mathrm{t}}=\mathrm{crp}_{\mathrm{t}}+\operatorname{crg}_{\mathrm{t}}-(\mathrm{R}-\delta) \mathrm{pe}_{\mathrm{t}-1}-(\mathrm{R}-\chi) \operatorname{int}_{\mathrm{t}-1}-\mathrm{rd}_{\mathrm{t}}-\mathrm{adv}_{\mathrm{t}} \\
& \mathrm{E}\left[\mathrm{roi}_{\mathrm{t}+1}\right]=\operatorname{crp}_{\mathrm{t}+1}+\operatorname{crg}_{\mathrm{t}+1}-(\mathrm{R}-\delta) \mathrm{pe}_{\mathrm{t}^{-}}(\mathrm{R}-\chi) \mathrm{int}_{\mathrm{t}}-\mathrm{rd}_{\mathrm{t}+1^{-}} \operatorname{adv}_{\mathrm{t}+1} \\
& \mathrm{E}\left[\mathrm{roi}_{\mathrm{t}+1}\right]=\left(\omega_{\mathrm{pp}} \mathrm{crp}_{\mathrm{t}}+\omega_{\mathrm{gg}} \mathrm{crg}_{\mathrm{t}}+\omega_{\mathrm{pa}} \mathrm{adv}_{\mathrm{t}}+\omega_{\mathrm{pp}} \operatorname{prodfac}_{\mathrm{t}}+\omega_{\mathrm{pc}} \mathrm{caprd}_{\mathrm{t}}\right)-(1-\delta) \mathrm{pe}_{\mathrm{t}^{-}}(1-\chi) \text { int }_{\mathrm{t}}- \\
& \operatorname{rd}_{\mathrm{t}+1^{-}} \operatorname{adv}_{\mathrm{t}+1}
\end{aligned}
$$

Using the formula from Feltham and Ohlson (1996): $g w_{t}=\beta_{t+1}\left\{\mathrm{E}\left[\right.\right.$ roi $\left.\left._{t+1}+g w_{t+1}\right]\right\}$, plug the above equations into the formula to get:

$\alpha_{\text {roi }}$ roi $_{t}+\alpha_{g} \operatorname{crg}_{t}+\alpha_{\mathrm{r}}$ rd $_{\mathrm{t}}+\alpha_{\mathrm{a}} \mathrm{adv}_{\mathrm{t}}+\alpha_{\mathrm{f}}$ prodfac $_{\mathrm{t}}+\alpha_{\mathrm{c}} \mathrm{caprd}_{\mathrm{t}}+\alpha_{\mathrm{pe}} \mathrm{pe}_{\mathrm{t}-1}+\alpha_{\mathrm{i}}$ int $_{\mathrm{t}-1}=\beta\left\{\mathrm{E}\left[\left(\alpha_{\mathrm{roi}}+1\right) \mathrm{roi}_{\mathrm{t}+1}+\right.\right.$ $\left.\left.\alpha_{\mathrm{g}} \mathrm{crg}_{\mathrm{t}+1}+\alpha_{\mathrm{r}} \mathrm{rd}_{\mathrm{t}+1}+\alpha_{\mathrm{a}} \mathrm{adv}_{\mathrm{t}+1}+\alpha_{\mathrm{f}} \operatorname{prodfac}_{\mathrm{t}+1}+\alpha_{\mathrm{c}} \mathrm{caprd}_{\mathrm{t}+1}+\alpha_{\mathrm{pe}} \mathrm{pe}_{\mathrm{t}}+\alpha_{\mathrm{i}} \mathrm{int}_{\mathrm{t}}\right]\right\}$

Substitute components of roi :

$\alpha_{\text {roi }}\left(\operatorname{crp}_{\mathrm{t}}+\operatorname{crg}_{\mathrm{t}}-(\mathrm{R}-\delta) \mathrm{pe}_{\mathrm{t}-1^{-}}(\mathrm{R}-\chi)\right.$ int $\left._{\mathrm{t}-1}-\mathrm{rd}_{\mathrm{t}}-\mathrm{adv}_{\mathrm{t}}\right)+\alpha_{\mathrm{g}} \mathrm{crg}_{\mathrm{t}}+\alpha_{\mathrm{r}} \mathrm{rd}_{\mathrm{t}}+\alpha_{\mathrm{a}} \mathrm{adv}_{\mathrm{t}}+\alpha_{\mathrm{f}} \operatorname{prodfac}_{\mathrm{t}}+\alpha_{\mathrm{c}} \mathrm{caprd}_{\mathrm{t}}+$ $\alpha_{\mathrm{pe}} \mathrm{pe}_{\mathrm{t}-1}+\alpha_{\mathrm{i}} \mathrm{int}_{\mathrm{t}-1}=\beta\left\{\mathrm{E}\left[\left(\alpha_{\mathrm{roi}}+1\right)\left(\mathrm{crp}_{\mathrm{t}+1}+\mathrm{crg}_{\mathrm{t}+1}-(\mathrm{R}-\delta) \mathrm{pe}_{\mathrm{t}^{-}}(\mathrm{R}-\chi) \operatorname{int}_{\mathrm{t}}-\mathrm{rd}_{\mathrm{t}+1^{-}} \mathrm{adv}_{\mathrm{t}+1}\right)+\alpha_{\mathrm{g}} \mathrm{crg}_{\mathrm{t}+1}+\alpha_{\mathrm{r}} \mathrm{rd}_{\mathrm{t}+1}\right.\right.$ $+\alpha_{\mathrm{a}} \operatorname{adv}_{\mathrm{t}+1}+\alpha_{\mathrm{f}}$ prodfac $_{\mathrm{t}+1}+\alpha_{\mathrm{c}} \mathrm{caprd}_{\mathrm{t}+1}+\alpha_{\mathrm{pe}} \mathrm{pe}_{\mathrm{t}}+\alpha_{\mathrm{i}}$ int $\left.\left._{\mathrm{t}}\right]\right\}$

Substitute $\left(\operatorname{prodfac}_{t}+\delta \mathrm{pe}_{\mathrm{t}-1}\right)$ for $\mathrm{pe}_{\mathrm{t}}$ and $\left(\operatorname{caprd}_{t}+\chi \operatorname{int}_{\mathrm{t}-1}\right)$ for int $\mathrm{t}$ :

$\alpha_{\text {roi }}\left(\operatorname{crp}_{\mathrm{t}}+\operatorname{crg}_{\mathrm{t}}-(\mathrm{R}-\delta) \mathrm{pe}_{\mathrm{t}-1^{-}}(\mathrm{R}-\chi)\right.$ int $\left._{\mathrm{t}-1}-\mathrm{rd}_{\mathrm{t}}-\mathrm{adv}_{\mathrm{t}}\right)+\alpha_{\mathrm{g}} \mathrm{crg}_{\mathrm{t}}+\alpha_{\mathrm{r}} \mathrm{rd}_{\mathrm{t}}+\alpha_{\mathrm{a}} \mathrm{adv}_{\mathrm{t}}+\alpha_{\mathrm{f}} \operatorname{prodfac}_{\mathrm{t}}+\alpha_{\mathrm{c}} \mathrm{caprd}_{\mathrm{t}}+$ $\alpha_{\mathrm{pe}} \mathrm{pe}_{\mathrm{t}-1}+\alpha_{\mathrm{i}} \mathrm{int}_{\mathrm{t}-1}=\beta\left\{\mathrm{E}\left[\alpha_{\mathrm{g}} \mathrm{crg}_{\mathrm{t}+1}+\left(\alpha_{\mathrm{roi}}+1\right)\left(\mathrm{crp}_{\mathrm{t}+1}+\operatorname{crg}_{\mathrm{t}+1}-(\mathrm{R}-\delta)\left(\operatorname{prodfac}_{\mathrm{t}}+\delta \mathrm{pe}_{\mathrm{t}-1}\right)-(\mathrm{R}-\chi)\left(\operatorname{caprd}_{\mathrm{t}}+\right.\right.\right.\right.$ $\left.\left.\chi_{\text {int }}\right)-\operatorname{rd}_{t+1^{-}} \operatorname{adv}_{t+1}\right)+\alpha_{\mathrm{r}} \mathrm{rd}_{\mathrm{t}+1}+\alpha_{\mathrm{a}} \mathrm{adv}_{\mathrm{t}+1}+\alpha_{\mathrm{f}} \operatorname{prodfac}_{\mathrm{t}+1}+\alpha_{\mathrm{c}} \mathrm{caprd}_{\mathrm{t}+1}+\alpha_{\mathrm{pe}}\left(\operatorname{prodfac}_{\mathrm{t}}+\delta \mathrm{pe}_{\mathrm{t}-1}\right)+$ $\alpha_{\mathrm{i}}\left(\operatorname{caprd}_{\mathrm{t}}+\chi\right.$ int $\left.\left.\left._{\mathrm{t}-1}\right)\right]\right\}$

Use information dynamics to express expected $t+1$ terms in current information:

$\alpha_{\text {roi }}\left(\operatorname{crp}_{\mathrm{t}}+\operatorname{crg}_{\mathrm{t}}-(\mathrm{R}-\delta) \mathrm{pe}_{\mathrm{t}-1^{-}}(\mathrm{R}-\chi)\right.$ int $\left._{\mathrm{t}-1}-\mathrm{rd}_{\mathrm{t}^{-}} \mathrm{adv}_{\mathrm{t}}\right)+\alpha_{\mathrm{g}} \mathrm{crg}_{\mathrm{t}}+\alpha_{\mathrm{r}} \mathrm{rd}_{\mathrm{t}}+\alpha_{\mathrm{a}} \mathrm{adv}_{\mathrm{t}}+\alpha_{\mathrm{f}} \operatorname{prodfac}_{\mathrm{t}}+\alpha_{\mathrm{c}} \mathrm{caprd}_{\mathrm{t}}+$ $\alpha_{\mathrm{pe}} \mathrm{pe}_{\mathrm{t}-1}+\alpha_{\mathrm{i}} \mathrm{int}_{\mathrm{t}-1}=\beta\left\{\left[\left(\alpha_{\mathrm{roi}}+1\right)\left[\omega_{\mathrm{pp}} \mathrm{crp}_{\mathrm{t}}+\omega_{\mathrm{gg}} \mathrm{crg}_{\mathrm{t}}+\omega_{\mathrm{pa}} \mathrm{adv}_{\mathrm{t}}+\omega_{\mathrm{pf}}\right.\right.\right.$ prodfac $_{\mathrm{t}}+\omega_{\mathrm{pc}} \mathrm{caprd}_{\mathrm{t}}-(\mathrm{R}-$ $\left.\delta)\left(\operatorname{prodfac}_{\mathrm{t}}+\delta \mathrm{pe}_{\mathrm{t}-1}\right)-(\mathrm{R}-\chi)\left(\operatorname{caprd}_{\mathrm{t}}+\chi \mathrm{int}_{\mathrm{t}-1}\right)-\omega_{\mathrm{rr}} \mathrm{rd}_{\mathrm{t}}-\left(\omega_{\mathrm{aa}} \mathrm{adv}_{\mathrm{t}}+\omega_{\mathrm{ar}} \mathrm{rd}_{\mathrm{t}}\right)\right]+\alpha_{\mathrm{g}} \omega_{\mathrm{gg}} \mathrm{crg}_{\mathrm{t}}+\alpha_{\mathrm{r}} \omega_{\mathrm{rr}} \mathrm{rd}_{\mathrm{t}}+$ $\alpha_{\mathrm{a}}\left(\omega_{\mathrm{aa}} \mathrm{adv}_{\mathrm{t}}+\omega_{\mathrm{ar}} \mathrm{rd}_{\mathrm{t}}\right)+\alpha_{\mathrm{f}}\left(\omega_{\mathrm{ff}} \operatorname{prodfac}_{\mathrm{t}}+\omega_{\mathrm{fr}} \mathrm{rd}_{\mathrm{t}}\right)+\alpha_{\mathrm{c}} \omega_{\mathrm{cc}} \mathrm{caprd}_{\mathrm{t}}+\alpha_{\mathrm{pe}}\left(\right.$ prodfac $\left._{\mathrm{t}}+\delta \mathrm{ppe}_{\mathrm{t}-1}\right)+\alpha_{\mathrm{i}}\left(\mathrm{caprd}_{\mathrm{t}}+\right.$ $\left.\left.\left.\chi \operatorname{int}_{t-1}\right)\right]\right\}$

Collect terms:

$\alpha_{\text {roi }} \operatorname{crp}_{\mathrm{t}}+\left(\alpha_{\mathrm{g}}+\alpha_{\text {roi }}\right) \operatorname{crg}_{\mathrm{t}}+\left(-(\mathrm{R}-\delta) \alpha_{\text {roi }}+\alpha_{\mathrm{pe}}\right) \mathrm{pe}_{\mathrm{t}-1}+\left(-(\mathrm{R}-\chi) \alpha_{\mathrm{roi}}+\alpha_{\mathrm{i}}\right)$ int $_{\mathrm{t}-1}+\left(\alpha_{\mathrm{r}}-\alpha_{\mathrm{roi}}\right) \mathrm{rd}_{\mathrm{t}}+\left(\alpha_{\mathrm{a}}-\alpha_{\mathrm{roi}}\right) \mathrm{adv}_{\mathrm{t}}+$ $\alpha_{\mathrm{f}} \operatorname{prodfac}_{\mathrm{t}}+\alpha_{\mathrm{c}} \operatorname{caprd}_{\mathrm{t}}=\beta\left\{\left[\left(\alpha_{\mathrm{roi}}+1\right) \omega_{\mathrm{gg}}+\alpha_{\mathrm{g}} \omega_{\mathrm{gg}}\right] \mathrm{crg}_{\mathrm{t}}+\left(\alpha_{\mathrm{roi}}+1\right) \omega_{\mathrm{pp}} \mathrm{crp}_{\mathrm{t}}+\left[\left(\alpha_{\text {roi }}+1\right)\left(\omega_{\mathrm{pa}}-\omega_{\mathrm{aa}}\right)+\right.\right.$ $\left.\alpha_{\mathrm{a}} \omega_{\mathrm{aa}}\right] \mathrm{adv}_{\mathrm{t}}+\left[\left(\alpha_{\mathrm{roi}}+1\right)\left(\omega_{\mathrm{pf}}-(1-\delta)\right)+\alpha_{\mathrm{f}} \omega_{\mathrm{ff}}+\alpha_{\mathrm{pe}}\right]$ prodfac $\mathrm{t}+\left[\left(\alpha_{\mathrm{roi}}+1\right)\left(\omega_{\mathrm{pc}}-(\mathrm{R}-\chi)+\alpha_{\mathrm{c}} \omega_{\mathrm{cc}}+\alpha_{\mathrm{i}}\right] \mathrm{caprd}_{\mathrm{t}}+[\right.$ $\left.\left(\alpha_{\mathrm{roi}}+1\right) \delta(-(\mathrm{R}-\delta))+\delta \alpha_{\mathrm{f}}\right] \mathrm{pe}_{\mathrm{t}-1}+\left[\left(\alpha_{\mathrm{roi}}+1\right) \chi(-(1-\chi))+\chi \alpha_{\mathrm{i}}\right] \mathrm{int}_{\mathrm{t}-1}+\left[\left(\alpha_{\mathrm{roi}}+1\right)\left(-\omega_{\mathrm{rr}}-\omega_{\mathrm{ar}}\right)+\alpha_{\mathrm{r}} \omega_{\mathrm{rr}}+\alpha_{\mathrm{a}} \omega_{\mathrm{ar}}+\right.$ $\left.\alpha_{\mathrm{f}} \omega_{\mathrm{fr}}\right] \mathrm{rd}_{\mathrm{t}}$ 
Solve for each parameter, letting $\Phi_{\mathrm{i}} \equiv\left[\mathrm{R}-\omega_{\mathrm{ii}}\right]^{-1}$ for $\mathrm{i}=\mathrm{g}, \mathrm{p}, \mathrm{a}, \mathrm{f}, \mathrm{r}$, and substituting $\mathrm{R} \equiv \beta^{-1}$ :

solve for $\mathrm{crg}$

$\alpha_{\mathrm{g}}+\alpha_{\text {roi }}=\beta\left[\left(\alpha_{\text {roi }}+1\right) \omega_{\mathrm{gg}}+\alpha_{\mathrm{g}} \omega_{\mathrm{gg}}\right]$

$R \alpha_{\mathrm{g}}+\mathrm{R} \alpha_{\text {roi }}=\omega_{\mathrm{gg}} \alpha_{\text {roi }}+\omega_{\mathrm{gg}}+\alpha_{\mathrm{g}} \omega_{\mathrm{gg}}$

$\mathrm{R} \alpha_{\mathrm{g}}-\alpha_{\mathrm{g}} \omega_{\mathrm{gg}}=\omega_{\mathrm{gg}} \alpha_{\mathrm{roi}}-\mathrm{R} \alpha_{\mathrm{roi}}+\omega_{\mathrm{gg}}$

$\left(\mathrm{R}-\omega_{\mathrm{gg}}\right) \alpha_{\mathrm{g}}=\alpha_{\mathrm{roi}}\left(\omega_{\mathrm{gg}}-\mathrm{R}\right)+\omega_{\mathrm{gg}}$

$\left(\mathrm{R}-\omega_{\mathrm{gg}}\right) \alpha_{\mathrm{g}}=\omega_{\mathrm{gg}}-\alpha_{\text {roi }}\left(\mathrm{R}-\omega_{\mathrm{gg}}\right)$

$\alpha_{\mathrm{g}}=\Phi_{\mathrm{g}} \omega_{\mathrm{gg}}-\alpha_{\text {roi }}$

solve for crp

$\alpha_{\text {roi }}=\beta\left[\left(\alpha_{\text {roi }}+1\right) \omega_{\mathrm{pp}}\right]$

$\mathrm{R} \alpha_{\mathrm{roi}}=\alpha_{\mathrm{roi}} \omega_{\mathrm{pp}}+1 \omega_{\mathrm{pp}}$

$\left(\mathrm{R}-\omega_{\mathrm{pp}}\right) \alpha_{\mathrm{roi}}=\omega_{\mathrm{pp}}$

$\alpha_{\text {roi }}=\Phi_{\mathrm{p}} \omega_{\mathrm{pp}}$

solve for pe $\mathrm{e}_{\mathrm{t}-1}$

$-(\mathrm{R}-\delta) \alpha_{\mathrm{roi}}+\alpha_{\mathrm{pe}}=\beta\left[\left(\alpha_{\mathrm{roi}}+1\right) \delta(-(1-\delta))+\delta \alpha_{\mathrm{f}}\right]$

$\mathrm{R} \alpha_{\mathrm{pe}}-\delta \alpha_{\mathrm{pe}}=\alpha_{\mathrm{roi}}\left(\mathrm{R}^{2}-\mathrm{R} \delta-\mathrm{R} \delta-\delta^{2}\right)+\delta \mathrm{R}-\delta^{2}$

$(\mathrm{R}-\delta) \alpha_{\mathrm{pe}}=\alpha_{\mathrm{roi}}(\mathrm{R}-\delta)(\mathrm{R}-\delta)+\delta(\mathrm{R}-\delta)$

$\alpha_{\mathrm{pe}}=\alpha_{\mathrm{roi}}(\mathrm{R}-\delta)+\delta$

$\alpha_{\mathrm{pe}}=(\mathrm{R}-\delta)\left(1-\alpha_{\mathrm{roi}} \delta\right)$

$\alpha_{\mathrm{pe}}=\left[\mathrm{R} \omega_{\mathrm{pp}}-\delta\left(\mathrm{R}-\omega_{\mathrm{pp}}\right)-\delta \omega_{\mathrm{pp}}\right] /\left(\mathrm{R}-\omega_{\mathrm{pp}}\right)$

$\alpha_{\mathrm{pe}}=\left[\mathrm{R} \omega_{\mathrm{pp}}-\delta \mathrm{R}+\delta \omega_{\mathrm{pp}}-\delta \omega_{\mathrm{pp}}\right] /\left(\mathrm{R}-\omega_{\mathrm{pp}}\right)$

$\alpha_{\mathrm{pe}}=\left[\mathrm{R} \omega_{\mathrm{pp}}-\delta \mathrm{R}\right] /\left(\mathrm{R}-\omega_{\mathrm{pp}}\right)$

$\alpha_{\mathrm{pe}}=\mathrm{R} \Phi_{\mathrm{p}}\left(\omega_{\mathrm{pp}}-\delta\right)$

solve for int $\mathrm{t}_{\mathrm{t}-1}$ by symmetry with pe $\mathrm{t}_{\mathrm{t}-1}$

- $(\mathrm{R}-\chi) \alpha_{\text {roi }}+\alpha_{\mathrm{i}}=\beta\left[\left(\alpha_{\text {roi }}+1\right) \chi(-(1-\chi))+\chi \alpha_{\mathrm{i}}\right]$

$\alpha_{\mathrm{i}}=\mathrm{R} \Phi_{\mathrm{p}}\left(\omega_{\mathrm{pp}}-\chi\right)$

solve for $\mathrm{rd}_{\mathrm{t}}$

$\alpha_{\mathrm{r}}-\alpha_{\text {roi }}=\beta\left[\left(\alpha_{\text {roi }}+1\right)\left(-\omega_{\text {rr }}-\omega_{\text {ar }}\right)+\alpha_{\mathrm{r}} \omega_{\text {rr }}+\alpha_{\mathrm{a}} \omega_{\mathrm{ar}}\right]$

$R \alpha_{\mathrm{r}}-\mathrm{R} \alpha_{\mathrm{roi}}=\left(\alpha_{\mathrm{roi}}+1\right)\left(-\omega_{\mathrm{rr}}-\omega_{\mathrm{ar}}\right)+\alpha_{\mathrm{r}} \omega_{\mathrm{rr}}+\alpha_{\mathrm{a}} \omega_{\mathrm{ar}}+\alpha_{\mathrm{f}} \omega_{\mathrm{fr}}$

$\mathrm{R} \alpha_{\mathrm{r}}-\alpha_{\mathrm{r}} \omega_{\mathrm{rr}}=\mathrm{R} \alpha_{\text {roi }}-\omega_{\mathrm{rr}} \alpha_{\mathrm{roi}}-\omega_{\mathrm{rr}}-\omega_{\mathrm{ar}} \alpha_{\mathrm{roi}}-\omega_{\mathrm{ar}}+\alpha_{\mathrm{a}} \omega_{\mathrm{ar}}+\alpha_{\mathrm{f}} \omega_{\mathrm{fr}}$

$\left(\mathrm{R}-\alpha_{\mathrm{r}}\right) \omega_{\mathrm{rr}}=\alpha_{\mathrm{roi}}\left(\mathrm{R}-\omega_{\mathrm{rr}}\right)+\left(\mathrm{R}-\omega_{\mathrm{rr}}\right)-\mathrm{R}-\omega_{\mathrm{ar}} \alpha_{\mathrm{roi}}-\omega_{\mathrm{ar}}+\alpha_{\mathrm{a}} \omega_{\mathrm{ar}}+\alpha_{\mathrm{f}} \omega_{\mathrm{fr}}$

$\alpha_{\mathrm{r}}=\alpha_{\text {roi }}+1+\Phi_{\mathrm{a}}\left(\alpha_{\mathrm{a}} \omega_{\mathrm{ar}}+\alpha_{\mathrm{f}} \omega_{\mathrm{fr}}-\omega_{\mathrm{ar}} \alpha_{\mathrm{roi}}-\omega_{\mathrm{ar}}-\mathrm{R}\right)$

$\alpha_{\mathrm{r}}=\alpha_{\mathrm{roi}}+1+\Phi_{\mathrm{a}}\left(\omega_{\mathrm{ar}}\left(\alpha_{\mathrm{roi}}+\Phi_{\mathrm{a}} \mathrm{R} \lambda_{\mathrm{a}}+1\right)+\alpha_{\mathrm{f}} \omega_{\mathrm{fr}}-\omega_{\mathrm{ar}} \alpha_{\mathrm{roi}}-\omega_{\mathrm{ar}}-\mathrm{R}\right)$

$\alpha_{\mathrm{r}}=\alpha_{\mathrm{roi}}+1+\Phi_{\mathrm{a}}\left(\omega_{\mathrm{ar}} \alpha_{\mathrm{roi}}+\Phi_{\mathrm{a}} \mathrm{R} \lambda_{\mathrm{a}} \omega_{\mathrm{ar}}+\omega_{\mathrm{ar}}+\alpha_{\mathrm{f}} \omega_{\mathrm{fr}}-\omega_{\mathrm{ar}} \alpha_{\mathrm{roi}}-\omega_{\mathrm{ar}}-\mathrm{R}\right)$

$\alpha_{\mathrm{r}}=\alpha_{\text {roi }}+1+\Phi_{\mathrm{a}}\left(\Phi_{\mathrm{a}} \mathrm{R} \lambda_{\mathrm{a}} \omega_{\mathrm{ar}}+\alpha_{\mathrm{f}} \omega_{\mathrm{fr}}-\mathrm{R}\right)$

$\alpha_{\mathrm{r}}=\alpha_{\mathrm{roi}}+1+\Phi_{\mathrm{a}}\left(\mathrm{R} \Phi_{\mathrm{a}} \lambda_{\mathrm{a}} \omega_{\mathrm{ar}}+\mathrm{R} \Phi_{\mathrm{f}} \lambda_{\mathrm{f}} \omega_{\mathrm{fr}}-\mathrm{R}\right)$

$\alpha_{\mathrm{r}}=\alpha_{\text {roi }}+\Phi_{\mathrm{a}} \mathrm{R}\left(\Phi_{\mathrm{a}} \lambda_{\mathrm{a}} \omega_{\mathrm{ar}}+\Phi_{\mathrm{f}} \lambda_{\mathrm{f}} \omega_{\mathrm{fr}}-1\right)+1$

$\alpha_{\mathrm{r}}=\alpha_{\mathrm{roi}}+\Phi_{\mathrm{a}} \mathrm{R} \lambda_{\mathrm{r}}+1 \quad$ where $\lambda_{\mathrm{r}} \equiv\left(\Phi_{\mathrm{a}} \lambda_{\mathrm{a}} \omega_{\mathrm{ar}}+\Phi_{\mathrm{f}} \lambda_{\mathrm{f}} \omega_{\mathrm{fr}}-1\right)$ 
$\underline{\text { solve for } \mathrm{adv}_{\mathrm{t}}}$

$\alpha_{\mathrm{a}}-\alpha_{\mathrm{roi}}=\beta\left[\left(\alpha_{\mathrm{roi}}+1\right)\left(\omega_{\mathrm{pa}}-\omega_{\mathrm{aa}}\right)+\alpha_{\mathrm{a}} \omega_{\mathrm{aa}}\right]$

$R \alpha_{a}-R \alpha_{r o i}=\omega_{\text {pa }}\left(\alpha_{\text {roi }}+1\right)-\omega_{\text {aa }}\left(\alpha_{\text {roi }}+1\right)+\alpha_{a} \omega_{\text {aa }}$

$\mathrm{R} \alpha_{\mathrm{a}}-\alpha_{\mathrm{a}} \omega_{\mathrm{aa}}=\mathrm{R} \alpha_{\mathrm{roi}}-\omega_{\mathrm{aa}} \alpha_{\mathrm{roi}}-\omega_{\mathrm{aa}}+\omega_{\mathrm{pa}} \alpha_{\mathrm{roi}}+\omega_{\mathrm{pa}}$

$\left(\mathrm{R}-\omega_{\mathrm{aa}}\right) \alpha_{\mathrm{a}}=\alpha_{\mathrm{roi}}\left(\mathrm{R}-\omega_{\mathrm{aa}}\right)+\left(\mathrm{R}-\omega_{\mathrm{aa}}\right)-\mathrm{R}+\omega_{\mathrm{pa}} \alpha_{\mathrm{roi}}+\omega_{\mathrm{pa}}$

$\alpha_{\mathrm{a}}=\alpha_{\text {roi }}+1+\Phi_{\mathrm{a}}\left(\omega_{\mathrm{pa}} \alpha_{\mathrm{roi}}+\omega_{\mathrm{pa}}-\mathrm{R}\right)$

$\alpha_{\mathrm{a}}=\alpha_{\mathrm{roi}}+1+\Phi_{\mathrm{a}}\left(\omega_{\mathrm{pa}} \Phi_{\mathrm{p}} \omega_{\mathrm{pp}}+\omega_{\mathrm{pa}}-\mathrm{R}\right)$

$\alpha_{\mathrm{a}}=\alpha_{\mathrm{roi}}+1+\Phi_{\mathrm{a}}\left(\left(\omega_{\mathrm{pa}} \omega_{\mathrm{pp}}\right) /\left(\mathrm{R}-\omega_{\mathrm{pp}}\right)+\left(\mathrm{R} \omega_{\mathrm{pa}}-\omega_{\mathrm{pa}} \omega_{\mathrm{pp}}\right) /\left(\mathrm{R}-\omega_{\mathrm{pp}}\right)-\mathrm{R}\right)$

$\alpha_{\mathrm{a}}=\alpha_{\mathrm{roi}}+1+\Phi_{\mathrm{a}}\left(\mathrm{R} \omega_{\mathrm{pa}} /\left(\mathrm{R}-\omega_{\mathrm{pp}}\right)-\mathrm{R}\right)$

$\alpha_{\mathrm{a}}=\alpha_{\text {roi }}+1+\Phi_{\mathrm{a}}\left(\mathrm{R} \Phi_{\mathrm{p}} \omega_{\mathrm{pa}}-\mathrm{R}\right)$

$\alpha_{\mathrm{a}}=\alpha_{\mathrm{roi}}+\Phi_{\mathrm{a}} \mathrm{R}\left(\omega_{\mathrm{pa}} \Phi_{\mathrm{p}}-1\right)+1$

$\alpha_{\mathrm{a}}=\alpha_{\text {roi }}+\Phi_{\mathrm{a}} \mathrm{R} \lambda_{\mathrm{a}}+1$

where $\lambda_{\mathrm{a}} \equiv\left(\omega_{\mathrm{pa}} \Phi_{\mathrm{p}}-1\right)$

$\underline{\text { solve for prodfac }} \underline{t}_{t}$

$\alpha_{\mathrm{f}}=\beta\left[\left(\alpha_{\mathrm{roi}}+1\right)\left(\omega_{\mathrm{pf}}-(\mathrm{R}-\delta)\right)+\alpha_{\mathrm{f}}+\alpha_{\mathrm{pe}}\right]$

$\alpha_{\mathrm{f}}=\beta\left[\left(\omega_{\mathrm{pf}}-(\mathrm{R}-\delta)\left(\alpha_{\mathrm{roi}}+1\right)+\alpha_{\mathrm{pe}}+\alpha_{\mathrm{f}} \omega_{\mathrm{ff}}+\alpha_{\mathrm{roi}} \omega_{\mathrm{pf}}\right)\right]$

$\mathrm{R} \alpha_{\mathrm{f}}=\omega_{\mathrm{pf}}-(\mathrm{R}-\delta)\left(\alpha_{\mathrm{roi}}+1\right)+\alpha_{\mathrm{pe}}+\alpha_{\mathrm{f}} \omega_{\mathrm{ff}}+\alpha_{\mathrm{roi}} \omega_{\mathrm{pf}}$

$\mathrm{R} \alpha_{\mathrm{f}}-\alpha_{\mathrm{f}} \omega_{\mathrm{ff}}=\omega_{\mathrm{pf}}-\left(\mathrm{R} \alpha_{\mathrm{roi}}+\mathrm{R}-\delta \alpha_{\mathrm{roi}}-\delta\right)+\mathrm{R} \Phi_{\mathrm{p}}\left(\omega_{\mathrm{pp}}-\delta\right)+\alpha_{\mathrm{roi}} \omega_{\mathrm{pf}}$

$\left(\mathrm{R}-\omega_{\mathrm{ff}}\right) \alpha_{\mathrm{f}}=\omega_{\mathrm{pf}}-\mathrm{R} \Phi_{\mathrm{p}} \omega_{\mathrm{pp}}-\mathrm{R}+\delta \Phi_{\mathrm{p}} \omega_{\mathrm{pp}}+\delta+\mathrm{R} \Phi_{\mathrm{p}} \omega_{\mathrm{pp}}-\delta \mathrm{R} \Phi_{\mathrm{p}}+\omega_{\mathrm{pf}} \Phi_{\mathrm{p}} \omega_{\mathrm{pp}}$

$\left(\mathrm{R}-\omega_{\mathrm{ff}}\right) \alpha_{\mathrm{f}}=\omega_{\mathrm{pf}}+\delta \Phi_{\mathrm{p}} \omega_{\mathrm{pp}}+\delta-\delta \mathrm{R} \Phi_{\mathrm{p}}+\omega_{\mathrm{pf}} \Phi_{\mathrm{p}} \omega_{\mathrm{pp}}-\mathrm{R}$

$\left(\mathrm{R}-\omega_{\mathrm{ff}}\right) \alpha_{\mathrm{f}}=\omega_{\mathrm{pf}}+\delta+\Phi_{\mathrm{p}}\left(\delta \omega_{\mathrm{pp}}-\delta \mathrm{R}+\omega_{\mathrm{pf}} \omega_{\mathrm{pp}}\right)-\mathrm{R}$

$\left(\mathrm{R}-\omega_{\mathrm{ff}}\right) \alpha_{\mathrm{f}}=\Phi_{\mathrm{p}}\left(\omega_{\mathrm{pf}}+\delta\right)\left(\mathrm{R}-\omega_{\mathrm{pp}}\right)+\Phi_{\mathrm{p}}\left(\delta \omega_{\mathrm{pp}}-\delta \mathrm{R}+\omega_{\mathrm{pf}} \omega_{\mathrm{pp}}\right)-\mathrm{R}$

$\left(\mathrm{R}-\omega_{\mathrm{ff}}\right) \alpha_{\mathrm{f}}=\Phi_{\mathrm{p}}\left(\mathrm{R} \omega_{\mathrm{pf}}-\omega_{\mathrm{pf}} \omega_{\mathrm{pp}}+\delta \mathrm{R}-\delta \omega_{\mathrm{pp}}\right)+\Phi_{\mathrm{p}}\left(\delta \omega_{\mathrm{pp}}-\delta \mathrm{R}+\omega_{\mathrm{pf}} \omega_{\mathrm{pp}}\right)-\mathrm{R}$

$\left(\mathrm{R}-\omega_{\mathrm{ff}}\right) \alpha_{\mathrm{f}}=\Phi_{\mathrm{p}}\left(\mathrm{R} \omega_{\mathrm{pf}}-\omega_{\mathrm{pf}} \omega_{\mathrm{pp}}+\delta \mathrm{R}-\delta \omega_{\mathrm{pp}}+\delta \omega_{\mathrm{pp}}-\delta \mathrm{R}+\omega_{\mathrm{pf}} \omega_{\mathrm{pp}}\right)-\mathrm{R}$

$\left(\mathrm{R}-\omega_{\mathrm{ff}}\right) \alpha_{\mathrm{f}}=\Phi_{\mathrm{p}}\left(\mathrm{R} \omega_{\mathrm{pf}}\right)-\mathrm{R}$

$\left(\mathrm{R}-\omega_{\mathrm{ff}}\right) \alpha_{\mathrm{f}}=\mathrm{R}\left(\omega_{\mathrm{pf}} \Phi_{\mathrm{p}}-1\right)$

$\alpha_{\mathrm{f}}=\mathrm{R} \Phi_{\mathrm{f}}\left(\omega_{\mathrm{pf}} \Phi_{\mathrm{p}}-1\right)$

$\alpha_{\mathrm{f}}=\mathrm{R} \Phi_{\mathrm{f}} \lambda_{\mathrm{f}}$

where $\lambda_{\mathrm{f}} \equiv\left(\omega_{\mathrm{pf}} \Phi_{\mathrm{p}}-1\right)$

solve for caprd ${ }_{t}$ by symmetry with prodfac $c_{t-1}$

$\left.\alpha_{\mathrm{c}}=\left[\left(\alpha_{\mathrm{roi}}+1\right)\left(\omega_{\mathrm{pc}}-(\mathrm{R}-\chi)+\alpha_{\mathrm{c}}+\alpha_{\mathrm{i}}\right]\right)\right]$

$\alpha_{\mathrm{c}}=\mathrm{R} \Phi_{\mathrm{c}} \lambda_{\mathrm{c}}$

where $\lambda_{\mathrm{c}} \equiv\left(\omega_{\mathrm{pc}} \Phi_{\mathrm{p}}-1\right)$ 